\title{
Operational Readiness Review Final Report For F-Canyon Restart Phase 1 (U)
}

by

A. F. McFarlane

Westinghouse Savannah River Company

Savannah River Site

Aiken, South Carolina 29808

J. B. Spangler

Westinghouse Savannah River Company

SC USA

\section{DISCLAIMER}

This report was prepared as an account of work sponsored by an agency of the United States Government. Neither the United States Government nor any agency thereof, nor any of their employees, makes any warranty, express or implied, or assumes any legal liability or responsibility for the accuracy, completeness, or usefulness of any information, apparatus, product, or process disclosed, or represents that its use would not infringe privately owned rights. Reference herein to any specific commercial product; process, or service by trade name, trademark, manufacturer, or otherwise does not necessarily constitute or imply its endorsement, recommendation, or favoring by the United States Government or any agency thereof. The views and opinions of authors expressed herein do not necessarily state or reflect those of the United States Government or any agency thereof.

DOE Contract No. DE-AC09-89SR18035

This paper was prepared in connection with work done under the above contract number with the U.S. Department of Energy. By acceptance of this paper, the publisher and/or recipient acknowledges the U.S. Government's right to retain a nonexclusive, royalty-free license in and to any copyright covering this paper, along with the right to reproduce and to authorize others to reproduce all or part of the copyrighted paper.

$\propto$ 


\section{DISCLAIMER}

Portions of this document may be illegible in electronic image products. Images are produced from the best available original document. 
ESH-ORR-940015-O

\section{OPERATIONAL SAFETY EVALUATION} DEPARTMENT

\section{ESH\&QA DIVISION \\ OPERATIONAL READINESS REVIEW FINAL REPORT \\ FOR \\ $\therefore$}

F-CANYON RESTART PHASE 1 (U)

(WSRC ORR 93-0)

REV. 0

August 5, 1994

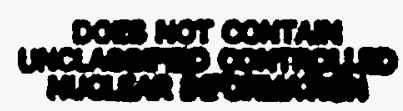

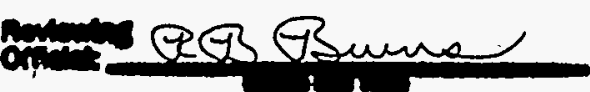

$8 / 5 / 94$ 
ESH-ORR-940015-O

OPERATIONAL SAFETY EVALUATION DEPARTMENT

ESH\&QA DIVISION

OPERATIONAL READINESS REVIEW BOARD FINAL REPORT

FOR

F-CANYON RESTART

FINAL REPORT APPROVALS -

$\frac{\text { C.9.m Tarlane } 8 / 5 / 94}{\text { D.F.McFarlane }}$
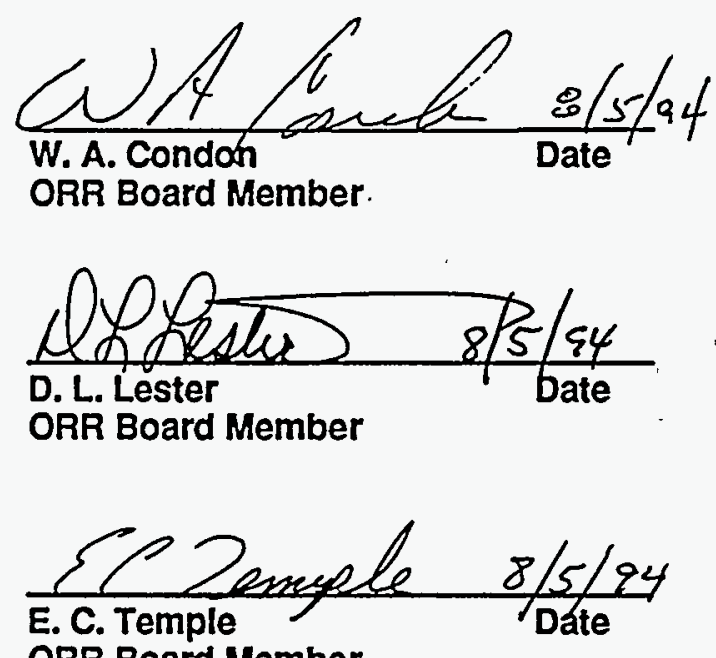

ORR Board Member

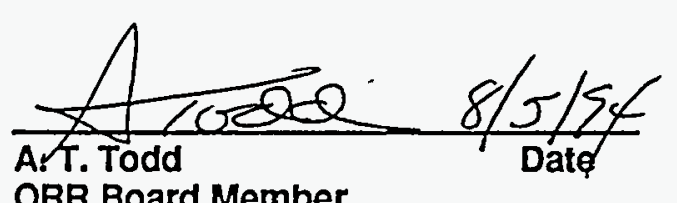

ORR Board Member
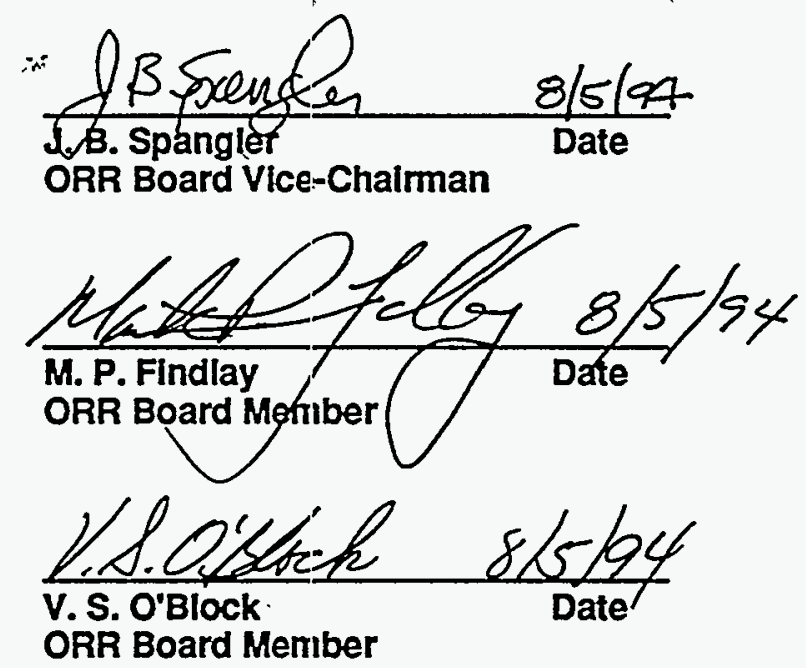

RDIhamis $8 / 5 / 94$

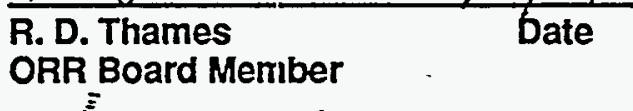

ORR Board Member

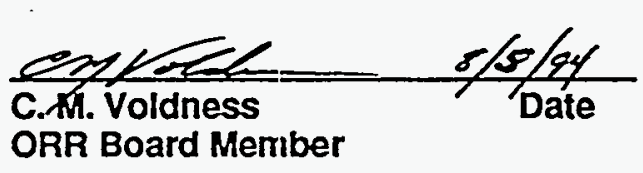




\section{TABLE OF CONTENTS}

Secction

Page

Executive Summary

1

I. 0 Introduction 3

2.0 Purpose 4

$\begin{array}{lll}3.0 & \text { Scope } & 4\end{array}$

4.0 Readiness Self Assessment Activities 5

5.0 Functional Area Reviews 6

5.1 ORR Methodology $\quad 6$

5.2 Functional Area Results 6

5.2.1 Review Criteria $\quad \because \quad 6$

5.2.2 Review Observations and Conclusions; $\quad 7$

5.2.3 ORR Findings and Corrective Actions 32

5.2.4 RSA Findings and Corrective Actions $\quad 75$

5.3 DOE Order Compliance Assessment 79

5.4 ORR Compliance with DOE Order $5480.31 \quad 80$

6.0 ORR Organization and Staffing 83

6.1. ORR Staffing $\quad 83$

6.2 ORR Functional Area Assignments 83

6.3 ORR Personnel Biographical Sketches 84

$\begin{array}{lll}7.0 & \text { Lessons Learned } \quad 85\end{array}$

8.0 References 85

$\begin{array}{lll}\text { Appendix ORR Checklist Forms } & 87 \text {. }\end{array}$ 


\section{F-CANYON RESTART \\ OPERATIONAL READINESS REVIEW FINAL. REPORT}

\section{EXECUTIVE SUMMARY}

An independent WSRC Operational Readiness Review was performed for the restart of Phase 1 processing in F-Canyon, Building 221-F. Readiness to restart the Second Plutonium Cycle process and solvent recovery was assessed. The ORR was conducted by an ORR Board of ten members with the support of a subject matter expert. The Chairman and four members were drawn from the Operational Safety Evaluation Department, ESH\&QA Division; additional members were drawn from other WSRC divisions, independent of the F-Canyon operating division (NMPD).

The ORR Board reviewed the Functional Areas that were selected by the facility in the Restart Plan. These consisted of 12 of the 22 Functional Areas defined by the WSRC Source and Compliance Document SCD-4, Operational Readiness Functional Area Requirements. The Restart Plan was approved by the Department of Energy.

The ORR Board reviewed and approved the Restart Plan and the facility Readiness Self Assessment (RSA) Plan and performed oversight and review of the facility RSA. In the RSA report, the facility identified a number of deficiencies and corrective actions. and at the time of commencement of independent field verification there remained eleven open punchlist $A$ items to be completed before restart. A later, supplementary, facility assessment added two more RSA findings.

In addition to those deficiencies identified by the facility during the conduct of the RSA, the ORR field verifications identified one hundred (100) findings. These findings generated 225 Punchlist A (pre-restart) corrective actions and 62 Punchlist B (postrestart) items. The corrective actions proposed by the facility and approved by the Board were selected to address the root causes of the deficiencies. The table below summarizes the number of findings and corrective actions by' Functional Area. WSRC Manual $12 Q$ requires formal verification by the ORR Board of closure of all the Punchlist A corrective actions associated with ORR findings and the RSA punchlist $A$ items. The Board has verified successful implementation of the pre-restalt corrective actions.

Therefore, based on the results of the readiness verification assessmients performed according to the ORR plan and the validation of pre-restart corrective actions, the WSRC independent ORR Board has concluded that the facility has achieved the state of readiness committed to in the Restart Plan. Also, based on the scope of the ORR, it is the opinion of the Board that F-Canyon Phase 1zprocesses can be restarted without undue risk to the safety of the public and on-site workers and without undue risk to the environment. 


\section{Summary of findings}

Functional Area

Training and Qualification

Procedures

Safety Documents

Environmental Protection

Quality Assurance

Maintenance and Surveillance

Radiological protection

Fire Protection

Ėmergency Preparedness

Issue Management

Occupational Safety and Health

Conduct of Operations

Sub-Total

RSA open items

Supplementary RSA items

Total

$\begin{array}{ccc}\text { ORR } & \begin{array}{c}\text { Punchlist A } \\ \text { Findings } \\ \text { Corrective } \\ \text { Actions }\end{array} & \begin{array}{c}\text { Punchlist B } \\ \text { Corrective } \\ \text { Actions }\end{array}\end{array}$

6

10

8

3

7

3

15

57

8

3

7

3

7

$4 \quad 5 \quad 0$

$\begin{array}{lll}11 & 21 & 3\end{array}$

13. $\therefore \quad 25 \quad 9$

$\begin{array}{llll}6 & 8 & 7\end{array}$

$9 \quad 14 \quad 6$

$18.36 \quad 10$

$\begin{array}{lll}100 & 225 & 61\end{array}$

$11 \quad 11 \quad 0$

$\begin{array}{lll}2 & 5 & 0\end{array}$

$113 \quad 241 \quad 62$

$\bar{z}$ 


\section{-1.0 INTRODUCTION}

F-Canyon discretionary (non-essential) process operations were suspended in March 1992, as a result of a positive Unreviewed Safety Question (USQ) determination on the F-Canyon stack liner and ventilation system. WSRC completed its analysis of the USQ, and, using the WSRC ORR process, determined the F-Canyon to be ready to resume discretionary operations in December 1992. A request to resume operations was transmitted to DOE in February 1993, following a DOE ORR. Prior to receiving permission to resume operations, a Nuclear Materials Processing Division (NMPD) assessment and other reviews identified significant facility deficiencies in the Training and Conduct of Operations Functional Areas. It was determined that improvements to these areas were necessary prior to allowing resumption of operations. In addition, an NMPD management assessment determined that implementation of planned improvements in the Functional Areas of Safety Documentation, Fire Protection, Emergency Preparedness and Occupational Safety and Health would also be required prior to Restart.

It was determined that a contractor Operational Readiness Review (ORR) was required for this restart. (Reference 1).

According to the F-Canyon Restart Plan (Reference 2) the restart of F-Canyon operations is to be conducted in two phases. The first phase originally encompassed Dissolver operations and Second Plutonium Cycle/ Solvent Recovery operations. This was modified to postpone restart of Dissolver operations to the second phase (Reference 3). The second phase is now planned to consist of Dissolver, First Cycle/ Solvent Recovery, Second Uranium Cycle/ Solvent Recovery, A-Line, and Head End Clarification systems and operations. Specifics pertaining to the scope of the restart processes may be found in the F-Canyon Restart Plan. This ORR report is for the first phase of Restart.

Following completion of the upgrades identified for the first phase of restart in the pertinent Functional Areas, facility line management performed a Readiness SelfAssessment (RSA) as described in the RSA Plan (Reference 4).

An Operational Readiness Review (ORR) was conducted in accordance with WSRC Manual 12Q (Revision 1, 4/1/93) and was performed as described in the ORR Plan (Reference 5). The ORR included oversight of the facility's RSA and an independent field verification of operational readiness. A sample of the Restart Plan criteria was verified with emphasis on performance based assessments wherever possible. The ORR was based on the facility Restart Plan and concentrated on the areas critical to the safe operation of Phase 1 processes.

ORR Board oversight of the facility Readiness Self Assessment began on September 1 , 1993. The ORR field verification phase began in various stagjes; each Functional Area beginning when the RSA portion, including the corrective action closure packages, was deemed by the Board to indicate a sufficient state of readiness. Field verification for the first Functional Areas began on November 12, 1993, and the last Functional Area began on January 7, 1994. Field verifications, using the Lines of Inquiry in the ORR Plan, were initially completed by February 15, 1994. In response to correspondence received from 
the Department of Energy (References 6 and 7), field verification was reopened in May 1994 for three functional Areas; namely, Environmental Protection, Radiological Protection and Conduct of Operations. Three additional Board members were appointed and further assessments were performed in these areas. These were completed by June 17, 1994.

\title{
2.0 PURPOSE
}

The purpose of the F-Canyon Restart ORR, Phase 1, is to validate the facility Readiness Self Assessment and to obtain independent assurance of the facility operational readiness to commence Second Plutonium Cycle operations. The ORR verifies that restart improvements identified in the Restart Plan have been made, and that the facility and processes will be operated in a safe and secure manner by trained and competent personnel, with no undue risk to the employees, public, or the environment.

\subsection{SCOPE}

The scope of the ORR followed Phase I of the facility Restart Plan (Reference 2), which in turn defined the scope for the facility Readiness Self Assessment Plan (Reference 4) and the ORR Plan (Reference 5).

A graded approach was taken for the restart of F-Canyorl, concentrating on those Functional Areas for which previous NMPD management a.ssessments and external reviews had identified needed improvements.

This resulted in primary emphasis being placed on the following six Functional Areas:

Training and Qualification

Safety Documents

Fire Protection

Emergency Preparedness

Occupational Safety and Health

Conduct of Operations

A small number of criteria were selected for the following additional six Functional Areas on the basis of previous satisfactory assessments and the ongoing operation in FCanyon of some waste handling and other operations known as the non-discretionary processes.

\author{
Procedures \\ Quality Assurance \\ Environmental Protection. \\ Maintenance and Surveillance \\ Radiation Protection \\ issue Management
}

Further discussion of the selection of the scope for the restart readiness review may be found in Reference 8. 


\subsection{READINESS SELF ASSESSMENT ACTIVITIES}

The Readiness Self-Assessment (RSA) consisted of verification by the facility that acceptance criteria contained in the Restart Plan were met. The ORR Board reviewed and commented on the Restart Plan and reviewed and concurred in the Readiness Self Assessment Plan. The Board also provided oversight of the RSA process by observation of selected field activities and by assessing the completeness of documentation of the RSA, including closure documentation for the pre-restart corrective actions.

The facility readiness self assessment team consisted of personnel assigned to each of the six major functional areas defined by Revision 0 of the Restart Plan. Functional Area Leaders developed lines of inquiry for each of the criteria listed in the Restart Plan. Through completion of the lines of inquiry, the team verified compliance with the restart criteria. The Board commented on the RSA reports and on the documentation provided for closure of corrective actions. As a result of these comments, revisions were made to the reports for three of the six Functional Area reports; specifically Safety Documents, Training and Qualification, and Occupational Safety and Health. The Board delayed commencement of the field verification phase of the ORR until these reports and the completion of corrective actions were considered to indiciate an adequate state of readiness with respect to the restart criteria. The Board decided on a phased start to field verification with the first Functional Areas (Quality Assurance, Radiological Protection and Issue Management) deemed sufficiently ready on November 12 and the final one (Fire Protection) ready on January 7 . The ORR Plan follows the structure of Revision 1 of the Restart Plan and has twelve Functional Areas.

In the RSA Report (Reference 9) the facility identified 132 indings with 96 corrective actions to be completed before restart. At the commencement of ORR field verifications there remained 11 pre-restart corrective actions still to be completed. A summary of these items is provided in Section 5.2.4 of this ORR report.

In a supplementary RSA report (Reference 10), the facility documented the results of a reassessment of Environmental Protection and Radiological Protection. This supplementary report identified two new RSA findings in Radiological Protection. These findings are listed in Section 5.2.4 with the Corrective Actions which were approved and tracked to closure by the ORR Board. 


\subsection{FUNCTIONAL AREA REVIEWS}

\subsection{ORR Methodology}

This ORR was conducted according to WSRC Manual $12 Q$ (Revision 1, 4/1/93) in which the Operational Safety Evaluation Department provides an ORR Board which is independent of facility management. Organization and staffing of the ORR Board is described in Section 6.0 of this report. Details pertaining to the criteria selected for verification and the verification approach, including lines of inquiry, may be found in the F-Canyon Restart ORR Plan (Reference 5).

As described above, ORR field verifications commenced on acceptance of the facility Readiness Self Assessment. Results of the ORR assessment are documented in the following sections, with further detail in the Checklist Forms completed by each Board member and subject matter expert. Copies of the completed checklists are provided in the Appendix.

In accordance with the WSRC Manual 12Q process, on discovery of a deficiency against the commitments made in the Restart Plan the Board member documents a finding which is. presented to the Board for confirmation. Prie-restart (Category A) and post-restart (Category B) corrective actions for the deficiencies are proposed by the facility and approved by the Board. A listing of the finclings and the associated corrective actions is provided in Section 5.2.3.;

\subsection{Functional Area Results}

\subsubsection{Review Criteria}

Acceptance criteria used by the ORR Board to verify readiness of the applicable Functional Areas were selected from the facility Restart Flan. The criteria chosen represented a sample or subset of the Restart Plan criteria and concentrated on the Functional Areas of primary importance. The verification approach emphasized performance based measures of readiness by observing operations, maintenance and emergency drills, and by interviewing personnel and inspecting the facility. Selected documentation was also reviewed for compliance to requirements. Lines of inquiry appropriate to the criteria to be assessed were developed by the ORR Board and are provided in the attachment to the ORR Plan.

During the course of the ORR field verification, additional lines of inquiry were pursued when observations of deficiencies warranted further investigation. These are summarized in the report, and further details are provided in the Checklists in the Appendix. 


\subsubsection{Review Observations and Conclusions}

\section{Functional Area 4 - Training and Qualification}

The Board review and assessment of Training and Qualification concentrated on the additional training that the Restart Plan identified as a prerequisite for restart.- According to the Restart Plan, successful completion of incremental training was required for the control room operators and control room supervisors who would be on shift during Phase I operations, i.e. during operation of the second plutionium cycle and solvent recovery: Formal training and qualification is also required for the Shift Technical Engineers who are required on shift as a compensatory measiure for the lack of certain fundamentals and system training that is identified by DOE Order 5480.20 as required for process operators.

The Restart Plan also committed to provide additional training to other Canyon staff such as building operators, sample aisle operators, crane operators and crane supervisors. This additional training consisted of the same training provided to the control room staff who are qualified for Phase 1 operations, with the exception of the process specific training for Second Plutonium Cycle operations. The facility considers these personnel, who are necessary to support the ongoing non-discretionary operations, to be already qualified for their positions without supplementary training.

The facility has qualified a sufficient number of Phase 1 operations control room personnel to staff two shifts (out of five total). Phase I operations are batch operations which will be shut down when the minimum complement of qualified personnel is not on shift.

The ORR Board reviewed the basis for the development of the incremental training provided to operators, supervisors and STEs. The Board also reviewed the learning objectives, lesson plans and examinations. Board members observed a sample of the oral boards conducted by facility senior management for the final qualification of Phase I operators, supervisors and STES.

The ORR Board prepared a written examination with three or four questions from each of the required courses; this was administered to operators and supervisors. The ORR Board also interviewed Phase I operators and supervisors with a number of questions selected from the same courses.

To assess the basis for the development of the restart training program, the ORR Board reviewed the facility's status in compliance with the two DOE orders related to training. DOE Order 5480.18 "Accreditation of Performance-Based Training for Category A Reactors and Nuclear Facilities" requires a Training Program Accreditation Plan. The facility has received DOE approval of an exemption from this order. DOE Order 5480.20 "Personnel Selection, Qualification, Training and Staffing Requirements at DOE Reactor and Non-Reactor Nuclear Facilities" requires the submittal to DOE headquarters of a Training Implementation Matrix (TIM). The ORR Board review of the F-Canyon TIM identified that the TIM has been approved by the DOE Savannah River Operations Office and DOE headquarters. The ORR Board also interviewed facility management to verify their knowledge of the commitments contained in the TIM. 
Since the facility will not accredit the training program, the basic focus of the ORR Board was to determine if enough of the performance based training process is in place to provide the necessary operator training and qualification to support facility operation. This was accomplished by: (1) observing classroom lectures, facility operations, oral qualification boards and an Emergency Preparedness drill (2) reviewing lesson plans, completed examinations and training plans (3) conducting orial evaluations of operating crew and oral interviews of management, and (4) providing a written examination with questions selected by the Board. It should also be noted that when training issues were identified in other functional areas, they were captured in that area.

The Training Implementation Plan (TIM) has been written and approved by DOE-SR. Facility management is aware of the status of the facility relative to the TIM. Operators, First Line Supervisors (FLS) and Shift Operating Managers (SOM) were interviewed to assess knowledge level of trainees. It was determined that iriterviewed personnel have satisfactorily retained material taught. A review of the training records for 16 individuals indicated an auditable system which contained proper documentation for training material presented. Non-operational personnel (e.g. Maintenance and Radiological Control Operations) have been required to attend and successfully complete $F$-Canyon Safety Related Systems training.

The focal point of the facility operator training program is thei development of the Shift Technical Engineer Training Program. The facility developed in depth process and systems training lesson plans and study guides. The lesson plans covered considerably more material than the lesson plan objectives.identified. The fact that the STE training program lacked objective evidence of a knowledge and skills analysis was recorded in Finding 04-01/1.

Qualification standards were developed as a result of the Readiness Self Assessment (RSA). The qualification standards identify the training and qualification requirements for the facility Operator positions. A review of these documents identified two problems. First, the Operator Qualification Standard did not require the operators to be trained on facility systems (i.e. piping systems and electrical distribution); this is not consistent with the DOE Guide to Good Practice for Training and Qualification of Chemical Operators (Finding 04-03/1). Second, the Supervisor Training program did not identify the increased depth of knowledge required of a supervisor based on his increased responsibility as is required by DOE Order 5480.20 (Finding 04-02/1).

The Restart Plan identified the need to conduct an analysis of all fundamentals training requested for facility operators. The plan further stated that mathematics and chemistry fundamentals training would be completed for Operators, Supervisors and Shift Operations Managers. Some training has been conducted; however, it was not based on the recent analysis of Science fundamentals needs (Finding 04-06/1).

Interviews with qualified Phase I operations personnel and the results of the ORR Board written examination indicated satisfactory retention of the material tested. One supervisor had not completed the incremental training (Finding 04-02/2); this is discussed further in Functional Area 22, Conduct of Operations. 
A review of completed oral examinations and observation of the oral board process identified a weakness in examination security. Specific problems identified were: (1) the same written examination was given on different days without changing content, and (2) oral boards were given at widely ranging scheduled times using the same questions (Finding 04-05/1).

Six deficiencies noted in this area are documented as Findings: 04-1/1, 04-02/1, 04-02/2, 04-03/1, 04-06/1 and 04-05/1.

Corrective Actions for these Findings were proposed by the facility and approved by the ORR Board; they are documented in Section 5.2.3 of this report. Implementation of these Corrective Actions, with ORR Board validation, provides assurance that the facility has achieved the state of readiness for this Functional Area as defined in the Restart Plan.

\section{Functional Area 5 - Procedures}

The ORR Plan for review of this Functional Area selected two of the four criteria listed in the Restart Plan. During the course of the review, this was expanded to include all the Restart Plan criteria, and the additional requirement from WSFIC Manual 11Q to perform Unreviewed Safety Question screening for all procedure chianges. The ORR Board reviewed selected Administrative, Operations and Maintenance procedures and conducted interviews with operators, mechanics, procedure writers and various levels of management.

Personnel responsible for processing new and revised adrninistrative and operating procedures were generally knowledgeable about their responsibilities. Interviews with and observation of Operations personnel indicated that they had received training on, and understood, the requirement to fully comply with procedures and to take whatever action is necessary during emergency conditions to place the process/facility/personnel in a safe condition.

The review also verified the existence of appropriate interaction between the technical and operations departments in the development and review of operating procedures. However, they had not been instructed to perform an Unreviewed Safety Question screening for Administrative Procedures. This generated a finding in the Safety Documents Functional Area (Finding 06-07/3).

A sample of the historical records revealed a problem with documentation of the walkdown process. Signatures of operational personnel were missing from walkdown sheets. (Finding 05-02/1).

Alarm Response Procedures have been issued :and approved. Under Conduct of Operations it was noted that guidelines for the use of Alarm Response Procedures had not been properly communicated (Finding 22-08/1).

A review of procedure adequacy, in terms of format and content, was not included in the ORR Plan lines of inquiry; however, two procedure deficiencies were noted during observation of activities in Functional Area 7, Environmental Protection. A waste 
handling procedure contained steps to be initialed and was categorized as a training and reference only procedure (Finding 05-02/2). Another waste handling procedure contained an action in the scope section which was routinely rot being followed (Finding 07-01/1).

During observation of Second Plutonium Cycle simulated runs it was noted that procedure changes were frequently required. This indicated that the simulated runs were providing a valuable check of the procedures. An equivalent verification had not yet been performed for all the Phase 1 procedures. This was documented as Finding 05-02/3. Because of a reduction in the scope of Phase 1 restart, closure of this finding was modified to exclude procedures specific to the dissolving process.

Six deficiencies noted in this area are documented in Findings 05-02/1, 05-02/2, 05$02 / 3,06-07 / 3,07-01 / 1$ and $22-08 / 1$.

Corrective Actions for these Findings were proposed by the facility and approved by the ORR Board; they are documented in Section 5.2.3 of this report. Implementation of these Corrective Actions, with ORR Board validation, provides assurance that the facility has achieved the state of readiness for this Functional Area as defined in the Restart Plan.

\section{Functional Area 6 - Safety Documentation}

The twenty eight Lines of Inquiry for the ORR Board assessment of Safety Documentation were designed to provide independent verification of the following:

- the Authorization Basis Documents (ABDs) are comprehensive and have the required approvals from WSRC and DOE,

- Unreviewed Safety Question (USQ) screenings are being applied for proposed activities,

- the Shift Technical Engineers understand the USQ process,

- requirements are consistent throughout the AEDs and are implemented appropriately by procedures,

- the units used for observed quantities are clearly defined in implementing procedures and consistent with instrumentation,

- instrumentation uncertainties are included in alarrns/interlock set points,

- the engineering and operations staff are knowledgeable about and properly use the ABDs;

- the $A B D s$ represent the as-built and as-operated facility,

- the facility is in compliance with procedures related to Test Authorizations, Test Conclusions, Test Standards and Process Hazards Reviews, and 
- corrective actions for the FA-6 Category " $A$ " Findings from the F-Canyon Readiness Self Assessment are properly closed.

The evaluation was performed by review of the Authorization Basis documentation and procedures, interviews with engineering and operations staff, and walkdown of the 2816F Segregated Cooling Water Monitoring System to assess if the P\&IDs reflected the as-built configuration.

Five Surveillance Requirements (SRs) specified in the OSRs were selected and reviewed to verify that they are properly incorporated into the operating procedures. A printout of the list of implementing procedures for these SRs was obtained using the SR Test Program Tickler System, and the corresponding SR implementing procedures were selected. A review of these procedures determined that, in all cases, the OSR Surveillance Requirements were found to be properly incorporated. The SR Test Program Tickler System and Basic Data for SR Tests is exciellent and provides clear and concise information regarding cross references to applicable OSRs, Technical Standards, drawings and implementing procedures.

Addendum 2 to the SAR re-evaluates the consequences of applicable accidents using revised source terms. This $A B D$. was reviewed to verify that it includes thorough documentation of the assumptions used in the safety analysis, and these assumptions are consistent with other $\mathrm{ABD}$ and implementing documents. The assumptions utilized by this Authorization Basis document were thoroughly documented. The majority of these assumptions are technical assumptions applicable only to this SAR Addendum. A small number of assumptions would be applicable to other documents. One of these assumptions is that the Sand Filter efficiency is $99.51 \%$. This assumption is consistent with the assumptions and values employed by other Authorization Basis documents (DPSTSA-200-10, Supplement 4 and the OSRs), the implernenting procedure (SOP211-F-1502), and the criteria for acceptable filter efficiency test results.

Several lines of inquiry evaluated the knowledge of the ABDs of the operating staff. This evaluation was made by interviewing a selection of operators, shift management, shift technical engineers, and engineering management. The results of these interviews were satisfactory. Three operators were interviewed to assess their knowledge of limits imposed by the ABDs and surveillance requirements. Five shift staff members were interviewed to determine their knowledge of the OSRs and the requirements related to changes in process, equipment, and procedures. Three control room supervisors and two shift technical engineers were interviewed to determine their knowledge of the generation and control of Test Authorizations. The knowledge of those interviewed was considered to be satisfactory.

An evaluation was made on the controls applied to the use of jumpers in the canyon. It was determined that there are operating procedures (SOP 221-F-10223 \& 10255) which provide good control of the use of jumpers. In addition, special procedures and piping modifications are subject to control by the F-Canyon USQD process.

The F-Canyon SAR does not meet the requirements of COE Order 5480.23. An exemption request has been prepared for this deficiency. Five of the proposed 
Compensatory Measures for this deficiency were reviewed and their implementation verified.

Approval packages for Technical Standards were reviewed, and it was determined that the Technical Standards were reviewed and approved independently from the preparer. However, as noted in the Readiness Self Assessment (RSA) final report, the uncertainties section is missing from all Technical Standards although the controlling procedure for Technical Standards (Manual 11Q, section 3.0') requires performance of an uncertainty analysis. The corrective action for this RSA finding evaluates uncertainties for safety related equipment. The implementing procedures for these evaluations require performance of an uncertainty analysis. The instrumentation uncertainties were calculated using the methodology specified in Procedures T408 and T408A of the WSRC E7 Manual. The uncertainty analysis for two safety related instruments was also reviewed and judged to be adequate; however, the evaluation for the Recycle Vessel Vent low pressure alarm notes that the setpoint needs to be readjusted to be within SAR limits. This modification is on the restart schedule, and will be completed prior to restart. In addition, the engineering manager demonstrated adequate knowledge of the uncertainty methodology. This review indicated that instrumentation errors were being handled in an acceptable manner.

Six Operational Safety Requirements. (OSR) limits were selected from the facility ABDs to verify that they were contained in appropriate operating and maintenance procedures, and they were at least as conservative as the ABD requirements. Technical Standards and operating procedures that implement these OSR requirements were selected using the F-Canyon Linking Document and the F-Canyon Safety Document Database. In all cases, the OSR requirements were found to be clearly and concisely incorporated into the Technical Standards and operating procedures, and at least as limiting as the ABD requirements. However, an error in the OSRs was found during the RSA which has not yet been corrected, and is identified in Finding 06-04/3.

The Process Hazards Reviews (PHRs) for the second plutonium cycle were reviewed and found to be approved and reviewed according to the requirements of the $11 \mathrm{Q}$ Manual. However, the PHR for " $\mathrm{F}$ and $\mathrm{H}$ Canyons Outside Facilities Vulnerability to a Tomsk-Like-Incident" had not been approved by WSRC. (Finding 06-12/1)

Five operating procedures were reviewed to verify that the units in the procedures were easily understood and consistent with those on the control panels. Four out of five were easily understood and the units were consistent with those on the control panel: however, the load test procedure for the 292-F diesel does not specify units for several data (Finding 06-05/1), and in addition an out of range reading had not been noted (Finding 06-05/2).

Five procedure modifications, two Test Authorizations, and seven work packages were reviewed to ensure that an associated USQ screening or evaluation was performed. All of the proposed activities contained in this sample had associated USQ screenings or justification for excluding such screenings except one. This review found that the administrative procedures and Radiological Control Manual 5Q1.4 procedures were not receiving a USQ screening, nor were they properly exempted from such screenings (Findings 6-07/2 and 6-07/3. During the completion of this effort, it was determined that 
the boundaries of Safety Related Systems are not clearly and unambiguously defined (Finding 06-07/1).

The consistency of the currently approved ABDs used by operations and engineering was verified by comparing a current listing of the approved ABDs used by engineering and by determining which $A B D$ s are used by operations. The currently approved ABDs were not found and were not readily available in or near the 221-F Control Room for use by the STE or operating staff (Finding 06-03/1). At the time of the review, the STES were not on shift. Also, WSRC approved changes to Technical Standards had not been approved by DOE (Finding 06-03/2).

A review of selected portions of Chapter 3 of the SAR and discussions with engineering personnel determined that the SAR contains outdated and erroneous information (finding 06/02/2). In addition, it was determined that all Sections of the SAR and several of the ABDs (e.g. the Basis for Interim Operation (BIO), all but one Test Authorization, SAR Addendum \#2) had not been reviewed to ensure that the operating procedures accurately and consistently reflect operational requirements identified in all $A B D s$ (Finding 06-04/1).

A facility memorandum concludes that the accountability tarık liquid level and specific gravity instruments and sump liquid level instruments are not required to be designated as being safety related in the Safety Related Systems procedure. The assessment fails to address whether these instruments are necessary to satisfy the "double contingency" requirements for inadvertent criticality control required by DCE Order 5480.24 (Finding 06-02/1).

As a result of interviews with the Shift Technical Engineers, system engineer, an engineering manager, and walkdown of the 281-6F Segregated Cooling Water Monitoring system, it was determined that the Safety Related System boundaries are not clearly and unambiguously defined. In addition, the walkdown of the 281-6F system, conducted to verify that the as-built configuration agreed with the P\&IDs used by the system engineer, determined that discrepancies exist between the two P\&IDs and the as-built configuration (Finding 06-01/1).

Closure reports and associated documentation were reviewed to verify if the pre-restart corrective actions, identified in the facility response to the April 1993 Annual Safety Appraisal report, have been closed. Although scheduled, all of these items had not been closed (Finding 06-07/04).

During completion of the FA 22 Conduct of Operations review, it was noted that the procedure SOP $221-\mathrm{F}-50133$ would authorize deviations from minimum staffing requirements and not consider this a violation. The minimum staffing is identified in the WSRC approved $\mathrm{BIO}$, and procedures cannot autkorize deviations from this document (Finding 06-07/5).

Finding 06-04/2, which related to an inconsistency between the SAR and OSR for the surveillance test interval of $1 \mathrm{~A} / 2 \mathrm{~B}$ Bank Neutron monitors and interlocks, was not presented to the ORR Board, since the surveillance test interval in the OSR is consistent with the WSRC approved Basis for Interim Operation. 
There are four findings in FA-6 from the RSA, that were not closed at commencement of field verification, related to DOE. approval of the following documents: the Basis for Interim Operation (RSA Corrective Action RSA-06-01), the DOE Order 5480.23 Exemption Request (RSA-06-02), SAR Addendum (DPSTSA-200-10, Supplement 4, Addendum 2) (RSA-06-03), and DOE Order 5480.22 Exemption Request (RSA-06-03).

Fifteen (15) deficiencies noted in this area are documented in Findings 06-01/1, 06$02 / 1,06-02 / 2,06-03 / 1,06-03 / 2,06-04 / 1,06-04 / 3,06-05 / 1,06-05 / 2,06-07 / 1,06-07 / 2$, $06-07 / 3,06-07 / 4,06-07 / 5$, and 06-12/1.

Corrective Actions for the above RSA and ORR Findings were proposed by the facility and approved by the ORR Board; they are documented in Section 5.2.3 of this report. Implementation of these Corrective Actions, with ORR Board validation, provides assurance that the facility has achieved the state of readiness for this Functional Area as defined in the Restart Plan.

\section{Functional Area 7 - Environmental Protection}

Based on the justification of readiness in the Restart Plan, a limited scope review was conducted for the Environmental Protection (EP) Functional Area. The assessment consisted of five Lines of Inquiry which focused on the completeness of training and the adequacy of knowledge retention of F-Canyon Operations personnel who have duties related to Environmental Protection. Operators and management were interviewed, records were reviewed and a waste transfer/handling operation was observed. The assessment was performed in two field verification periods, the first in December 1993 and the second in June 1994. The facility performed an adclitional self assessment of this functional area in May 1994 without any findings.

Training records (16 individuals) were reviewed to determine if selected Phase I Startup personnel had received appropriate EP training. The audit revealed that training records were complete and current. Appropriate personnel had received facility identified required training, and it was properly documented.

Four process operators, one building (waste handling) operator, two Shift Operations Managers, two First Line Supervisors (FLS), one waste handling FLS and management were interviewed with respect to EP knowledge and skills. Selected questions were asked of operational personnel in an interview. Waste handling personnel were interviewed with pre-selected questions on the job site. Expected answers had also been prepared. It was determined that operational personnel (waste generators) were knowledgeable of environmental protection concerns, and were familiar with procedures used in their area.

A waste bagging operation was observed. The waste handlers, a building operator and supervisor, were interviewed following the operation. Through a set of prepared questions it was determined that they were knowledgeable in this area. As a result of observing the operation, reviewing the procedures in use, and discussions with the waste handlers, it was determined that one procedure contained a decision to be made by waste handling personnel (221-F-55021, Section 2.0 Scope) when, in practice, 
personnel are required by management directive to send all waste collected from a contaminated area to B-25 boxes. The contradictory instruction on waste categorization and waste minimization was documented as an Environmerital Protection finding (0701/1). The Conduct of Operations deficiency noted in this observation, namely, Operations personnel did not take appropriate action when faced with contradictory instructions, was also documented as a finding (see FA 22, firıding 22-08/6).

Additionally, procedure (221-F-55035, Rev. 2) was categcrized as a "Training and Review" procedure but was required to be used every time with initials and signatures. This was documented as a finding in FA-5, Procedures (05-02.12).

In June 1994 a re-assessment of Environmental Protection training and operator knowledge was performed. Interviews of Operations personnel were performed in greater depth than previously. Additional questions were asked related to their knowledge of environmentally related topics associated with the operation of F-Canyon. Also, the maintenance of appropriate training documentation was reviewed.

The assessment determined that the facility did not have a clearly identified program associated with the establishment of environmental training. Recently developed or modified qualification cards were unclear as to specifics of training requirements on environmental protection topics. Much of the knowledgei expected of operations personnel was to be obtained from "required reading" programs and informal training on operational procedure revisions. Training documentation was available, but the timeliness and accuracy of many of the : KRAIN recorcls and facility files was questionable (responsible facility personnel having to spend considerable resources in the review of records and in requesting corrections). Interview of operating personnel indicated that individual knowledge of environmental topics was good in senior personnel and in those fulfilling specific environmental protection functions (such as the Mixed Waste Staging Area Alternate Custodian). Operations personnel interviewed had not been trained on more than rudiments of environmerital topics related to the performance of their assignments, and were not able to satisfactorily answer questions related to unusual situations which might occur during the course of their jobs. While operators correctly indicated that they would seek assistance from either their supervisor, the shift manager, or Separations Environmental Protection personnel, it was felt that the general level of knowledge needed to be strengthened.

Additionally, the facility issued a revised procedure for the handling of low level radioactive wastes for which personnel had not received training at the time of the assessment.

As a result of the review of training documentation, records, procedures and the interview of operations personnel, the reassessment of Checklist 07-01 identified two additional findings against $F$-Canyon. Finding 07-61/2 was written to track deficiencies in the identification of required training on environmental topics and maintenance of training records. Two pre-restart corrective actions were agreed upon and performed by F-Canyon. An Environmental Training Matrix for Operations personnel was developed and approved by the facility, and a schedule for the completion of required training was developed and approved. The completion of the training was agreed to be a postrestart corrective action and is being tracked in the Commitment Tracking System. 
Finding 07-01/3 was written to identify the need to enhance the knowledge of personnel specifically related to the handling of Resource Conservation and Recovery Act (RCRA) hazardous materials, which might become hazardous wastes at F-Canyon and contingency plans for mixed waste staging areas. F-Canyon agreed to provide training and an assessment of knowledge for personnel associated with procedure SOP 221-F55025 (the new procedure for handling low level radioactive wastes at F-Canyon). A Shift Order was issued to ensure that only personnel who had received this training would be allowed to handle low level wastes, and the facility indicated that they would limit this initially to Day Operators. Following completion of training, the ORR Board member administered a test to determine the level of knowledge retained by Day Operators and others who had taken the training. An unacceptable level of retention was identified. As a result, the facility performed retraining of personnel. Separations Training developed and administered a test comparable to that developed by the ORR Board. Facility personnel, following their retraining, successfully passed the facility test. Contingency plan training was identified as a post restart corrective action, because the current.mixed waste staging area is empty, and the contingency plan is undergoing a change. Completion of this training is being tracked by the Commitment Tracking System.

Five deficiencies noted in this area are documented in Findings 07-01/1, 07-01/2, 07$01 / 3,22-08 / 6$ and $05-02 / 2$.

Corrective Actions for these Findings were proposed by the facility and approved by the ORR Board; they are documented in Section 5.2.3 of this report. Implementation of these Corrective Actions, with ORR Board validation, provides assurance that the facility has achieved the state of readiness for this Functional Area as defined in the Restart Plan.

\section{Functional Area 8 - Quality Assurancé}

The ORR Board assessment in this functional area focused on verification that Phase I Startup activities were being performed with commensurate controls and oversight. The assessment was performed using review methodologies including document reviews, interviews of appropriate personnel and confirmation walkdowns to verify completion of corrective actions.

Audit reports were reviewed to determine that findings have been dispositioned. Of the two audit reports selected for review all items have been either closed or dispositioned with future due dates.

Additionally two surveillance reports were reviewed. One had 22 deviations, one of which remained open (i.e. a revision to a laundry procedure, now in draft), and the other had 12 deviations, with one remaining open (i.e. revise or cancel a maintenance procedure).

Three reports (two surveillance and one audit) were selected randomly for field verification of status of deviations. It was found that all deviations from these selected reports had been listed as closed. Verification indicated that all were closed. 
A review of procedure documentation and control was conducted as one of the lines of inquiry for this functional area. Procedure SOP 221-F-50650, Records Management Program Overview, was reviewed. It appears to be satisfactory; however, practice indicates that some records are not available or easily auditable. For example, some fire protection system test records were not retrievable (Finding 12-02/7), a completed procedure for the 221-F diesel load test, conducted in November 1993, could not be found (Finding 10-01/2), and Preliminary Investigation records for reportable occurrences are not being filed according to procedural requirements (Finding 17-02/2). Taken together these findings indicate a systematic problem with record retention and retrieval (Finding 08-02/1).

Four SOPs were randomly selected to check location and control of revisions. All versions were correctly stored in the F-Canyon Control Roorn and controlled, with the correct revision in use.

NCRs and CARs were reviewed for prioritization; 14 had been dispositioned with only 1 pertaining to Phase I restart.

Software control was reviewed to determine the status of F-Canyon software in accordance with $1 Q$ in QAP 20-1. It was determined that discrepancies exist in software nomenclature between lists as well as functional classifications (Finding 08 04/2). Additionally, it was determined that an approved soltware Quality Assurance Plan (SQAP) did not exist for 221-F MacSym (Finding 08-04/1).

Three discrepancies were noted in this area and are documented in Findings 08-02/1, 08-04/1 and 08-04/2.

Additionally, the ORR review of Functional Area 10, Maintenance and Surveillance, identified deficiencies in quality assurance that are reported in the next section of this report. These additional deficiencies led to Quality Assurarice Findings 08-05/1, 0805/2, 08-05/3 and 08-05/4.

Corrective Actions for these Findings were proposed by the facility and approved by the ORR Board; they are documented in Section 5.2.3 of this report. Implementation of these Corrective Actions, with ORR Board validation, provides assurance that the facility has achieved the state of readiness for this Functional Area as defined in the Restart Plan.

\section{Functional Area 10 - Maintenance and Surveillance}

ORR Board assessment of the Maintenance and Surveillance Functional Area focused on verification that the major elements of the maintenance program were in place and functioning properly to assure that maintenance activities were conducted appropriately in support of operations with an adequate level of administrative support.

Assessments included evaluation of the Installed Process Instrument (IPI) Calibration Program, review of Preventive Maintenance and Surveillance Testing activities and a determination of the adequacy of the maintenance administrative support programs: 
Assessments were performed by a variety of established methods, including document reviews, personnel interviews, field walkdowns and personal obseryations.

Documentation for the calibration of equipment classified as Nuclear Safety (NS) and Critical to Protection (CP) for phase I operations was reviewed to verify completeness of required historical records and compliance with administrative procedures. Reviews of completed work packages indicated that approved procedures were in place and referenced.

Surveillance testing is scheduled, tracked, and statused as required; relevant information is maintained in the "Surveillance Tests Status report".

Three Work Control planners were interviewed to determine their understanding and implementation of Work Control administrative procedures. Each of the three had an acceptable level of knowledge of the appropriate procedural requirements and had received both administrative and on-the-job training as well as an independent over check to ensure that they carried out the procedural requirements properly.

Maintenance field activities were observed to verify that procedures were being utilized and followed correctly. Observations included electrical troubleshooting of a Motor Control Center, calibration of a strip chart recorder and replacement of a leaking steam gasket. These activities were conducted appropriately; no deficiencies were noted.

Interviews with field personnel revealed that calibrations of IPI were not being performed in accordance with procedural requirements stating that Measuring and Test Equipment (M\&TE) used to calibrate IPI shall have an uncertainty of one-fourth that of the IPI being calibrated. Technical justifications, for this deviation from procedural requirements, were not being provided on an individual basis(Finding 08-05/1).

A review of the IPI database for Phase I calibrations revealed that calibration frequencies had been extended for sixteen NS Class components. Properly approved technical justifications for these extensions were not available in the IPI history files (Finding 08-05/2). Additionally, a review of calibrations for the period June-October, 1993, revealed that six NS/CP instruments had failed calibration. The associated IPI history files did not contain or reference completed and evaluated Out-of-Calibration Notices (Finding 08-05/3). Review of the M\&TE files revealed that records for two NS component calibrations (of four sampled) did not provide required traceability documentation (Finding 08-05/4).

A review of Preventive Maintenance (PM) activities for January, 1994 indicated that PM was either worked as scheduled, within the allowable grace period, or appropriately deferred. A check of Surveillance testing records for November and December, 1993 revealed that a completed design load test procedure, performed on 11/23/93, for the 221-F diesel (NS Class) was not retrievable. Although the facility can take credit for the previous semi-annual load test, conducted in May 1993, to meet the twelve month OSR test requirement, a Finding (10-01/2) was approved to allow the facility to properly address the issue of the missing test procedure. 
Four completed PM packages were reviewed to verify compliance with requirements of Work Control and Preventive Maintenance F-Canyon procedures. This review showed that $P M$ delinquencies were not being signed by the area maintenance manager (Finding 10-01/1).

An evaluation of field-complete work packages concluded that a significant number (105) were not yet through the closure process which includes a review by both Technical and Quality personnel. The oldest of these packages dated back one year (Finding 10-02/2). Review of packages and discussions with personnel also revealed that Work Clearance Permits were routinely discarded at the completion of field work, rather than filed and maintained as required by published site requirements (Finding 1002/3). A review of six corrective maintenance (CM) work packages in the ready-to-work category, and twelve completed packages for NS/CP Class equipment was conducted; content of the packages and compliance with procedural requirements were acceptable.

Nine maintenance procedures were reviewed to verify completeness and compliance with administrative requirements. Although the reviewed procedures were generally acceptable, it was determined that when procedures were canceled, i.e. replaced with a more relevant procedure, there was not an administrative mechanism in place to ensure that the Installed Instrument Database was updated with more current information. As a result, there were procedures incorrectly referenced as current calibration procedures on instrument data sheets that had been canceled some months earlier (Finding 1003/1). In all cases reviewed, an over check conducted routinely by Work Control personnel identified the correct procedure prior to field work being performed.

Nine deficiencies noted in this area are documented in Findings 08-05/1, 08-05/2, 08$05 / 3,08-05 / 4,10-01 / 1,10-01 / 2,10-02 / 2,10-02 / 3$, and 10-03/1.

Corrective Actions have been proposed by the facility, and approved by the Board, to address the programmatic nature of the findings in this functional area. Implementation of these Corrective Actions, with ORR Board validation including field checks to verify successful implementation, provides assurance that the facility has achieved the state of readiness for this Functional Area as defined in the Restart Plan.

\section{Functional Area 11 - Radiation Protection}

Based on the justification of readiness in the Restart Plan, this Functional Area received only a limited scope assessment. The review addressed the completeness of Radiological Work Permits (RWPS) and the proper use of RWPs during work in progress. As a result of observations incidental to the plarined lines of inquiry, the assessment was extended to include calibration of installed area gamma monitors and personnel monitors, and the use of deficiency tags on area monitors. The assessment was performed in two field verification periods, the first in December 1993 and the second in June 1994. The facility performed an additional self assessment of this functional area in May 1994 and had two findings described in Section 5.2.4.

During the first assessment period, work performed by maintenance personnel in Contaminated Areas was observed on two occasions. The Radiological Work Permits used were inspected for completeness and proper approvals and were found 
satisfactory. An interview with the Radiological Control Operations manager verified that they are reviewed before and after the job for ALARA considerations. During performance of this work, no violations of the RWP requirements or RadCon good practices were observed.

As the result of the observation of an out of service Area Radiation Monitor (ARM) in Section 13 of the Canyon second level, a review was performed of compliance with the requirements for operable ARMs. The technical justification for the number and placement of ARMs in the Canyon and Outside Facilities was reviewed (NMP-EFA930235). This document states that if an ARM is out of senvice it is the Control Room supervisor's responsibility to request compensatory monitoring from RCO if an increase in radiation field could occur in that area due to planned transfers. On interviewing a Control Room supervisor it was determined that there was no record kept in the Control Room of ARMs out of service. This generated finding 11-01/2 for which the corrective action was to use Operations Deficiency Tags for ARMs (rather than RCO deficiency tags) and log them in the Control Room log book.

One case of a missing current calibration label was noted on a gamma monitor; it was corrected immediately. An inspection of thirty more fixed and portable radiation monitors found this to be an isolated case.

During the second assessment period, further observations were performed of different phases of eight jobs involving work in RCAs, including Operator rounds, maintenance work, and a Radiological Control survey. In addition, a general tour of the F-Canyon RCAs was conducted. A review of documents included nine Radiological work Permits, three ALARA reviews and three Separations work procedures. Interviews were conducted of personnel involved in radiological work.

It was noted, during a number of observations and discussions relating to the RWPs in use, that there was incomplete understanding of the proper use of estimates of extremity dose. When extremity dose could be the limiting exposure for a job, pre-job briefings did not adequately cover the precautions. The facility self assessment also identified weaknesses in the understanding and use of inforrnation contained in RWPs (Finding RSA-11-01), and the corrective actions that were implemented specifically addressed the weaknesses noted by the Board.

On several occasions it was observed that excess materials were carried into RCAs unnecessarily generating contaminated waste. Also, recyclable rubber gloves were not being recycled (Finding 11-01/3).

It was also noted that tool control practices were unsatisfactory. This had been noted by the facility in their self assessment and a finding generated (Finding RSA-11-02). The corrective actions for this finding addressed the Board's concern.

Observations of work in progress in potential airborne contamination areas indicated that Radiological Control Operations was not taking air samples that are sufficiently representative of the atmosphere in the vicinity of the workers (Finding 11-01/4). During the same observations, personnel were observed using full-face respirators more than 
once while in a contamination area. This is not in accordance with WSRC Manual $5 Q$ (Finding 11-01/5).

The deficiencies noted in this area are documented in Findings 11-01/2, 11-01/3, 11 $01 / 4$, and 11-01/5.

Corrective Actions for these Findings were proposed by the facility and approved by the ORR Board; they are documented in Section 5.2.3 of this report. Implementation of these Corrective Actions, with ORR Board validation, provides assurance that the facility has achieved the state of readiness for this Functional Area as defined in the Restart Plan.

\section{Functional Area 12 - Fire Protection}

Fire protection aspects of the F-Canyon were examined to ensure adequate protection of personnel, equipment, and overall structure: In addition to a review of pertinent documents and program plans, walkdowns of the facility were conducted. Operators and supervision responsible for facility operation were interviewed to determine their level of knowledge of fire protection programs, fire system operation, fire alarms and appropriate responses, and fire hazards of the facility.

The Fire Protection Program Plan (FPPP), SOP-221-F-51120, was reviewed for compliance to WSRC requirements and DOE Orders; Plan content was determined to be adequate. A review and walkdown were conducted of the Life Safety and Security interfaces for compliance with WSRC requirements and DOE Orders which revealed no deficiencies in documentation. The Fire Department Preplan (WSRC-2Q2-4-F) was reviewed for proper format and content, including: facility construction and fire systems, hazardous materials inventory and emergency response conditions, and facility interaction during emergencies. This review concluded that the Preplan document contained sufficient information. Operators, supervision, and facility emergency response personnel were interviewed to evaluate their knowledge of the Fire Protection Program Plan and emergency response procedures. All personnel were knowledgeable of contents and requirements of the Fire Protection Program Plan and associated emergency response requirements.

Review of the Fire Hazards Analysis (FHA), M-FHA-F-00026, for correct content and approvals, and a walkdown of the facility were made to determine the adequacy of FHA contents. The review and walkdown revealed deficiencies in the technical content of the FHA (Finding 12-01/1). Also, the facility response to previously conducted Emergency Light Surveys had not been submitted stating corrective actions and completion dates (Finding 12-01/2).

Compensatory Actions contained in the Compliance Schedule Assessments (CSAs) Numbers 026, 065, and Short Term Compliance Schedule (STCS) Number 93-013 were reviewed for content and applicability. This review found that scheduled firewatch rounds were inconsistent and unaccounted for (Finding 12-02/5), and the program lacked justification for the rationale for locations toured and the amount of time allotted for rounds (Finding 12-02/6). 
A walkdown was conducted to verify proper implementation of the FPPP. Deficiencies that were identified in proper implementation of the plan included inadequacy of fire detection equipment in the Hot and Warm canyons, needed correction of PA system problems and potential impact on facility ventilation by the loss of the 292-F Emergency Generator (Findings 12-02/1, 12-02/2 and 12-02/3). The Emlergency Light program is inadequate in that impaired lights are not replaced with spares to maintain continuous coverage in an emergency (Finding 12-02/4). Additionally, required records could not be located to verify that specific Fire Protection equipment had been tested as required (Finding 12-02/7).

Deficiencies were noted in the Life Safety and Security interfaces where the potential exists to inadvertently lock personnel in rooms and restrict means of exit (Finding 12$03 / 1)$.

The walkdown that was conducted to check the Fire Department Preplan content against facility components, hazards, and fire systems identified lack of training for some personnel on operation of manual fire systems located at the Hot and Warm Canyons and located at the four Motor Control Centers (Finding 12-05/1).

Board members observed a facility emergency drill for proper response to the drill scenario and attended the drill critique to evaluate facility response to drill conditions. Deficiencies noted with credibility of the scenario were documented as Finding 13-01/1 in the Emergency Preparedness Functional Area.

Eleven discrepancies were noted in this area and are documented in Findings 12-01/1, $12-01 / 2,12-02 / 1,12-02 / 2,12-02 / 3,12-02 / 4,12-02 / 5,12-02 / 6,12-02 / 7,12-03 / 1$ and $12-$ $05 / 1$.

Corrective Actions for these Findings were proposed by the facility and approved by the ORR Board; they are documented in Section 5.2.3 of this report. Implementation of these Corrective Actions, with ORR Board validation, provides assurance that the facility has achieved the state of readiness for this Functional Area as defined in the Restart Plan.

\section{Functional Area 13- Emergency Preparedness}

The scope of the review of the Emergency Preparedness (EP) Functional Area was based on selected criteria from the F-Canyon Startup Plan with the objective of validating EP program adequacy. Several aspects of the program were examined including program planning, event classification, emergency equipment, and personnel training in Emergency Preparedness.

The ORR review of this Area was accomplistred through both compliance and performance based assessment techniques. These techniques included review of lesson plans, exercise scenarios, procedures, and other E:P-related documentation (Material Safety Data Sheets, Emergency Action Levels, training records, etc.). In addition, several facility personnel with EP-related responsibilities were interviewed and two emergency preparedness exercises were observed. 
Interviews with facility personnel indicated that they had received appropriate training and were adequately aware of EP procedures and their responsibilities in an emergency situation. Emergency Plan procedures were found to have received required reviews and approval signatures and Emergency Action Level (EAL) criteria were established and incorporated into the EP Implementing Procedures (EPIPS). Procedure reviews and walkdowns of both normal and emergency facilities revealed that procedures utilized in equipping the facilities for emergency response were satisfactory as was their implementation. Equipment was found to be stored in sufficient quantity in appropriate locations throughout the facility and was inspected on a regular basis, although evidence of monthly EP equipment inspections which are required by procedure could not be produced (Finding 13-05/1).

Further review of EP-related issues identified deficiencies in the scope of the training. In particular:

- F Canyon emergency responders had not received hazardous training for responding to hazardous material spills (Finding 13-01/2), and

- drill scenarios for quarterly and ORR evaluated drills were limited in scope in that hazardous material emergencies were not considered (Finding 13-01/1).

Investigation into the qualifications of EP personnel revealed that the $\mathrm{F}$ Canyon EP Coordinator was not adequately qualified to perform this function. Although assistance is provided to compensate for this inadequacy by the F-Area EP Coordinator, it is done on an informal basis which does not meet the intent of the SRS Emergency Plan Manual (Finding 13-02/1). It was also noted that although the F Canyon organization charts identified the position of an EP Coordinator, no job clescription existed for this position (Finding 13-02/2).

Additional review of personnel qualifications revealed that not all Shift Managers and FCanyon Control Room supervisors had taken the Area Emergency Controller (AEC) and Facility Emergency Controller (FEC) Overview within the last 12 months and were therefore not qualified as AECs or FECs (Finding 13-07/1).

The scope of the procedures was found to be deficient in that all hazardous materials are not adequately covered (Finding 13-04/1). It was also noted that a Hazards Assessment with compensatory measures has not been prepared; however, this inadequacy is covered by a Compliance Schedule Agreemert (CSA) which is pending approval by DOE. The review also revealed a discrepancy between F Canyon and FB Line Implementing Procedures for stack radiological release rates for Notification of Unusual Events (Finding 13-04/2). While the FB Line threshold for an Unusual Event is $0.30 \mathrm{mCi}$, the release for $\mathrm{F}$ Canyon was arbitrarily set at $0.270 \mathrm{mCi}$.

The review of EP procedures also indicated that the F-Cianyon and F-Area EPIPS contradicted each other in the required responses to an event. The F-Area procedure required personnel to remain indoors for a radiological event while the F-Canyon procedure states that this action is to be taken only for a toxic gas release (Finding 13$03 / 1)$. 
The ORR assessment included observation of two Emergency Preparedness drills which were conducted on January 14 and February 24,1994. The drills resulted in several observations, both positive and negative in nature, which are discussed in detail in ESH-ORR-94-0002-O and ESH-ORR-94-0004-O. Of these observations, two were deemed to be of sufficient significance to warrant their being categorized as a finding. These are:

- The AEC incorrectly classified the initial incident when it was the FECs duty to classify the event. During follow-up investigation of this deficiency it was noted that EPIPS specify that the AEC is to classify emergencies for F-Area while the FEC is responsible for classifying emergencies for $F$-Canyon. This practice contradicts the Concept of Operations for normal activities as discussed in the report on the drill, ESH-ORR-0002-O (Finding 13-07/02).

- Radio coverage and phones in the OSC were inadequate to support emergency response requirements during the exercise (Finding 13-06/1).

- Areas were also noted in which the PA system could not be relied upon for effective communications, which is addressed in Functional Area 12, Fire Protection (Finding 12-02/2).

The ORR drill observers noted that certain deficiencies observed during the drill had been observed during previous $\mathrm{F}$-Canyon drills. Follow-up reivealed that the corrective actions for shift drill deficiencies were not tracked and were therefore, not being implemented in a timely manner (finding 13-01/3). The Board also noted that a tracking system for F-Canyon Emergency Response Ofganization drill participation did not exist (Finding 13-07/3). Procedure EPAP-303, Drills and Exercises, will be revised to require all drill deficiencies to be entered into a data base system and tracked to closure.

Thirteen (13) discrepancies noted in this area are documented in Findings 13-01/1, 13$01 / 2,13-01 / 3,13-02 / 1,13-02 / 2,13-03 / 1,13-04 / 1,13-04 / 2,13-05 / 1,13-06 / 1,13-07 / 1$, $13-07 / 2$, and $13-07 / 3$.

Corrective Actions for these Findings were proposed by the facility and approved by the ORR Board; they are documented in Section 5.2.3 of this report. Implementation of these Corrective Actions, with ORR Board validation, provides assurance that the facility has achieved the state of readiness for this Functional Area as defined in the Restart Plan.

\section{Functional Area 17 - Issue Management}

Based on the Restart Plan, Issue Management is a secondary Functional Area for which a limited number of criteria are to be evaluated for restart. The objective of the ORR review was to examine the end product of the facility process by verification that abnormal events were identified and investigated by qualified personnel, that notification and reporting were accomplished according to procedure, and that corrective actions were adequate, properly prioritized, and tracked to completion.

The evaluation consisted of verifying the existence, adequacy and implementation of procedures associated with the handling of abnormal events (e.g., notifications, 
investigations, tracking of corrective actions). In particular, the ORR examined the Commitment Tracking System (CTS) and prioritization of work initiators and corrective actions. Compliance of the facility trending and lessons learned programs was evaluated. This review was accomplished through procedure reviews, interviews with personnel involved in the processes, observation of corrective action prioritization meetings, and walkdown of corrective actions identified as being completed.

Positive observations pertaining to the handling of abnormal events were noted during the review of the Issues Management Functional Area. Personnel responsible for the conduct of Preliminary Investigations (PI), or Critiques, were found to be knowledgeable of the process and investigative techniques. A sampling of recent Occurrence Reports revealed adequate documentation of these events. Also noted was the process used for determination of whether a corrective action listed in the Commitment Tracking System was a pre-startup or post-startup item. Several of the Board members attended prioritization meetings conducted by the facility. The meetings were found to be attended by the appropriate personnel with a thorough discussion of those items whose status was questionable. Facility personnel were later interviewed regarding their impression of the process and were found to be satisfied with the process and final restart status of corrective actions. A sampling of prioritized corrective actions by the Board found the classification of the actions to be reasonable.

A sampling of Commitment Tracking System (CTS) closure packages, including all those associated with the Readiness Self-Assessment corrective actions, revealed the packages to be complete with the Separations.Quality Assurance organization providing a thorough review of the packages prior to final closure. A walkdown of a sampling of corrective actions identified as being completed indicated that they had been properly implemented.

The review noted deficiencies in implementation of event reporting and investigation procedures. These included the lack of facility-level event handling procedures, although an adequate site level procedure was in use (Fincling 17-02/1), and SIRIM training for event report writers (Finding 17-02/5). The Preliminary Investigation (PI), or Critique, process was also examined and personnel responsible for conducting the investigations were found to be knowledgeable of the process and investigative techniques. However, review of PI documentation revealed that Critique Report Forms, which require documentation of the initial analysis of the event and short-term corrective actions to prevent recurrence, were not being used or filed as required by procedures (Findings 17-02/2 and 22-04/1).

A sampling of Occurrence Reports noted adequate documentation of the event. However, deficiencies in Justifications for Operation (JCO) associated with Occurrence Reports (ORs) were observed which included failure to address the time periods during which the corrective actions are to remain in effeet, and arbitrary assignment of JCO expiration dates (Finding 17-02/4).

It was determined that the procedural compliance deficiencies noted during the review were partially due to a lack of adequate oversight by the Separations Operations Review Committee (SORC). This oversight is required by procedure but a review of SORC meeting minutes indicates that the Committee had not performed oversight of the 
occurrence reporting process (Finding 17-01/2). Specific, procedure-required functions which did not appear to be addressed include: (a) confirming the appropriate closure methods for all corrective actions and action items involving occurrences, and (b) ensuring periodic audits of the occurrence reporting and investigation process are performed.

The F-Canyon lessons learned and trending programs were examined for compliance with site procedure compliance. Trending was noted to be in conformance with site requirements, but the lessons learned program had not been effectively implemented on the facility level. A facility procedure defining an effective facility program was found to have been drafted but not formally approved and implemented (Finding 17-02/3).

One Readiness Self-Assessment finding which addressed a backlog of overdue Occurrence Reports (Finding RSA-17-01) was still open at the commencement of field verification of this Functional Area.

Seven (7) discrepancies noted in this area are documented in Findings 17-01/2, 17$02 / 1,17-02 / 2,17-02 / 3,17-02 / 4,17-02 / 5$, and 22-04/1.

Corrective Actions for these Findings were proposed by the facility and approved by the ORR Board; they are documented in Section 5.2.3 of this report. Implementation of these Corrective Actions, with ORR Board validation, provides assurance that the facility has achieved the state of readiness for this Functional Areal as defined in the Restart Plan.

\section{Functional Area 20 - Occupational Safety Health}

Occupational safety and health aspects of the F-Canyon were evaluated to ensure that life safety protection was adequate and in compliance with WSRC requirements and DOE Orders, including: safety training, personnel safety clothing and equipment, and hazardous materials handling and control. Operations and supervisory personnel were interviewed to determine their level of knowledge of safety programs and procedures.

Interviews were held with operators and supervisors to determine their level of knowledge in identification and use of protective clothing and equipment, safety policies and programs, and industrial hygiene requirements. Interviewed personnel were knowledgeable of types of safety equipment and its use. Personnel knew facility safety policies and procedures applicable to the workplace, and they understood hygiene procedure requirements. Personnel understood the Hazards Communication Program and how to access hazardous materials information from Material Safety Data Sheets.

Safety policies, the Quality Improvement Suggestion System (QISS), the Safety Hot Line, and the Safety Observer Program were reviewed to determine compliance with WSRC requirements and DOE Orders. A walkdown of policies and programs was conducted to determine adequacy of safety programs, including: Work Control, Electrical, Welding/Cutting, and Lockout/Tagout. This review identified lack of full attendance at required safety training sessions (Finding 20-01/1), and the facility Safety Program is not fully developed (Finding 20-01/2). 
A review was conducted to evaluate the adequacy of safety equipment requirements, including preventative maintenance and tool inspections. A walkdown was conducted to verify proper application and availability of safety equipment. Deficiencies were identified with inconsistent management safety inspection reporting format (Finding 2003/4), housekeeping (Finding 20-01/3), impaired safety equipment (Finding 20-02/1), management inspections not being done on a regular schedule (Finding 20=03/3), and some Caution Tags not accounted for in the Control Room Log (Finding 20-03/1).

An evaluation was conducted of safety and hygiene audits, surveillances, and inspections for compliance with WSRC requirements. This review included: equipment ticklers for testing and maintenance, OSHA assessments, ESH\&QA oversight, and deficiency tracking. A walkdown was conducted to evaluate the adequacy of safety and hygiene functions, and correction of deficiencies. This review found that a corrective action tracking system does not exist (Finding 20-03/2).

The Hazards Communication Program and hygiene procedures were reviewed to determine compliance with WSRC requirements and DOE Orders, including: protective clothing and equipment, breathing air, heat stress, carcinogens, and noise abatement. A walkdown was conducted to verify proper implementation of programs. The facility has no procedure for working with lead and a finding generated for this deficiency (20-04/1) was canceled when a site level procedure clarified the requirement to make it only applicable to certain forms of lead not present in F-Canyon. The review found required Blood-borne Pathogen training had not been taken by E\&I Mechanics (Finding 20-04/2).

Nine discrepancies noted in this area are documented in Findings 20-01/1, 20-01/2 $20-01 / 3,20-02 / 1,20-03 / 1,20-03 / 2,20-03 / 3,20-03 / 4$ and 20-014/2.

Corrective Actions for these Findings were proposed by the facility and approved by the ORR Board; they are documented in Section 5.2.3 of this report. Implementation of these Corrective Actions, with ORR Board validation, provides assurance that the facility has achieved the state of readiness for this Functional Area as defined in the Restart Plan.

\section{Functional Area 22 - Conduct of Operations}

The review of the Conduct of Operations Functional Area was based on selected principles from the WSRC Conduct of Operations Manual. The review included assessing the adequacy of Control Room personnel awareness of facility status, identification of and response to deficiencies, procedure aclequacy and compliance, implementation of the lockout/tagout program, equipment labeling, and implementation of the Shift Technical Engineer position. The ORR review was conducted over two separate periods. The first review was performedin accordance with the ORR plan in February and March 1994. An additional review, repeating many of the same lines of inquiry, was performed in June 1994.

The determination of the adequacy of compliance with the criteria pertaining to these areas was accomplished through interviews with Operations personnel (including Shift Technical Engineers), and through observation of routine Control Room activities, 
conduct of cold-chemical runs, and an Emergency Preparedness drill. In addition, procedures and procedure compliance were examined, shift turnovers were observed, logbooks were reviewed, and facility walkdowns were conducted to assess labeling and verify compliance with lockouts/tagouts procedural requirements.

The ORR review found that Operations management is committed to eontinuous improvement in the Conduct of Operations. Additional training in Conduct of Operations requirements and practices has been provided to all personnel. Interviews revealed that Operations personnel have, in general, an adequate knowledige of proper practices and requirements pertaining to communications, procedure complliance, lockout/tagout, etc. Shift turnover practices were observed and found to be in compliance with Conduct of Operations guidelines. Turnover effectiveness was assessed through personnel interviews which noted that personnel possessed a thorough awareness of overall facility status and anticipated evolutions. Effective control of access to control areas and the use of proper independent verification techniques were also noted and Operations personnel stated that problems with equipment, arid concerns, were typically addressed in a timely and effective manner.

However, deficiencies were noted in the implementation of some requirements. During observation of Control Room activity and an Emergency -Preparedness drill, weaknesses were noted in implementation of Conduct of Operations guidelines for communications as stated in the 2S Manual, Procedure 2.1. In particular, operating directions were not acknowledged by repeating the information back (Finding 22-08/2) .

An additional finding pertaining to implementation of Conduct of Operations guidelines was noted in procedure compliance. Several completed and audited Operations procedures did not have a signature for the verification of correct revision numbers. Also, failure to circle abnormal data points on Operations round sheets was found to be at a higher than acceptable rate (Finding 22-02/1). Failure to comply with procedure use guidelines was also noted during a waste disposal operation. Contrary to Conduct of Operations guidelines, a procedure prerequisite was routinely not complied with (Section 2.0 of SOP 221-F-55021, Rev. 2) and personnel performing the procedure did not initiate a needed procedure change request (Finding 22-08/6). (See discussion under FA-7, Environmental Protection).

Also relating to procedures, a deficiency was noted in operator awareness of Alarm Response Procedure usage requirements. Guidelines for use of Alarm Response Procedures had not been clearly defined and interviews revealed that Control Room personnel were not clear as to whether these procedures were in use or whether their use is optional or mandatory (Finding 22-08/1).

Observation of Cold Feed startup operations revealed another concern when it was noted that certain sections of the procedures in use contained critical steps but had no initial or checkoff spaces as required by the S1 Manual. Guidelines for use of initialed steps were modified following approval of this Finding, with $S 1$ requirements being superseded by the 2S Manual. The guidelines now state that only those steps which would affect certain specific concerns (e.g., quality, safety, environment, technical limits) require initialing. The facility has stated that all steps which would affect these concerns 
have been previously identified and are already required to be initialed. Therefore, the finding (22-08/5) was canceled.

Other deficiencies were noted in the record of equipment status maintained in the Control Room. Specifically, the Control Room Deficiency Tag Log Book was found to contain a transcription error in the entry for a tag, a duplicate entry for another tag, and was missing the entry for another tag (Finding 22-03/1).

A deficiency related to the tagout/lockout process included the observation that facility locks were not adequately controlled. The Second Level 221-F Lock board was found by an ORR Board member to be unlocked which is a violation of the $8 Q$ Manual, Procedure 32, Section 6.13 and 6.14 (Finding 22-06/2). Additionally, the Canyon Shift Managers, who are responsible for authorizing installation and removal of lockouts/tagouts for the Outside Facilities, were found to be not listed in the Outside Facilities Operations Lockout/Tagout Authorization List (Finding 22-06/1).

Related to this finding was the observation that adequate control of the Control Room safe was not maintained. The safe was noted to be continually open with classified documents in view and not in the direct line-of-sight of Ciontrol Room personnel. Unauthorized personnel had ready and unnoticed access to classified documents on several occasions (Finding 22-08/4).

Review of the use of operator aids resulted in a single finding addressing two related issues. The S1 Manual, Procedure OP2.17, Attachment 8.1 defines operator aids as including plaques, conversion charts, and formulas posted in the vicinity of installed indicating equipment (e.g., gages, meters, recorders, etc.). There are several specific gravity meters in the Control Room with "semi-permanent" labiels which are conversion formulas. These labels are not listed in the Operator Aid logbook. The facility operator aid procedure definition of operator aids allows use of these labels without their being logged, indicating a discrepancy in the procedures (Finding 22-08/3). In addition to and included in Finding 22-08/3, it was noted that there is a conversion chart on the stack monitor which is contained in the Radiological Control Operator Aid log but is not in the Operations Operator Aid log.

The interview process revealed that an individual serving as the Shift Manager did not appear to be qualified as required by the Restart Plan coinmitment to DOE Order 5480.20 requirements. Further investigation revealed that, although not qualified per the current qualification standards, it was the position of the facility that the individual was qualified to oversee non-discretionary operations per the prior qualification standards. No corrective actions were deemed necessary by the facility except to restrict the range of activity which the Shift Manager was allowed to supervise (Finding 04-02/2).

As. a result of the investigation involved with Finding 04-02/2 (above), an additional Finding was documented. It was noted that the F-Canyon "Basis for Interim Operation" (U) (WSRC-RP-93-1215 (Draft), Section 6.2.9 requires a Control Room Supervisor or a designated, qualified individual in the Control Room at all times. SOP 221-F-50133, "FCanyon Shift Operating Crew Staffing Requirements (U)" states that "authorized deviations from minimum staffing requirements are not consiclered to be. violations". A 
facility procedure must be in compliance with the Authorization Basis and cannot authorize deviations from Authorization Basis requirements (Finding 06-07/5).

Review of the facility labeling program revealed that equipment and system components are currently being renumbered and re-labeled to meet Conduct of Operations Manual guidelines. ORR interviews with facility personnel could not verify that all consequences of component renumbering (e.g., work packages, drawings, authorization basis documentation) had been adequately determined and assesised (Finding 22-09/2). In addition, temporary paper labels which had deteriorated were observed in the facility (Finding 22-09/1). The labels were in the Hot Gang Valve Corridor and were intended to identify changes to connections made when a particular valve was operated.

It was noted during interviews with Shift Technical Engineers (STES) that STE duties are not clearly defined or understood and that no description of the position responsibilities existed (Finding 22-10/1).

Review of the Preliminary Investigation process (i.e., reportable occurrence critique process) noted that event data collection was thorough. However, the Critique Report Forms (Attachment B of Manual 2S, Procedure 5.2) were not being used or filed as required by the $2 S$ Manual (Findings 22-04/1 and 17-02/2).

During the second assessment of Conduct Of Operations in June 1994, several observations were made of work in progress in $221-\mathrm{F}$ and of the simulated dry runs for Second Plutonium Cycle.

Weaknesses in the use of operator round sheets continued to be noted (see description of Finding 22-02/1 above). Specifically red circled (abnormal) data was not always appropriately annotated with an explanation. Changes were sometimes made in initial reading values without appropriate review and approval. Limit values for an OSR related item were not specified on the round sheet procedure. Rounds were not always performed within the specified time periods and the justification was not documented. These deficiencies were documented as Finding 22-02/2.

The performance of several lockouts was observed and the associated documents were reviewed. On one occasion a lockout was prepared without adequate reference documents and without a field walkdown of the actual configuration. On two occasions it was observed that incorrect work activity numbers were entered on the lockout. On one occasion the valve operation sequence was not followed correctly. Finding 22-06/3 was generated and corrective actions were implemented to acldress these deficiencies.

It was observed that the administrative control of immediate procedure changes (IPCs) was inadequate in that they were not always available to personnel the next time the procedure was due to be performed and, in one casse, were not retained as retrievable documentation for a temporary modification which was still in place (Finding 22-08/7).

During observation of routine testing of a valve it was noted that the test acceptance criteria were inadequate in that subjective judgment of the mechanic was required. Follow-up revealed that the test did not comply with vendol recommendations. This 
generated Finding 22-08/8 and the corrective action included an engineering. review of acceptance criteria for the testing and calibration of similar equipment and instruments.

The ORR Board was of the opinion that all of the above Conduct of Operations deficiencies, and others that were not by themselves of sufficient significance to warrant a finding, indicated that management oversight of Operations and the management assessment process was lacking in some respects. The ORR Board observed that the management assessments that were being conducted according to Manual $2 S$ assessment cards were too narrowly focused. Also the operators, mechanics and supervisors, who should be the first line of defense against errors, did not have a sufficiently 'questioning attitude to confusing, incomplete $\mathrm{cr}$ inadequate procedures. Finding 22-01/1 was generated to capture these deficiencies.

The corrective actions for Finding 22-01/1 placed added emphasis on management observations of preparations for, and performance of, routine and non-routine job evolutions, including review of the supporting documents. Weaknesses observed by management are to be communicated to personnel as evaluative contacts and formal remedial training will be provided, as appropriate.

During validation of closure of this finding the Board observed successful implementation of the corrective actions by accompanying management on two assessments and by reviewing the documentation for six: assessments performed according to the revised guidelines. The Board does not expect that these actions by themselves will produce a step change improvement in F-Canyon Conduct of Operations. However, if the management emphasis is maintiained over the long term, a steadily improving trend should result. The facility management is committed to continuous improvement in Conduct of Operations.

Twenty-one (21) discrepancies were noted in this area and are documented in Findings $04-02 / 2,06-07 / 5,17-02 / 2,22-01 / 1,22-02 / 1,22-02 / 2,22-03 / 1,22-04 / 1,22-06 / 1,22-$ $06 / 2,22-06 / 3,22-08 / 1,22-08 / 2,22-08 / 3,22-08 / 4,22-08 / 6,22-08 / 7,22-08 / 8,22-09 / 1$, $22-09 / 2$, and $22-10 / 1$.

At commencement of the ORR field verification for this Functional Area, there was one unclosed Readiness Self-Assessment finding, namely, orly two of fourteen safety related systems operating procedures have been revised to include Independent Verification requirements (Finding RSA-22-01).

Corrective Actions for these Findings were proposed by the facility and approved by the ORR Board; they are documented in Section 5.2.3 of this report. Implementation of these Corrective Actions, with ORR Board validation, providess assurance that the facility has achieved the state of readiness for this Functional Areal as defined in the Restart Plan. 


\subsubsection{ORR Review Findings and Corrective Actions}

This section lists the findings identified by the ORR Board during the performance of the review. The finding numbers correspond to the applicable Functional Area checklist, with multiple findings on the same checklist numbered consecutively. The-Corrective Action Completion Dates are the dates proposed by the facility and are the dates by which Corrective Actions are, or were, anticipated to be ready for Separations QA completion review. Corrective actions are considered closed when the ORR Board has reviewed the Punchlist $A$ closure packages and has validated completion by further field assessments where appropriate.

\section{Iraining and Quallification}

04-01/1 The F-Canyon Restart Plan establishes training for, and use of, Shift Technical Engineers (STE) in a compensatory role for a lack of knowledge/expertise in operator and supervisors. No objective evidence can be found to indicate an analysis of what knowledge and skills are necessary for the STE to ensure safe and reliable operation of the processes.

Corrective Action(s) -

1) Perform a "content analysis" of the STE systems training.

Punchlist Category A Completion Date-03/01/94

2) Facility management review and approve identified objectives for STE systems training.

Punchlist Category A Completion Date - 03/05/94

3) Evaluate the current STE systems training test against the newly identified learning objectives, and retrain / retest if needed, on the delta per standard sampling plan.

Punchlist Category A Completion Date-03/15/94

4) Complete systems training for Operations Operators, FLS, and SOM.

Punchlist Category B Completion Date-12/31/94

04-02/1 DOE ORDER 5480.20 (Chapter 4, paragraph $5 \mathrm{c}$ ) states that "the supervisor training program .... shall be of increased depth to reflect the added responsibility of the supervisor position". Objective eviclence of an analysis of "increased depth" of supervisor operational training cannot be found.

Corrective Action(s) -

1) Revise Qualification Cards / Standards to include "enhanced" training for supervisor personnel.on "systems", and "processes".

Punchlist Category A Completion Date -03/31/94

2) Reconstruct the "needs analysis" for 2nd Pu, and Dissolving for the FLS and SOM for enhanced technical training. 
Punchlist Category B Completion Date -6/30/94

3) Perform a "needs analysis" for all other Quality Areas in F-Canyon.

Punchlist Category B Completion Date-6/30/94

4) Compare the current training to the "needs analyses", and review and revise training materials, as needed.

Punchlist Category B Completion Date - 8/30/94

5) Complete any additional training identified for FLS / SCM.

Punchlist Category B Completion Date-12/31/94

04-02/2 The F-Canyon Restart Plan states that Organization and Staffing in F-Canyon meets the requirements of the referenced governing DOE and WSRC procedures. Observation and interviews have indicated use of a non-qualified shift manager as sole supervisor for relief in the Control Room.

Corrective Action(s) -

1) The F-Canyon policy on required qualifications, "Pre restart" and "At restart", as stated in NMP-SFC-94-0115, dated $3 / 1 / 94$, will be issued formally to $F$ Canyon Operations Personnel.

Punchlist Category A Completion Date-3/31/94

2) At restart the watch standing list used for the assignment of shift personnel will clearly show who is qualified for non-discretionary operations and who is additionally qualified for Phase I operations (Second Pu Cycle operations and Dissolver operations).

Punchlist Category A Completion Date-3/31/94

04-03/1 DOE Order 5480.20 requires operators to be trained on facility systems. The DOE Guides to Good Practices for Qualification of Chemical Process System Operators provides further guidance. The qualification standard developed for operators does not identify systems training as a requirement for qualification.

Corrective Action(s) -

1) Revise Qualification Cards / Standards to show requirements for "systems training" for qualified F-Canyon Operations personnel.

Punchlist Category A Completion Date-03/31/94

04-05/1 DOE Order 5480.20, Chapter 1, paragraph 8.a. requires that procedures be established for examinations (both written and oral) which cover, among other things, security and administration of examinations. Objective evidence is not available to ensure examination security forwritten or oral examinations. Oral boards were given at widely ranging scheduled times with like sets of questions. Written exams appear to have been repeated several times before creating new versions.

Corrective Action(s) - 
1). Issue memo describing Facility Manager confidence in the product of the qualification process.

Punchlist Category A Completion Date-3/11/94

2) Develop a facility (or F-Area) procedure describing the "control and administration of exams" (similar to the procedure in use in Tritium).

Punchlist Category B Completion Date -3/31/94

3) Develop oral board questions based upon learning oljectives of the required training materials

Punchlist Category B Completion Date - 3/31/94

04-06/1 DOE ORDER 5480.20 requires that "individual operator training shall be sufficiently comprehensive to cover areas which are fundamental to the candidates assigned task". F-Canyon Startup Plan says a fundamentals analysis will be completed for operator and supervisor positions prior to restart. It also stated that all operators would receive Math and Chemistry fundamentals training prior to restart. Although Math and Chemistry fundamentals was complete it was not based on the analysis and needs of the F-Canyon.

Corrective Action(s) -

1) Develop the "delta" Math and Chemistry course.

Punchlist Category A Completion Date -03/01/94

2) Teach the "delta" Math and Chemistry to all who have already completed the original Math and Chemistry.

Punchlist Category A Completion Date-05/31/94

3) Revise all Basic Engineering Technology (BET) fundamentals courses to include the topics identified as required by the F-Area Fundamentals Analysis. Each course will be revised before it is taught. All must be complete by the end of 1994.

Punchlist Category B Completion Date-12/31/94

\section{Procedures}

05-02/1 2S and S-1 Procedure OP 2.16.02, Rev. 2 (Procedure Administration) requires a walkdown of each operating procedure prior to approval/use. Walkdown "sheets" are included in each procedure historical file. In the Phase 1 procedures audited, some walkdown sheets were not assigned reviewers or signed.

Corrective Action(s) - $\quad$;

1) Review/update all approved Phase 1 Restart procedure packages for proper documentation.

Punchlist Category A Completion Date-01/07/94

2) Develop checklist identifying documentation required for each procedure package. 
Punchlist Category B Completion Date - 12/13/93

3) Train clerical support on using checklist to ensure enclosure of proper documentation and prevent recurrence:

Punchlist Category B Completion Date - 12/14/93

05-02/2 Procedure 221-F-55035, Rev 0, dated 6/26/91 is listed as a Category 3 (T\&R) but Section 4, Procedure, requires initials for each step and has a completed by signature block at the end.

Corrective Action(s) -

1) Develop and approve SOP 221-F-55025 Handling Solid Waste in 221-F/OF$F(U)$ to the $2 S$ Manual format.

Punchlist Category A Completion Date - 03/31/94

2) Cancel SOP 221-F-55035, Handling and Storage of Fladioactive Waste (U).

Punchlist Category B Completion Date - 04/29/94

3) Reformat the remainder of the waste handling procedures (i.e., the 55000 series procedures) not incorporated into SOP 221-F-550:25.

Punchlist Category A Completion Date - 03/31/94

4) Make Training Determination on procedure revisions.

Punchlist Category A Completion Date - 03/31/94

05-02/3 Review and walkdown verification of recently revised procedures for Phase 1 restart is not complete.

Corrective Action(s) -

1) Identify procedures necessary for Phase 1 Operations.

Punchlist Category A Completion Date - 06/23/94

2) Perform a technical review and walkdown of procedures for Phase 1 Restart.

Punchlist Category A Completion Date - 07/011/94

3) Perform training (FOEP) for revised procedures for Phase 1 Restart.

Punchlist Category A Completion Date - 07/05/94

\section{Safety Documents}

06-01/1 Based upon a walkdown of the 281-6F Segregated Water Monitors with the Systems Engineer, the P\&IDs did not accurately' reflect the as-built configuration, which limits the ability of the Systems Engineers and Shift Technical Engineers to provide engineering technical support to the F-Canyon proposed activities and off-normal operations. Examples: drawing S5-2-6358 (Table A) does not show a valve and pipe stub located between the alpha 
monitor and valve \#12; drawing W742070 (Table B) does not show a valve and line connecting the 0608-301-09 pump suction and discharge; sensor indicator SRIT-1-ETT0150 CS6 shown on drawing does not exist in the system; potable water line to flush trap not shown on drawing; drawing does not show unique component numbers.

Corrective Action(s) -

1) Define the compensatory actions in place that ensule that use of drawings that do not reflect the configuration will be used as a supporting document only and that the key features pertinent to the task at hand (e. g., modifications; procedures, troubleshooting) will be verified as appropriate.

Punchlist Category A Completion Date - 04/01/94

2) Ensure that compensatory measures are documented.

Punchlist Category A Completion Date-04/01/94

3) Train the Systems Engineers, and Shift Technical Engineers on compensatory measures.

Punchlist Category A Completion Date - 04/10/94

4) Validate, via walkdowns, alignment of major equipment and components of safety-related systems with denoted primary drawings as in system boundary package.

Punchlist Category B Completion Date - 10/14/94

5) Issue walkdown closure report.

Punchlist Category B Completion Date - 10/14/94

6) Resolve discrepancies by issuing DCFs.

Punchlist Category B Completion Date-10/14/94

7) Review last performed functional test to validate alignment of system operational requirements and logic flows between both documents (i.e., test procedure and primary drawing) and resolve any discrepancies including retesting as required. Document the review.

\section{Punchlist Category B Completion Date - 10/14/94}

06-02/1 The memorandum NMP-EFA-930226 from C. B. Cochran to L. D. Olson, dated November 18,1993, concludes that a) the accountability tank liquid level and specific gravity instruments (Table 6.2) and b) sump liquid level instruments are not required to be designated as being Safety related in the Safety Related Systems procedure. The assessment fails to address whether these instruments are necessary to satisfy the "double contingency" requirements for inadvertent criticality control required by DOE Order 5480).24.

Corrective Action(s) -

1) Evaluate and document existing controls, or corrective actions, necessary to satisfy the double contingency requirements to prevent inadvertent criticality in the accountability tanks and F-Canyon_sumps. (Specilically address whether 
the accountability tanks liquid level, specific gravity, or sump level detectors are required to satisfy double contingency requirements.)

Punchlist Category A Completion Date -03/31/94

2) Make a determination per the requirements of DOE Order 5480.24 of whether the Item 1 corrective actions need to be completed pre- or post-restart, and enter these corrective actions into the Commitment Tracking System (CTS).

Punchlist Category A Completion Date - 04/15/94

3) Document the training determination on documentation revisions due to completing these corrective actions.

Punchlist Category A Completion Date-04/15/94

06-02/2 The SAR contains some outdated descriptive material arroneous information, e.g. a) contrary to the statement in the SAR Section 3.2.3.4.8 that the NIM's alarm when the total dose received at the detector within one minute exceeds 50 $\mathrm{mR}$, the only alarm setpoint is a dose rate threshold of $1 \mathrm{R} / \mathrm{hr} . \pm 5 \%$, (Manual $Y$ 7.1, Procedure 510543, Revision 12), and b) Section 3.2.3.4.9 and page 3-36 discusses the Data Logger System that will be installed; however, a Data Logger System has been installed and is operational.

Corrective Action(s) -

1) Include clarification in the BIO of which material in the SAR is superseded by the $\mathrm{BIO}$ and which material remains applicable.

Punchlist Category A Completion Date-03/31/94

2) Obtain WSRC approval of the BIO.

Punchlist Category A Completion Date - 04/30/94

3) Obtain DOE approval of the BIO. (Further corrective action is addressed in the finding for the open RSA item RSA-06-01, CTS \#1066i)

Punchlist Category A Completion Date-04/29/94

06-03/1 During interviews with two Shift Technical Engineers (STEs), they stated their duties would require ready access to Authorization Basis Documents to support operations; however, there is no formal mechanism to ensure the Shift Technical Engineers (STEs) have ready access to current Authorization Basis (AB) documentation in or near the F-Canyon central Control Room, and b) there is no formal mechanism to inform the STEs of modifications to these documents.

Corrective Action(s) -

1) Provide controlled distribution copies of current $A B$ listi and documentation in the 221-F West Blister office (which serves as STE office while on-shift).

Punchlist Category A Completion Date - 01/28/94

2) Assign an $A B$ Coordinator to ensure that STEs are informed of $A B$ modifications.

Punchlist Category A Completion Date_-01/28/94 
3) Issue formal memorandum documenting \#2 roles and responsibilities.

Punchlist Category A Completion Date - 02/17/94

4) Train USQ originators (includes STES) on Authorization Basis through Required Reading.

Punchlist Category A Completion Date-03/31/94

06-03/2 WSRC approved changes to Technical Standards DPSTS-221-FC- $(-300,-310$, $-320,-350$, includes changes to bring into compliance with NFPA- 69 for lower flammability limit), and DPSTS-221-FC-200 (revised to upgrade nuclear criticality safety) have not been approved by DOE.

Corrective Action(s) -

1) DOE approvẹ and issue Technical Standards (DPSTS-221-FC-200, -300 , -320 , and -350 ) before restart.

Punchlist Category A Completion Date-03/04/94

2) Revise WSRC-IM-93-61 (AB Listing) to include approved Technical Standards.

Punchlist Category A Completion Date -03/11/94

3) Issue revised $A B$ list and copies of revised Technical Standards as required reading to USQD originators (includes STES and System Engineers).

Punchlist Category A Completion Date -03/11/94

4) Revise \& issue procedure changes to SOP $221-F-40150$ and SOP $221-F$ 40155

Punchlist Category A Completion Date - 03/25/94

5) Train Operators and Shift Technical Engineers on Technical Standard revisions and procedure changes.

Punchlist Category A Completion Date - 04/01/94

06-04/1 All Authorization Basis (AB) documents, e. g. all sections of the SAR, the BIO, SAR Addendum 2, and all but one Test Authorization, have not been reviewed to ensure that the operating procedures accurately and consistently reflect operational requirements identified in these documents.

Corrective Action(s) -

1) Define and document implementable safety related requirements in the WSAC approved BIO (including valid SAR information referenced in the $\mathrm{BIO}$ ) required to be proceduralized or to be reflectēd in plant procedures.

Punchlist Category A Completion Date-06/27/94

2) Review WSRC approved BIO and document which procedures reflect these implementable safety requirements. 
Punchlist Category A Completion Date-07/11/94

3) Review approved active Test Authorizations and document which procedures reflect these implementable safety requirements.

Punchlist Category A Completion Date-06/15/94

06-04/2 (This number was allocated to a draft finding that was nol presented for a Board vote.)

06-04/3 The memorandum NMP-EFA-930226, C. C. Cochran to L. D. Olson, "Follow-up to RSA Checklist C-2.03 for Functional Area $6^{*}$, identifies an error in the OSRs which has not been corrected (Table 2.2 refers to concluctivity meters on first cycle being in error since the requirement applies to the :?nd Plutonium cycle as is noted in Section 2.4).

Corrective Action(s) -

1) Review the OSR for technical accuracy and document: the review.

Punchlist Category A Completion Date - 03/18/94

2) Include in the BIO correction or clarification of any deficiencies identified.

Punchlist Category. A Completion Date - 03/31/94

3) Obtain DOE approval of BIO (further corrective acticin addressed in finding for open RSA item RSA-06-01 (CTS \#1066).

Punchlist Category A Completion Date-04/30/94

06-05/1 The Power Operations Load Test Procedure 292-F "Portiable Diesel Generator", page 5 of 7, Items 14.I, J, K and L, and respective data sheets for Battery Charger, Ammeter, Radiator Fan Ammeter, Engine Splace Ammeter and Oil Pressure, respectively, does not specify the units for thetse data (e.g., amps or psig, for the expected range of these parameters).

Corrective Action(s) -

1) Revise the 292-F Portable Diesel Generator load test procedure to include the appropriate units for the Battery Charge Ammeter, Fiadiator Fan Ammeter, Engine Space Ammeter, and the oil pressure.

Punchlist Category A Completion Date -03/18/94

2) Review $100 \%$ of all F-Area Power Operations test procedures related to safety related equipment for similar conditions and revise and issue procedures as needed. Document results of this review.

Punchlist Category A Completion Date - 03718/94

3) Train all F-Area Power Operations personnel on procedure revisions.

Punchlist Category A Completion Date-03/18/94

06-05/2 The Power Operations Load Test Procedure 292-F, "Portable Diesel Generator", Index No. F-15-93, page 5 of 7, Item 14.L, has a 5 minute oil pressure reading 
of 84 which is outside the expected range of $30-80$. This out of expected range is not noted as being out of range and is not evaluated nor dispositioned in the Attachment 1 data sheet.

Corrective Action(s) -

1) Issue memo to all F-Area Power Operations personnel stating the required actions to be taken when out-of-limit readings are encountered while performing procedures or routine operating rounds and place memo in required reading so that review / training can be documented.

Punchlist Category A Completion Date-03/18/94

2) Review $100 \%$ of all F-Area Power Operations procedures related to safety related equipment for similar conditions and correct procedures as needed. Document results of this review.

\section{Punchlist Category A Completion Date-03/18/94}

3) Revise the load test procedure so that it clearly definis the expectations for readings that may be outside of the operating parameters during the first five (5) minutes of run time on this diesel.

Punchlist Category A Completion Date -03/18/94

$06-07 / 1$

The BIO and Safety Related Systems Procedure have listed the Safety Related Systems; however, the definition of the systems is incomplete, since the equipment, components, and structures contained within the boundaries of the Safety Related Systems are not clearly and unambiguously defined and documented. Compliance with the Restart Plan NMP-SFC-93-0241 statement on page 52 (Configuration Management) that "Functionality of all safety-related systems/components has been verified by approved procedures per the requirements in a facility specific implementing procedure" cannot be verified due to the lack of clearly defined system boundaries.

Corrective Action(s) -

1) Document that system boundary information in Operability Analysis for all Phase I Restart safety related systems is consistent with the information in the Safety Related Systems Procedure. (SOP 221-F-51230) Revise as necessary.

Punchlist Category A Completion Date-04/10/94

2) Document instruction to system engineers to use System Operability Analysis to capture system boundary descriptions for all work on system (e. g., modifications, procedure changes, troubleshooting) as appropriate.

Punchlist Category A Completion Date - 04/15/94

3) Train the Systems Engineers and Shift Technical Engineers on the contents of the Operability Analysis documents defining the system boundaries for Phase I Restart.

Punchlist Category A Completion Date-04/15/94 
4) Develop system boundary instruction package which includes a brief description of system, list of main equipment and comporients, drawing list, and other pertinent references.

Punchlist Category B Completion Date - 09/30/94

5) Indoctrinate each system engineer on system boundary package.

Punchlist Category B Completion Date -09/30/94

6) Each system engineer will bound their respective safety related system(s) in accordance with system boundary package.

Punchlist Category B Completion Date - 09/30/94

7) Ensure Integrated Data Processing (IDP) number system hierarchy is aligned with system boundaries and document results.

Punchlist Cätegory B Completion Date -09/30/94

$06-07 / 2$

USQ screenings have not been performed for changes to 281-6F water monitoring calibration procedures in HP Manual 5Q1.4, contrary to the Manual $11 Q$, Procedure 3.10 requirement to perform a USQ screiening for all proposed activities, e.g. new or revisions to procedures. The HP "Administrative Procedure Manual" Q1-1, Procedure 605, Rev. 5, "HP Priscedure Development, Review Approval, and Administration" does not require ai USQ screening to be performed for new or revised procedures.

Corrective Action(s) -

1) Identify and document existing approved procedures for interfacing / support organizations (e. g. RCO, CSWE, Power, Fire Department, etc.) that may require a USQ screening based on F-Canyon safety related system impact.

Punchlist Category A Completion Date-04/04/94

2) Separations Engineering to review list of interfacing / support organization procedures generated in action \#1 above and provide written concurrence.

Punchlist Category A Completion Date-04/11/94

3) Revise Administrative Control Procedures for interfacing / support organizations (e.g. RCO, CSWE, Power, Fire Department, etc.), such as 605 in Manual Q1-1 for Radiological Control, to require a USQ screening to be performed for new or revised procedures that perform work directly on F-Canyon safety related systems.

Punchlist Category A Completion Date-04/15/94

4) Indoctrinate interfacing / support organization procedure writing personnel on procedure revisions as a result of action $\# 3 \underset{\xi}{\text { above }}$

Punchlist Category A Completion Date - 04/15/94

5) Develop a schedule for completing USQ screenings on interfacing organization procedures identified in action \#1 above and agreed to in action \#2 above. 
Punchlist Category A Completion Date - 04/15/94

$06-07 / 3$

Contrary to the Manual 11Q, Procedure 3.10 requirement to perform a USQ screening for all proposed activities, e.g. new or revisions to procedures, USQ screenings have not been performed for administrative type procedures, e.g. SOP\#221-F/OF-F-10255, Rev. 12. No exception to this requirement has been justified and documented.

Corrective Action(s) -

1) Document determination of which categories of administrative procedures and minor revisions do not require USQ screenings on new or revised procedures.

Punchlist Category A Completion Date-02/28/94

2) Perform a USQ Screening and Evaluation on the exemption of the identified categories from USQD process.

Punchlist Category. A Completion Date - 03/18/94

3) Obtain SORC / FOSC and ESH\&QA approval of the UISQE.

Punchlist Category A Completion Date -03/31/94

4) Identify the specific procedures which fall into the exempted categories and issue the list to Technical procedure approvers and USQD originators as required reading.

$\therefore$

Punchlist Category A Completion Date-04/15/94

06-07/4 As required by the Restart Plan NMP-SFC-93-0241, Functional Area 6, Phase 1 Acceptance Criteria 1.11, there is no objective evidence that all pre-restart (Priority 1) actions form the April 1993 ASA of F-Canyon have been field verified as being closed. i.e. C-FCAN-93-01-05, C-FCAN-93-10-1)2, O-FCAN-91-11-01, C-FCAN-93-08-02, C-FCAN-93-08-04, O-FCAN-91-10-01, O-FCAN-93-08-05, and C-FCAN-93-01-03 (this last item is closed in CTS: however, there is no objective evidence that training on the use of the Authorization Basis documents for USQ Preparation has been performed).

Corrective Action(s) -

1) C-FCAN-93-01-05 - Document completed training (for F-Canyon USQ preparers) on referencing authorization basis documents in USQs.

Punchlist Category A Completion Date-03/31/94

2) C-FCAN-93-10-02 - Document the determination whether-or-not to periodically flush or replace process vessel vent filters as a result of ammonium nitrate buildup.

Punchlist Category A Completion Date-03/31/94

3) O-FCAN-91-11-01 - Document completion of installation of isokinetic sampling system (Project S-4441).

Punchlist Category A Completion Date - 02/28/94 
4) C-FCAN-93-08-02 - Document completion of training on "improving the level of documentation in the round sheets and logs".

Punchlist Category A Completion Date - 03/18/94

5) C-FCAN-93-08-04 - Identify and document work requiest essential for restart and add to Facility Restart Schedule.

Punchlist Category A Completion Date-02/28/94

6) O-FCAN-91-10-01 - Provide a copy of the latest salety documents NMPD Integrated Schedule (which includes F-Canyon and Outside Facilities combined).

Punchlist Category A Completion Date -02/28/94

7) O-FCAN-93-08-05 - Document repair of the railroad tunnel airlock blowers and the DOP testing of the associated fan HEPA filters.

Punchlist Category A Completion Date -03/30/94

8) C-FCAN-93-01-03 - Document completed training (for F-Canyon USQ preparers) on referencing authorization basis documents in USQs.

Punchlist Category A Completion Date -03/31/94

06-07/05

The F-Canyon Basis for Interim Operation (BIO) (U) [WSRC-RP-93-1215 (Draft)], Section 6.2 .9 requires a Control Room Supervisor or a designated, qualified individual in the Control Room at all times. SOP 221-F-50133, FCanyon Shift Operating Crew Staffing Requirements (U) states that "authorized deviations from minimum staffing requirements are not considered to be violations." A facility procedure must be in compliance with the Authorization Basis and cannot authorize deviations from Authorization Basis requirements."

Corrective Action(s) -

1) Revise SOP 50133 to clarify that authorized deviations from the procedural staffing levels must still maintain the minimum staffing level set by the BIO.

Punchlist Category A Completion Date - 02/25/94

2) Train Operations Shift Managers, Operations Managers, and Facility Manager on the revision.

Punchlist Category A Completion Date-03/25/94

3) Following DOE approval of the BIO, review SOP 510133 to verify that the procedural minimum staffing level is sufficient to maintain the minimum staffing level set by the BIO. (Corrective actions associated with approval of the $\mathrm{BIO}$ are addressed in a separate finding)

Punchlist Category A Completion Date - 05/13/94

06-12/1 WSRC approval of the Process Hazard Review (PHR) for Phase 1 restart has not been completed, since the Phase 1 Special PHR for $F$ and $H$ Canyons and Outside Facilities Vulnerabilities for TOMSK-Like "Red Dil Reactions" has not been approved by WSRC. 
Corrective Action(s) -

1) Obtain WSRC approval \& issue the special PHR.

Punchlist Category A Completion Date -01/28/94

2) Develop a plan for implementation of PHR corrective actions, and entereach action with its specific implementation into the Commitment Tracking System.

Punchlist Category A Completion Date - 02/28/94

3) Make training determination on revisions made as a result of implementing corrective actions.

Punchlist Category A Completion Date-03/31/94

4) Issue PHR as required reading to Systems Engineers and Technical Support Engineers.

Punchlist Category A Completion Date 03/31/94

\section{Environmental Protection}

07-01/1 Procedure SOP 221-F-55021, Rev. 2, Paragraph 2.0 Scope, is confusing in that it refers to a decision to be made by operators between taking waste from a contaminated area and sending it to compactable boxing or to B-25's. By Management direction all waste from a contaminated area goes into B-25's

Corrective Áction(s) -

1) Develop and approve SOP 221-F-55025, Handling Solid Waste in 221-F/OF$F(U)$ to incorporate the differences in handling compactable and noncompactable low level waste (LLW), per the 1S Manual.

Punchlist Category A Completion Date 03/31/94

2) Cancel SOP 221-F-55021, Handling Compactable Waste (U) and all other waste handling procedures that were incorporated into SOP 221-F-55025.

Punchlist Category B Completion Date 04/29/94

3) Revise the remainder of the waste handling procedures (i.e., the $\mathbf{5 5 0 0 0}$ series procedures) not incorporated into SOP 221-F-5502:5.

Punchlist Category A Completion Date 03/31/94

4) Make Training Determination on procedure revisions.

Punchlist Category A Completion Date 03/31/94

07-01/2 F-Canyon has not sufficiently identified trăining requirements nor are they maintaining training records on applicable environmental protection topics. For example, training associated with management of activities at mixed waste staging areas identified in WSRC 3Q, ECM 6.21 does rot appear to be being performed. Reliance on required reading of procedures does not appear to ensure sufficient information is being retained by personnel on environmental topics contained in operating procedures. 
Corrective Action(s) -

1) Develop an Environment Protection Training Recjuirements Matrix for Operations personnel.

Punchlist Category A Completion Date 06/17/94

2) Develop a schedule for completion of training of F-Canyon operations personnel on the Environmental Protection Training requirements identified in Corrective Action (1). 6/17/94 A

Punchlist Category A Completion Date 06/17/94

3) Complete training on the Environmental Protection requirements as identified in the training matrix for operations personnel (to include as a minimum the following: SIRIM, RCRA, waste handling, outfall monitoring, Mixed Waste Staging Area Contingency Plan).

Punchlist Category B Completion Date 12/31/94

$07-01 / 3$

F-Canyon personnel interviewed did not have sufficient knowledge of specific RCRA hazardous materials which might be present in their facility. This included poor knowledge of hazardous materials and their labeling per the requirements of WSRC 4Q Manual procedures, and what to do if a hazardous material was found in an unauthorized waste container (i.e., compactable waste). Additionally, personnel have not received trainirig on the mixed waste staging area contingency plan as required by WSRC 3Q, ECM 6.21.

Corrective Action(s) -

1) Train specific day operations personnel on the requirements for handling wastes contained in procedure SOP 221-F-55025, Revision 0.

Punchlist Category A Completion Date 06/17/94

2) Facility perform an assessment of the knowledge of Day Operators on waste handling procedures contained in SOP 221-F-55025 following completion of training.

Punchlist Category A Completion Date 06/17/94

3) Provide contingency plan training to appropriate F-Canyon personnel as defined by the matrix.

Punchlist Category B Completion Date 07/29/94

\section{Quality Assurance}

08-02/1 Contrary to SOP 221-F-50650, Rev. 2 (Records Management Program Overview), problems with records retention have been noted on multiple occasions (i.e., findings \#12-02/7, 10-01/2, 08-04/2, 17-02/2)

Corrective Action(s) -

1) Revise, approve \& submit 221-F-50650 to the Operating Experience Program (OEP) and make a training determination to ensure that F-Canyon 
personnel understand retention requirements and the importance of submitting records to document control.

Punchlist Category A Completion Date 03/31/94

2) Separations Quality perform a surveillance on document control / records management implementation and verify restart documents are retrievable .

Punchlist Category A Completion Date 03/31/94

3) Identify the types of records / documents required for formal document control.

Punchlist Category A Completion Date 03/31/94

4) Implement an effective tracking system (i.e., transmittals) for documents of record.

Punchlist Category A Completion Date 03/31/94

5) Identify the records / documents required for Phase I Restart as identified in number 3 above.

Punchlist Category A Completion Date 03/31/94

08-04/1 The software program "221-F MacSym", functionally clässified as NS (Nuclear Safety) does not have an approved Software Quality Assurance Plan (SQAP) as required by QAP 20-1. (see ESH-ORR-94-0001-O for further details).

Corrective Action(s) -

1) Issue documentation for the 221-F MacSym, approved by Operations, CTF, CQF, and DC\&SD, that meets the requirements for a SQAP per QAP 20-1, Rev.

2.

Punchlist Category A Completion Date-03/31/94

2) Revise System support request to show 221-F MacSy'm as NS.

Punchlist Category A Completion Date-03/09/94

08-04/2 There are inconsistencies in the lists of software in use by F-Canyon and support groups: a. Complete list as required by QAP 20.1 has not been defined or approved b. consistent nomenclature identifying the software is not being used. c. functional classification discrepancies exist between the software lists being used. (see ESH-ORR-94-0001-O for further details)

Corrective Action

1) Process Control and Computer Systems will issue and maintain quarterly updates per EPD-TPC-94-2002.

Punchlist Category A Completion Date -01/26/94

2) Nomenclature will be made consistent between SQAP and software list provided by Process Control \& Computer.

Punchlist Category B Completion Date - 01/26/94 
3) Functional Classification will be corrected on software. list provided by Process Control \& Computer Systems.

Punchlist Category A Completion Date - 01/26/94

08-05/1 Calibrations of Installed Process Instrumentation are not being performed in compliance with Procedure 291-912, Rev. 5, Section 4.10.9, which requires that M\&TE used to calibrate IPI shall have an uncertainty of four times less than the specified uncertainty for the IPI being calibrated. Technical justifications on an individual basis are not being provided as required.

1) For loops that will be considered in the uncertainty calculations for safety related systems, an analysis of the 4:1 rule will be included. For any components that do not meet the 4:1 rule, the uncertainty of the M\&TE will be considered in the loop calculation.

Punchlist Category A Completion Date 01/18/94

2) Canyon Maintenance Manager to issue memo of instruction to Maintenance supervisors explaining their responsibilities for compliance with requirements of QAP 12-2 and Procedure 291-912.

Punchlist Category A Completion Date - 01/14/94

08-05/2 Installed Process Instrumentation (IPI) database indicätes calibrations have been extended for sixteen NS Class components. Technical Justifications, approved by CTF and CQF, as required by Procedure 291-912, Rev. 5, Section 4.8.1, are not available in IPI files. Tag. ID's are 141S, 1.41XG, 141XL, 141XY, 142S, 142XG, 142XL, 142XY, 161S, '161XG, 161XL, 161XY, 162S, 162XG, $162 X \mathrm{~L}$, and $162 X Y$.

Corrective Action(s) -

1) Locate the above IPI extensions and include them in the history files.

Punchlist Category A Completion Date 01/03/94

2) Three to five working days before the end of each month, issue to Operations, Engineering and Maintenance a list of IPI that's due for calibration.

Punchlist Category A ,Completion Date 12/28/93

3) IPI Custodian will write justification for extension, put copy in file and issue original for approval.

Punchlist Category A Completion Date 01/30/94

4) Operations to issue deficiency tag for IPI not calibrated after exceeding the grace period.

Punchlist Category A Completion Date - 02 $\overline{7} 01 / 94$

08-05/3 IPI history files did not contain or reference six completed and evaluated out-ofcalibration notices for dissolving/second $\mathrm{Pu}$ calibrations as required by QAP 122 when as-found conditions are unsatisfactory. IPI tag nos. are 2027FT-2, 3151LSH, FE081, FE146, FE793, and FD540.

Corrective Action(s) - 
1) Issue and evaluate OCNs for the above 6 IPIs.

Punchlist Category A Completion Date-01/03/94

2) Train the applicable engineers, maintenance and operations personnel on the requirements of QAP $12-2$.

Punchlist Category B Completion Date - 03/31/94

3) IPI Coordinator to make a copy of each calibration data sheet and out-ofcalibration notice before sending it out for approval.

Punchlist Category A Completion Date 01/03/94

4) Review all 2nd Pu and dissolving IPI files for missing OCNs. Issue/evaluate OCNs as required.

Punchlist Category A Completion Date 01/21/94

5) Upgrade 2nd $\mathrm{Pu}$ and dissolving history files to meet CIAP 12-2 requirements.

Punchlist Category A Completion Date-02/15/94

6) Perform self-assessment to $1 Q 12-2$.

Punchlist Category B Completion Date 03/31/94

$08-05 / 4$

Records for two NS component calibrations (of four sampled) did not provide required traceability documentation as required by QA,P 12-1, Section 4.7.1. Properly completed M\&TE Use Reports were not in MI\&TE files as required. Calibrations were authorized under Work Package no. SVQE4; Instruments 9214 LT and 9216 LT.

Corrective Action(s) -

1) Review M\&TE Use Reports for $100 \%$ of NS/CP calibrations completed by Separations Maintenance for Phase I Operations from 9/1/93 through 2/7/94 for compliance with QAP12.1.

Punchlist Category A Completion Date-03/29/94

2) Conduct training session with M\&TE room attendants.

Punchlist Category A Completion Date-02/11/94

3) Conduct one on one training with all users identified during the review that did not meet the requirements.

Punchlist Category A Completion Date-03/15/94

4) Conduct instructional class for all M\&TE users in F Canyon on M\&TE use report.

Punchlist Category A Completion Date - 03/29/94

5) Revise 291-051 to delete this requirement. Modify Work Control WPD-6 form to comply with revision. 
Punchlist Category B. Completion Date 06/01/94

Malntenance and Survelllance

10-01/1 Preventive maintenance that becomes delinquent is not signed by the Maintenance Group Manger (Level 3) as required by SOP 291-051, Section 4.7.2.

Corrective Action(s) -

1) Revise 291-051 to delete this requirement. Modify Work Control WPD-6 form to comply with revision.

Punchlist Category B Completion Date - 06/01/94

10-01/2 Facility personnel are unable to tocate and retrieve the ccimpleted procedure for 221-F Diesel design load test conducted on 11-23-93. This is a scheduled surveillance test of Safety-Related equipment.

Corrective Action(s) -

1) Provide documentation of the annual 221-F Emergency Diesel Generator test performed in May of 1993 verifying test was perfolmed in required OSR time limit.

$\because \quad$ Punchlist Category A Completion Date - 02/11/94

2) Perform and document audit of the Surveillance Test Database to verify documentation is available of all surveillance tests in their current frequency.

Punchlist Category A Completion Date-03/31/94

10-02/1 (This number was allocated to a draft finding that was not presented for a Board vote.)

10-02/2 Backlog of "field complete" work packages requiring Post Work Review as specified in SOP 291-059, Rev. 5, Section 4.11.1, is excessive. As of 12/2/93, 105 packages, dating back to $12 / 92$ (Nuclear Safety Calibrations), are awaiting verification.

Corrective Action(s) -

1) Closure date will not exceed the field completion date by more than seven working days for NS / CP packages and 30 working days 'ior PS / GS packages.

Punchlist Category A Completion Date-04/01/94

2) All safety related systems packages for Phase I activities must be closed prior to restart.

Punchlist Category A Completion Date-04/01/94

3) Appropriate administrative procedures must be revised and training conducted to reflect closure requirements.

Punchlist Category B Completion Date 06/01/94 
4) Appropriate performance objectives should be established for closure activities and assigned to F-Canyon / Outside Facilities Work Control Manager.

Punchlist Category A Completion Date-04/01/94

10-02/3 Manual 8Q, Procedure 35, "Work Clearance Permits", requires that Work Clearance Permits be maintained in accordance with MRP 3.31 and Manuāl 1Q, QAP 17-1. Presently, these records are discarded at the completion of each work activity.

Corrective Action(s) -

1) Write and approve new procedure for implementing WCP retention requirements

Punchlist Category A Completion Date -03/20/94

2) Provide training to Operations, Separations Maintenance, and other work groups that routinely perform activities in F-Canyon on WCP Retention Requirements.

Punchlist Category A Completion Date-03/25/94

3) Implement procedural requirements.

Punchlist Category A Completion Date - 04/01/94

10-03/1 Mechanism does not exist for providing IPI database with current procedure numbers for performing instrument cálibrations. Specifically, Procedure SOPW-834002 was canceled 5/11/93, and replaced with SOF'-W-834019; instrument datasheets continue to be sent to Work Control for Calibration Work Packages referencing the canceled procedure.

Corrective Action(s) -

1) The IPI Custodian shall be added to the distritiution list of canceled calibration procedures.

Punchlist Category A Completion Date - 02/08/94

2) The IPI Custodian shall update the Loveland Database with correct procedure number from the Calibration Datasheet (CDS).

Punchlist Category A Completion Date-04/01/94

3) Add requirement to update Database to IPI Custodian Job Requirements.

Punchlist Category A Completion Date - 04/01/94

4) Update Loveland Database with correct procedure requirements.

Punchlist Category A Completion Date-04/01/94

\section{Radlological Protection}

11-01/1 Radiation monitor (Victoreen Vamp) in NE corner of Old Hot Crane cab does not have a current calibration label. 
The Board voted to cancel this finding based on it being an isolated instance not warranting a restart finding.

Health Protection deficiency tags for Area Radiation Monitors are not recorded in Control Room, resulting in potential for Shift Manager to be unaware of requirement for special backup area monitoring if a highly' radioactive transfer is made.

Corrective Action(s) -

A Facility HP Equipment Deficiency Tag Log Book has been established and placed under the control of the Shift Manager. The six Area Radiation Monitors which are deficient have been tagged using Facility Deficiency Tags, which have been logged in the Facility HP Equipment Deficiency Tag Log Book.

Punchlist Category A Completion Date-12/18/93

11-01/3 It was observed, during a general tour of 221-F and during observations of work in progress, that waste minimization practices were not being followed in accordance with Manual 5Q, Article 442. (e.g. excess materials carried into RCAs, incorrect disposals of recyclable rubber gloves.)

Corrective Action(s) -

1) Conduct OEP brief per FOEP-1994-0115 to F-Canyon personnel (including Operations, Maintenance, Construction, RCO, and other applicable support personnel) on waste minimization. Areas to include: carrying excess material into a RCA; provide disposal of rubber gloves - recycle; job planning to minimize waste; tool control to minimize waste.

Punchlist Category A Completion Date -06/22/94

$11-01 / 4$

Observations of work in progress indicated that Radiological Control Operations is not taking representative work place air samples in accordance with Manual 5Q1.2, Procedure 132, Section 5.3.

Corrective Action(s) -

1) Shift Order issued 6/13/94 required 221-F Radiological Control Inspectors and First Line Supervisors to receive training on work place air sampling (Manual 5Q1.2, Procedure 132, Section 5.3) prior to conducting work in the 221F Facility.

Punchlist Category A Completion Date-06/13/94

2) Develop training based on Manual 5Q1.2, Procedure 132, Section 5.3.

Punchlist Category A Completion Date-06/13/94

3) Conduct training and document training phïor to inspectors working in facility.

Punchlist Category A Completion Date-06/17/94

11-01/5 F-Canyon personnel were observed using full-face particulate respirators more than once while in a contamination area. In addition, the respirators were in the contamination area unprotected (not in a respirator bag) between uses. This is not in accordance with Manual 4Q1.6, Procedure 202, Section 5.9. 
Corrective Action(s) -

1) Conduct OEP brief per FOEP-1994-0115 to F-Canyon personnel on Manual 4Q1.6, Procedure 202, Section 5.9 on "one time use".

Punchlist Category A Completion Date - 06/16/94

\section{Fire Protection}

$12-01 / 1$

$12-01 / 2$

$12-02 / 1$
The Fire Hazards Analysis (FHA) M-FHA-F-00026 is delicient in certain areas. Deficiencies include: $221-\mathrm{F}$ Third Level hazards during licjuid transfer operations at tanks; the means of detection of potential fire in the Canyons; the correct identification of PA System problems; impact on facility, ventilation by the potential loss of the 292-F Emergency Generator.

Corrective Action(s) -

1) Fire Hazards Analysis (FHA) M-FHA-F-00026 will be revised to address these issues.

Punchlist Category A Completion Date-02/18/94

The facility response to deficiencies, as noted in the previous Emergency Light Survey (FPOS-93-198), has not been submitted to state what the corrective actions are and their completion dates.

Corrective Action(s) -

$\therefore$

1) A memorandum specifying the restart corrective actions to be taken will be issued.

Punchlist Category A Completion Date-02/18/94

2) All restart corrective actions will be completed.

Punchlist Category A Completion Date-03/09/94

The non-rated heat detection system in the Hot and. Warm Canyons used for detection of fires is deficient in that all or part of the systems are consistently impaired due to malfunctions, and the systems are not regularly tested or maintained. (5480.7A, NFPA-72E).

Corrective Action(s) -

1) A review or assessment of the heat detection systems operability will be performed to determine if it can be considered operable and placed in service. A memo will be issued to report status.

Punchlist Category B Completion Date - 04/30/94

2) If the assessment indicates that the system is not operable the deficiencies noted in the Heat Detection System Assessment will be repaired and the system placed in service.

Punchlist Category B Completion Date - 06/30/94 
3) Impairments to the detection system, and periodic testing and maintenance of detectors will be included in the SOP on Fire Control Systems.

Punchlist Category B Completion Date-06/30/94

12-02/2 Facility Personnel Annunciation (PA) System is deficient in the following areas (NFPA-101, 7-6.3, NFPA-72):

1. Some portions of system are either inoperative or gartiled in occupied areas.

2. Lack of emergency procedure for emergency aninunciation in case PA system is impaired.

3. "Dead Zone" areas lack adequate visual posting and procedure for occupancy of the areas.

Corrective Action(s) -

1) Increase the frequency of the PA system audibility test from its annual frequency to every six months and correct those deficiencies identified during this test or any deficiencies identified during EP drills.

Punchlist Category A Completion Date - 3/31/94

2) SOP 221-F-51136 "Access Log for 221-F and OF-F Public Address (PA) Dead Zone Areas" will be modified to add steps to dispatch personnel from the Canyon Control Room with portable radios and notify building occupants of situation and appropriate actions.

Punchlist Category A Completion Date 03/04/94

3) Additional "PA Dead Zone" signs wiil be added.

Punchlist Category A Completion Date 02/18/94

12-02/3 The operational integrity of the manual valves on each manual dry pipe sprinkler system in the Motor Control Centers (4) are potentially deficient. The valves have not been operated or maintained since 1981. (NFPA-13, WSRC-2Q, Procedures $1 \& 6$ )

Corrective Action(s) -

1) The Manual Valve Operation in the MCC Dry Pipe Sprinkler Systems will be tested prior to restart and a periodic test will be added to the PM Program.

Punchlist Category A Completion Date - 02/28/94

12-02/4 Emergency Light program is deficient as impaired lights are not replaced with spare lights to maintain continuous coverage in case of an emergency. (NFPA$101,5-9)$. At this time there are tagged, deficient lights in 221-F.

Corrective Action(s) -

1) Those emergency lights identified as deficient will be corrected or replaced prior to restart.

Punchlist Category A Completion Date-02/28/94

2) The Emergency Light Inspection Procedure will be modified to specify that the correction or replacement of impaired emergency lights will be performed 
within 24 hours and a training determination will be made for the procedure revision.

\section{Punchlist Category A Completion Date-02/28/94}

The facility fire watch program is deficient as it cloes not adequately provide compensatory actions (CSA-026) and it does not comply with SOP 221-F-51100 and 51101. The main deficiencies include rounds missed due to: Lack of personnel to conduct tours, lack of lunch break personnel, performance of other tasks, respirator use required, or no reason given on record for rounds missed. Other deficiencies include a lack of sufficient tours every 24 hours to cover the facility each hour, and facility files do not contain all fire watch tour records.

\section{Corrective Action(s) -}

1) Route all fire watch round sheets (221-F-51100 and 221-F-51101) to the Facility Fire Protection Coordinator to be audited orı a weekly basis.

\section{Punchlist Category A Completion Date - 03/31/94}

2) Define specific reportability requirements for missed fire watch rounds and modify fire watch procedures to include these requirements. The number and percentage of missed fire watch rounds will be tracked and published.

Punchlist Category A Completion Date-03/31/94.

12-02/6 The Compensatory Actions are deficient as contained in Compliance Schedule Assessment (CSA) 93-026 and Short Term CSiA (STCS) 013 in that: 1) Firewatch rounds, as a compensatory measure, do not adequately provide the capability to detect and respond to the facility fire protection hazards as defined in the FHA, the program lacks a basis for the 1 hour interval and for locations inspected. 2) The Firewatch Post at the MCC (for the) Emergency Diesel Generator needs to be evaluated as to effective implementation to meet the CSA commitment.

Corrective Action(s) -

1) An evaluation of the firewatch program and procedures for $F$-Canyon will be performed and documented to assess the adequacy of the one hour interval frequency and inspected areas where deficiencies have been entered into the CSA.

\section{Punchlist Category A Completion Date-03/11/94}

2) Revise procedures and correct deficiencies as necessary to address results of evaluation, which may include installation of a wet-pipe sprinkler system over the 221-F Diesel Generator, which may preclude the need for firewatch at this location.

\section{Punchlist Category A Completion Date-03/31/94}

12-02 $/ 7$ The facility fire protection equipment testing and maintenance program is deficient as records do not exist to verify that: 1) The Canyon deluge fire systems were tested in 1993, and 2) the South Dock anti-freeze system is annually tested and maintained. (WSRC-2Q, Procedure 8. NFPA-13, SOP 221F-51120)

Corrective Action(s) - 
1) Provide records verifying testing of deluge valves in question.

Punchlist Category A Completion Date-03/31/94

2) Provide Fire Department records verifying performance of anti-freeze system test in question.

Punchlist Category A Completion Date-03/31/94

3) Test the systems in question if records cannot be lociated. Develop records to demonstrate tests conducted.

Punchlist Category A Completion Date-03/31/94

12-03/1 Manual lock hasps installed on the corridor or entry side of doors throughout the facility are not in compliance with NFPA-101 and must be removed. The hasps create the potential for personnel to be locked in rooms and unable to exit the building during emergency conditions (NFPA-10, 5.2.1.5).

Corrective Action(s) -

1) Manual lock hasps in question will be removed.

Punchlist Category A Completion Date-02/18/94

2) An inspection will be performed to yerify that hasps are not present on other doors within 221-F Canyon and OF-F where personnel cusuld be trapped.

Punchlist Category A Completion Date-03/31/94

3) Add appropriate cautions on the use of Hasps in the Facility Safety and Industrial Hygiene Procedure.

Punchlist Category A Completion Date-03/31/94

12-05/1 Established, periodically scheduled training does nòt exist for operations personnel on the operation of the manual fire suppression systems in the Motor Control Centers (4) and the Hot and Warm Canyon deluge suppression systems. (WSRC-2Q, Procedure 2; SOP 221-F-51110).

Corrective Action(s) -

1) Train Operations Personnel on MCC-Dry-Pipe Sprinkler and Canyon Cell Deluge System. (manual valve operation).

Punchlist Category A Completion Date-02/28/94

2) Incorporate MCC and Deluge Systems manual valve operation in annual Facility Specific Fire Training Schedule.

Punchlist Category A Completion Date-03/31/94

\section{Emergency Preparedness}

13-01/1 The WSRC ORR Emergency Preparedness drill (1/14/94) and proposed DOE ORR drill scenarios are limited to a fire and radiological release and did not 
address other hazards associated in F-Canyon (DOE 5500.3A). Additionally, the shift drills provided in the fourth quarter of 1993 (2 different scenarios) did not include a scenario for hazardous materials other than radiation, i.e., fire, personnel injury, and radiological release.

Corrective Action(s) -

1) Conduct a remedial evaluated drill to include objeclives for response to a chemical spill and HAZMAT Team response.

Punchlist Category A Completion Date-03/01/94

2) F-Area EP management will develop and publish an annual drill schedule that encompasses all scenarios required by SRS Emergency Plan 6Q.

Punchlist Category A Completion Date-03/01/94

13-01/2 F-Canyon emergency responders have not received hazardous materials response training which allows for response to hazardous material spills, i.e., per 29 CFR 1910.120.

Corrective Action(s) -

1) Determine specific ERO positions and required training in reference to 29 CFR 1910.120 for F-Canyon.

Punchlist Category A Completion Date-04/15/94

2) Revise EPAP-301, F-Canyon to iñdicate which ERO positions that require Hazardous Material Response Training.

Punchlist Category B Completion Date - 06/30/94

3) Revise Qualification Cards and Program Descriptions to include the training requirements of the ERO positions.

Punchlist Category B Completion Date - 09/30/94

4) Complete ERO training for all F-Canyon personnel identified in EPAP-301.

- Punchlist Category B Completion Date-09/30/94

13-01/3 Controller / player comments were identified and added to the shift drill reports by the Lead Drill Team Controller but a) corrective actions are not tracked, and b) items identified did not get corrected in a timely manner, and c) in many instances re-appeared in later drills and exercises as comments.

Corrective Action(s) -

1) SRS ESD to develop a deficiency tracking database.

Punchlist Category A Completion Date-03/01/94

2) All open drill deficiencies from previous drills will be entered into this database.

Punchlist Category A Completion Date-03/01/94 
3) This tracking system will be formatted with a revision to EPAP-303, Drills and Exercises, requiring all-drill deficiencies to be tracked to closure by this database system in a timely manner.

Punchlist Category A Completion Date - 03/01/94

13-02/1 The F-Canyon EP Coordinator identified in the F-Canyorl Organization chart, is not knowledgeable to complete the functions of that position as defined in $6 Q$ (Savannah River Site Emergency Plan). While the F-Area EP Coordinator is attempting to provide assistance, there is not formal reporting relationship between these positions (matrixed or otherwise). The SS\&ES Emergency Services Department has assigned a level three manager to F-Area and the FArea EP Coordinator has been informally matrixed to this manager to compensate for this individual's limited emergency preparedness knowledge and experience. The compensatory action does not meet the requirement.

Corrective Action(s) -

1) SRS ESD will assign an EP Manager full-time for the F-Area program. All FArea EP personnel will report directly to this manager.

Punchlist Category A Completion Date-03/01/94

2) SRS ESD will develop and implement a professional development plan based on 5500.3A for F-Area Facility EP Coordinators.

Punchlist Category B Completion Date - 08/31/94

3) Develop a Memorandum of Underständing (MOU) between SRS ESD and FArea management to include a commitment for professional development based on 5500.3A of F-Area Facility EP Coordinators.

Punchlist Category A Completion Date-03/01/94

13-02/2 No job description exists for the F-Canyon Emergency Preparedness Coordinator.

Corrective Action(s) -

1) Memo of Understanding (MOU) will be issued defining duties and responsibilities of F-Canyon EP Coordinator.

Punchlist Category A Completion Date-03/01/94

2) Supervisor will develop and publish job description for F-Canyon EP Coordinator.

Punchlist Category B Completion Date-07/01/94

13-03/1 The F-Canyon and F-Area Protective Actions are not compatible, i.e., EPIPFSEP-003 utilizes Remain in Doors for a radiological event and F-Canyon procedure EPIP-FCAN-002 utilizes Remain in Doors only for a toxic gas release (reference Memorandum dated 1/18/94 from Mark P. Finclay to Allan McFarlane ESH-ORR-94-0002-0).

Corrective Action(s) - 
1) Revise EPIP-FSEP-003 to delete requirement for Protective Action of Remain in Doors.

Punchlist Category A Completion Date-02/01/94

13-04/1 EPIP-FCAN-001, Emergency Classifications (EALS), limits hazardous material emergency classifications to nitric acid incidents and does not allow for other hazardous materials located in F-Canyon (DOE 5500.3A).

Corrective Action(s) -

1) The F-Canyon EAL procedure (EPIP FCAN-001) will be revised in Phase II of the Hazards Assessment to reflect source terms found in the F-Canyon Safety Analysis Report (SAR), Addendum Two (2), and BIO. (There is a Compliance. Schedule Agreement (CSA) between WSRO and DOE to upgrade the EAL Procedure using F-Canyon SAR, Addendum 2 siurce terms.)

Punchlist Category B Completion Date - 07/08/94

13-04/2 - The EPIP-FCAN-001 and EPIP-FBL-001 (Emergency Classification Levels) are not integrated as to the radiological release rates from the stack for a Notification of Unusual Event, i.e., $\geq .270 \mathrm{mCi}$ (FB-Line) v. $\geq .30 \mathrm{mCi}$ (F-Canyon). Additionally, the F-Canyon EPIP-001 was arbitrarily charged from $\geq .270 \mathrm{mCi}$ (FCanyon) for a radiological release from the stack.

Corrective Action(s) -

1) EPIP-FCAN-001 will be revised to reflect correct trigger point of $>.270 \mathrm{mCi}$ for radiological release from stack.

Punchlist Category A Completion Date-03/01/94

2) EPIP-FCAN-001 will receive USQD to ensure compliance with facility SAR.

Punchlist Category A Completion Date-03/01/94

3) Add EPIPS to list of procedures requiring USQD before change is implemented.

Punchlist Category A Completion Date-03/01/94

4) All other EPIPS will be USQD reviewed.

Punchlist Category B Completion Date 07/01/94

13-04/3 F- Canyon utilizes Immediately Dangerous to Life and Health (IDLH) hazardous chemical concentrations instead of Emergency Response Planning Guides 2 (EPRG-2) levels per 6Q, Section 4.1 definitions.

The Board voted to cancel this finding on the basis that the finding is invalid given that there exists a WSRC approved DOE Order compliance schedule request for this non-compliance.

13-05/1 Emergency Equipment (SCBAs, First Aid Cabinets) is not inspected according to time intervals identified per procedure SOP 221-F-5105i1.

Corrective Action(s) - 
1) Tickler to support monthly inspection using SOF' $221-F-51051$ will be generated. Emergency Equipment will be inspected in January.

\section{Punchlist Category A Completion Date-01/31/94}

13-06/1 Phones in the OSC were inadequate to support emergericy response during the WSRC ORR F-Canyon EP Exercise. Additionally, radio coverage throughout the facility was inadequate to support emergency response (reference Memorandum ESH-ORR-94-0002-O dated 01/18/94 friom Mark P. Findlay to Allan McFarlane).

Corrective Action(s) -

1) Repair defective phones in the OSC.

Punchlist Category A Completion Date-03/01/94

2) EP procedure (EPIP-303) will be revised requiring periodic operational checks for phones. This requirement will be added to the F-Canyon Operations Tickler system.

\section{Punchlist Category B Completion Date -09/01/94}

3) AECs will be briefed to use either phones or runners for emergency communications when radios cannot be effectively used in the Canyon.

Punchlist Category A Completion Date-03/01/94

4) SRS ESD Training Department will revise AEO Trailing indicating when to use phones, radios or runners in the Canyon for emergericy communication.

Punchlist Category B Completion Date-09/01/94

13-07/1 Two Shift Managers on shift in F-Canyon Control Room and at least one Supervisor on-shift in F-Canyon have not requalified on the AFEC Overview course which is required per the 6Q Manual, SRS Emergency Plan.

Corrective Action(s) -

1) All required personnel who have expired AEC/FEC training will be rescheduled.

Punchlist Category A Completion Date-02/11/94

2) AEC trained First-Line Supervisors will be available on any shift whose SOM has expired AEC/FEC training as a compensatory measure.

Punchlist Category A Completion Date-02/11/94

3) 30 Day and 10 Day notices of expiration will continue to be sent to all FCanyon personnel who require AEC/FEC trấning.

Punchlist Category A Completion Date-01/14/94

4) Qualifications will be suspended immediately if AE:C/FEC training is not attended, and the expiration date is exceeded. This will be the responsibility of the F-Canyon Training Manager to alert the Facility Manager that this has happened. 
Punchlist Category A Completion Date-03/01/94

$13-07 / 2$

The Concept of Operations for emergency operations identified in the F-Canyon Emergency Plan Implementing Procedures (EPIPS) does not adequately reflect the Concept of Operations for normal activities (referense Memorandum dated 1/18/94 from Mark P. Findlay to Allan McFarlane ESH-ORR-94-0002-O), i.e., the AEC (Shift Manager) only classifies emergencies for F-Area and the FEC (Control Room Supervisor who reports to the Shift Managger) for F-Canyon.

Corrective Action(s) -

1) Revise FCAN EPIPs Procedures to clarify AEC/FEC responsibilities.

Punchlist Category A Completion Date - 03/01/94

2) EP Coordinator will perform shift briefings with AEC/FEC on procedure changes (all five shifts).

Punchlist Category A Completion Date-03/01/94

3) Provide a drill schedule for when remaining shifts will be evaluated/drilled on procedure changes.

Punchlist Category A Completion Date-03/01/94 *

13-07/3 . There is no tracking system to track the F-Canyon Emergency Response Organization drill participation training requirement.

Corrective Action(s) -

1) Proceduralize the record keeping process for emergency drill participation.

Punchlist Category A Completion Date-03/15/94

2) Collect the 1993 drill participation rosters from ESD, and deliver to NMPT to get into records and TRAIN.

Punchlist Category A Completion Date-02/18/94

Issue Management

17-01/1 The Commitment Tracking system has redundant corrective actions and several improper or severely late due dates. In addition there are corrective action descriptions which may actually entail several separate corrective actions. No evidence of these separate corrective actions having been evaluated for restart applicability has been found.

The Board voted to cancel this finding based on the facility taking action to correct entry errors, and the concern not being sufficiently significant to restart to warrant a pre-restart corrective action.

17-01/2 A review of the Separations Operations Review Comrnittee meeting minutes indicates that the Committee does not perform all aspects of its responsibilities as defined in Separations Procedure OP 2.03-01 (Flev. 8), Section 2.4.5. Specifically, functions which do not appear to be addressed include: 
- confirming the appropriate closure methods for all corrective actions and action items involving occurrences; and

- ensuring periodic audits of the occurrence reporting and investigation process are performed.

Corrective Action(s) -

1) A commitment tracking system (CTS) has been put in place that assures all corrective actions (CA) identified in occurrence reports al'e captured for tracking through to closure. In addition, a weekly review of new C.A's is accomplished to assure that all actions are prioritized with respect to restart vs. non-restart. This assures that those actions important to restart are completed first.

\section{Punchlist Category A Completion Date-01/13/94}

2) Although periodic audits were not done as required under the procedure for Separations Operations Review Committee (SORC), SORC will be replaced with a Facility Operations Review Committee (FOSC). The FOSC for F-Canyon will replace SORC by $3 / 31 / 94$ and will adhere to the requirements in MRP 4.19 titled, "Requirements for Oversight Review Committees".

Punchlist Category B Completion Date-03/31/94

$17-02 / 1$

Separations Department Procedure OP-2.07-01, Rev. 8, Section 2.4.6, requires the Area Separations Manager to establish procedures for executing the requirements of OP 2.07-01. These procedures do not appear to exist for $F$ Canyon.

Corrective Action(s) -

1) The F-Canyon Manager will write a memo stating that OP 2.07-01 is the FArea Procedure for "Identification \& Reporting of E:vents, Conditions, \& Concerns". Another procedure will not be written.

Punchlist Category A Completion Date-02/01/94

2) Complete a "training determination" for this procedure (i.e., specify people to be trained and training method).

Punchlist Category A Completion Date-02/01/94

3) F-SEP-0001, Personnel Selection \& Training Requirements, Rev. 1, 12/17/93, paragraph 4.1.1.3, will be revised to include SIRIM training for all Shift Managers and higher.

Punchlist Category A Completion Date-02/01/94

17-02/2 Review of recent Occurrence Report files indicates that critiques (Preliminary Investigation Records) are not being filed in accordances with requirements as stated in Manual S1-1, Procedure OP 2.07-01, Section 3.0.

Corrective Action(s) -

1) The F-Canyon Manager will write a memo stating that the minutes of all PIs will be sent to the $F$-Canyon Document Control Custoclian for filing. A list of reports for which there are no PI minutes will be generiated to document their status. 
Punchlist Category A Completion Date - 02/04/94

2) The F-Area Separations . Manager will issue a memo formulating an organization to centralize and maintain Occurrence Report information, including PI minutes, reports, and closure packages for corrective actions.

Punchlist Category B Completion Date - 03/01/94

3) QA will verify proper filing of the PI reports.

Punchlist Category B Completion Date - 03/25/94

$17-02 / 3$

The F-Canyon Lessons-Learned Procedure (SOP-F-00C3, "F-Area Separations Operating Experience Program" $(U))$ is still in draft form and has not been implemented.

Corrective Action(s) -

1) Approve SOP-F-SEP-0003, "Operating Experience Program Procedure".

Punchlist Category A Completion Date-12/31/93

2) Implement (i.e. approve procedure, establish database, start to input data) the OEP.

Punchlist Category B Completion Date-01/31/94

17-02/4 Deficiencies have been noted in Justifications for Operation (JCO) associated with Occurrence Reports (ORs). 1) Sếction 2 of the OR JCO form (Manual S11, OP 2.07-01, Att. 5.4) requires interim or compensatory corrective actions to be stated along with the time period they are expected to remain in effect. However, a sampling of JCOs indicate that they do not address the time periods the corrective actions are to remain in effect: 2) Expiration of the JCO appears to be automatic and based on an arbitrarily assigned date rather than based on a determination of whether or not the evaluation is complete and the need for a revision to the JCO (see Manual S1-1, Rev. 7, Section 4.5.4.4, and Attachment 5.2).

Corrective Action(s) -

(1) Conduct and document a review which verifies that expiration date for JCOS associated with all non-finalized ORs are appropriate.

Punchlist Category A Completion Date-01/30/94

(2) Ensure that OR authors \& approvers are aware of the intent \& requirements pertaining to OR JCO expiration dates.

Punchlist Category B Completion Date-01/30/94

(3) Revise OP 2.07-01 to clearly define the expiration date requirements for OR JCOs.

Punchlist Category B Completion Date - 02/15/94

(4) Implement the 9B Manual.

Punchlist Category B Completion Date-03/31/94 
17-02/5 OP 2.07-01, Section 2.8, requires SIRIM training for the Facility Manager and report writers. It appears that all report writers have not received the required training.

Corrective Action(s) -

1) Additional SIRIM training is being conducted for personnel who may be involved in FCAN Occurrence Report preparation.

Punchlist Category A Completion Date-01/14/94

\section{Occupational Safety and Health}

$20-01 / 1$

Personnel training in the Seven Basic Safety courses is presently only $60 \%$ complete. All personnel are required to have training. (WSRC-8Q, Procedure 1)

Corrective Action(s) -

1) Complete Training for Seven Basic Safety Courses for delinquent F-Canyon employees.

Punchlist Category A Completion Date-02/20/94

20-01/2 As required by WSRC Procedure Manual $8 Q$ the F-Canyon facility has not developed a Facility Safety and Hygiene Program to implement the requirements of WSRC-8Q. (WSRC-8Q, Procedure 1)

Corrective Action(s) -

$\therefore$

1) A facility procedure (SOP- 211 - F- 50003) will be prepared that outlines the facility safety program and gives instructions on how to imiplement the program.

Punchlist Category A Completion Date-03/01/94

2) Personnel will be trained on the procedure through required reading.

Punchlist Category B Completion Date-03/31/94

20-01/3 Facility housekeeping practices are not fully in compliance with WSRC-8Q, Procedures $6 \& 12$ and SOP 221-F-51105, 50003. Deficiencies were noted during ORR facility walkdowns, and throughout the First Level Fan Room and other areas of the First Level. Major deficiencies include blocked emergency exits, congested storage in normally unoccupied areas, improper location of flammable liquid cabinets and electrical equipment / installation deficiencies.

Corrective Action(s) -

1) Document resolution of deficiencies that were noted by the ORR Board Member during facility walkdown.

Punchlist Category A Completion Date-03/31/94

2) Replace portable electrical cords with hardwire and conduit service in the Maintenance First Level Shop.

Punchlist Category B Completion Date -03/31/94 
3) Separations Quality to perform surveillance on housekeeping practice vs. compliance with WSRC-8Q, procedures 6 \& 12 and SOP :21-F-50003.

Punchlist Category B Completion Date-06/30/94

$20-02 / 1$

Facility Safety procedures do not list compensatory actions for impaired equipment (safety showers, self-contained breathing apparatus, etc.). (WSRC$8 Q$. Procedures 1, 4.1.2.9 \& 5.1.1.1).

Corrective Action(s) -

1) Revise the following procedures to incorporate comperisatory actions and corrective actions when systems are found impaired.

SOP 221-F-51111 "Monthly Inspection of Fire Extinguishers, Building 221-F", SOP 221-F-62110, "Breathing Air Manifold Filter Inspection",

SOP 221-F-51057, "Inspecting and Testing Safety Showers and Eyewash Stations",

SOP 221-F-51050, "Emergency Battery Light Inspection",

SOP 221-F-51060, "Monthly Inspection of Scott Air Packs",

SOP 221-F-51054, "Inspection of Stretchers",

SOP 221-F-51041, "Emergency Cabinets",

SOP 221-F-51053, "Rescue Cabinets and Emergency Velicle",

SOP 221-F-51052, "Decon Cabinets"

Punchlist Category A Completion Date-03/01/94

2) Training determination will be made on procedures.

Punchlist Category A Completion Date - 03/31/94

20-03/1 The Facility Caution Tag Logbook system is deficient in that Caution Tags placed on equipment, processes, etc. prior to the Caution Tag Logbook system are not accounted for. (WSRC-8Q, Procedure 31). (Unrecorded Caution Tags noted at Level I Compressor Area and Idle Cesium Cell Equipment)

Corrective Action(s) -

1) Perform an inspection / audit of the caution tag program in 221-F.

Punchlist Category A Completion Date-02/19/94,

2) Verify all tags are updated per WSRC-8Q, Procedure 31.

Punchlist Category A Completion Date -03/10/94

3) Separations Quality to perform surveillance.

Punchlist Category B Completion Date - 05/31/94

20-03/2 Safety deficiencies found during facility and WSRC/DOE: safety-related audits, assessments, inspections, etc., such as Management Safety inspections, Safety Observers, Fire Watch, WSI Guard tours, ESH\&QA and DOE tours, Safety and Fire equipment inspections, are not tracked to completion. This includes deficiencies with Danger-Unsafe Condition Tags that are not being corrected in a timely manner. (WSRC-8Q, Procedure 1).

Corrective Action(s) - 
1) SOP 221-F-50003 the 221-F/OFF Safety and Industrial Hygiene program will address tracking Housekeeping and Safety deficiencies. The SOP outlines the requirement of a Level 4 Manager review and possibly the deficiency being entered into the Commitment Tracking Center if warranterd.

Punchlist Category A Completion Date-02/25/94

2) Train all members of 221-F / OF-F supervision on the 221-F / OF-F Safety and Industrial Hygiene program.

\section{Punchlist Category A Completion Date - 03/04/94}

20-03/3 Facility management / supervisory weekly and bimonthly safety and housekeeping inspections are not conducted on a regular basis as outlined by the Facility. (SOP 221-F-50003, WSRC-80, Procedure 1). NOTE: Field walkdown of Facility by Board Member noted safety deficiencies that were give to Facility for correction.

Corrective Action(s) -

1) SOP 221-F-50003 "221-F / OF-F Safety and Industrial Hygiene Program" will address the requirements for facility management / supervisor's to conduct weekly and bimonthly safety and housekeeping inspections on a regular basis.

Punchlist Category A Completion Date - 02/25/94

2) Provide training to all members of $221-F / O F-F$ supervision on the requirements for conducting audits $/$ inspections as outlined in SOP 221-F-
50003 .

Punchlist Category A Completion Date-03/04/94

3) Separations Quality to perform surveillance on weekly and bimonthly housekeeping inspections as outlined per SOP 221-F-50C103.

Punchlist Category B Completion Date - 06/30/94

20-03/4 The reporting format containing findings as found during management weekly and bimonthly housekeeping inspections is deficient. A uniform reporting format is not used. Some reports consist of handwritten pages and some consist of various printed inspection checklists.

1) SOP 221-F-50003 "221-F/OFF Safety and Industrial Hygiene Program" will address the reporting format and outline the guidelines for performing weekly and bimonthly safety and housekeeping inspections.

Punchlist Category A Completion Date-02/25/94

2) Train all members of 221-F / OF-F Supervision on the OSR Form that will be used to document weekly and bimonthly housekeeping in:spection of the facility.

Punchlist Category A Completion Date-03/04/94

3) Separations Quality to perform surveillance on reporting format used during weekly and bimonthly housekeeping inspections.

Punchlist Category B Completion Date - 06/30/94 
The facility carcinogen / hazardous material program is deficient as the handling of lead (cutting, grinding, hot work) is not accomplished under procedure as required by WSRC-4Q, IH-302.

Facility Statement -

Since this finding was written, WSRC-4Q, IH-302 has been rewritten (effēctive 1/17/94). It now requires Plans, Protocols, or Procedures for use and disposal of carcinogens as defined in WSRC $4 Q$, Appendices A or B. The only item listed in these Appendices containing lead is lead chromate, which we do not have in the facility. Therefore no corrective action is required.

\section{Closure-}

Finding canceled with Board accepting facility justification above.

20-04/2 Training in the facility Blood borne Pathogen program is deficient as the E\&I Mechanics do not receive the training as required by 548:0.10 and WSRC-4Q, IH 1201.

Corrective Action(s) -

1) Complete Blood-borne Pathogen Program training for all Canyon E\&l Mechanics.

Punchlist.Category A Completion Date-06/01/94

\section{Conduct of Operations}

Miscellaneous observations and tours of 221- $\mathrm{F}$ have indicated that there is an acceptance of less than adequate procedures and improperly completed paperwork for job control and job completion. It is also observed that some individuals, operators, mechanics, inspectors, and supiervisors, do not take it upon themselves to ensure that corrections and improvements are made by whoever is responsible. Examples: 1) A lockout removal was observed when the instructions for removal disagreed with the procedule for post maintenance testing. Operations proceeded with removal against the advice of maintenance and a problem developed. 2) M\&TE gages in use in the control room had expired calibration stickers and this was not questioned by the users. 3) Expired "temp mod" tags are not updated when the temp mod is extended (noted on 221-F EDG). 4) Other findings contain further examples, namely: $22-06 / 3,22-08 / 7,22-08 / 8$

Corrective Action(s) -

(The management assessment program will be used in conjunction with direct immediate feed back to address this issue of procedural adherence and performance expectations.)

1) Deputy Facility Manager will assume FAM (Functional Area Manager) duties.

Punchlist Category A Completion Date-06/23/94

2) Supplemental lines of inquiry will be added to all FA-22 Assessment Cards. The supplemental lines of inquiry will include observation of work.practices before, during and after jobs performed by Operations and Maintenance 
personnel. They will focus on personnel performance criteria and procedure expectations and execution.

Punchlist Category A Completion Date - 06/23/94

3) Assessment frequency of six topical areas $(2 S, 2.2,2.3,2.8,2.11,2.12$, and 2.16) will be temporarily increased from quarterly to monthly for the period $6 / 94$ to $9 / 94$, as a minimum.

Punchlist Category A Completion Date - 06/23/94

4) The initial management assessment of the six topical areas will be completed in June using the supplemental lines of inquiry for at least six performed jobs. Observations will be documented and the deficiencies dispositioned. To increase effectiveness, assessors will provide immediate feed back to the personnel assessed on results, both positive and negative. Individual deficiencies will be documented and corrected through the use of personnel contacts (OSR-25-33) or through formal remediation developed by the F-Area Training Department, as appropriate.

\section{Punchlist Category A Completion Date - 07/01/94}

5) Facility Management will review results from Management Assessments for disposition of deficiencies.

Punchlist Category B Completion Date - 010/01/94

Procedure compliance is inadequate. Specifically:

- several Operations procedures did not have the revision check on Page 1 signed;

- several abnormal data points were not circled on Operations round sheets.

\section{Corrective Action(s) -}

1) Complete $2 S$ Training for Operations Personnel.

Punchlist Category A Completion Date - 02/25/94

2) Separations Quality to perform surveillance of completed procedures for compliance with $2 S$ Manual, Procedure 1.3, Steps B.1.1, E.3.3, and E.3.4.

Punchlist Category B Completion Date-06/01/94

22-02/2 Performance of WCCR Round Sheets is inadequate. Specifically:

- Limits specified within the procedure were changed without initiating a procedure change resulting in operator confusion.

- OSR limits were not identified within the procedure and could not be identified by operations personnel.

- Pen and ink changes were made outside of the procedure change process.

- Rounds did not always start within one hour of the specified time and no explanation was provided as required by $2 \mathrm{~S}$.

- Red circled data was not always explained in narrative log and out of service points were inappropriately N/A'ed.

Corrective Action $(s)$ - 
1) Issue Shift Order direction / reminder that, per 2S SOMs can not correct typographical errors with out the proper approval signatures 6/13/94 A

Punchlist Category A Completion Date-06/13/94

2) Specific direction will be included in the 221-F/OF-F Shift Orders as to the expectations opposite operator rounds and the completion of round sheets. NOTE: 221-F/OF-F management realizes that the above corrective action may not be a long term solution to the identified operator round inadequacies. However, the root cause of this finding has been identified by WSRC ORR finding 22-01/1. The corrective action addressing this finding will ensure long term effectiveness.

Punchlist Category A Completion Date-06/22/94

3) Revise WCCR round sheets to remove OSR annotations where they are not applicable and to specify boundary limits where they are applicable.

Punchlist Category A Completion Date-06/23/94

On 1/13/94 deficiencies were noted in implementatior। of SOP 221-F-50080, "221-F/OF-F Deficiency Tagging (U)", specifically : Control Room Deficiency Tag Log Book contains a transcription error in the entry for tag \#B04288, 10/25/93 (should be \#B04287), no entry for tag \#B13909, 12/20/93, and a duplicate entry for tag \#B04065.

Corrective Action(s) -

1) Perform and document a field and log book audit to ensure that no other errors remain.

Punchlist Category A Completion Date-01/18/94

2) Correct all errors noted.

Punchlist Category A Completion Date-01/18/94

22-04/1 Critique Report Forms (Attachment B of Manual 2S, Procedure 5.2) are not being filled out as required by Step C.1.

Corrective Action(s) -

1) Implement the Event Critique / Investigation procesis Section 5, Evaluation and Reporting of the 9B Manual.

Punchlist Category B Completion Date - 03/31/94

2) Separations $Q A$ will verify facility compliance with the $9 B$ Manual.

Punchlist Category B Completion Date - 04701/94

22-06/1 During back shifts, the Canyon Shift Manager peniorms the function of authorizing installation and removal of lockouts $/$ tagouts for the Outside Facilities. However, none of the Canyon Shift Managers are listed in the Outside Facilities Operations Lockout / Tagout Authorization List.

Corrective Action(s) - 
Guidelines for use of Alarm Response Procedures have not been clearly defined. Interviews indicate, that Control Room personnel are not clear as to whether these procedures are in use or whether their use is optional or mandatory.

Corrective Action(s) -

1) Complete $2 S$ Manual Training for Operations Personnel.

Punchlist Category A Completion Date 02/25/94

2) Issue a Standing Order to define Alarm Response Procedures (ARP) Guidelines.

Punchlist Category A Completion Date - 02/25/94

3) Inform operations personnel of ARP policy in Shift Briefings

Punchlist Category A Completion Date 03/11/94

4) Separations Quality to perform a surveillance to verify proper ARP usage.

Punchlist Category B Completion 06/01/94

22-08/2 Communications practices in the Control Room do not metet the requirements as stated in the $2 S$ Manual, Procedure 2.1, Sections B, C, and D. In particular, operating directions are not acknowledged by repeating the information back.

Corrective Action(s) -

1) Complete $2 S$ Manual Training for Operations Personnel.

Punchlist Category A Completion Date-02/25/94

2) Increase coaching on communications by Operations Line Management.

Punchlist Category A Completion Date-03/25/94

3) Separations Quality to perform surveillance to verify Communications Compliance with 2S Manual, Procedure 2.1, Sections B, C, and D.

Punchlist Category B Completion Date-06/01/94

22-08/3 Deficiencies were noted in the use of Operator Aids. Specifically;

1) The S1 Manual, Procedure OP2.17, Attachment 8.1 defines operator aids as including plaques, conversion charts, formulas posted in the vicinity of installed indicating equipment (e.g., gauges, meters, recolders, etc.). There are several labels which have conversion charts for specific gravity meters in the Control Room which are not in the Operator log book. The facility operator aid procedure definition of operator aids allows use of these labels without their being logged, indicating a discrepancy in the procedures. 2) There is a conversion chart on the stack monitor which is contained in the HP Operator Aid Log but not in the Operations Operator aid log.

Corrective Action(s) - 
1) Submit Procedure Change Request (PCR) to $2 S$ Mariual, Procedure 5.10 to remove definition of permanent labels / plates with conversion data as operator aids.

Punchlist Category A Completion Date-02/25/94

2) Include Stack Monitor Conversion Chart into the F-Ianyon OperatorAids Log.

\section{Punchlist Category A Completion Date-02/25/94}

Adequate control of the Control Room safe is not maintained. The safe is typically left open with classified documents in view and is often not in direct line-of-sight of Control Room personnel. Unauthorized personnel had ready and unnoticed access to classified documents on several occasions.

\section{Corrective Action}

1) Change the status of 221-F Conirol Room Repositon/ \#1355 from normally open to normally closed.

\section{Punchlist Category A Completion Date-3/15/94}

2) Issue memo through required reading to all individuals on the authorization access list explaining (1) The importance of locking the repository, (2) Explaining when a repository can be open and (3) Summarize the requirements of 70 manual, Procedure PP-202, "Repository Lock \& Key Control".

Punchlist Category A Completion Date-3/15/94

3) Separations Quality to perform a surveillance on Docurnent Control / Records Management Implementation, particularly Repository \#13!55.

Punchlist Category B Completion Date-3/30/94

22-08/5 During observation of Cold Feed startup operations, particularly SOP 221-F40500 , it was noted that certain sections of the procedure containing critical steps had no initial or checkoff spaces for operator use as required by the S1 Manual, OP 2.16.

Facility Statement -

This finding was based on SOP $221-\mathrm{F}-40500$ being a Category 1 Procedure as defined in the S1 Manual. The S1 Manual section on procedures was recently superseded by issuance of the $2 S$ Manual, Section 1 on $1 / 28 / 94$ which restricts steps required to be initialed to those which effect conditicns specifically defined in Section E.5 of 2S Manual Procedure 1.2. These conditions include control of criticality, control of process hazards as defined by Processs Hazards Reviews, design requirements as defined by design agencies, environmental protection, quality, safety or technical limits. It is the position of the facility that all steps in F-Canyon procedures which could effect those concerns specified in Section E.5 of Procedure 1.2 have been identified and are already required to be initialed. Therefore, there is no corrective action necessary.

Closure-

The ORR Board approved this finding on 2/10/94 based on a requirement in WSRC-SCD-5 (9/1/93), Conduct of Operations Manual, Chapter 16 . This 
document was, at that time, the basis for SRS site compliance to DOE Order 5480.19. The requirement stated "Individual sign-offs shall be provided for critical steps". On 2/11/94 the WSRC 2S Manual was re-issued as the site standard for compliance with DOE Order 5480.19. As stated above by the facility, Procedure 2S 1.2 provides more definitive calegories for procedure steps that must be initialed. The procedure steps which are the subject of the finding do not unambiguously fall into one of these categories. Thus the-ORR Board agreed to cancel this finding.

$22-08 / 6$

Contrary to Conduct of Operations training received, a procedure prerequisite was routinely not complied with (Section 2.0 of SOP 221-F-55021, Rev. 2) and personnel performing the procedure had not initiated a procedure change request.

1) Train all F-Canyon personnel, including managers, on the 2S Manual Procedure 1.3, "Procedure Compliance" requirements to include the instruction to request procedure revision if the procedure is confusing or cannot be followed as written.

Punchlist Category A Completion Date-3/31/94

22-08/7 Procedure change process inadequate. Specifically:

- IPC 94-245 could not be located following approval although changes were incorporated into the affected procedure. (See finding 08:02/1)

- IPC 94-246 failed to include all identified discrepancies.

- IPC 94-164, 165, 166 to support compensatory measures associated with TMC-94-006 were not maintained active even though Temp Mod was still in place.

$\therefore$

Corrective Action(s) -

1) Develop and implement administrative controls for IPCs, including:

- Checksheets will be developed and used to ensure, by initials and signatures, that all current IPCs have been reviewed for incorporation into new revisions.

- IPC numbers will not be issued until the IPC has been approved by all reviewers.

- During off shift hours the IPC log will be maintained under SOM control.

- IPC record originals will be placed in "locked" drop poïnt pending procedure clerk receipt

Punchlist Category A Completion Date - 06/24/94

22-08/8 inadequate Calibration Procedure. Specifically:

- SOP W-730002 failed to specify adequate acceptance criteria.

- SOP W-730002 specified a test pressure which exceeded vendor specified test criteria.

Corrective Action(s) -

1) Verify procedure is in place for engineering review of acceptance criteria on NS \& CP systems calibrations.

Punchlist Category A Completion Date-06/30/94

2) Review all system calibration procedures, independent of safety class, and identify procedures with inadequate acceptance criteria. If necessary, recalibrate identified discrepancies for NS and CP systems or equipment. 
Punchlist Category A Completion Date - 07/15/94

3) Have system engineer review all questionable procedures and generate adequate acceptance criteria for identified procedures.

Punchlist Category B Completion Date - 07/29/94

Temporary paper labels were observed in the Hot Gang 'Valve Corridor, Section 6 , identifying a change to the connection made when a valve is operated. The use of adhesive paper labels is inappropriate in an environment in which the adhesive may deteriorate.

Corrective Action(s) -

1) Replace deteriorated tags in HGVC Section 6.

Punchlist Category A Completion Date-02/04/94

2) Perform a walkdown of the facility to verify no deteriorated or illegible tags exist on equipment that would hamper the safe operation of the facility.

Punchlist Category A Completion Date-02/07/94

3) Revise tickler \#113 to include appropriate areas to be walkdown / inspection of temporary paper labels.

Punchlist Category A Completion Date-02/10/94

4) Verify all temporary labels meet $2 S$ Manual Section 5.11 requirements.

Punchlist Category A Completion Date - 02/14/94

22-09/2 F-Canyon system components are currently being thoth renumbered and relabeled. A transition plan which would address concerns associated with changes to procedures, safety documentation, trainirig, etc., and operator awareness of these changes does not appear to exist.

Corrective Action(s) -

1) Develop and issue plan for 221-F Implementation of WSRC 2S, Procedure 5.11, Equipment and Piping Labeling.

Punchlist Category A Completion Date - 02/28/94

2) Issue the Configuration Management Implementation Plan for F-Canyon and develop implementation schedule.

Punchlist Category A Completion Date-03/31/94

22-10/1 Interviews with Shift Technical Advisors (STEs) indicate that STE duties and responsibjities are not documented and are not clearly uriderstood.

Corrective Action(s) - 
1) The job description containing defined STE responsililities will be issued as required reading to all STEs and Operations Supervisors on shift.

Punchlist Category A Completion Date-03/01/94

2) STEs will be assigned to shifts and will receive at least 7 shifts of operational experience prior to startup.

Punchlist Category A Completion Date-03/18/94 


\subsubsection{RSA Findings and Corrective Actions}

(RSA findings for which the corrective action was incomplete at the commencement of field verification).

RSA-04-01 Training records are not in an auditable state for Operations personnel minimum staffing. (Checklist B-2.02, Verification Result 1, and Checklist B-2.07, Verification Result 1) (4-F12)

Corrective Action(s) -

Correct deficiencies in records for other personnel included in the minimum staffing list for Phase 1 operations. (RSA 4-CA12B)

Punchlist Category A Completion Date-12/20/93

RSA-06-01 The BIO has not been approved by DOE. (Checklist C-i2.01, Verification Result 3 , and Checklist C-2.10, Verification Results 1 \& 2) (6 - F1)

Corrective Action(s) -

Revise and obtain DOE approval on the BIO. Verify compensatory measures have been added to the CTS, which includes field verification, prior to closure. (RSA-6-CA1B)

Punchlist Category A Completion Date-12/20/93

RSA-06-02 The exemption request for DOE 5480.23 has not been approved by DOE. (Checklist C-2.01, Verification Results $1 \& 4$, and Checklist C-2.10 Verification Result 4) (6-F2)

Corrective Action(s) -

Obtain DOE approval on the exemption request for DOE 5480.23. Verify compensatory measures have been added to the CT:S, which includes field verification, prior to closure. (RSA-6-CA2B)

Punchlist Category A Completion Date-12/20/93

RSA-06-03 The SAR Addendum (DPSTSA -200-10, Supp.4 Add.2) has not been approved by DOE. (Checklist C-2.01.01, Verification Result 1) (6-F3)

Corrective Action(s) -

Obtain DOE approval on the SAR Addendum. (DPSTSA-200-10, Supplement 4, Addendum 2). Verify compensatory measures have been added to the CTS , which includes field verification, prior to closure. (RSA-6-CA3B)

Punchlist Category A Completion Date $-12 / 20 / 93$ 
RSA-06-04 The exemption request for DOE 5480.22 has not been approved by DOE. (Checklist C-2.04, Verification Results 1 \& 3)

Corrective Action(s) -

Obtain DOE approval on the exemption request for DOE 5480.22. Verify compensatory measures have been added to the CTS;, which includes field verification, prior to closure. (RSA-6-CA-12B)

Punchlist Category A Completion Date-12/20/93

RSA-08-01 Procedure Manual 1Q, QAP 20-1, Rev. 2, "Software QA1", requires a Software Quality Assurance Program to be established to inclucle the requirement for Software Quality Assurance Plans (SQAPS) for designated software. SQAPs for designated F-Canyon software are not completed and approved.

Corrective Action(s) -

SQAPS were completed and approved for designated F-Canyon software.

Punchlist Category A Completion Date-12/13/93

RSA-12-01 Request for Approval (RFAs) for DOE 5480.7A are not approved, and likewise compensatory measures not verified.

(Checklist D - 2.03, Verification Results $2,3,4$ and 5$)(12-1 / 3)$

Corrective Action(s) -

Obtain DOE approval and issue CSAs for DOE 5480.7A. (RSA-12-CA3B)

Punchlist Category A Completion Date-12/7/93

RSA-12-02 The approved FHA was revised and rerouted for review and approval. The FHA shall be approved prior to restart. (Checklist D-2.01, Verification Result 1)

Corrective Action(s) -

Obtain approval on the revised FHA, required prior to closing the ORR. (RSA12-CA13)

Punchlist Category A Completion Date 12/21/93

RSA-13-01 CSA compensatory measures for DOE 5500 series have not been verified as implemented. (Checklist E - 2.04, Verification Result 4) ('I3 - F5)

Corrective Action(s) -

Obtain DOE approval for CSA compensatory measures for DOE 5500 series. (RSA-13-CA5B)

Punchlist Category A Completion Date-12/20/93 
RSA-17-01 RSA Corrective Action 22-CA8 requires the facility to reduce the backlog of overdue Occurrence Reports to less than 5 prior to facility restart. The backlog as of the start of the ORR field verification phase of the Issues Management Functional Area (11/12/93) is 8.

Corrective Action(s) -

A. Backlog of overdue Occurrence Reports (ORs) reducied to less than 5.

Punchlist Category A Completion Date-11/19/93

B. Corrective actions from approved ORs have been prioritized, restart actions scheduled for completion prior to restart, and tracked in the Commitment Tracking System (CTS).

Punchlist Category A Completion Date-12/10/93

RSA-22-01 SOPs for onily 2 of 14 safety related system have been revised to include Independent Verification requirements. (Checklist G-2.11), Verification Result 2) (22- F42)

Corrective Action(s) -

Revise SOPs for the remaining safety related system to include Independent Verification requirements. (RSA-22-CA42)

Punchlist Category A Completion Date-12/7/93

$$
\cdots
$$

The Following two findings were generated during the facility reassessment performed in May 1994. See supplementary RSA report Reference 10.

RSA-11-01 F-Canyon personnel are not knowledgeable in their uriderstanding of RWPs. (Checklist G - 2.16.02, Verification Result 1) (22-F55)

Corrective Action(s) -

1) Conduct OEP per FOEP-1994-0115 for F-Canyon personnel on RWPs with emphasis on: radiological conditions; suspension limits; greater than 7 feet and below grade; extremity dosimetry requirements, job description and planning.

Punchlist Category A Completion Date - 06/17/94

2) F-Canyon RadCon personnel conduct procedure requirement refresher training per shift orders on the following procedures: 5C11.2, 217, Rev 10, Use of Dosimetry; 5Q1.1, 504, Rev 1, Radiological Work Perınit; 5Q1.1, 505, Rev 1, ALARA Review Procedure.(parts applicable to extremity exposure)

Punchlist Category A Completion Date - 06ً̃/17/94 
RSA-11-02 F-Canyon has not adequately implemented tool control. (Checklist G - 2.16.02, Verification Result 2) (22-F56)

Corrective Action(s) -

1) Brief per FOEP-1994-0115 all F-Canyon personnel (Operations, Maintenance, Construction, RCO, and other applicable personnel) on Tool Control Program, Procedure 1.13 of Y18 Manual, Maintenance Program Procedures.

Punchlist Category A Completion Date-06/17/94

2) Survey F-Canyon and insure only "yellow marked" tools are in contaminated areas.

Punchlist Category A Completion Date-06/17/94 


\subsection{DOE Order Compliance Assessment}

The ORR Board reviewed the facility DOE Order Compliarice Assessment program, which was active during the time frame of the ORR. The assessment was performed jointly for the F-Canyon and FB-Line facilities. The facility has prepared Compliance Assessment Packages (CAPs) for the 54 Level 1 DOE Orders. Sixty-six (66) CAPs are required to cover F-Area, FB-Line and F-Canyon compliance to these 54 Orders.

The FB-Line/F-Canyon assessment generated a total of 6i0 Requests for Approval (RFAs) for exemptions, compliance schedule approvals (CSAs) or short term compliance schedules. Thirty-six RFAs are required for F-Canyon; all have been approved as of the date of this report.

The facility conducted a field verification of compliance to DOE Orders. This field validation was structured by Functional Area using the criteria of WSRC-SCD-4; with the exception that the assessment of compliance to DOE Order 5480.19 used the methodology of WSRC Manual 2S, Conduct of Operations.

The ORR review determined that the facility status of compliance is being monitored and maintained, per WSRC Manual 1E7, Procedure A301, with corrective actions that are required by compliance schedules, or noted deficiencies, being tracked in the Commitment Tracking System.

This ORR is further validation of DOE Order compliance sirice the criteria chosen for assessment derive in most cases from DOE Order requirements.

The ORR reviews described in Section 5.2.2 of this report assessed the facility implementation of many of the compensatory measures described in Compliance Schedules and Exemption Requests that are within the scope of this ORR. For example, the effectiveness of the following compensatory measures was assessed:

Training (FA-4): - Use of Shift Technical Engineers (STES) as a compensatory measure for non-compliances in the operator training program.

Procedures (FA-5): - (None applicable to the scope of the ORR).

Safety Documentation (FA-6): - Use of the Basis for Interim Operation, SAR Addendum 2 , the Safety Related Systems Procedure and other documentation as compensatory measures for the SAR and OSRs not meeting Order requirements. Also the use of STEs as a source of knowledge, in the control room, of the Authorization Basis Documents.

Environmental Protection (FA-7): - The alternative disposal methods and procedures that are employed pending implementation of a compliant Waste Characterization process.

Quality Assurance (FA-8): Training programs and Management Assessment programs that are in the process of being upgraded. 
Maintenance and Surveillance (FA-10): - Existing training programs for maintenance personnel, and programs for tool control, that are in the process of being upgraded.

Radiological Protection (FA-11): Current implementation of WSRC Manual 5Q as a compensatory measure for DOE Order non-compliances.

Fire Protection (FA-12): - Compensatory measures for code deficiencies in fire detection and suppression systems, specifically the roving fire watch rounds.

Emergency Preparedness (FA-13): - Use of existing Authorization Basis Documents as interim substitute for a Hazards Assessment and use of IDLH limits instead of ERPG-2 limits in Emergency Action Levels.

Issue Management (FA-17): - (No compensatory actions identified).

Occupational Safety (FA-20): - Compensatory measures based on implementation of WSRC Manuals $1 Q$ through $8 Q$.

Conduct of Operations (FA-22): - In transition from the Separations S1 Manual to the WSRC 2S Manual in a graded approach to compliance.

Where:the implementation of compensatory measures was found to be deficient, ORR findings were generated and corrective actions were comrnitted by the facility with completion of pre-restart items verified by the Board.

Based on the assessments within the scope of the readiness review, the status of compliance with applicable DOE Orders and the compensatory measures for nonconformances maintain adequate protection of the public health and safety, worker safety, and the environment.

\subsection{Compliance of the ORR/Startup Process with DOE Order 5480.31}

Planning for the F-Canyon Operational Readiness Review began in April 1993, prior to November 1, 1993 effective date for DOE Order 5480.31, "Startup and Restart of Nuclear Facilities." The WSRC Compliance Assessment and Implementation Report for this Order, Reference 11, notes that the F-Canyon Restart ORR does not strictly comply with the Order requirements, although the intent of the Order has been satisfied. The following is a summary of the differences between the F-Canyon ORR and the major requirements of the Order. 


\section{ORR Determination}

DOE Order 5480.31, paragraph 9.a.(3)(a), requires determination of when an ORR must be performed to be based on the hazard category of the facility as defined in DOE 5480.23 and Attachment 1 of the Order. ORR Determination for F-Canyon, which occurred prior to the issue of DOE Order 5480.31, was a Type 5 Restart with a contractor ORR, based on DOE guidance documents effective at the time. DOE-HQ concurred with this determination on 5-26-93. Since a DOE-HQ ORR will occur for $F$ Canyon, there is no impact of this difference.

\section{Plan-of-Action '}

Paragraphs 9.b.(1), 9.b.(2), and 9.b.(3) require that a formal ORR plan-of-action be prepared which specifies the prerequisites for starting the responsible contractor's ORR. Also in the plan-of-action, line management is responsible for developing the breadth of the ORR by addressing a set of minimum core requirements specified in Attachment 2 of the Order. Paragraph 9.b.(4) requires that the plan-of-action be approved by the startup authority.

F-Canyon did not prepare an ORR plan-of-action. However, a restart plan based on then current WSRC and DOE requirements was written to describe the breadth of the restart. This plan was based on the 22 Functional Areas of WSRC SCD-4, which have been shown to address the minimum core requirements in the Order (Reference 12). The restart plan was approved by WSRC on 8-23-93 and again on 10-20-93 after incorporation of DOE comments. DOE-SR approved the restart plan on 11-10-93. A contractor ORR plan was also issued on 11-23-93. The contents of the Restart Plan and the ORR plan effectively satisfy the requirements of the CRR Plan-of-Action.

\section{ORR Implementation Plan}

Paragraphs 9.b.(1) and 9.b.(6) require that, using the ORR Plan-of-Action as a basis, the Operational Readiness Review Team determine the criteria and review approaches to be used in the Operational Readiness Review Implementation Plan. For the FCanyon restart, there does not exist an ORR Plan-of-Action. Thus, the ORR Plan was prepared based on the DOE-SR approved restart plan and was approved by WSRC on 11-23-93 (Reference 4). The restart plan and readiness self-assessment plan were utilized as a basis for the ORR plan. The impact of this difference is insignificant. 


\section{Readiness to Proceed with ORR}

Paragraph 9.b.(9) states that the ORR is a verification of line management having achieved readiness to startup or restart the facility. Therefore, the prerequisite for starting the ORR is that the line management certifies that readiness of the facility in its entirety has been achieved. The ORR for F-Canyon was started in a phased approach, as individual functional areas were declared ready by line management. However, the ORR did not reach its final conclusion of readiness in any Functional Area until all Functional Areas were declared ready and after assessment of integrated simulated operations. Therefore, the phasing of the start of ORR field verifications had no material effect on the ORR conclusions.

\section{ORR Reporting}

Paragraph 9.b.(11) requires that a statement be made in the ORR report as to whether any identified non-conformances or schedules for gaining compliance with applicable DOE Orders, Secretary of Energy Notices, and Standards/Requirements Identification Documents have been justified in writing, have been formally approved, and in the opinion of the ORR Team, maintain adequate protection of the public health and safety, worker safety, or the environment.

The ORR Board has reached its conclusion regarding this requirement, based on the scope of the DOE approved F-Canyon Restart Plan. Because of limited scope of the Restart Plan, approximately 30 of the Level $* 1$ DOE Orders have been addressed. However, because of the recent Phase I and Phase II Order Compliance effort completed for F-Canyon, it is believed that adequate assurance exists with respect to all Level 1 Orders. 


\title{
6.0 ORR ORGANIZATION AND STAFFING
}

\subsection{ORR Staffing}

Raymond J. Skwarek, Manager, OSED, is the ORR Board Authority for the F-Canyon restart ORR. The Board and subject matter expert support is constituted as follows:

-Chairman, Dr. Allan F. McFarlane, OSED, ESH\&QA Division

- Vice Chairman/Member, James B. Spangler, OSED, ESH\&QA Division

- Member, Charles M. Voldness, OSED, ESH\&QA Division

- Member, Albert T. Todd, OSED, ESH\&QA Division

-Member, Dr. Vencil S. O'Block, FSES/OSED, ESH\&QA Division

-Member, Mark P. Findlay, SS\&ER Division

- Member, Edward C. Temple, HLW/SWER Division

- Member, David L. Lester, OSED, ESH\&QA Division

- Member, R. Dean Thames, Radiological Control Operations, ESH\&QA

- Member, William A. Condon, Operations, Reactors Division

-Subject Matter Expert, Fire Protection and Occupational Safety \& Health, Ford W. Burgess, ESH\&QA Division

For some of the field reviews, the Board had the assistance of Robert Horne, James Domer, Robert Faris, Richard Bryden and Thomas Hurt, all of the Operational Safety Evaluation Department, also Ed Mann of the Environmental Protection Department, Steven.Pye of Reactor Operations and Peter Graef of Waste Management.

\subsection{ORR Functional Area assignments}

The Board assignments were as follows (the Functional Area numbering follows the WSRC SCD-4 Manual):

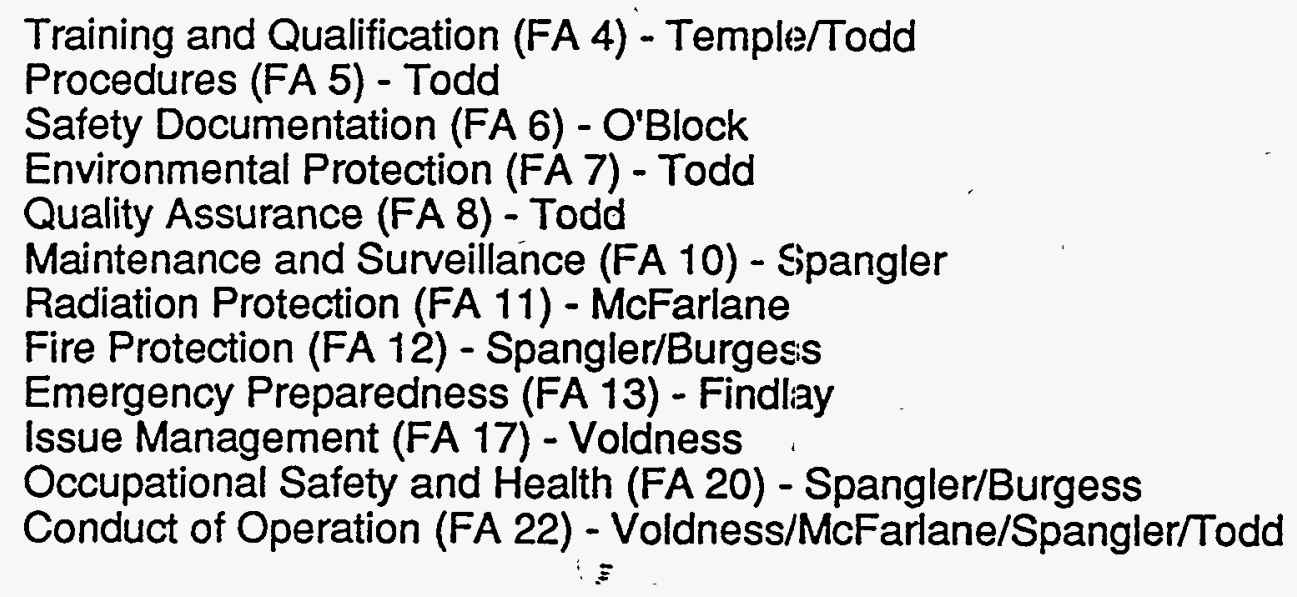

Additional Board members were added in June 1994 and they were assigned as follows:

\author{
Environmental Protection (FA 7) - Lester \\ Radiological Protection (FA 11) - Thames \\ Conduct of Operations (FA 22) - Condon, Pye (SME).
}




\subsection{Biographical Sketches}

Biographical sketches of seven ORR Board members and the subject matter expert for Fire Protection and Occupational Safety are provided in the ORR Plan (Reference 4). Biographies for the three Board members added in June 1994 follow.

\section{David L. Lester}

Mr. Lester has four years of experience at the Savannah River Site. Most recently, Mr. Lester has served as the Environmental Protection Department Unit Review Coordinator and has been responsible for the review of safety documentation associated with facility startups, restarts, and Operational Readiness Reviews. He has participated as a member of ORR Boards at SRS since March 1993. Prior to this assignment, Mr. Lester served as the SRS NEPA Coordinator and as Manager, Reactor Startup and Testing Department Administrative Section. Mr. Lester came to WSRC following over ten years of pre-operational testing, outage planning, and systems engineering supervisory work with various nuclear power generating facilities at the Tennessee Valley Authority and five years of service as an officer in the United States Navy. Mr. Lester has a BS degree in Physics from the United States Naval Academly and is matrixed to the Operational Safety Evaluation Department from the E:nvironmental Protection Department.

\section{R. Dean Thames}

Mr. Thames has a total of 12 years Health Physics/Radiation Protection experience, with the last 4 years at WSRC and the previous 8 as a Health Physics Contractor at various Nuclear Power Plants. Mr. Thames is currently assigned to the Radiological Controls - Startup and Project Management Group providing technical and operational support site wide. Prior to this assignment, he was a Senior Engineer in the Health Physics Technology - Field Technical Support Group in the Reactor Areas. His experience before that included 8 years commercial nuclear experience in Health Physics and Radiation Protection at various BWR and PWR power plants. Experience included work as a Radiological Engineer, ALARA Specialist, and Health Physics Technician. Mr. Thames has a BS degree in Nuclear Engineering Sciences from the University of Florida and a BS degree in Mathematics from Francis Marion University.

\section{William A. Condon}

Mr. Condon has 12 years of nuclear power experience consisting of commercial nuclear ( 8 years) and government nuclear ( 4 years). Mr. Condon has held various positions of responsibility including Core Design and Accident Analysis for Browns Ferry Nuclear Plant, Senior Reactor Engineer and Shift Technical Advisor for Sequoyah Nuclear Plant, WSRC Reactor Division Operations and Administrative Procedure Manager, K-Reactor Assistant Operations Manager, and Reactor Division Environmental Stabilization Manager. Mr. Condon is currently assigned as the Reactor Division Deputy Areas Manager for efforts such as development and implementation of the SRS Conduct of Operations Manual, implementation of DOE Radiation Control Manual, and oversight of maintenance and operation of five production reactors and the Heavy Water reprocessing facilities. Mr. Condon has a MS in Nuclear Engineering from the University of Tennessee, Knoxville. 


\subsection{Lessons Learned}

The Lessons Learned from the F-Canyon ORR will be issued as a separate report at a later date.

\subsection{References}

1. Letter W. H. Britton to C. C. Mason, "Strategy for Restart of F-Canyon and Outside Facilities," NMP-VP-93081, May 13, 1993.

2. "F-Canyon Facility Restart Plan," NMP-SFC-93-0241, Revision 1, October 19, 1993.

3. "F-Canyon Restart - Scope Change," Maher to Sjostrom, NMP-VP-94-185, August 2, 1994

4. "F-Canyon Restart Readiness Self Assessment Plarl," NMP-SFC-93-0252, Revision 0, September 7, 1993.

5. "Operational Readiness Review Plan for the Restart of F-Canyon (U)," ESH-ORR-93-0020-O, November 22, 1993.

6. Letter L. C. Sjostrom to R. Maher, "Interim Report of DOE-SR Validation Team on Oversight of F-Canyon and FB-Line ORRs," May 10, 1994.

7. Letter L. C. Sjostrom to R. Maher, "Results of DOE-SSR Validation of the FCanyon Restart Plan, Functional Area 11, Radiological Protection," May 19, 1994.

8. Memo L. D. Olson to T. C. Robinson, "Selection of F-Canyon Restart Criteria (U), " NMP-SFC-93-0545, December 10, 1993.

9. (a) "F-Canyon Restart Readiness Self-Assessment Fleport, Functional Area 4, Training and Qualification," NMP-SFC-93-0383, Revision 0, 10/26/93.

(b) "F-Canyon Restart Readiness Self-Assessment Report, Functional Area 6, Safety Documents," NMP-SFC-93-0384, Revision 0, 10/26/93.

(c) "F-Canyon Restart Readiness Self-Assessment Report, Functional Area 12, Fire Protection," NMP-SFC-93-0385, Revision 0, 10/26/93.

(d) "F-Canyon Restart Readiness Self-Assessment Report, Functional Area 13, Emergency Preparedness," NMP-SFC-93-0386, Revision 0, 10/26/93.

(e) "F-Canyon Restart Readiness Self-Assessment Report, Functional Area 20, OSHA," NMP-SFC-93-0387, Revision 0, 10/26/93.

(f) "F-Canyon Restart Readiness Self-Assessment Report, Functional Area 22, 
Conduct of Operations," NMP-SFC-93-0388, Revision 0, 10/26/93.

(g) "F-Canyon Restart Readiness Self-Assessment Feport, Functional Area 4, Training and Qualification," NMP-SFC-93-0383, Revision 1, 11/24/93.

(h) "F-Canyon Restart Readiness Self-Assessment Freport, Functional Area 20, OSHA," NMP-SFC-93-0387, Revision 0, 11/30/93.

(i) "F-Canyon Restart Readiness Self-Assessment Fieport, Functional Area 12, Fire Protection," NMP-SFC-93-0385, Revision 1, 12/13/93.

(j) "F-Canyon Restart Readiness Self-Assessment Report, Functional Area 6, Safety Documents," NMP-SFC-93-0384, Revision 1, 12/17/93.

10. "Final Readiness Self Assessment Report - Supplement," NMP-SFC-94-0326, June 8, 1994.

11. "Compliance Assessment and Implementation Plan for DOE Order 5480.31", WSRC-RP-93-668-056, June 16, 1994.

12. WSRC Manual 12Q, Procedure ORR-1, Revision !, Attachment C. 


\title{
Appendix
}

\author{
Checklist Forms
}

\section{F-CANYON RESTART}

OPERATIONAL READINESS REVIEW FINALL REPORT 


\section{Functional Area Title}

Training and Qualifications

\section{Element Title}

Training Requirements - GeneralTIM
ORR \#

Rov. \# 0

Checkllst :

04-01

Page 1 of

\section{Performance Objectlye}

A Training Implementation Matrix which defines and describes the application of the selection, qualification, and training requirements of this DOE Order $(5480.20)$ is prepared by the operating organization. The matrix defines the organziation, planning and administration of the qualification program and sets forth the responsiblity, authority, and methods of conducting training. [DOE 5480.20, Ch. I]

\section{Criterlon}

The F-Canyon Training Implementation Matrix is approved by the Facility Manager, and implernentation is in progress as scheduled.

\section{Verlfication Approach}

\section{Review approved TIM Plan.}

2. Observe field implementation.

3. Interview facility management.

\section{Lines of Inquiry}

1. Review TIM Plan for completion of selected actions/measures.

2. Select several items and observe implementation (e.g., definition and completion of qualification requirements for minimum staffing).

3. Interview facility management (operations, training and maintenance) to verify understandirgg/implemention status of TIM.

4. Administer a written examination to representative operators and supervisors to evaluate training effectiveness.

\section{Yerlflacation Besults}

1. Reviewed training implementation matrix (TIM) plan. It has been approved by the DOE Field Operations Office and submitted to DOE Headquarters for their approval.

2. Several topics (qualification standards and examinations) were selected to determine completion for Phase I restart. Qualification standards for Operators, Shift Technical Engineers (STE) and Shift Operating Managers (SOM) are available and in use. Further investigation revealed a lack of objective evidence of an analysis indicating what knowledge and skills are necessary for the STEs in the assigned compensatory roles. This is a finding (04-01/1). Examinations, both written and oral, are available and used for Phase I restart. Additional information on examinations can be found in Checksheet 04-05.

3. Facility management members were interviewed to assess knowledge of the TIM and its stalus affecting Phase I restart. Principal training managers and facility management are aware of this TIM and its implications. Mid-level canyon management (SOM/FLS) were not as knowledgable. 4. A comprehensive examination covering material relevant to Phase I restart was developed and administered to about 20 employees (Operators/FLS) on 1/13/94 and 1/14/94. Results indicatis that FLS scored an average of $83 \%$ and operators averaged $81 \%$. Math and chemistry basic fundamentals appeared to be the lowest scores of any subject material. Questions included subject material from Second PU, dissolving, facility hazards, facility emergencies, safety documentation, independent verification, alarm response procedures, nuclear criticality safety, RadCon, Conops and emergency preparedness. The results are satisfactory.
Documents Revlewed

Training Implementation Matrix.

Letter dated 12 Jan 94 , Exam Schedule

Letter dated 19 Jan 94, Results of Exams.

Qual standards for Operators, SOM and STE.

Comprehensive exam administered.
Finding? $\underset{\text { Yes }}{\square} \square_{\text {No }}^{\square}$

If yes, complete OSR 28-131
ORR Board Member:

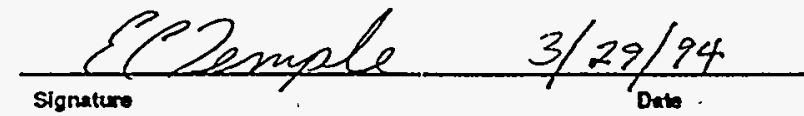

Reviewed By: 
Functlonal Area Title

Training and Qualifications
Element Title

2.33 Specific Training - Supervisors
Clieckllst \#

04-02
Rev. \# 0

Page 1 of 1

\section{Performance Oblectlve}

The supervisor training program includes the categories and on-the-job training specified for operators and fissionable material handlers to the extent to which they are applicable. This training is of increased depth to reflect the added responsibility of the supervisor position. [DOE 5480.20, Ch. IV]

\section{Criterion}

2.33.2 Procedure(s) are implemented that require technical training for supervisors be of greater depth than the training given to operators or fissionable material handlers. [DOE 5480.20, Ch. IV]

\section{Verifleation Approach}

1. Review lesson plans and examinations.

2. Observe oral boards.

3. Interview selected personnel.

\section{Lines of Inquiry}

1. Review two lesson plans and two written examinations to determine if material is of greater depth than that given to operators.

2. Observe 2 FLS, 2 Shift Managers and two STE oral boards to assess knowledge level of personnel.

3. Interview two FLS, two Shitt Managers and two STEs to assess competency.

\section{Verlfication Results}

1. Reviewed lesson plans NSAOFCO8L0600 (Second Plutonium cycle), NSAOFCO4L0500 (Dissolving) and NSAG0004L0100 (Safety Related Systems) and found no objective evidence of an analysis to support training "in greater depth" for supervisory personnel. This is a finding (04-02/1). It appears that the same lesson plan was delivered to all personnel (i.e., supervisors and operators).

2. Observed two Operator, one FLS and five STE oral boards. Oral boards were organized and formalized per the joint efforts of training and operational management. The board members wore senior facility managers that had been selected by the facility manager and had received board training prior to convening. A bank of questions was developed and issued to each board for use. Board members were able to pick questions from those listed and "peel the onion" as necessary. Results of questions and answers were recorded and maintained. In one case observed, the candidate failed to meet board expectations, was debriefed accordingly with training personnel present, and remedial training was scheduled immediately.

3. Two FLS, one SOM and one STE were interviewed, plus observation of oral boards conducted, to ascertain knowledge retention of materials presented in training. It was determined that these individuals had retained and understood material to a satisfactory level. It was noted that one SOM had not received the restart training (Finding 04-02/2). This SOM will not be assigned to Phase I operations until trained and qualified.

\section{Documents Revlewed}

Lesson plans for Dissolving, Second $\mathrm{Pu}$, and safety related systems training.

Oral board procedure.

Oral board examination material.

FInding? $\sum_{Y \in S} \square_{\text {No }}$ ORR Board Member:

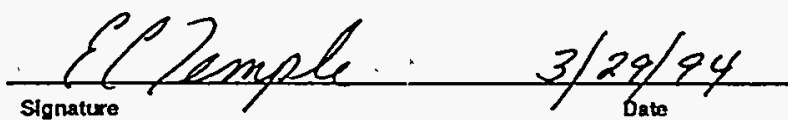

If yes, complete OSR 28-131

Reviewed By: $\quad \frac{Q .7 . w 47 a r l a n e}{3 / 29 / 94}$




\begin{tabular}{|c|c|c|c|}
\hline WSRC & ORR - CHECKLIST FORM & \multicolumn{2}{|c|}{ ORR \# } \\
\hline $\begin{array}{l}\text { Functlonal Area Title } \\
\text { Training and Qualifications }\end{array}$ & $\begin{array}{l}\text { Element Title } \\
\text { 2.22 Operator and Supervisor Examination }\end{array}$ & $\begin{array}{l}\text { Checkllst \# } \\
04.03\end{array}$ & $\begin{array}{l}\text { Rev. \# } 0 \\
\text { Page } 1 \text { of } 1\end{array}$ \\
\hline
\end{tabular}

\section{Performance Objectlve}

Written and oral examinations and operational evaluations are prepared and administered to demonstrate that certified operators and supervisors possess the required knowledge and skills. Written examinations and operational evaluations are prepared and adminstered for the qualification of other operators and supervisors. [DOE 5480.20, Ch. 1]

\section{Criterlon}

2.22.1.1 Documentation includes written and oral exams and operational evaluations that meiasure the required knowledge and skills identifed in the task analyses for the certified operator and supervisor positions. [DOE 5480.20, Ch. 1]

\section{Verlfication Approach}

Roviow qualification requirements for positions requiring pre-restart qualifications.

\section{Lines of Inquiry}

1. Review approved qualifications standards and supporting documentation (e.g., lesson plans) for consistency with SAR/BIO and TIM requirements.

\section{Verlflcation Results}

Reviewed qualification standards and supporting documentation for F-Canyon Operators and Shift Technical Engineers. Qualification standards were in place and used for these positions. It was found that the qualification standard for chemical process operators did not identify systems training as a requirement for qualification. This is a finding (04-03/1). This shortfall has been accounted for in the Phase I startup by the compensatory action of STE presence. The operator qualification standards should be upgraded to include systems training completion prior to removal of this compensatory measure:

\section{Documents Reviewed}

Qualification standards for STE and operators.

Finding? $\underset{Y \in S}{\square}$

If yes, complete OSR 28-131
ORR Board Member:

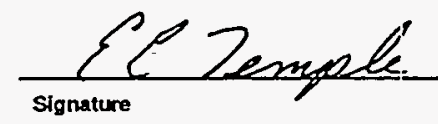

Reviewed By: Q.7.m Zarleme 
WSRC ORR - CHECKLIST FORM

\section{Functional Area Titlo}

Training and Qualifications

\section{Element Title \\ 2.22 Operator and Supervisor Examination}

ORR \#

93-0

\section{Performance objective}

Written and oral examinations and operational evaluations are prepared and administered to demonstrate that certified operators and supervisors possess the required knowledge and skills. Written examinations and operational evaluations are prepared and administered for the qualification of other operators and supervisors. [DOE 5480.20, Ch. 1]

\section{Criterlon}

2.22.1.2 Documentation includes completed exams and evaluations for all certified operators and supervisors to meet minimum staffing requirements of the FSAR. [DOE 5480.20 , Ch. 1]

\section{Verifleatlon Approach}

1. Review training records.

2. Interview operators.

\section{Lines of Inquiry}

1. Review 20 randomly selected $F$ Canyon personnel training records to determine if personnel have successfully completed process and supplemental training.

2. Interview five operators to assess knowledge level of proceśs and supplemental training.

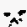

\section{Verlfication Besults}

1. Reviewed 16 individual training records of personnel involved in Phase I restart including operators, FLS and SOM. Verified that training associated with Phase I restart (i.e., Second Fu cycle, Dissolving, safety related systems, fundamentals of math and chemistry, etc.) had been presented, successfully completed and documented. Found evidence that the records systern was auditable.

2. Interviewed four operators and found the level of knowledge of material taught in association with Phase I restart to be satisfactory.

\section{Documents Revlewed}

16 individual training records.

Lesson plans for course presentations in Second $\mathrm{Pu}$, Dissolving, fundamentals and safety related systems.

\section{Flnding? $\quad \square \quad$ Yos}

If yes, complete OSR 28-131

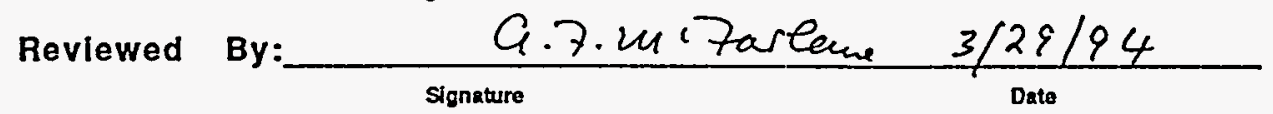


Functlonal Area Title

Training and Qualifications

\section{Element Title \\ 2.22 Operator and Supervisor Examination}

ORR \#

Rev. \# 0

Page 1 of 1

\section{Performance Oblective}

2.22.3 Written procedures are established for written and oral examination and operational evaluations (as required). [DOE 5480.20, Ch. 1]

\section{Criterion}

2.22.3.1 Procedure(s) are implemented that require written and oral exams and operational evaluation. [DOE 5480.20, Ch. 1]

\section{Verlficatlon Approach}

1. Review training documentation.

2. Observe oral boards and procedure walkdown.

\section{Lnes of Inquiry}

1. Review training documentation material relative to process operations evaluations (both witten and oral testing).

2. Observe through a walkdown with operators selected portions of process operations. (Select procedures from restart processes and observe walkdown by qualified operator(s) to assess effectiveness of operational training and evaluations).

\section{Yerifleation Results}

1. Reviewed 11 written examinations (six from safety related systems, three from Dissolving and two from Second Pu cycle. Found examination to be developed and approved in accordance with procedures. Questions were tied to learning objectives. Found problems with examination security (i.e., control of questions or trainees during writted and oral testing). This is a finding (04-05/1).

2. Observed an operation in progress (cold chemical runs). While observing, watched procedure compliance operation by operator and FLS. Operator and FLS appeared to be knowledgeable in the process and in procedure use/compliance.
Documents Bevlewed

The following 11 examinations plus oral board examination material for STE and Operator:

NSAG0004E1101

NSAG0004E1301

NSAG0004E1500

NSAG0004E1202

NSAG0004E1601

NSAG0004E1401

NSAOFCO4E0101

NSAOFCO4E1301

NSAOFCO4E0200

NSAOFCO8E1400

NSAOFCO8E1300

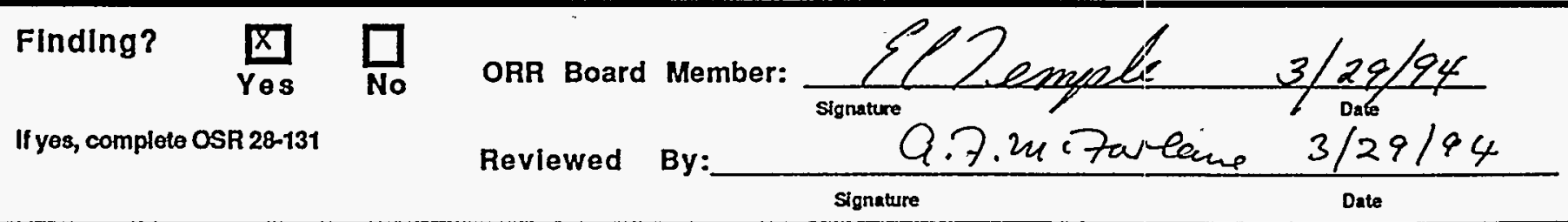




\begin{tabular}{|l|l|l|l|}
\hline \multicolumn{2}{|c|}{ WSRC ORR - CHECKLIST FORM } & \multicolumn{3}{c|}{ ORR \# 93-O } \\
\hline $\begin{array}{l}\text { Functlonal Area TItle } \\
\text { Training and Qualifications }\end{array}$ & $\begin{array}{l}\text { Element Title } \\
\text { 2.31 Specific Training - Operators }\end{array}$ & $\begin{array}{l}\text { C4-06 } \\
\text { Rev. \# }\end{array}$ & $\begin{array}{l}\text { Reve } \\
\text { Page } 1 \text { of }\end{array}$ \\
\hline
\end{tabular}

\section{Performance Oblectlve}

2.31.2 A core of subjects such as industrial safety, instrumentation and control, basic physics, chemistry, industrial operating experience, and major facility systems is established. [DOE 5480.20, Ch. IV]

\section{Criterlon}

2.31.2.1 Procedure(s) are implemented that establish a core of subjects. [DOE 5480.20, Ch. IV]

\section{Verifleatlon Approach}

1. Review lesson plans/training records.

2. Interview selected personnel.

\section{Lines of inquilry}

1. Review lesson plans for basic math and chemistry courses for content and formal approval to teach. Determine that reviewers/approvers are qualified.

2. Review twenty training records to insure basic math and chemistry have been successfully completed for $F$ Canyon restart operations personnel.

3. Interview five operators, two shift managers and two STEs to determine basic math and chrmistry knowledge level.

\section{Veriflagtion Besults}

1. Reviewed lesson plans for fundamentals courses basic math and basic chemistry. Both lesson plans have been properly developed and approved by training and facility management. In attempting to determine the level of basic math and chemistry taught to F-Canyon personnel, objective evidence of an analysis was discovered (Memo from NMPT to F Area Training Manager, Subject, Matrix of F Area Analysis for Fundamentals, dated 11/2/93). However, the level of material analyzed as necessary does not equate with the level of material presented. The analysis showed a greater depth of material was desired than was presented. This is a finding (06-06/1). 2. Sixteen individual training records of personnel associated with Phase I restart were reviewed. Records were found to be auditable in this area and training completion was documented for basic math and chemistry.

3. Four operators, two SOMs and two FLSs were interviewed and a number of oral boards were' observed (5) to determine if these personnel have a satisfactory level of knowledge retention/understanding in this knowledge area. It has been determined that the STE in particular, is knowledgeable and that the operators have retained what was taught.
Documents Reviewed

Lesson plans for basic math and basic chemistry

fundamentals.

Sixteen individual training records.

\section{Finding? $\underset{\text { Yes }}{\square} \square_{\text {No }}$ ORR Board Member:}

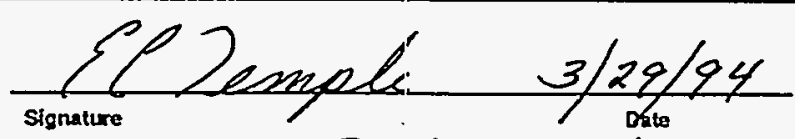

If yes, complete OSR 28-131

Roviewed By: $\quad$ Q.7.2n'Farlane $3 / 29 / 94$ 


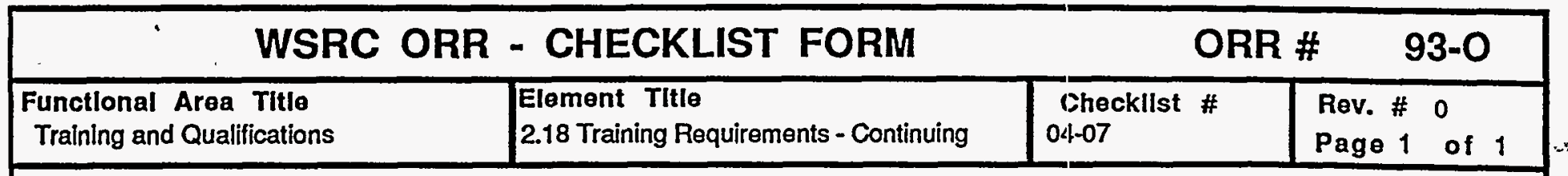

\section{Performance Qbjective}

2.18.1 Continuing training programs maintain and enhance the proficiency of operating organization personnel who perform functions associated with safety-related structures, systems, and components identified in the facility Safety Analysis Report. [DOE 5480.20, Ch. 1]

\section{Criterion}

2.18.1.1 Approved list of safety-related structures, systems and components identified in the FSAR is prepared. [DOE 5480.20, Ch. 1]

\section{Yerlfleation Approach}

1. Review lesson plans/raining records for safety related systems courses.

2. Interviow selected personnel.

\section{Lines of Inquiry}

1. Review lesson plans to determine extent of safety related systems training.

2. Interview five operators, two shitt managers and two STEs to assess level of safety related systems knowledge.

\section{Verification Results}

1. Reviewed safety related systems lesson plan. It appears that material has been covered in sufficient detail. The lesson plan was developed according to proper procedures with approval of facility management.

2. Interviewed four operators, Two FLSs and two SOMs and attended five STE oral boards. Knowledge of the presented material was satisfactory.

\section{Documents Reviewed}

Safety related system lesson plan.

16 individual training records.

$\begin{array}{llll}\text { Finding? } & \text { ORR Board Member: } \\ \text { If yes, complete OSR 28-131 } & \text { No } & \text { Reviewed By: }\end{array}$




\begin{tabular}{|l|l|l|l|l|}
\hline \multicolumn{1}{|c|}{ WSRC ORR } & \multicolumn{2}{c|}{ CHECKLIST FORM } & \multicolumn{2}{c|}{ ORR \#-0 } \\
\hline $\begin{array}{l}\text { Functlonal Area Title } \\
\text { Training and Qualifications }\end{array}$ & $\begin{array}{l}\text { Element Title } \\
\text { 2.19 Tech. and Maint. Personnel Training }\end{array}$ & $\begin{array}{l}\text { Checklist \# } \\
04-08\end{array}$ & $\begin{array}{l}\text { Rev. \# } \\
\text { Page } 1\end{array}$ of 1 \\
\hline
\end{tabular}

\section{Performance Objective}

2.19.2 Training on safety-related systems identified in the Facility Safety Analysis Report is conducted for all personnel who perform work on those systems. [DOE 5480.20, Ch. I]

\section{Criterion}

2.19.2.1 Procedure(s) are implemented that require training on safety related systems for all personnel who perform work on those systems. [DOE 5480.20, Ch. 1]

\section{Verlfication Approach}

1. Review safety related systems procedures.

2. Review training documentation.

\section{Llnes of Inquiry}

1. Review procedures to ensure that training is required on safety related systems for all personnel who perform work on those systems.

2. Review training records or supervisors record of experience to ensure non-operations personnel (e.g., maintenance mechanics, Power Department operators, HP inspectors) who perform work or calibrations on safety related systems have been appropriately trained.

\section{Verlflcatlon_Results}

1. F-Canyon requires supporting personnel (i.e., Mechanics, HP) to attend and successfully passs safety related systems training.

2. Reviewed records which indicate that supporting personnel did successfully complete this training.

\section{Documents Revlewed}

Individual records.

Class data sheets.

\section{Finding? $\square_{\text {Yes }} \mathbb{X}_{\text {No }}$ ORR Board Member:}

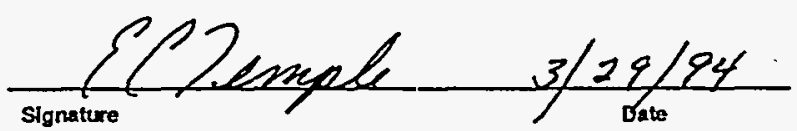

If yes, complete OSR 28-131

Revlewed

By:

Q.7.2m 7artame

Signature
$3 / 29 / 94$ 


\section{WSRC ORR - CHECKLIST FORM}

\section{Functlonal Area Title}

Training and Qualifications
ORR \#

Checkllst \# 04.09

\section{Performance objective}

2.1.2 The duties, responsibilities, qualifications, and authority of training organization personnel are documented, and managerial responsibilities and authority are clearly defined.

\section{Criterion}

2.1.2.6 Training records are maintained in an auditable manner consistent with DOE requirements. Training records support management information needs and provide required data on each individual's training participation, performance and verification of medical evaluations. [DOE 5480.18A, TAP 1, Objective 1.9]

\section{Yerifleatlon Approach}

Review training documentation.

\section{Lnes of Inquiry}

1. Review training records (20) to ensure records are auditable.

2. Review a sampling of training records that are used by managers, supervisors to assign personnel. Verify accuracy of those records with contral training records.

\section{Yeriflcation Results}

1. Reviewed sixteen training records of F-Canyon personnel involved in Phase I restart. Found records to be auditable. No discrepancies noted.

2. Reviewed two SOM and two FLS records of personnel involved in Phase I restart and found them to be auditable with no discrepancies noted.
Documents Reviewed 16 individual training records.

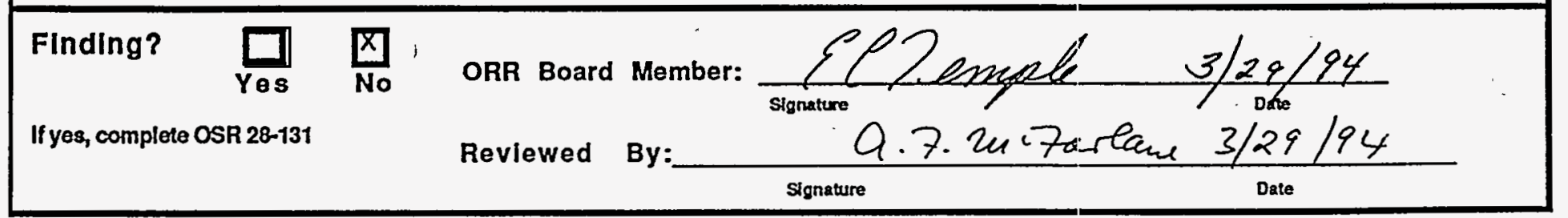




\begin{tabular}{|l|l|l|l|}
\hline \multicolumn{1}{|c|}{ WSRC ORR - CHECKLIST FORM } & \multicolumn{1}{c|}{ ORR \# } & 93-0 \\
\hline $\begin{array}{l}\text { Functionai Area Title } \\
\text { Procedures }\end{array}$ & $\begin{array}{l}\text { Element Title } \\
\text { Procedure Use }\end{array}$ & $\begin{array}{l}\text { Checklist \# } \\
05-01\end{array}$ & $\begin{array}{l}\text { Rev. \# } 0 \\
\text { Page } 1 \text { of } 1\end{array}$ \\
\hline
\end{tabular}

Performance eblective

Operations are conducted in accordance with written procedures that reflect the facility design basis.

\section{Criterlon}

Procedure users are aware that they are authorized to take whatever action is necessary during emergency conditions to place the facility in a safe condition and to protect equipment, personnel and public safety without first initiating a procedure change. [DOE 5480.19, Ch. 16; WSRC-2S, 1.3]

\section{Verlficatlon Approach}

1. Review training lesson plan on procedure usage.

2. Interviow selected personnel.

\section{Lines of Inquiry}

1. Review procodure training to assess training completeness.

2. Interview five operators, two shift managers, three maintenance mechanics and one maintinnance supervisor to determine training effectiveness.

\section{Yerlfication Results}

1. Reviewed procedure training, both in Separations Department General and as it relates to CONOPS training. The $100 \%$ procedure compliance, Procedure Change Request (PCR) and other applicable procedure information is adequately covered.

2. Interviewod four operators, 2 SOMs and 2 FLSs and found their knowledge in the procedure process to be adequate. They are aware of the procedure compliance concept and all had used and seen positive results from the PCR system.
Documents Reyiewed NMMGOOOg-CONOPS Lesson Plan

SOP 221-F-50602

Required Reading

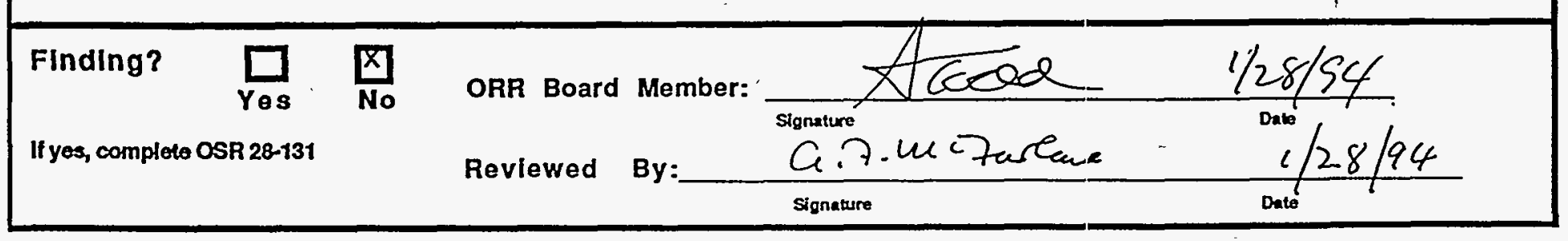


OSR 28-130 (REV. QNO3)

WSRC ORR - CHECKLIST FORM

ORR \#

$93-0$

\section{Functional Area Title}

Procedures

Eloment Title
Procedure Review

Checklist \#

05-02

Rev. \# 0

Page 1 of 1

Performance Objectlve

Procedures are reviewed before issue and at periodic intervals.

\section{Criterlon}

New or revised procedures require technical review.

\section{Yerlfleatlon_Approach}

Interview procedure control personnel.

Intervlew technical reviewers.

Review sample of procedure history files.

\section{Lines of Inquiry}

1. Verify personnel knowledge of procedure review requirements.

2. Verify involvement of Separations Engineering and Operations in procedure review and apploval.

3. Verify documentation of review and approval of recent procedure revisions for Phase I and safety related systems.

\section{Yerlfication Results}

1. Both operational and procedure administrative personnel were knowledgeable of the administrative procedural requirements within F-Canyon.

2. Both operational and engineering personnel were involved in the administrative procedural system, to include the review and approval process.

3. Documentation review indicated that USQ screenings were conducted as required; however, procedure historical files were not complete in that some files did not have an operations

"walkdown reviewer" assigned or signatures were missing from walkdown sheets. This is a finding (05-02/1).
Documents Revlewed

S-1, OP 2.16.02

221-FC-31500

221-FC-40506

221-FC-45505

221-FC-20153

221-FC-40181

\begin{tabular}{|c|c|c|c|c|c|}
\hline \multirow{3}{*}{$\begin{array}{l}\text { FInding? } \\
\text { If yes, complete OSR 28-131 }\end{array}$} & Wo & ORR Board & Member: & & $3 / 25 / 54$ \\
\hline & & Reviewed & By: & Qignaturé & $3 / 29 / 94$ \\
\hline & & & & Signature & Date \\
\hline
\end{tabular}




\title{
Functlonal Area Title SAFETY DOCUMENTS
}

\author{
Element Title \\ Safety Analysis
}

Checkllst \#

Rev. \# 0

0ti-01

Page 1 of 2

\section{Performance Oblectlve}

The Safety Analysis Report (SAR) provides detailed examination of those events that have the potential for causing significant human health effects to persons on-site or off-site. The Safety Analysis Report (SAR) provides descriptions of the facility, systems, operations, and the processes in sufficient detail to support the assumptions and conditions associated with the operational analyses.

\section{Criterlon}

The SAR identifies and demonstrates conformance with safety design bases, codes and standards. (SCD-4, FA-6, Criteria 2.1.1.1, 2.1.1.2, 2.1.1.6 through 2.1.1.8, and 2.1.1.10 through 2.1.1.15)

\section{Verlfleation Approach}

Document Review of Exemption Request (ER) for DOE 5480.23

Walkdown Safety Related System

\section{Lines of Inquiry}

1. Select at least five compensatory measures and/or compliant items identified in the ER for DOE 5480.23 and verify their implementation.

2. Perform a walkdown of the 281-6F Segregated Water Monitors to verify that the as-built configuration agrees with that provided in the Authorization Basis Documents (ABD).

\section{Verlfication Results}

Line of Inquiry 6-01-01: "5 compensatory measures"

Selected 5 compensatory actions specified in the exemption request for DOE Order 5480.23 . The 5 selected were Hazards Analysis, Derivation of TSRs, Accident Analysis, Criticality, and Quiality Assurance.

For Hazards Analysis the F-Canyon Basis for Interim Operation (BIO) was reviewed to verify that it documented that the F-Canyon is a Categary 2 hazard and that it identified any chemicals in excess of Threshold Planning Quantity (TPQ). In addition, Addendum 2 of the F-Canyon SAR was reviewed to verify that the dose conversion factors were updated to ICRP 30 and the source tarm has been updated.

For Derivations of TSRs, it was verified that the Safety Related Systems Procedure contained surveillance requirements and action statements. OSR DPW-85-101 was reviewed to verify that it contains a bases section. A Building 221 Technical Standard was reviewed to verify that it contains a bases section.

For Accident Analyses, the 11Q Manual was reviewed to verify that it requires independent review, approval and oversight.

(continued on next page)
Documents Revlewed

1. 221 Bldg. Tech. Stds., DPTS-221, 12/1/80

2. WSRC-IM-43-13, Rev. 0 , 2/93

3. WSRC S1 Manual, OP 4.14, Rev. 0, 3/27/92

4. Safety Related Systems Procedure, SOP 221-F-51230, 10/14/93

5. OSR DPW-85-101, Rev. 1 . $6 / 88$

6. 221 Tech. Stds., DPSTS221-FC-0.01, Rev. 2, 1/93 7. F-Canyon BIO, WSRC-RP93-1215

8. F-Canyon SAR Add. 2 , DPSTSA-200-10, Supp. 4, App. F

9. 1Q Manual

10. Ch. 12, QA, of Generic SRS SAR, WSRC-RP-91-188

Finding? $\underset{Y \in S}{\square}$

If yes, complete OSR 28-131
ORR Board Member:

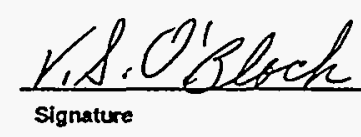

Reviewed
Q.7. un Tartecie

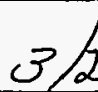

Date 


\section{WSRC ORR - CHECK LIST FORM}

\section{Functlonal Area 'Title SAFETY DOCUMENTS}

Element Title

Safety Analysis
Check LIst \#

$06-01$
Rev. \# 0

Page 2 of 2

Veriflcation Results (continued)

Line of Inquiry 6-01-01: "5 compensatory measures"

Documents Revlewed (cont.)

(continued from previous page)

For Criticality, 5 Technical Standards were reviewed to confirm that they contained criticality limits, also reviewed the Site Criticality Manual to verify that it contained a site criticality safety program, and reviewed the WSRC S1 Manual to verify that it does implement a criticality safety program and describes the site nuclear criticality safety program.

For Quality Assurance, the 1Q Manual was reviewed to verify that the specified sections were present and contained the indicated subject matter. Generic Chapter 12 of the SAR was reviewed to verify that it contained a description of the site and F-Area QA programs and organization.

Line of Inquiry 6-01-01.is satisfied.

Line of Inquiry 6-01-02: "Walkdown"

The segregated water monitors in Building 281.6F were walked down and a comparison made between the as-built condition and that shown on P\&ID W742070 and S5-2-6358. The results revealed that the P\&ID drawings used by one of the systems engineers for 281-6F Segregated Water Monitors (Safety Related System) do not reflect the current field configuration.

Examples: drawing S5:2-6358 (Table A) does not show a valve and pipe stub located between the alpha monitor and valve \#12; drawing W742070 (Table B) does not show a valve and line connecting the 0608-301-09 pump suction and discharge; sensorfindicator SRIT-1-E/T0150 CS6 shown on drawing does not exist in the system; potable water line to flush trap not shown on drawing; drawing does not show unique component numbers. This resulted in Finding 06-01/1.

1. Drawing \#S5-2-6358 -

"Segregated Process Cooling Water System - Radiation Monitor"

2. Drawing \#W742070 - "Savannah River Plant Bldg. 281-6F 200 Area Outside SEG. Water Line P\&I Diagram"

\section{Finding? \ $\square$ ORR Board Member:}

By:
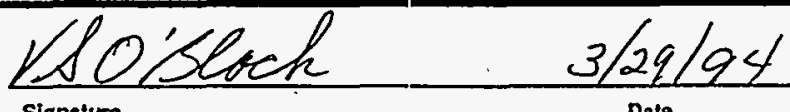
WSRC ORR - CHECKLIST FORM

ORR \#

Functlonal Area Titlo

SAFETY DOCUMENTS

Element Title

C:heckllst \#

06-02

Rev. \# 0

Page 1 of 2

\section{Performance Qblective}

The safety analysis report provides detailed examination of those events that have the potential for causing significant human health effects to persons on-site or off-site. The Safety Analysis Report (SAR) provides descriptions of the facility, systems, operations, and the processes in sufficient detail to support the assumptions and conditions associated vith the operational analyses.

\section{Criterlon}

The Safety Analysis Report (SAR) defines the safety basis, documents the logic of its derivation, and demonstrates adherence to the safety basis, it includes documentation of the assumptions employed in the safety analysis, and it also includes the results of the safety analysis that identifies the dominant contributors to the risk of the facility. (SCD-4, FA-6, criteria 2.1.1.3, 2.1.1.3, 2.1.1.4 and 2.1.1.5).

\section{Verifleatlon Approach}

Document Review

Lines of Inquiry

1. Review the Authorization Basis Documents (ABDs) to verify that they include thorough documentation of the assumptions used in the safety analysis and that they are self consistent (i.e. values and assumptions are the same in each document, or more conservative in implementing documents).

Yerlflcatlon Results

Line of Inquiry 6-02-01: "Review ABDs for thorough documentation"

SAR Addendum DPSTSA-200-10 Supp-4, Addendum 2 re-evaluates the corisequences of applicable accidents using revised nominal source terms, as well as maximum source terms with appropriate frequencies. The assumptions utilized in this evaluation are thoroughly documented in this Addendum. Assumptions utilized by other Authorization Basis Documents (e.g. DPSTSA-200.- 10 SUP-4, SUP-7, and SUP-10) are not as well documented. Therefore, this verification concentrated on the SAR Addendum assumptions. The majority of these assumptions are technical assumptions applicable to only the SAR addendum. These assumptions were judged to stand alone and be tiechnically valid. An assumption utilized by both Supp-4 and Addendum 2 is the Sand Filter efficiency = 99.51\%. This assumption is conservative and consistent with implementing documents. The CSR requires the sand filter to be on-line for operation of the $B$ Lines, canyons, or Building 235-F production facilities and requires the filter efficiency to be tested every 18 months. Implementing Procedure SOP 211-F-1502 requires the filter banks to be $99.95 \%$ efficient. The test on 10-22-92 was performed within the last 18 months and shows the sand filter efficiency to be $99.99 \%$.

During the completion of this effort, additional deficiencies not directly related to this LOI were discovered. One related to the acoountability tank liquid level and specific gravity instruments and the other to the sump liquid level instruments not being required to be designated as safety reliated in the Safety Related Systems procedure. The assessment fails to address whether these instruments are necessary to satisfy the "double contingency" requirements for inadvertent
Documents Revlewed

1. DPSTSA-200-10 SUP-4

2. DPSTSA-200-10 SUP-4 Addendum 2

3. DPSTSA-200-10 SUP-7

4. DPSTSA-200-10 SUP-10

5. DPW-85-101, Rev. 1

6. SOP-211-F-1502

7. FTR-92-422, 10-22-92
FInding?
$\underset{Y Q S}{\mathrm{Y}}$
$\square_{\text {No }}$
ORR Board Member:

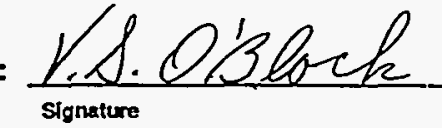
$3 / 2$
Signature
Date
If yes, complete OSR 28-131
Revlewed
By: $\frac{\text { Q.7.u }}{\text { signature }}$
$3 / 29 / 94$ 


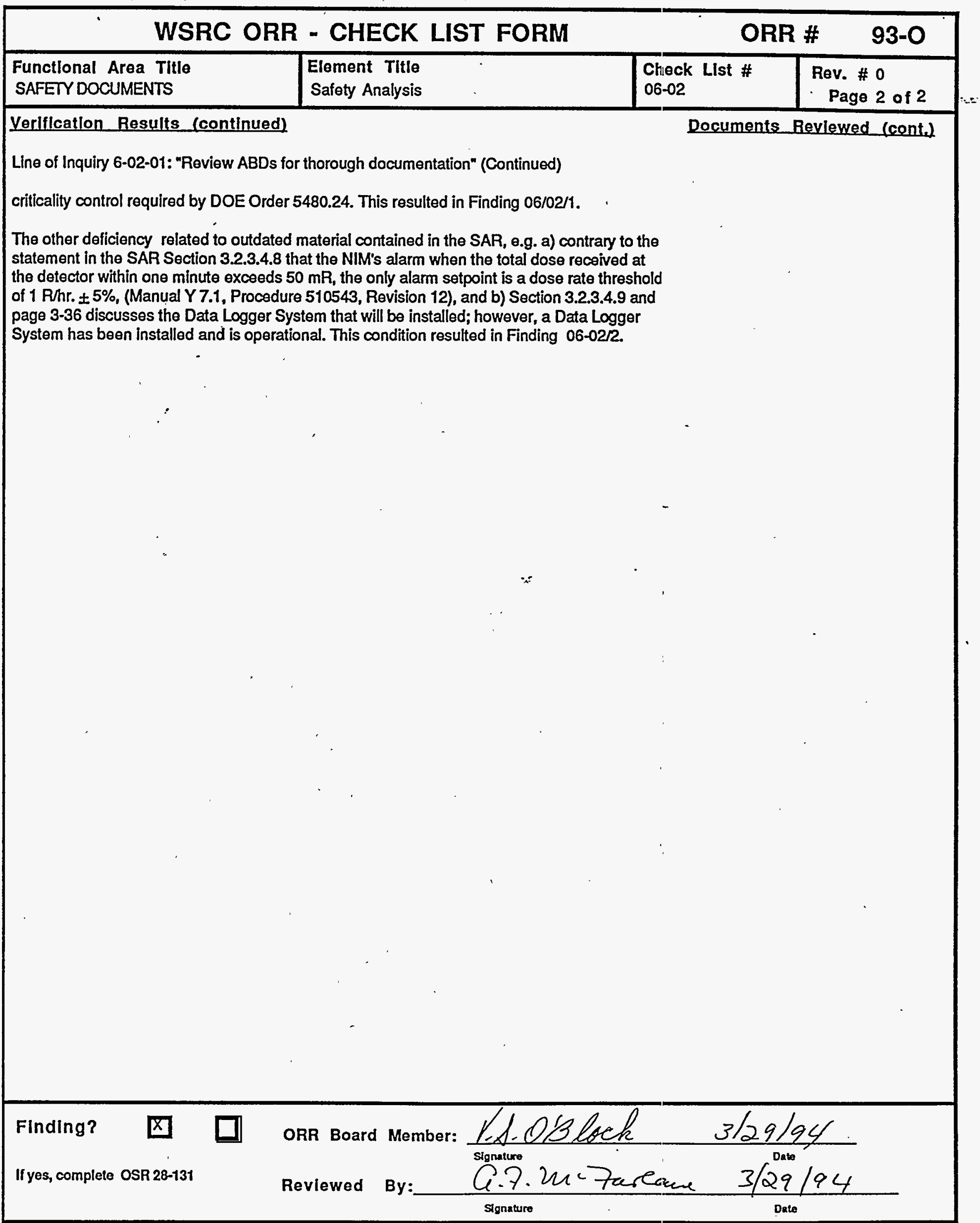




\section{WSRC ORR - CHECKLIST FORM}

Functlonal Area Title SAFETY DOCUMENTS

Element Title
Safety Analysis

ORR \#

93-0
Checkllst \# 06-03
Rev. \# 0

Page 1 of 1

\section{Performance Oblectlye}

The safety analysis report provides detailed examination of those events that have the potential for causing significant human health effects to persons on-site or off-site. The Safety Analysis Report (SAR) provides descriptions of the facility, systems, operations, and the processes in sufficient detail to support the assumptions and conditions associated with the operational analyses.

\section{Criterlon}

A specilic list of authorization basis documents is established identifying the most recently approved revisions. This list includes DOE approved Safety Analysis Report (SAR) and Addenda, Operational Safety Requirements, Technical Standards, Test Authorizations, safety analyses of positive Unreviewed Safety Questions not incorporated in the SAR, and Nuclear Incident Monitors Technical Standards. (SCD-4, FA-6, criterion 2.1.1.9).

\section{Yerlfication Approach}

Document Review

Observe availability of authorization basis documents

\section{Lines of Inquiry}

1. Verify that current approved Authorization Basis Documents (ABDs) exist in the field for operations use by comparing a current listing of the approved ABDs used by Engineering and by determining which ABD documents are used by Operations.

Verlficatlon_Results

Line of Inquiry 6-03-01: "Verify current ABDs"

Performed a comparison of the $A B$ documents available in the 221-F Control'Room with the current listing of the approved ABDs used by Engineering. A notebook in the control room contains the Authorization Basis list. However, this list was not the latest list (DPSTSA-200-10-SUPP-4 Addendum 2, Rev. 0 was missing from this list). The latest OSRs were in the Control Room but were contained in an uncontrolled copy. The latest Technical Standards were available in the Control Room with the exception of Nuclear Incident Monitors Technical Standard

(DPSTS-NIM-85). The latest Tests Authorizations and Safety Analysis Reports were not available. It was stated that the SARs could be found in Room 168. However, these documents could not be located at this location. It was pointed out that operations relies upon procedures and not the Authorization Basis Documents to perform its duties. The Shift Technical Engineers will require the use of the Authorization Basis Documents; however, these individuals are still being trained and are not currently on shift. The current approved ABDs do not exist in the field for operations us: which resulted in Finding 6-03/1.

During the completion of this effort, an additional deficiency not directly related to this LOI was: noted. WSRC approved changes to Technical Standards had not been approved by DOE. This resulted in Finding 06-03/2.
Documents Reviewed

1. Authorization Basis List

2. Discussion with Control Room Personnel (Dan Davis)

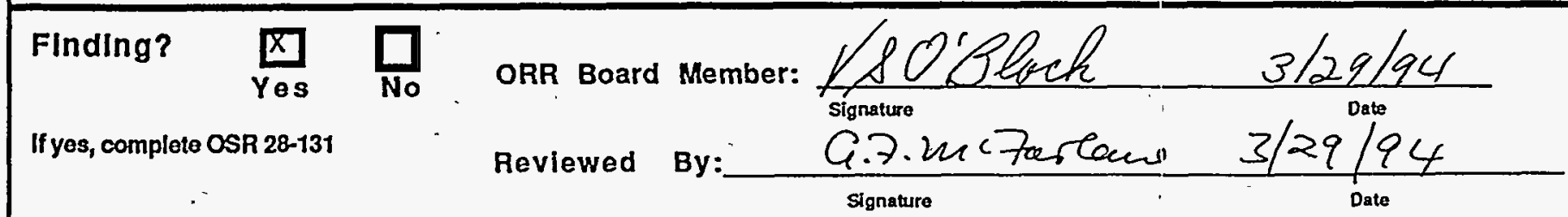




\section{WSRC ORR - CHECKLIST FORM}

\section{Functional Area Titlo}

SAFETYDOCUMENTS

Element Title
Safety Analysis

ORR \#

93-0

\section{Performance Objective}

The safety analysis report provides detailed examination of those events that have the potential for causing significant human health effects to persons on-site or off-site. The Safety Analysis Report (SAR) provides descriptions of the facility, systems, operations, and the processes in sufficient detail to support the assumptions and conditions associated with the operational analyses.

\section{Criterion}

F-Canyon facility specific procedures and other documents implement the requirements of the OSRs. (SCD-4, FA-6, criterion 2.1.1.16)

Veriflcation Approach

Document Review of procedures.

Interview Operations Managers and Operations Supervisors

\section{Lines of Inquiry}

1. Select at least 5 OSR limits on operation and verify that limits and values are contained in appropriate operating and maintenance procedures and are at least as limiting as the OSR requirement.

2. Select at least 5 limiting conditions of operation from the facility Authorization Basis Documents (ABDs) and verify that they are contained in appropriate operating and maintenance procedures and that they are at least as conservative as the ABD requirements. 3. Interview at least three operators to assess their knowledge, as appropriate, of the limits on operations imposed by the ABDs.

\section{Verlfication Results}

Line of Inquiry 6-04-01: " 5 OSR limits on operation"

Based on a review of the OSRs, the following OSR requirements were selected for verification: 1.1.C. 4 - entrained organic not to exceed $0.5 \mathrm{vol} \%$ (ARU)

1.1.C. 4 - evaporator temperature not to exceed $139 \mathrm{deg}$ C (ARU)

1.1.C.5 - entrained organic not to exceed 0.5 vol \% (AS)

1.1.C.5 - entrained organic not to exceed $0.5 \mathrm{vol} \%$ (LAW)

1.2.3.C.1 - maximum solvent temperature (2nd Pu cycle)

Technical Standards (TSs) and operating procedures that implement these OSR requirements; were selected based on the F-Canyon Linking Document and the F-Canyon Safety Document Data'jase. These documents were reviewed to ensure that they contained the appropriate OSR limit and that the requirements specified were at least as limiting as the OSR requirements. Discussions regarding these requirements were also conducted with Mr. Dan Snow who is responsible for the F-Canyon Linking Document and the Safety Documentation Database.

In all cases reviewed, the OSR requirements were found to be both properly incorporated into the TSs and operating procedures, and at least as limiting as the OSR requirements; however, RSA Checklist C-2.03 identifies an error in the OSRs which has not been corrected. This resulted in Finding 06-04/3. A potential concern on the frequency of an OSR surveillance on the neutron monitor was given Finding Number 06-04/2 but it was found that the BIO explained the inconsistency so the finding was not presented to the Board.
Findlng? $\underset{Y \in S}{\square} \square_{\text {No }}$

If yes, complete OSR 28-131
ORR Board Member:

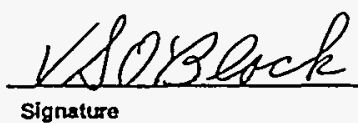

Reviewed By:

\section{Documents Revlewed}

1. DPW-85-101, Rev. 1

2. SOP 221-F-40825, Rev. 4

3. SOP 221-F-40506, Rev. 8

4. DPSTS-221-FC-600, Rev. 1

5. SOP 221-F-1101, Rev. 7

6. SOP 221-F-40612, Rev. 1

7. SOP 221-F-40815, Rev. 2

8. DPSTS-221-FC-400, Rev. 0

9. SOP 221-F-40505, Rev. 3

10. SOP 221-F-1117, Rev. 9 11. DPSTS-221-FC-710 Rev. 0 12.WSRC-RP-93-1215, Rev. 0 


\begin{tabular}{|l|l|l|l|}
\hline \multicolumn{1}{|c|}{ WSRC ORR - CHECK LIST FORM } & \multicolumn{2}{c|}{ ORR \# 93-0 } \\
\hline $\begin{array}{l}\text { Functlonal Area Titlo } \\
\text { SAFETY DOCUMENTS }\end{array}$ & $\begin{array}{l}\text { Element Title } \\
\text { Safety Analysis }\end{array}$ & $\begin{array}{l}\text { Check List \# } \\
\text { Rev. \# } 0 \\
\text { Page } 2 \text { of } 2\end{array}$ \\
\hline
\end{tabular}

Verification Results (continued)

Documents Reviewed (cont.)

Line of Inquiry 6-04-02: "5 Limiting conditions of operation"

This was done as part of Line of Inquiry 6-04-01; however, based on interviews with engineering personnel, it was determined that all Authorization Basis Documents (e.g., all Sections of the SAR, BIO, SAR Addendum \#2, and all but one Test Authorization) have not been reviewed to ensure that the operating procedures accurately and consistently reflect operational requirements identified in these documents. This resulted in Finding 06-04/1.

Line of Inquiry 6-04-03: "Interview 3 operators"

A crane operator, a building operator, a control room supervisor, and three control room operators were interviewed to determine their knowledge of the F-Canyon Authorization Basis Documents, their location, and the significance of LCOs safety limits, and OSRs. They were also asked to name 3 limits imposed on operation by the ABDs. All responded appropriately.

Line of Inquiry 6-04-03 is satisfied.

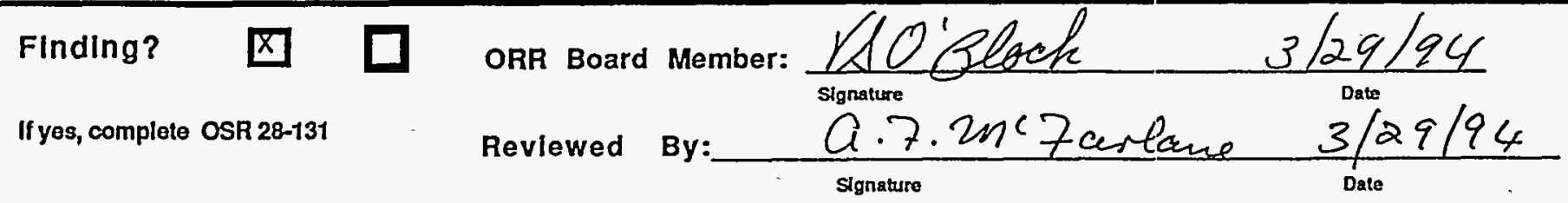


WSRC ORR - CHECKLIST FORM

\section{Functlonal Area Title \\ SAFETY DOCUMENTS}

Element Title

Administrative Controls

ORR \#

93-0

\section{Performance objective}

Safety analyses, safety documentation, design information, safety system descriptions and hazard analyses are used to identify administrative controls, and safety related administrative control requirements.

\section{Critarion}

Operating limits set forth in the OSRs have been incorporated into facility procedures and administrative controls and are specilied in units that can be readily determined by operations. (SCD-4, FA-6, criteria 2.2 .12 and 2.2.13)

\section{Yerlfication Approach}

Interview Operations personnel on safety related systems procedure OSR requirements

Document Reviow of safety related systems procedure

\section{Llnes of Inquiry}

1. Select 5 operating procedures and verify that the units they contain are easily understood and consistent with those used on the control panels.

2. Select 5 surveillance requirements specified in the OSRs and verify that they are properly incorporated into the operating procedures.

3. Interview three operators or shift managers to verify that they are adequately knowledgeable of surveillance requirements.

\section{Yerlfleation Besults}

Line of Inquiry 06-05-01: "5 operating procodures"

With the help of Control Room personnel (Dan Davis) and by reviewing control panel instrumentation, it was verified that the units specified by the following procedural steps were consistent with those shown on the control panel:

- SOP F-810002, Step 4.3.1.13.1:HZ-24 Molytek Recorder displays temperature reading attor between 117.3 degreos $\mathrm{C}$ and 118.5 degrees $\mathrm{C}$ on Channel 9 , when the alarm activates.

- SOP-221-F-40815, Step 4.2.5: If the Boiling Sp gr reading ditts 0.03 or more units outside minimum or maximum SP gr ranges shown in the table below...

- DPSOL F-810003, Step 5: If the interlocks or alams are not functioning properly...

- SOP F-826017, Step 4.29.1: Verify that the 2AF OSR High Temperature Interlock alarmed at/or between 72.34 and 7296 ohms.

- SOP F-810016, Step 4.1.20: Verify multipoint recorder reflects calibrator values of 126 to 128 Deg. C...

- Power operations Load Test Procodure 292-F does not specify units for several data This rosultod in Finding $06-05 / 1$. In addition an out of range reading is not so noted resulting in Finding $05-05 / 2$.
Documents Revlewed

1. SOP F-810002, Rev. 4, $10 / 28 / 92$

2. SOP 221-F-40815, Rev. 2 6/3/92

3. DPSOL F-810003, Rev.1, 7/29/87

4. SOP F-826017, Rev. 2 , $10 / 19 / 93$

5. SOP F-810016, Rev. 0 , $12 / 12 / 91$

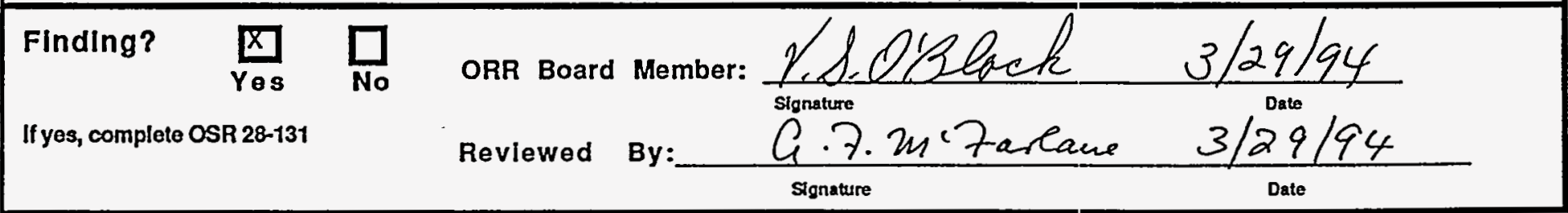




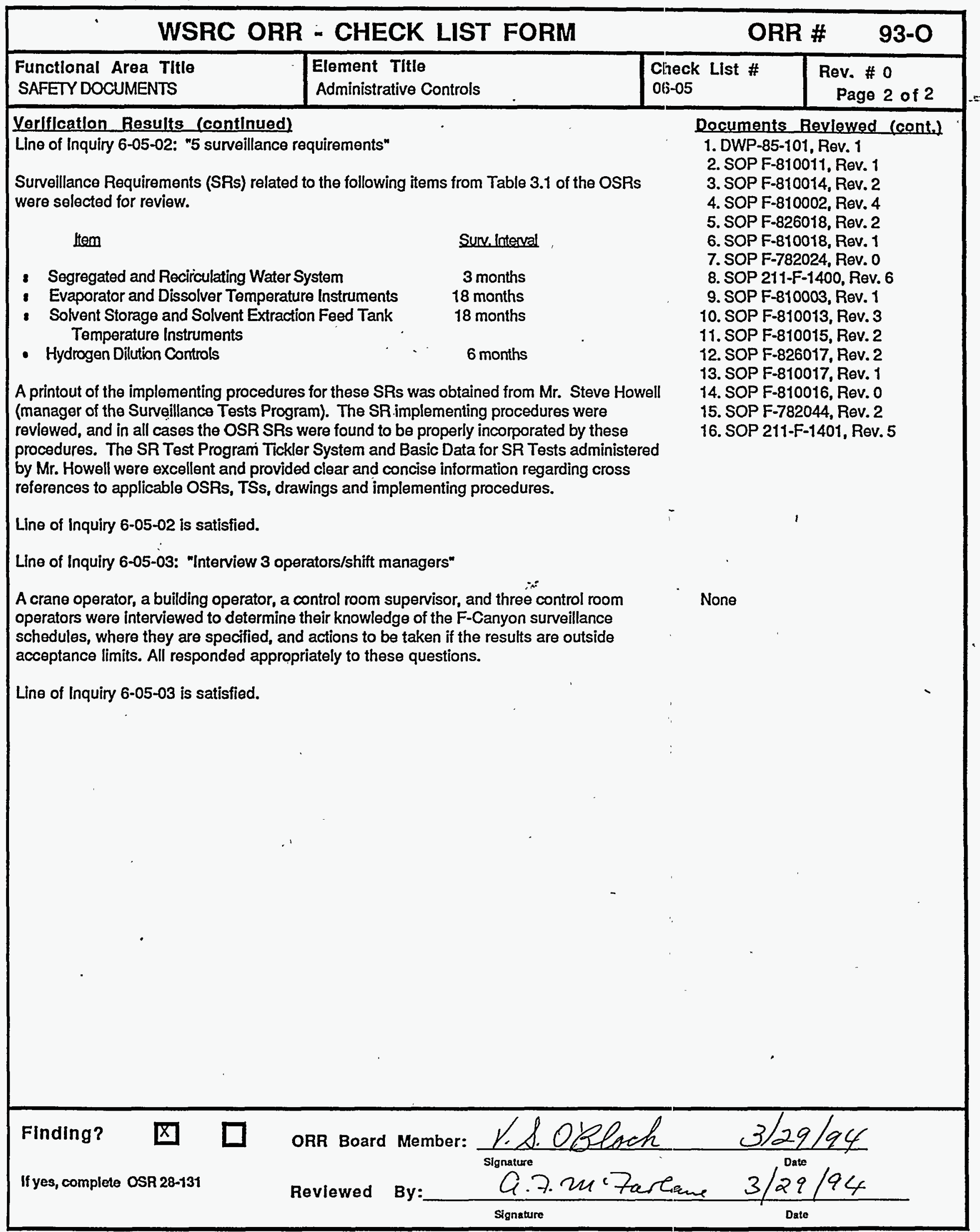




\section{WSRC ORR - CHECKLIST FORM}

\section{Functional Area TItlo} SAFETY DOCUMENTS

\author{
Element Title \\ Administrative Controls
}

ORR \#

93-0

Ciheckllst \#

Rev. \# 0

Page 1 of 1

\section{Perfermance Objectlve}

Safety analyses, safety documentation, design information, safety system descriptions and hazard analyses are used to identify administrative controls, and safety related administrative control requirements.

\section{Criterion}

Affected facility personnel are trained to the current OSRs per the safety related systems procedure, number 221-F-51230, "Safety Related Systems". (SCD-4, FA-6, criterion 2.2.14)

\section{Verlfileatlon Approach}

Interview Shift Operations Managers, Operators, and Engineers on shift on safety documentation

\section{Lines of Inquiry}

1. Interview 5 shift staff members to verify that they are knowledgeable about the OSRs, and safety related systems procedure $221-\mathrm{F}-51230$.

\section{Verlflcatlon Besults}

Line of Inquiry 6-06-01: "Interview 5 staff member for knowledge of OSRs"

A crane operator, a building operator, a control room supervisor, three control room operators, and two STEs were interviewed to determine their knowledge of the F Canyon OSRs and Safety Related Systems Procedure. Specifically they were asked to name 3 categories of OSRs, to explain their purpose, and to discuss the ramifications of operations outside an OSR. All provided adequate responses to the questions asked.

Line of Inquiry 6-06-01 is satisfied.

\section{Finding?

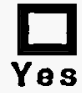 \\ 밈} If ye8, complete OSR 28-131
ORR Board Member:

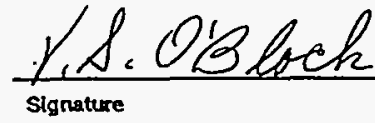

A.7. un Tartane

Revlewed By:
$3 / 29$

are used to identify




\begin{tabular}{|l|l|l|l|}
\hline \multicolumn{1}{|c|}{ WSRC ORR - CHECKLIST FORM } & \multicolumn{2}{c|}{ ORR \# } \\
\hline $\begin{array}{l}\text { Functlonal Area Title } \\
\text { SAFETY DOCUMENTS }\end{array}$ & $\begin{array}{l}\text { Element Title } \\
\text { Changes } N \text { SQs }\end{array}$ & $\begin{array}{l}\text { Checklist \# } \\
\text { o6-07 }\end{array}$ & $\begin{array}{l}\text { Rev. \# } 0 \\
\text { Page } 1 \text { of } 2\end{array}$ \\
\hline
\end{tabular}

\section{Performance Qbjective}

Changes made to the facility that directly or indirectly affect the authorization basis, and therefore its safety, are reviewed for USQs in accordance with DOE 5480.21. (DOE 5480.21, Sec. 8b)

\section{Criterion}

Changes made to the facility that directly or indirectly affect the authorization basis, and therefore its safety, are reviewed for USQs.

(SCD-4, FA-6, criteria 2.1.2.1, and 2.3.1 through 2.3.4)

\section{Yerifleatlon_Approach}

Document Review

Staff Interviows

\section{Lines of Inquiry}

1. Verify that the pre-restart corrective actions, in the facility response to the April 1993 Annual Safety Appraisal report, are closed.

2. Interview 5 shift personnel (representative of the minimum staffing of different shifts) to verify that they are knowledgeable of the requirements related to changes in process, equipment and procedures.

3. Select a minimum of five procedure modifications, Test Authorizations, or equipment modifications and ensure a USQD has been performed.

\section{Verlfleatlon Results}

Line of Inquiry 06-07-01: "Verify pre-restart corrective actions"

Pre-réstart corrective actions have been identified for FCAN-CTS \#437, 439; 440, 444, 448, 457, $460,511,512,1015,1010,1013,1018,1017,1019$, and 1007. Closure reports do not exist for 1015 (C-FCAN-93-01-05), 1010 (C-FCAN-93-08-02), 1013 (G-FCAN-93-08-04), 1018

(C-FCAN-93-10-02), 1017 (O-FCAN-91-10-01), 1019 (O-FCAN-91-11-01) and 1007

(O-FCAN-93-08-05). Closure documentation for the remaining pre-restart corrective actions has been reviewed. This documentation was judged adequate to verify closure, with the exceptiori of FCAN-CTS \#440 (C-FCAN-93-01-03). This action item states "Develop and give training on us? of Authorization Basis Documents and references in USQs." The closure package only verifies training on the use of references. This resulted in Finding 06-07/4.

Line of Inquiry 06-07-02: "Interview 5 shift personnel"

Five control room operators and five STEs were interviewed to determine their knowledge level concerning process, equipment, and procedures in general and of the USQ process specifically. The control room operators were not expected to be knowledgeable of the USQ process, but they were questioned on how operating procedure changes were initiated. All personnel questioned exhibited an adequate knowledge of the change process.

Line of Inquiry 6-07-02 is satisfied.
ORR Board Member:

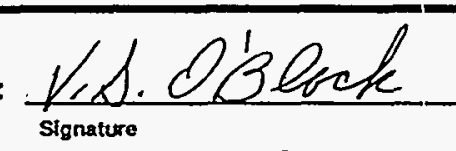

Documents Revlewed

1. NMP-SFC-93-0399

2. ESH-FSE-930407

3. FCAN-CTS \#437, 439, 440, $444,448,457,468,511$, 512,179 and 187

Reviewed By: $\quad 9.7 .2 u c 7 a r k a n e$ 


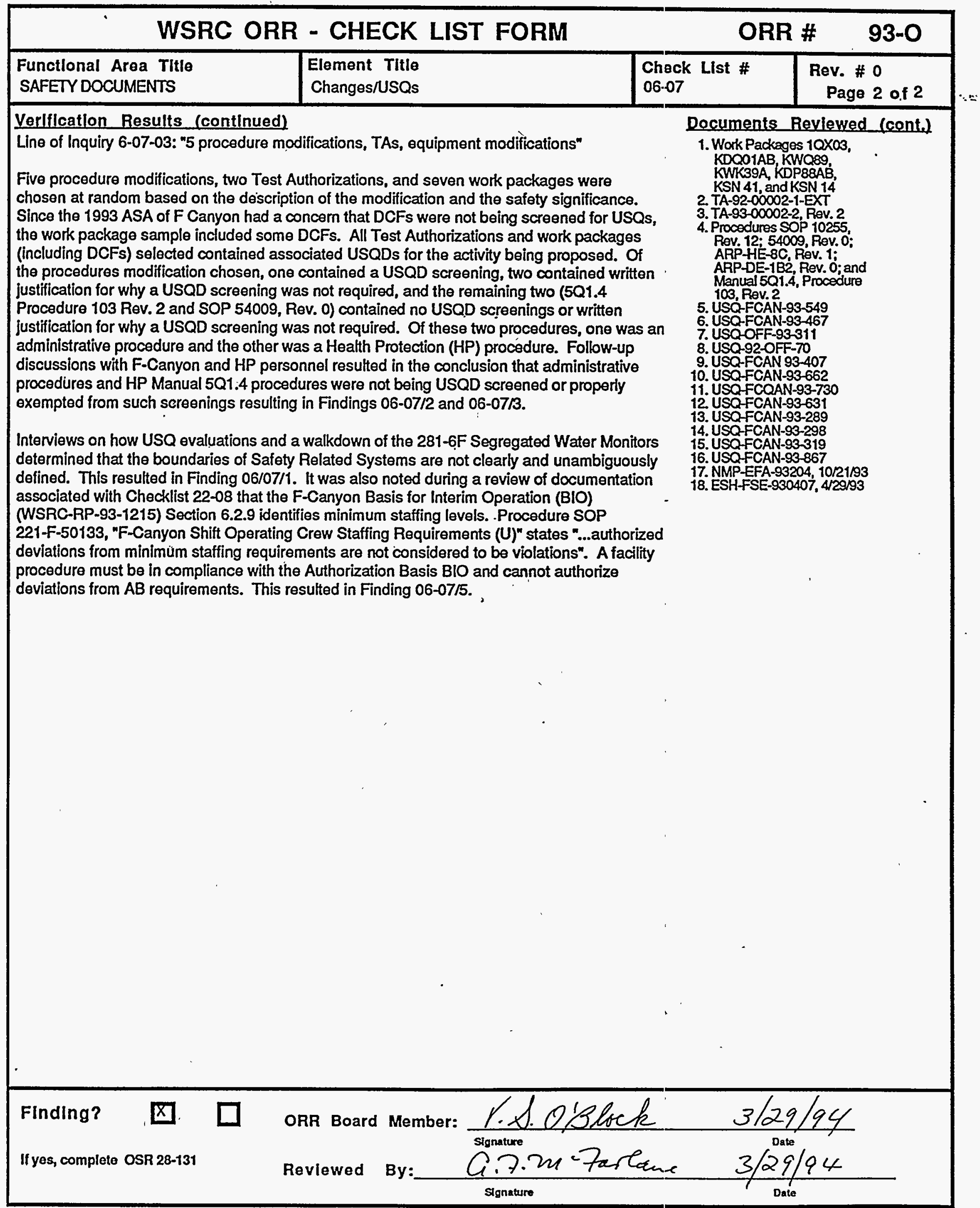




\section{WSRC ORR - CHECKLIST FORM}

\section{Functlonal Area Titlo SAFETY DOCUMENTS}

\begin{tabular}{|l|l|}
\hline Element Title & Checkllst \# \\
Test Authorization/Test Conclusions & $08-08$
\end{tabular}

Rev. \# 0

Page 1 of 2

\section{Performance Qblectlve}

There are provisions for control and authorization of operation outside normal operating conditions or processes with alternate equipment or material.

\section{Criterion}

Preparation roviow and approval of a Test Authorization (TA) is required prior to any of the following: (SCD-4, FA-06, criterion 2.4.1)

- Temp opn outside Tech Stds or study trials with new/substitute/altemative equipment/materials that may significantly affect nuclear or process safety.

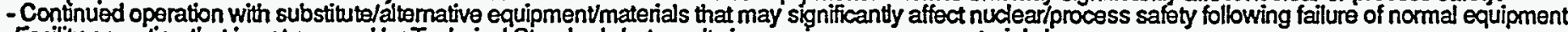

-Facility operation that is not covered by Technical Standards but results in a major process or material change

Significant changes in performance of safety-related equipment, even if within Technical Standards

\section{Yerlfication Approach}

Document Review of TAs

Interview Shift managers and Operators

\section{Llines of Inquiry}

1. Review at least two unexpired TAs to verify that the limits established in the TA are within the limits of applicable OSRS/ABDs.

2. Interview at least 3 control room supervisors and one or more cognizant technical support personnel to determine their degree of familiarity with the generation and control of TAs.

3. Verify that use of jumpers in the canyon is covered by appropriate administrative procedures.

4. Review at least two approved TAs to verify that they provide a justification for any increase in risk imposed by the TA.

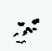

\section{Verifleation Results}

Line of Inquiry 6-08-01: "2 unexpired TAs"

Two TAs and related OSRs/ABDs were reviewed, and the limits specified in the TAs were found to be within the limits specified in the applicable OSRs/ABDs.

Line of Inquiry 6-08-01 is satisfied.

Line of Inquiry 6-08-02: "Interview 3 supervisors/technical support"

Three Control Room Supervisors, two STEs, and a Control Room Operator were interviewed to evaluate their knowledge and familiarity with the generation, control, approval, and specifics cf currently open Test Authorizations. All who were interviewed exhibited adequate knowledge of the subject.

Line of Inquiry 6-08-02 is satisfied.
Documents Revlewed

1. WSRC-TA-92-00002-1, Ext.

2. WSRC-TA-93-00002-2, Rev. 0

3. USQ-FCAN-93-319

4. DPW-85-101, Rev. 1

5. USQ-FCAN-93-289

6. USQ-FCAN-93-298

7. DPSTS-221-FC-350, Rev. 0

None

\begin{tabular}{|c|c|c|c|c|c|}
\hline \multicolumn{6}{|c|}{ ORR Board Member: } \\
\hline If yes, complete OSR 28-131 & & Reviewed & By: & 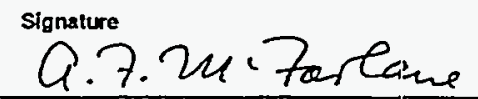 & $3 / 29 / 94$ \\
\hline
\end{tabular}


WSRC ORR - CHECK LIST FORM

ORR \#

Functlonal Area Title

SAFETY DOCUMENTS

\section{Element Title}

Test Authorization/Test Conclusions
Check List \# 06.08
Verification Results (continued)

Line of Inquiry 6-08-03: "Verify use of jumpers"

SOP 221-F-10223 provides detailed steps for updating the 221-F Canyon Control Room scroll to accurately reflect piping changes in the 221-F Canyon. The purpose of the 221-F Canyon Control Room scroll is to record the location of remote equipment and piping installed in the Canyon, to indicate the flow of process materials from vessels throughout the Canyon, as well as to facilities outside the Canyon Building; and to show various services, chemical additions, instrumentation, electrical, steam, water, air, etc. at each vessel; and to refer the user to specific drawings, equipment piece numbers and blueprint file numbers.

SOP 221-F-10255 provides detailed steps for repairing or replacing existing jumpers or rack pipes and repairing leaks on installed flex hoses. This procedure states that any change to piping configuration shall be covered by a special procedure. This procedure further states that the scroll in the control room shall be updated at the end of any piping job to reflect current conditions.

Special procedures and piping modifications would also be subject to additional control by the F Canyon USQD process.

Line of Inquiry 6-08-03 is satisfied.

Line of Inquiry 6-08-04: "2 approved TAs"

TwoTAs reviewed provided adequate descriptions regarding associated risks. Neither of these TAs represented any increase in risk, and associated USQDs were reviewed to verify this.

Line of Inquiry 6-08-04 is satisfied.
Documents Reviewed (conts)

1. SOP 221-F-10223, Rev. 8, $11 / 4 / 93$

2. SOP 221-F-10223, Rev. 12 , $12 / 28 / 93$
1. WSRC-TA-92-00002-1, Ext 2. WSRC-TA-93-00002-2, Rev. 0

3. USQ-FCAN-93-319

4. DPW-85-101, Rev. 1

5. USQ-FCAN-93-289

6. USQ-FCAN-93-298

7. DPSTS-221-FC-350, Rev. 0
FlndIng?

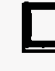

If yes, complete OSR 28-131
ORA Board Member:

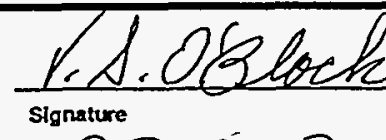

Revlewed
Rev. \# 0

Page 2 of 2 


\section{WSRC ORR - CHECKLIST FORM}

\section{Functional Area Titlo} SAFETYDOCUMENTS

\begin{tabular}{l|l}
\hline Element Title & Checkllst \# \\
Test Authorization/Test Conclusions. & $06-09$
\end{tabular}

ORR \#

93-0

\section{Performance Objectlve}

There are provisions for control and authorization or operation outside normal operating conditions or processes with alternate equipment or material.

\section{Criterion}

Upon completion of the work conducted under a Test Authorization the results and recommendations are reported in a Test Conclusion. (SCD-4, FA-06, criterion 2.4.7)

\section{Yorlfleatlon_Approach}

Document Review of TA procedure.

\section{Lines of Inquiry}

1. Verify that Test Conclusions were prepared for TAs which have been completed since the lequirement for Test Conclusions was added by procedure.

\section{Yerlfleation Results}

Line of Inquiry 6-09-01: "Test Conclusions prepared for TAs"

This item was evaluated in the F-Canyon 1993 Restart RSA (Checklist Item C-2.06.04, Lines of Inquiry \#1 \& 3). As documented in the F-Canyon Restart RSA report, this item resulted in a finding because Test Conclusions (TCs) had not been prepared for all completed TAs.

TCs still have not been prepared for all completed TAs. TCs are being prepared and are currently scheduled for completion by 1/30/94. This effort is being tracked under " $\mathrm{B}$ " Corrective Actions, 6-CA21 in the F-Canyon Restart RSA report. It was considered a " $B$ " item because there was no work done under most of the TAs and thus the preparation of a TC is a formality. The exception is still active.

Line of Inquiry 06-09-01 is satisfied.
Documents Bevlewed

1. NMP-SFC-93-0384, Rev. 0

2. WSRC-TA-93-00002-2,

Rev. 0

3. WSRC-TA-92-00002-1, Ext

4. WSRC-TA-93-00002-1, Rev. 0

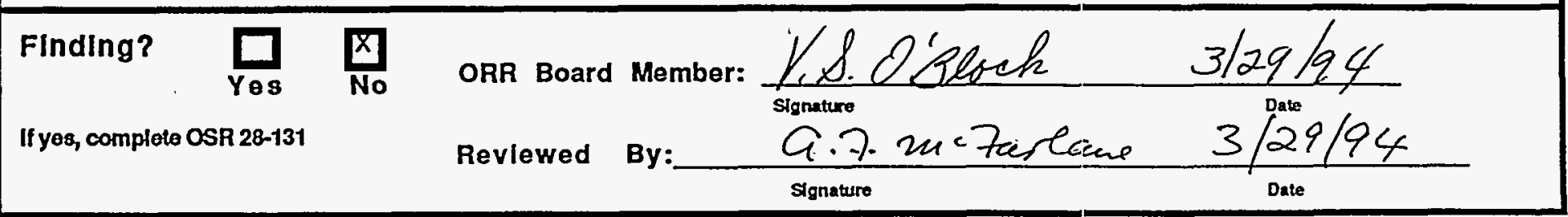




\begin{tabular}{|l|l|l|l|}
\hline \multicolumn{2}{|c|}{ WSRC ORR - CHECKLIST FORM } & \multicolumn{2}{c|}{ ORR \# 93-O } \\
\hline $\begin{array}{l}\text { Functlonal Araa TItle } \\
\text { SAFETY DOCUMENTS }\end{array}$ & $\begin{array}{l}\text { Element TItle } \\
\text { Technical Standards }\end{array}$ & $\begin{array}{c}\text { Checklist \# } \\
06 \mathrm{i}-10\end{array}$ & $\begin{array}{l}\text { Rev. \# } \\
\text { Page 1 of 2 }\end{array}$ \\
\hline
\end{tabular}

\section{Performance Objective}

Technical Standards provide a formal instrument which augments the Operational Safety Recuirements in establishing boundries for administrative control of all nuclear processes. (WSRC-11Q, Sec. 3.02 Par. 2.0)

\section{Criterlon}

The content and format of a Technical Standard include the following: applicability and scopi, objectives, limits and requirements, bases, references, and limits for process variables are specified only for those which are both measurable and controllable. Technical Standards also specifiy limit, conditions, and requirements for an entire process or area of interest. (SCD-4, FA-06, criteria 2.5.1, 2.5.2, and 2.5.8)

\section{Yerlflcation Approach}

Document Review of TSs

\section{Lnes of Inquiry}

1. Review 3 Technical Standards to verify that the information required by the Criteria is included.

2. Verify that they contain a reference to the information from which any limit or requirement is derived as well as how the limits were determined.

\section{Yerlficatlon Results}

Line of Inquiry 6-10-01: "Review 3 TSs"

TSs were reviewed to verify that they address the format and content requirements in Criteria 2.5.1, FA-06, Manual SCD-4. The format and content of the TSs is different depending on their age; however, they do not contain all the information required by the SCD-4 Criteria.

This item was evaluated in the F-Canyon Restart RSA (FA-6, Checklist Item C-2.07, \#1). Efforts are underway to revise the TSs to meet the SCD-4 format requirements by $3 / 30 / 94$, and this work is being tracked as a "B" Corrective Action (6-CA22) in NMP-SFC-93-0384, Rev. 0 . The change in format and content will not result in the generation of any new or revised technical information that would impact the facility operating safety envelope.

Line of Inquiry 06-10-01 is satisfied.
Documents Revlewed

1. DPSTS-221

2. NMP-SFC-93-0384, Rev. 0

\section{FindIng?

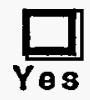 \\ $\frac{x]}{\text { No }}$}

If yes, complete OSR 28-131
ORR Board Member: Signature

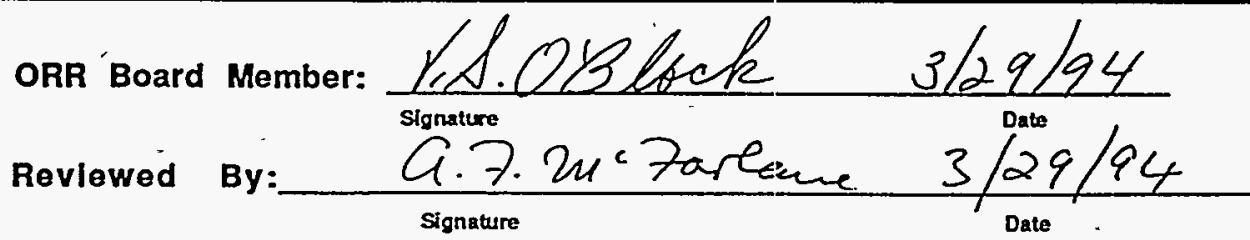

Revlewed By: 


\begin{tabular}{|c|c|c|c|}
\hline \multicolumn{2}{|c|}{ WSRC ORR - CHECK LIST FORM } & \multicolumn{2}{|c|}{ ORR \# } \\
\hline $\begin{array}{l}\text { Functlonal Area TItle } \\
\text { SAFETY DOCUMENTS }\end{array}$ & $\begin{array}{l}\text { Element Titte } \\
\text { Technical Standards }\end{array}$ & $\begin{array}{l}\text { Check List \# } \\
\text { 06-10 }\end{array}$ & $\begin{array}{l}\text { Rev. \# } 0 \\
\text { Page } 2 \text { of } 2\end{array}$ \\
\hline \multicolumn{2}{|c|}{$\begin{array}{l}\text { Verlficatlon Results (continued) } \\
\text { Line of Inquiry 6-10-02: "Verify TSs contain reference" }\end{array}$} & \multicolumn{2}{|c|}{$\begin{array}{l}\text { 1. DPSTS-221 } \\
\text { 2. NMP-SFC-93-0384, Rev. } 0\end{array}$} \\
\hline
\end{tabular}

F-Canyon Restart RSA FA-6, Checklist Item C-2.07.01, \#2). As was the case in LO1 06-10-01, the older TSs do not contain adequate justification regarding how the various limits were determined.

Efforts are underway to revise the TSs to include this information by $3 / 30 / 94$, and this work is being tracked as a "B" Corrective Action (6-CA22) in NMP-SFC-93-0384, Rev. 0 . The change in format and content will not result in the generation of any new or revised technical information that would impact the facility operating safety envelope.

Line of Inquiry 6-10-02 is satisfied.

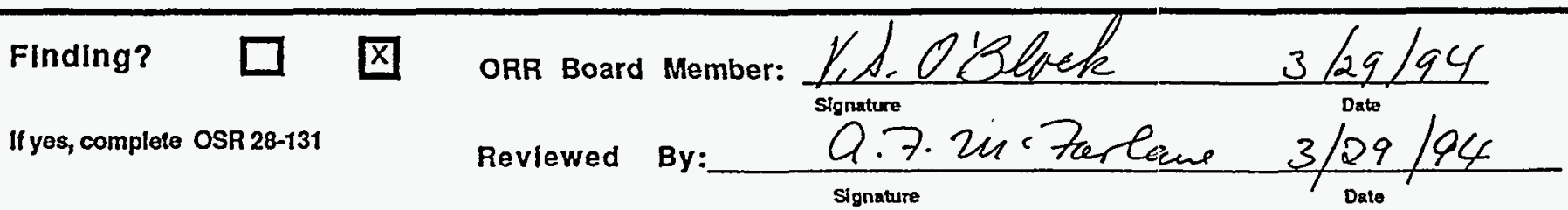


WSRC ORR - CHECKLIST FORM

ORR \#

93-0

\section{Functlonal Area Title \\ SAFETY DOCUMENTS}

\author{
Element Title \\ Technical Standards
}

Checkllst \#

06-11
Rev. \# 0

Page 1 of 2

\section{Performance Qbjectlve}

Technical Standards provide a formal instrument which augments the Operational Safety Requirements in establishing boundries for administrative control of all nuclear processes. (WSRC-11Q, Sec. 3.02 Par. 2.0)

\section{Criterlon}

Important uncertainties or possible errors in deriving the limits and requirements or in the related capability of either the equipment or personnel needed to implement them, is defined. (SCD-4, FA-06, criterion 2.5.4)

\section{Verlfleatlon Approach}

Document Review of Technical Standards.

Interviow

\section{Lines of Inquiry}

1. Verify that the controlling procedure for TSs requires the performance of an error analysis for the TS.

2. Review 2 TSs to verify that an error analysis is included per the requirements of the $11 Q$ manual.

3. Interview engineering manager and determine his/her knowledge of how uncertainties or possible errors in deriving the limits and requirements, or in the related capability of either the equipment or personnel needed to implernent them are defined and implemented into the Technical Standards and Calibration Procedures.

4. Reviow all TSs to verify that they received review and approval independent of the preparer.

5. Review at least 2 Technical Standards and verify that the TSs limits are at least as restrictive as the approved OSRs.

Yeriflcatlon Results

Line of Inquiry 6-11-01: "Verify controlling procedure for TSs"

As noted in RSA C-2.07.02, the uncertainties section is missing from all Technical Standards, although the controlling procedure for TSs (Manual 11Q, Section 3.02) requires performance of an uncertainty analysis. The corrective action for this RSA finding (6CA30 and 6CA28) evaluates uncertainties for safety related equipment. The implementing procedures for these evaluations are T408 and T408A from WSRC Manual E7. These procedures require performance of an uncertainty analysis. Also, Memo NMP-EFA-930200 further details the methodology used for uncertainty analysis. The methodology utilized for evaluating uncertainties is judged to be valid and follow:s ANSI and IEEE guidelines. This Line of Inquiry is satisfied.

Line of Inquiry 6-11-01 is satisfied.
Documents Reviewed

1. Manual 11Q, Sec. 3.02

2. DPSTS-221

3. NMP-SFC-93-0384

[FCAN-0310, 0335, and 0730]

4. T408A, Rev. 0

5. T408, Rev. 0

6. NMP-EFA-930200
Finding?

If yes, complete OSR 28-131
ORR Board Member:

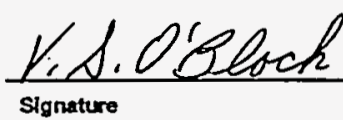

Reviewed By: Q.7. we Turtane

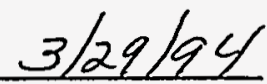
Date $3 / 29 / 94$ 


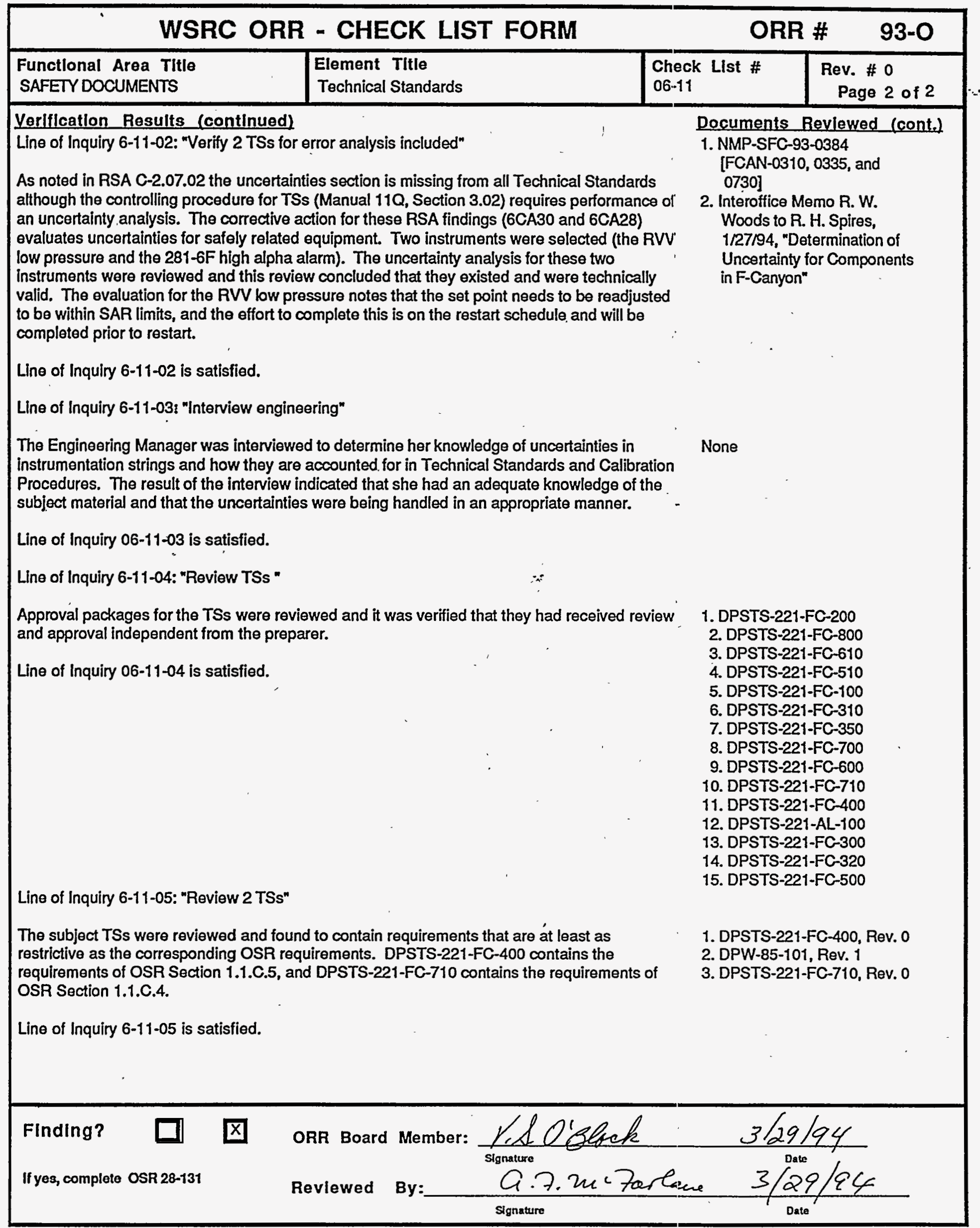


WSRC ORR - CHECKLIST FORM

\section{Functlonal Area Titlo SAFETY DOCUMENTS}

\section{ORR \#}

93-0

Checkllst \#

$06 \cdots 12$
Rev. \# 0

Page 1 of 2

\section{Performance Oblective}

Reviews are performed on new processes and modifications to existing processes to identify and evaluate hazards associated.

\section{Criterion}

Process Hazards Reviews (PHRs) are performed for new processes and modifications to existing processes. (SCD-4, FA-6, criterion 2.6.1)

\section{Yerlfication Approach}

Document Roview of PHRs

\section{Lines of Inquilry}

1. Verify that PHRs have been performed for at least 2 new processes and modifications for piase 1 of F-Canyon Restart if any are required.

2. Review at least two PHRs and verify that they received review and approval independent of -the preparer.

\section{Yerlfleation Results}

Line of Inquiry 6-12-01: "Verify PHRs have been performed"

PHRs were prepared for the F-Canyon dissolving process and for the second Pu cycle processi. However, the Special PHR for F and H Canyons and Outside Facilities covering the TOMSK-Like "Red Oil Reaction" has not been approved by WSRC as recorded in Finding 06-12/1.

\section{Documents Revlewed}

1. WSRC-PH-93-026, "Periodic Process Hazard's Review ReportDissolving", 11/4/93

2. NMP-ESE-93-0027, "Periodic Process Hazards Review-F-Canyon Second Plutonium Cyclo Process", $12 / 1 / 98$

3. QAAR 221-F-041, "QA

Assessment Report-Second Plutonium Solvent Extraction Cycle", 29182

4. Three pages from the 200 Area

Fault Tree Data Storage and Retrieval Sys. Database

5. WSRC-IM-90-135, "SRS Process Safely Management

Manual

6. F-Canyon Dissolving Incident Report Search, NMP-EFA-94-0021, 12009

7. Dissolving and Target Receipt \& Storage,

QAARS C. F. Hatcher to

Distribution, 10/10/85

\section{FIndIng? Yos No} If yes, complete OSR 28-131
ORR Board Member:

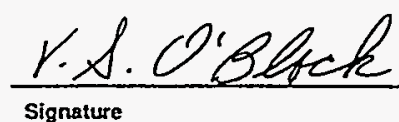

Revlewed
A.7. un Partane Signature

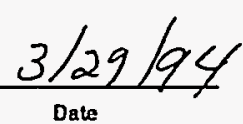
Date

Ifyea, comploto OSR 2Q-131

\begin{abstract}
By:
\end{abstract}


WSRC ORR - CHECK LIST FORM

Functional Area Title
SAFETY DOCUMENTS

Functional Area Title
SAFETY DOCUMENTS

Verlflcation Results (contlnued)

Line of Inquiry 6-12-02: "Review 2 PHRs"

Reviewed the PHRs for dissolution and the second plutonium cycle. They were both reviewed and approved according to the requirements of the $11 \mathrm{Q}$ Manual.

Line of Inquiry 06-12-02 is satisfied.
Element Title

Process Hazards Review
ORR \#

93-0

Check List \#

$06-12$
Rev. \# 0

Page 2 of 2 $=$

Documents Revlewed (cont.)

1. WSRC-PH-93-026, "Periodic Process Hazards Review Report-Dissolving", $11 / 4 / 93$

2. NMP-ESE-93-0027, "Periodic Process

Hazards Review-F-Canyon Second

Plutonium Cyde Procoss", 12/1/93

3. QAAR 221-F-041, "OA Assessment

ReportSecond Plutonium Solvent

Extraction Cycle", 2/9/82

4. Three pages from the 200 Area Fault

Tree Data Storage and Retrieval Sys.

Database

5. WSRC-IM-90-135, "SRS Process Safety Management

Manual

6. F-Canyon Dissolving Incident Report

Search, NMP-EFA-94-0021, 1/20193

7. Dissolving and Target Recoipt \& Storage, QAARS, C. F. Hatcher to Distribution, 10101055

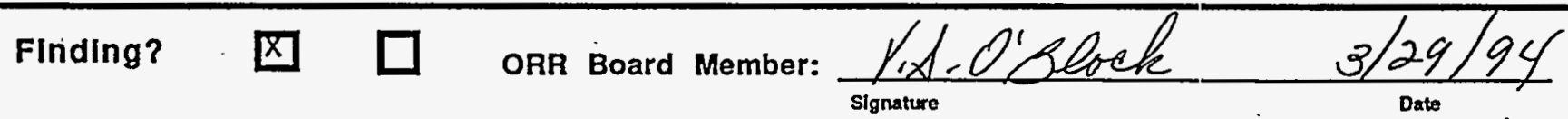

By:

A.7. nefarlane 
WSRC ORR - CHECKLIST FORM

Functlonal Area Title

ENVIRONMENTAL RROTECTION

Element Title

Waste Management

Checkllst \#

07.01

Rev. \# 0
Page 1 of 2

Performance Objectlve

Facility personnel have completed training associated with activities to ensure the protection of the environment.

\section{Criterlon}

A core of subjects for operators and Operations shift Managers and supervisors in F-Canyon has been given to address basic environmental, and waste handling and minimization requirements for assignment. The specific areas of training are SIRIM, RCRA satellite and staging areas, waste management practices, spill response, and permitted requirements such as stack and outfall discharges. (SCD-4, FA-4, criteria 2.31.2.1)

\section{Yerlfication Approach}

1. Review facility implementing procedures.

2. Review individual operator training records.

3. Interview operators, 4 shift managers and supervisors.

\section{Lines of Inquiry}

1. Roviow training program to identify training related to EP subjects.

2. Review five (5) training records of operators/FLS and shitt managers to determine if training was successfully completed.

3. Interview four (4) operators, 2 FLS and 1 shift manager to verify knowledge in areas as staled in above criteria.

4. Interview RCRA satellite custodian for knowledge of satellite area requirements.

5. Witness sample of performance of waste handling by facility waste operators.

\section{Yerlfication Results}

1. F-Canyon training program has identified, scheduled and presented Environmental Protection (EP) related training.

2. Reviewed training records for 16 individuals associated with Phase I Restart to verify that required Environmental Protection related training had been successfully completed. Found training documentation complete and auditable.

3. Interviewed four process operators, 2 SOM, 2 FLS, 1 building operator (waste handling), 1 waste handling FLS and 1 manager responsible for waste operations. Found process operators, SOM and FLS to be knowledgeable in topics presented in EP. Additionally they expressed they were comfortable with process procedures. Building operator and FLS interviewed exhibited a good grasp of knowledge presented.

4. Interviewed Area Satellite Custodian and found him to be very knowledgeable and experienced in his job including management of Satellite areas.

5. Observed a waste handling operation which included bagging of material from a contaminatisd area. A building operator, a standby building operator and an HP Technician were involved.

Governing procedures included 221-F-55019, 221-F-55021, 221-F-55035 and 221-F-55040. It was

noted that procedure 221-F-55035, Rev 2 Category 3 (Training \& Reference) requires initials for use every time for completion of Section 4 (Finding 05-02/2). It was also noted that while the bagging job was performed properly, confusion existed between the operator and FLS and procedure 221-F-55021. Paragraph 2.0, Scope, of this procedure calls for waste to be surveyıd and, if not contaminated, placed into compactable waste using the standards set in the paragraph.
Documents Beviewed

16 Individual Training Records 221-F-55019

221-F-55021

221-F-55035

221-F-55040
Finding? $\underset{Y \in S}{\square_{\text {No }}}$

If yes, complete OSR 28-131
ORR Board Member:

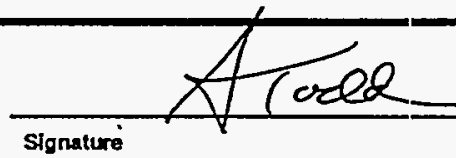

Reviewed By: $\quad$ G.7.2uc7arleme

Reviewed By:

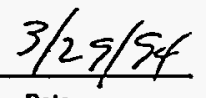

Date 


\section{WSRC ORR - CHECK LIST FORM}

\section{Functlonal Area Title}

ENVIRONMENTAL PROTECTION

\section{Veriflcation Results (continued)}

According to the personnel interviewed, they were operating under management directive which states that all waste removed from a contaminated area be placed into B-25 boxes. Therefore operators were not following procedure 221-F-55021 (Finding 07-01/1). Procedure 221-F-55021, Rev 2 is dated 12/9/93. Operators, FLS or management had not initiated efforts through the established system of Procedure Change Request (PCR) to update the procedure with management directives. This is a FA 22 Conduct of Operations finding.
Element Title

Waste Management
ORR \#

93-0

Check Llst \#

07-011

Rev. \# 0

Page 2 of 2

Documents Reviewed (cont) 
WSRC ORR - CHECK LIST FORM

Functional Area Title
ENVIRONMENTAL PROTECTION

ORR \#

93-0

\section{Performance Objective}

Facility personnel have completed training associated with activities to ensure the protection of the environment.

\section{Criterion}

A core of subjects for operators and Operations Shift Managers and supervisors in F-Canyon has been given to address basic environmental and waste handling and minimization requirements for assignment. The specific areas of training are SIRIM, RCRA satellite and staging areas, waste management practices, spill response, and permitted requirements such as stack and outfall discharges. (SCD-4, FA-4, criteria 2.31.2.1)

\section{Verification Approach}

1. Review facility implementing procedures.

2. Review individual operator training records.

3. Interview of operators, shift manager and supervisors.

\section{Lines of inquiry}

1. Review training program to identify training related to EP subjects.

2. Review five (5) training records of operators/FLS and shift managers to determine if training was successfully completed.

3. Interview four (4) operators, 2 FLS and 1 shift manager to verify knowledge in areas as stated in above criteria.

4. Interview RCRA satellite custodian for knowledge of satellite area requirements.

\section{Verification Results}

LOI 1: F-Canyon personnel were not able to provide a consolidated list of environmental topics and personnel training requirements for operations personnel. Finding 07-01/02 was written to document the lack of a consistent training program for environmental related topics. LOI 2: Review of training records for $F$-Canyon personnel did not identify specific requirements for training of personnel on environmental protection issues. Finding 07-01/02 was written to document the lack of environmental training requirements in training records. LOI 3: Performed interviews with four operators, two first line supervisors, and one shift manager to determine the effectiveness of the F-Canyon training program in providing sufficlent information on environmentally related topics for the safe and efficient operation of the canyon. Questions related to waste handling (RCRA) and to handling of hazardous materials were used as a gauge of the effectiveness of training to ensure personnel were aware of how to handle radioactive and hazardous wastes associated with F-Canyon operations. Operations personnel appeared to have adequate knowledge of activities directly related to their assignments, but had little knowledge on areas outside of their ken which could affect their activities.

\section{Documents Reviewed}

SOP 221-F-55011, "Controlled Purchasing Chemical Products," Revision 4 dtd 5/18/94

SOP 221-F-55019, "Handling Mixed Waste Other Than Contaminated Oil," Revision 1 dtd 5/3/93

SOP 221-F-55020, "Checking Waste Boxes for Hazardous Materials," Revision 0 dtd 11/4/92

SOP 211-F-1902A, "Inspection of F-Slab Mixed Waste Staging Area," Revision 6 dtd 5/25/94 $\begin{array}{ll}\text { Finding? } & \underset{Y e s}{\square_{N o}}\end{array}$

If yes, complete OSR 28-131

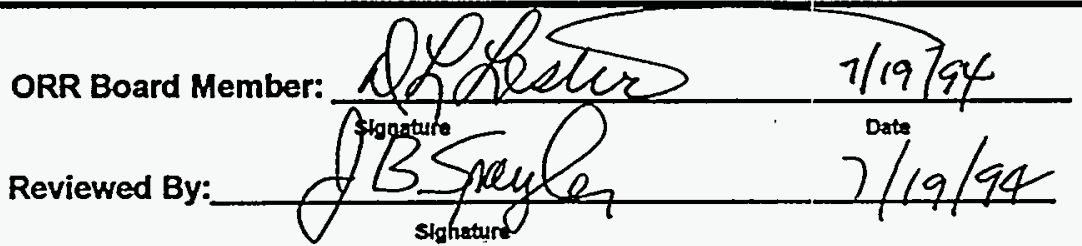




\begin{tabular}{|c|l|l|l|}
\hline $\begin{array}{c}\text { Functional Area Title } \\
\text { ENVIRONMENTAL PROTECTION }\end{array}$ & $\begin{array}{l}\text { Element Title } \\
\text { Waste Management }\end{array}$ & $\begin{array}{c}\text { Chizck List \# } \\
07-0 \%\end{array}$ & $\begin{array}{l}\text { Rev. \# } 1 \\
\text { Page } 2 \text { of } 3\end{array}$ \\
\hline
\end{tabular}

\section{Verification Results (continued)}

Shift manager interviewed was very knowledgeable on SIRIM, spill response, FECIAEC responsibilities, and general practices for handling wastes. SM had not received training on new waste handling SOP. Interviews of one Sample Operator and one Outside Facilities Operator indicated that both had sufficient knowledge of LLW handling practices and procedures as they currently are performed at F-Canyon, but neither had been trained on the new procedure. Additionally, the Outside Facilities Operator had received RCRA training in the past, but was not able to answer specific definition type questions related to RCRA. The Outside Facilities Operator did have good knowledge of spill sources and permit requirements for NPDES outfall samples and operation of the diesel generator. Intervlews with two Day Operators indicated that they were not knowledgeable on handling other than compactable wastes, and were not completely sure of how to deal with situations where an anomaly occurred in the waste handling process. The Day Supervisor First Line Supervisor interviewed indicated that the facility did not rely on the Day Operators to screen wastes and would expect them to contact supervision if there was a problem. The ORR Board member conducting the interviews could not be sure that the operators had been sufficiently trained to be able to verify when a problem existed (or what the concem really should have been). F-Canyon personnel issued a new procedure (SOP 221-F-55025) for the handling of solid low level waste in 221-F/OF-F. This procedure was created to initiate actions necessary for completion of activities in response to CSA 67 for DOE Order 5480.2A. The procedures was issued 5/26/94. During the interview of F-Canyon personnel on 6/3/94 and 6/6/94, none of the personnel had yet received training on this procedure. Based on these interviews, the ORR Board issued Finding 07-01/3. (Note: a second FLS was not interviewed because the ORR Board member felt sufficient information had been identified during the single FLS interview to justify development of the finding.)

In addition to the interviews performed by the ORR Board Member, a reviewi was performed of the supplimental assessment performed by Separations personnel of the Readiness Self Assessment Chocklist B-2.07. This supplemental assessment performed interviews of a type similar to that performed by the ORR Board and were used by the ORR Board Member to help focus questions and interview strategies on areas of potential training weakness.

LOl 4: Interviewed Alternate Mixed Waste Staging Area custodian (custodian was interviewed during initial performance of the ORR Checklist). Alternate Custodian was very knowledgeable of the requirements associated with the establishment, maintenance, and inspection requirements for mixed waste staging areas. (Note: the alternate custodian is an environmental professional in Separations Environmental Protection Group and serves a similar function for other organizations in F-Area (FB-Line)) No deficiencies or weaknesses were noted.
Documents Reviewed (cont.)

SOP 221-F-55021, "Handling Compactable Waste," Revision 2 dtd 12/9/93

SOP 221-F-55025, "Handling Solid Low Level Waste (LLW) in 221-F/F-OF," Revision 0 dtd $5 / 26 / 94$

SOP 221-F-55035, "Handling Radioactive Waste," Revision 1 dtd 2/28/94

SOP 221-F-55040, "Packaging Radioactive Waste for Burial Using B-25 Boxes," Revision 1 dtd 9/16/93

SOP 221-F-55051, "Clean Waste Oil Disposal," Revision 1 dtd $5 / 24 / 94$

SRS F-Canyon Qualification Card, NSAOQAUX, Revision $3 \mathrm{dtd}$ 3/24/94

SRS F-Canyon Qualification Card, NSASQOFF, Revision 0 dtd $3 / 24 / 94$

SRS F-Canyon Qualification Card, NSAOQCRO, Revision $3 \mathrm{dtd}$ $3 / 25 / 94$

SRS F-Canyon Qualification Card, NSAQCRM, Revision 0 otd 3/24/94

SRS F-Canyon Qualification Card, NSAWQSOM, Revision 2 dtd $3 / 24 / 94$

SRS F-Canyon Qualification Card, NSASQCRN, Revision 0 dtd 3/24/94

SRS F-Canyon Qualification Card, NSASQBLD, Revision 0 dtd 3/24/94

WSRC-IM-90-48, "Spill Prevention Countrol and Countermeasures Plan, Section 8.0

ESH-DMS-94-0178, "SRS-DOE-5820.2A-CSA-94-067, REV.6 ERRATA dtd 4/29/94

Finding?


WSRC ORR - CHECK LIST FORM

Functional Area Title ENVIRONMENTAL PROTECTION

\section{Verification Results (continued)}

Element Title

Waste Management
ORR \# 93-0

\begin{tabular}{l|l}
$\begin{array}{c}\text { Chrack List \# } \\
07-01]\end{array}$ & $\begin{array}{l}\text { Rev. \# } 1 \\
\text { Page } 3 \text { of } 3\end{array}$ \\
\hline
\end{tabular}

Documents Reviewed (cont.) Interview Records, F-Canyon Personnel

\section{Sample, F-Canyon Training} Records

F-Canyon 1993 Restart RSA Checklists, Supplimental Assessment Checklist B-2.07 and attendant documentation.

Finding? $\underset{\text { Yes }}{\square} \underset{\text { No }}{\square}$

If yes, complete OSR 28-131
ORR Board Member:

Reviewed By: 


\begin{tabular}{|l|l|l|l|}
\hline \multicolumn{2}{|c|}{ WSRC ORR - CHECKLIST FORM } & \multicolumn{3}{c|}{ ORR \# 93-O } \\
\hline $\begin{array}{l}\text { Functlonal Area Title } \\
\text { Quality Assurance }\end{array}$ & $\begin{array}{l}\text { Element Title } \\
\text { Audits }\end{array}$ & $\begin{array}{l}\text { Checkllst \# } \\
08.01\end{array}$ & $\begin{array}{l}\text { Rev. \# } 0 \\
\text { Page 1 of } 1\end{array}$ \\
\hline
\end{tabular}

\section{Performance Objectlve}

Planned and scheduled QA audits are performed to verify compliance with all aspects of the QA program and to determine program effectiveness. These audits are performed in accordance with written procedures or checklists by personnel who do not have direct responsibility for performing the activities being audited. Audit results are documented and reprorted to and reviewed by responsible management. Followup action is taken to ensure completion of remedial action.

\section{Crlterlon}

Planned and scheduled QA audits are performed to verify compliance with all aspects of the QA program and to determine program effectiveness. These audits are performed in accordance with written procedures or checklists by personnel who do not have direct responsibility for performing the activities being audited. Audit results are documented and reported to and reviewed by responsible management. Followup action is taken to ensure completion of remedial action.

\section{Verifleatlon Approach}

Roview QA audit reports and surveillances.

Walkdown selected findings.

\section{Lines of Inquiry}

1. Review $Q A$ audit reports to verify disposition of findings.

2. Review surveillance reports.

3. Select three findings to conduct field walkdown to verify implementation of corrective actions.

\section{Yerifleation Besults}

1. Reviewed two audit reports (92-2W-039 and 93-AR-12-0006). All findings had been dispositioned.
a. 92-2W-039 had two findings both of which were dispositioned and closed.

b. 93-AR-12-0006 has eight findings. All have been dispositioned and are open, awaiting a Feb. 94 due date (M\&TE Program per QAP 12-1, Rev.0, Traceability). Not required for restart. 2. Reviewed two surveillance reports (92-SUR-03-0097 and 92-SUR-03-0146) All deviations hald been dispositioned.

a. 92-SUR-03-0097 had 22 deviations, all of which have been dispositioned, one of which remiains open (a laundry procedure, now in draft).

b. 92-SUR-03-0146 had 12 deviations, all of which have been dispositioned, one of which remlains open (Separations Maintenance to revise or cancel SOP 291-905, due no later than 12/31/93).

3. Three findings/deviations were selected for field walkdown and verification of implementation of corrective actions.

a. 93-SUR-03-0003 had four deviations, all dispositioned and closed. Selected deviation \#1 for verification (it dealt with inlcuding GA6 in M\&TE database by 6/30/93. Data in database--also memo to Separations QA to verify closure-Separations QA successfully closed on 11/8/93.

b. 93-SUR-03-0084 consisted of three deviations. These-became 93-NCR-03-0182 which was closed 6/28/93. Final surveillance closure was $4 / 20 / 93$.

c. 93-1AR-25-07 dealt with MRP 4.08 (procedure training). Closure included a letter from T. C. Robinson (Sep 93) designating facility personnel who are authorized to sign NCRs and who are to review, approve and receive Corrective Action Reports. Letter is on file in F-Canyon Control Room.
Documents Revlewed

92-SUR-03-0097

92-SUR-03-0146

93-AR-12-0006

92-2W-039

93-SUR-03-0003

93-SUR-03-0084

93-1AR-25-07

93-NCR-03-0182

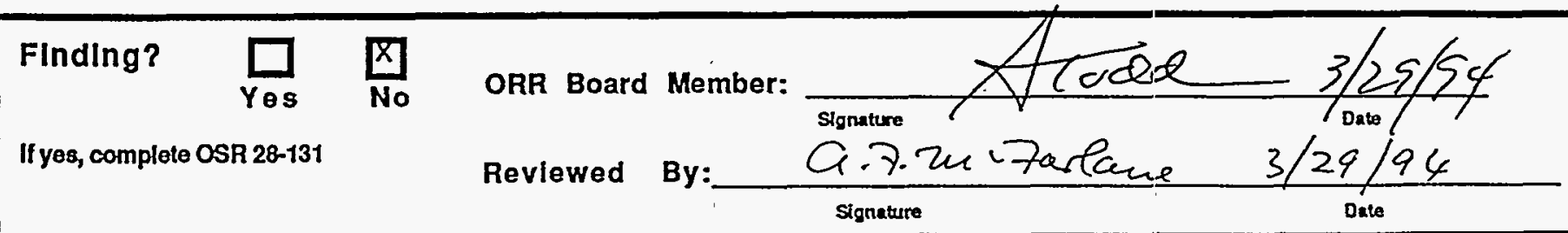




\begin{tabular}{|l|l|l|l|}
\hline \multicolumn{2}{|c|}{ WSRC ORR - CHECKLIST FORM } & \multicolumn{2}{c|}{ ORR \# } \\
\hline $\begin{array}{l}\text { Functional Area Title } \\
\text { Quality Assurance }\end{array}$ & $\begin{array}{l}\text { Element Title } \\
\text { Document Control }\end{array}$ & $\begin{array}{l}\text { Cleckllst } \\
08-32\end{array}$ & $\begin{array}{l}\text { Rev. \# } \\
\text { Page 1 of }\end{array}$ \\
\hline
\end{tabular}

\section{Performance Qbjective}

The preparation, issue, and change of documents that specify quality requirements or prescribe activities affecting quality are controlled to ensure that correct documents are being used. Such documents, including changes thereto, are reviewed and approved for release by authorized personnel.

\section{Criterion}

Procedures exist and are implemented for establishing document control activities. The procedures address these requirements: -documents are prepared, reviewed, approved, issued, used and revised per procedures

- designs, processes and requirements are documented by controlled documents

- preparation, issuance and changes to documents are controlled to ensure that correct documents are being used.

\section{Verifleation Approach}

1. Review document control procedures.

2. Walkdown selected procedures.

\section{Llnes of Inquiry}

1. Roview document control procedures to verify control process is in place.

2. Select four procedures to walkdown through the system to verify correct version, location and control.

\section{Verlfication Results}

1. Reviewed SOP 221-F-50650, Rev 2, 221-F/OF-F Records Management Program Overview (U) dated 5/10/93. This SOP explains the QA control process within the canyon. The process is working according to the SOP. This SOP effectively implements the requirements of QAP6-1, Document Control and QAP 17-1 Quality Assurance Records Management. However, several problems with record retention were noted throughout the review and have been addressed as Finding 08-02/4.

2. Randomly selected four SOPs from the F-Canyon listing, by number (see listing of documents reviewed). Went to the F-Canyon Control Room (location of SOPs) to verify location/version and control of the selected SOPs. All are located in the control room in fire retardant containers. A'I four were of the correct revision number and Canyon control room personnel were charged with control of the documents.
Documents Revlewed SOP 221-F-50650, REV 2 SOP 221-F-20042, REV O SOP 221-F-15609, REV 0 SOP 221-F-62047, REV 0 SOP 221-F-99007, REV 5

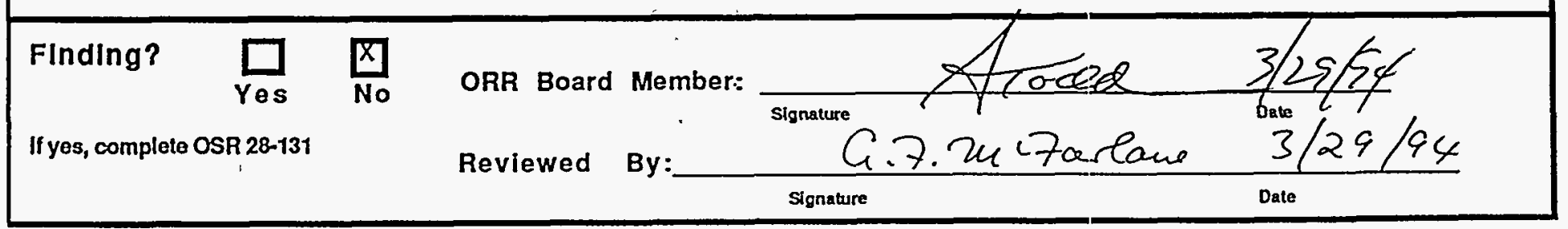


WSRC ORR - CHECKLIST FORM

Functlonal Area Titlo
Quality Assurance

Element TItle
Control of Nonconforming ltems
ORR \# 93-0

Checkllst \#

Rev. \# 0

Page 1 of 1

\section{Performance Objective}

Items and processes that do not conform to specified requirements are controlled to prevent inadvertent installation or use. Status of nonconforming items is indicated by such means a physical location, tags, markings, shop travelers, stamps, inspection records, or others. Nonconforming items and processes are controlled, dispositioned, reworked, repaired, re-inspected, and tested.

\section{Criterion}

Procedures exist and are implemented to establish control of nonconforming items. These procedures address the requirements specified in Criteria 1.4 of the Restart Plan.

\section{Verification Approach}

Review facility NCR's and CARs.

Walkdown to observe sample of QA hold tags.

\section{Lines of Inquiry}

1. Review NCRs and CARs to verify tracking and prioritization of open NCRs and CARs.

2. Review status of selected QA hold tags.

\section{Veriflcation Results}

1. Reviewed facility NCRs and CARs listed below:

a. NCRs as of 10/29/93-- 14 were dispositioned but still open and 1 (93-NCR-03-0402) was determined to be relative to F-Canyon restart-its disposition is to "use as is" and justifications are attached.

b. Reviewed six CARs, as listed below. Three are still open; 92-CAR-03-0002 (Victoreen Gammaguards); 92-CAR-03-0010 (AMOs--answer to QA 1/21/93--rejected 10/29/93-still operı QAR/QIP not developed); 92-CAR-03-0006 has one open item (to train on OP 3.13, rev 1) which has just been completed. The three other CARs reviewed are closed.

2. Selected 91-NCR-03C-115 and 93-NCR-03-0402 to review status of QA Hold Tags.

91-NCR-03C-115 had one hold tag (Located F-Canyon 3rd Level, Sec. 10). Verified its placement on the proper piece of equipment inside F-Canyon and verified reason stated. 93-NCR-03-0402 consisted of 16 holds tags for equipment in OF/F. Verified that tags were in place and valid.
Documents Reviewed NCR MONTHLY REPORT (OCT 93) CORRECTIVE ACTION STATUS -92-CAR-03-0002 CORRECTIVE ACTION STATUS-92-CAR-03-0011 93-CAR-03-0002 92-CAR-03-0002 92-CAR-03-0011 92-CAR-03-0010 92-CAR-03-0006 91-CAR-03-0003 92-CAR-03-0003 91-CAR-03C-115

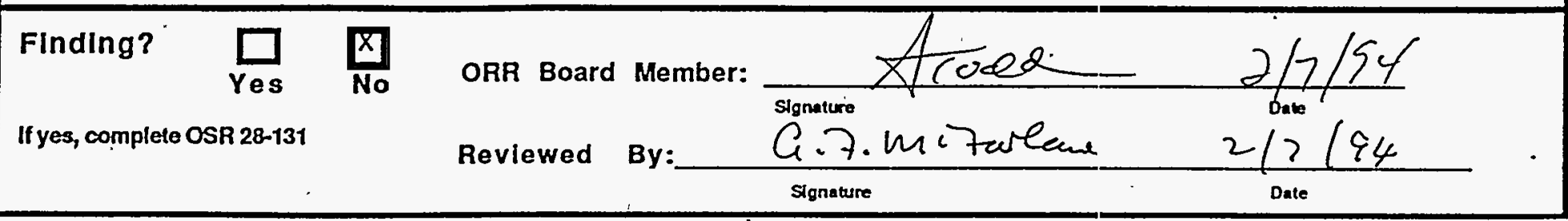




\begin{tabular}{|l|l|l|l|l|}
\hline \multicolumn{2}{|c|}{ WSRC ORR } & \multicolumn{2}{c|}{ ORR \# } & 93-O \\
\hline $\begin{array}{l}\text { Functlonal Area Title } \\
\text { Quality Assurance }\end{array}$ & $\begin{array}{l}\text { Element Title } \\
\text { ChangesNSQs }\end{array}$ & $\begin{array}{c}\text { Checklist \# } \\
08-04\end{array}$ & $\begin{array}{l}\text { Rev. \# } 0 \\
\text { Page } 1 \\
\text { of } 1\end{array}$ \\
\hline
\end{tabular}

\section{Perfermance Qbjective}

High Impact Software is developed, documented, approved, and controlled in accordance with WSRC Manual 1Q, QAP20-1. (Note -

Project Sponsor developed softward is developed and controlled under the same or equal provisions as a contracted design agency).

(SCD-4, FA-01, criterion 2.2.5).

\section{Criterion}

Software is developed, documented, approved, and controlled in accordance with WSRC Manual 1Q, QAP20-1. (SCD-4, FA-01, criterion 2.2.5).

\section{Verlfleation Approach}

Document Review of high impact software plans and procedures

\section{Lines of Inquiry}

1. Verify that there are procedures which define and control high impact software and that it meets the requirements of WSRC Manual 1Q, QAP-20-1.

2. Select one high impact software package and verify that it meets the requirements of the procedures identified in 1 above.

\section{Veriflcation Besults}

1. F-Canyon has produced SOP 200-QA-1201 which refers the user to QAP 20-1 Rev.1 (now Rev. 2). Therefore the F-Canyon procedure for defining and controlling facility software is the site procedure 1Q, QAP 20-1, Rev. 2.

2. 1Q, QAP 20-1, Rev. 2 requires that a Quality Assurance (QA) program be developed including identification of facility software, functional classification of the identified software and development of Software Quality Assurance Plans (SQAPs) for the identified software. Software is to be functionally classified as Nuclear Safety (NS), Critical Protection(CP). Production Support (PS), or General Services (GS). Two lists of identified software (Sep. QA letter dated 4/19/93 and Separations Engineering letter dated 10/8/93) were found with different listings of software identitied for F-Canyon, causing confusion as to which list is valid. Additionally at least one Identified software (2U/2PuDCS) differed between lists as being designated CP in the 4/1.9/93 letter to PS in the 10/8/93 letter. Changes from CP to PS should be justified and no letter of justification could be found. Finding 08-04/2. The software program "221-F-MACSYM", functionally classified as NS, does not have an approved SQAP. Finding 08-04/1.

\section{Documents Revlewed}

1Q, QAP 20-1, REV 2

SOP 200-QA-1201

93-SUR-03-0116

93-SUR-03-0132

Letter dated 4/19/93:

Software Systems

Supported/Developed in

Separations

Letter dated 10/8/93:

Software Quality Assurance

Plans (U)

ESH-ORR-94-0001-0

Finding? $\prod_{Y \in S} \square_{\text {No }}$

If yes, complate OSR 28-131
ORR Board Member:

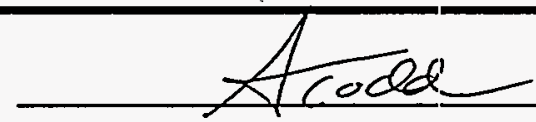

Signature

Reviewed By:
G.7. vertarlane

Signature

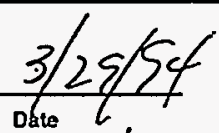

$3 / 29 / 94$ 
WSRC ORR - CHECKLIST FORM

Functlonal Area Title

Quality Assurance

Element Title

Control of Measuring \& Test Equipment
Chickllst \#

08-0.5
Rev. \# 0

Page 1 of 1

\section{Performance Qblectlve}

Equipment used for inspections and tests is calibrated at specified periods, adjusted, and maintained at prescribed intervals. The method and interval of calibration for each item is defined based on the type of the instrument, stability characteristics, required accuracy, intended use, and other conditions affecting measurement control.

\section{Criterlon}

Procedures exist and are implemented to establish requirements for control of measuring and test equipment. The procedures, address these requirements: (DOE 5700.6C, WSRC 1Q, QAP 12-1)

-measuring and test equipment is marked and calibration records are maintained to indicate calibration status and to provide traceability, and measuring and test equipment is calibrated at specified periods by qualified personnel using approved procedures.

\section{Verlficatlon Approach}

Walkdown

Document Review

\section{Lines of Inquiry}

1. Review installed process instrumentation (IPI) records to ensure that calibration requirements for safety related systems IPI have been established and calibration procedures approved.

2. Review all safety related systems IPI to verify that required calibrations are current.

3. Verify that calibration records provide traceability.

\section{Yerification Results}

1.Calibration results for NS/CP instruments for Phase I operations for the period June-October, 1993 were reviewed to ensure that appropriate requirements had been established and entered into the IPI database. A review of NS/CP work packages indicated that approved calibration procedures were in place and referenced. Calibrations of installed process instrumentation (IPI) were not being performed in accordance with procedure 291-912 which requires that $M$ \& TE used to calibrate IPI shall have an uncertainty of four times less than that for the IPI being calibrated. Finding 08-05/1. Technical justifications, on an individual basis, were not being provided as required.

2. A review of the IPI database for Phase I calibrations revealed that calibration frequencies has been extended for sixteen NS Class components. Properly approved technical justifications, as. required, were not available in the IPI history files. Finding 08-05/2. Additionally, a review of calibration results for the period June-October, 1993, revealed that six NS/CP instruments has falled calibration. The associated IPI history files did not contain or reference completed and evaluated Out-of-Calibration notices as required when the as-found conditions are unsatisfactory. Finding 08-05/3.

3. Records for two NS component calibrations (of four sampled) did not provide required tracability documentation as required by QAP 12-1. Properly completed M \& TE Use Reports were not in $M$ \& TE files as required. Finding 08-05/4.
Documents Revlewed

IPI Historical Reports, June-October, 1993.

Second Pu/Dissolving IPI History Files.

IPI Detail Sheets for NS components.

Second Pu/Dissolving IPI History Files.

Work Packages SVQE4, SUKD6 and STCU1
FInding?
$\underset{Y Q S}{X}$
No
ORR Board Member:

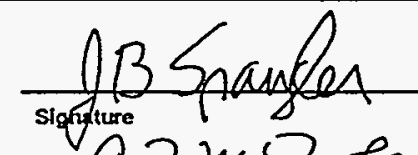
Reviewed By:
$3 / 29 \cdot / 94$
If yes, completo OSR 28-131

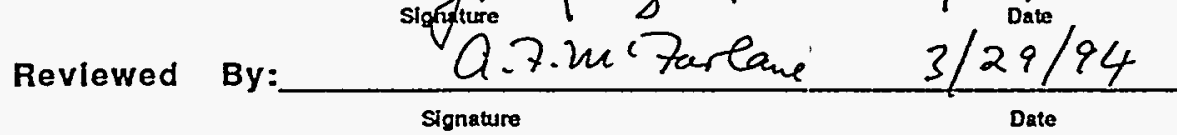


WSRC ORR - CHECKLIST FORM

ORR \#

93-0

\begin{tabular}{|l|l|l|l|}
\hline $\begin{array}{l}\text { Functlonal Area Title } \\
\text { Malntenance and Surveillance }\end{array}$ & Element Title & Checklist \# & Rev. \# 0 \\
Page 1 of 1
\end{tabular}

Performance Oblective

Preventive maintenance contributes to maximum performance and reliability of systems and equipment important to operations.

\section{Criterion}

The backlog of Preventive Maintenance (PM) and surveillances to safety related systems and equipment is minimized. PM and survellance activities are not waived beyond the grace period without management approval. (\$CD-4, FA-10, criterion 2.7.5).

\section{Verlfleation Approach}

Document Review

\section{Lines of Inquiry}

1. Review the PM and surveillance schedules to verify that PMs and OSR surveillances are current within stated objectives.

2. Review the PM activities that are scheduled prior to restart for safety related systems to verily compliance with schedule.

3. Review completed PM work packages to verify proper completion and documentation per requirements.

4. Verify that an administrative control procedure has been established for the scheduling, tracking, and status of OSR surveillance test procedures.

\section{Veriflcatlon Besults}

1. Preventive Maintenance (PM) performance was reviewed for December, 1993. PM was either worked as scheduled, within the allowable grace period or appropriately deferred. A check of Surveillance testing records for November and December, 1993 revealed that a completed design load test test procedure, performed on 11/23/93, for the 221-F diesel (NS Class) was not retrievable. Although the facility was allowed to take credit for the previous semi-annual load test conducted in May, 1993, to meet the twelve month OSR test requirement, a finding was approved to allow the facility to properly address the issue of the missing test procedure (Finding 10-01/2).

2. A review of records was conducted that included PM activities, Surveillance Testing requirements and installed instrument calibrations. At the time of ORR field evaluation, PM activities were worked as scheduled, within the allowable grace period or appropriately deferred.

3. Four completed PM packages were reviewed to verify compliance with requirements of Work Control and Preventive Maintenance F-Canyon procedures. PM delinquencies were not being signed by the area maintenance manager as required by SOP 291-051 (Finding 10-01/1).

4. Surveillance testing is scheduled, tracked and statused per the requirements of Manual 1E7, procedure no. T-405. An individual has been identified to coordinate testing and reporting activities and had developed and implemented the "Surveillance Tests Status Report".
Documents Revlewed

NMP-SMF-940024

Preventive Maintenance

Report (1/18/94)

NMP-SMF-940024

\section{Work Packages SNTQ9,} SLAL1, SLAU3 AND SPCO5. SOP 291-059, SOP 291-051

Manual 1E7, procedure T-405 SurveillanceTests Status report, dated 1/6/94. Various test records.

\section{Finding? $\quad \square_{\text {Yes }} \square_{\text {No }}$ ORR Board Member:}
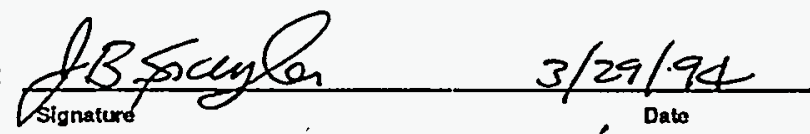

Reviewed By: 


\begin{tabular}{|l|l|l|l|l|}
\hline \multicolumn{1}{|c|}{ WSRC ORR - CHECKLIST FORM } & \multicolumn{2}{c|}{ ORR \# } & 93-O \\
\hline $\begin{array}{l}\text { Functlonal Area Title } \\
\text { Maintenance and Surveillance }\end{array}$ & $\begin{array}{l}\text { Element Title } \\
\text { Planning/Scheduling/Work }\end{array}$ & $\begin{array}{c}\text { Chisklist \# } \\
10-0 ?\end{array}$ & $\begin{array}{l}\text { Rev. \# } 0 \\
\text { Page } 1 \text { of } 1\end{array}$ \\
\hline
\end{tabular}

\section{Performance Objective}

The planning, scheduling, and control of work ensures that identified maintenance actions are properly completed in a safe, timely, and effective manner.

\section{Criterlon}

Work planning and scheduling includes conditions such as material, tool, and manpower requirements; prerequisites; Interdepartmental coordination; safety considerations; quality control requirements; and actions needed to minimize exposures to radiation and hazardous materials. (DOE 4330.4A, Ch 1, sec. 3.1.4 and Ch. II, Sec. 7; WSRC-5Q; WSRC-8Q)

\section{Yerlfication Approach}

\section{Document Reviow}

Interviows

\section{Lines of Inquiry}

1. Review at least five Corrective Maintenance work Packages that are in-process to verify compliance with procedural requirements for planning, scheduling, and coordination of work activities.

2. Interview work planning personnel to verify understanding and implementation of Work Control Procedure SOP 291-059.

3. Review at least five Safety Related System Work Packages to verify that stated requirements were met during the evolution of the Work Package.

\section{Verlflcation Results}

1. Six corrective maintenenace (CM) work packages, in the ready-to-work category, were reviewed to ensure compliance with Work Control procedural requirements. No deficiencies were noted in the content of the packages.

2. Three Work Control planners were interviewed to determine their understanding and implementation of procedure no. 291-059. Each of the three had an acceptable level of knowledge of the appropriate procedural requirements and had received both administrative and on-the-job training as well as work overcheck to ensure that they carried out the procedural requirements properly.

3. Twelve work packages for NS/CP Class equipment were reviewed to verify that requirements were met during the evolution of the work packages. Although the content of the packages was generally acceptable, a large number (105) of field-complete packages were not yet through the closure process which includes a review by both Technical and Quality personnel. The oldest of these packages dated back to 12/2/92. Finding 10-02/2. Review of packages and discussions with personnel also revealed that Work Clearance Permits were routinely discarded at the completion of field work, rather than filed and maintained as required by published site requirements. Finding 10-02/3.

(Note: The finding number 10-02/1 was assigned to a potential concern which was resolved without it being presented to the Board.)
Documents Reviewed

Work Packages IQR25, KSP94, KSP80, KSP02, IQW71 \& IQW78.

SOP $291-059$

Work Packages SNTQ9, SLAL1, SLAU3, SPCO5, IQR25, SVQE4, SVQE5, SUKD5 , KWK82, KWK83, KWK84 and SUKD6.

SOP 291-059

Manual 8Q, procedure no. 35

\section{Finding?}

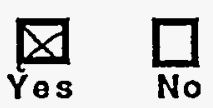

If yes, complete OSR 28-131
ORR Boárd Member:

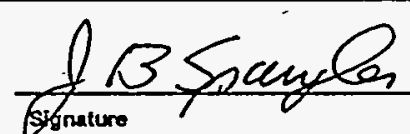

Reviewed
By:

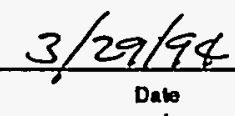

Dave 


\section{WSRC ORR - CHECKLIST FORM ORR \# 93-O}

\begin{tabular}{|l|l|l|l|l|}
\hline $\begin{array}{l}\text { Functlonal Area Title } \\
\text { Maintenance and Surveillance }\end{array}$ & $\begin{array}{l}\text { Element Title } \\
\text { Procedures and Documentation }\end{array}$ & $10-03$ & $\begin{array}{l}\text { Rev. \# } 0 \\
\text { Page } 1 \text { of } 1\end{array}$ \\
\hline
\end{tabular}

Rerformance Objectlve

Procedures and related documents provide appropriate directions and guidance for work and are used to ensure that maintenance is performed safely and effectively.

\section{Criterion}

Operations and Maintenance procedures are used and followed as required by facility policy. (SCD-4, FA-10, Criterion 2.9.4)

\section{Verifleatlon Approach}

Document Review

Interviews

Field Observations

\section{Lines of Inquiry}

1. Review at least five Maintenance and five Operations procedures to verify compliance with administrative procedures.

2. Observe three each of Operations and maintenance field activities to verify that procedures are being utilized and followed correctly.

\section{Yerlfication Results}

1. Nine maintenance procedures were reviewed to verify compliance with procedure 291-905. Although the reviewed procedures generally met the adminstrative requirements, it was determined that when procedures were cancelled, i.e. replaced with a more relevant procedure, there was not an adminstrative mechanism in place to ensure that the installed instrument database custodian was informed of the change. As a result, there were procedures incorrectly referenced as current calibration procedures that had been cancelled some months earlier. Fincling 10-03/1. In all cases reviewed, an overcheck conducted routinely by Work Control personnel identified the correct procedure prior to field work being performed.

2. Maintenance field activities were observed to verify that procedures were being utilized and followed correctly. Electrical troubleshooting of a Motor Control Center was properly executed via procedure SOP F-850011 (Workbook no. 1) and a chart recorder was correctly calibrated by using procedure no. W-798003 (Work Package SYFK4). In both cases the E \& I mechanic performing the work was familiar with the procedure requirements and completed them properly. Several strip chart recorder calibration verifications were observed that were performed using the Loveland Fastest method. No problems were noted. Additionally, A. McFarlane observed the performancas of work on 11/18/93 to replace a leaking steam gasket in Section 13, second level. Mechanics stated that a pre-job briefing had taken place including asbestos cautions, ALARA and tool control. The work was observed from pre-staging of tools and supplies to removal of protective clothing. Work Clearance Permit and RWP were inspected and found satisfactory. Job was completed competently and correctly per "skill of the craft" without a step-by-step procedure.
Documents Reviewed

Procedures $W-7.02002$, $W-794001, W-794003$, W-794018, W-826002, W-826013, W-834002, W-834003 \& W-834011.

Work Packages SVQE4 \& SVQE5.

Procedures SOP F-850011, W-798003; Work Package no. SYFK4.

RWP $93 F C 492$

Finding? $\quad \square_{\text {Yes }} \square_{\text {No }}$ ORR Board Member:

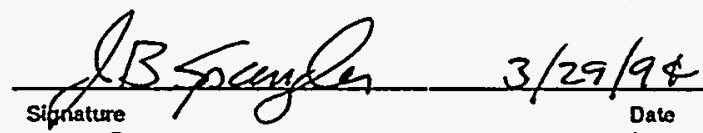

If yes, complete OSR 28-131

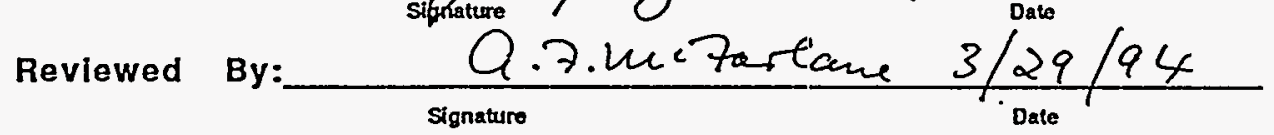


WSRC ORR - CHECKLIST FORM

Functional Area Title

RADIATION PROTECTION

Element Title

Radiological Protection Procodures \& Posting

\section{Perfermance Qbjectlve}

Radiation protection procedures for the control and use of radioactive materials and radiation generating devices provide for safe operations and for clearly identifed areas of potential consequences.

\section{Criterion}

Radiation work procedures (permits) are used for all radiation area work. These procedures are approved by health physics staff and contain adequate provisions for: -protective apparel; -work limitations; job descriptions; -radislogical conditions; -special instructions

\section{Verliflcatlon Approach}

Document Review

Observation of work in progress

\section{Lnes of Inquiry}

1. Verify completeness of the Radiation Work Permit (RWP) from a representative work package.

2. Verify use and adherence to RWP.

\section{Yeriflication Results}

LOI 1. Reviewed completeness of two RWPs for work performed in Contamination Areas. First weis for work performed on 11/18/93 to replace a leaking steam gasket in Section 13, Second Level. Second was for work performed on 12/1/93 to put yellow plastic bags on flanges on a transfer line. Both jobs required double protective clothing and full face respirators. Verified that all sections of the RWP were correctly completed including required approvals. Interviewed the RadCon manager with respect to the ALARA review and confirmed that these reviews are routinely performed.

LOI 2. Observed the performance of the above two jobs. During the first job, interviewed the mechanics and RCO inspector. Was told that pre-job briefing had taken place including asbestos cautions, ALARA, and tool control. Observed donning of protective clothing (PCs) and respirators, this was done correctly including respirator checks. Observed completion of the job including correct removal of PCs. The job was performed with no violations of the RWP or RadCon requirements. On the second job the RCO inspector in attendance was interviewed. He said he is qualified by incumbent experience but also is up to date on all his required training and job performance measures (JPMs). Observed the performance of the work for a short time. There were no violations of the RWP or RadCon requirements.

(See continuation sheet).

Finding?

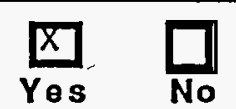

If yes, complete OSR 28-131
ORR Board Member: Q.7.2m Forlane $3 / 24 / 94$

Reviewed
Documents Reylewed

RWP 93FC492, 11/16/93

RWP 93FC519, 11/29/93
Rev. \# 06 Page 1 of 2 


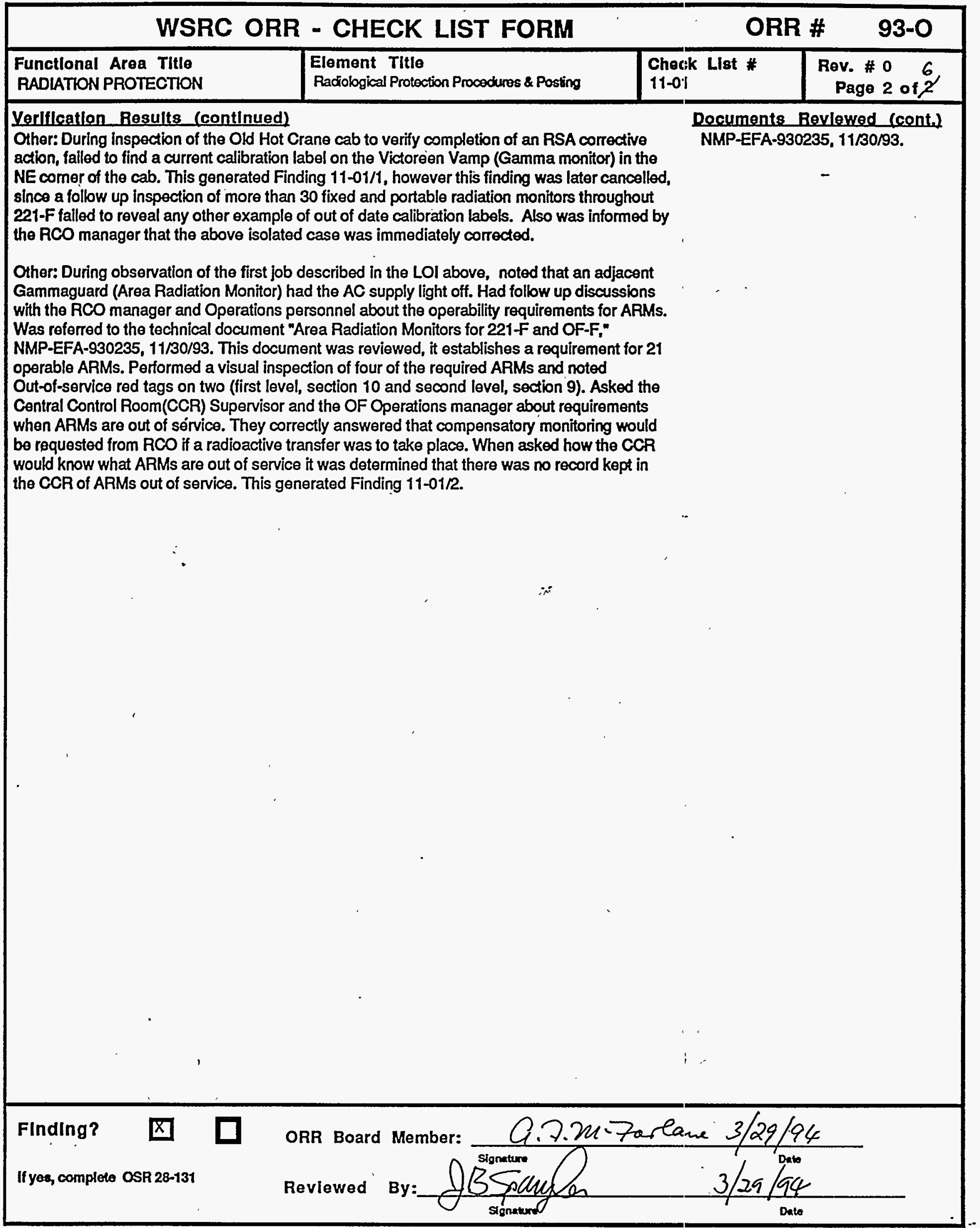


WSRC ORR - CHECKLIST FORM

ORR \# 93-0

\section{Functional Area Titlo RADIATION PROTECTION}

\author{
Element Title \\ Radiological Protection Procodures \& Posting
}

Checklist \#

11-01
Rev. \# 0

Page $\pi / 3$ of $\$ 6$

\section{Perfermance Objectlve}

Radiaton protection procedures for the control and use of radioactive materials and radiation generating devices provide for safe operations and for clearly identifed areas of potential consequences.

\section{Crilterlon}

Radiation work procedures (permits) are used for all radiation area work. These procedures are approved by health physics staff and contain adequate provisions for: -protective apparel; -work limitations; -job descriptions; -radiological conditions; -special instructions

\section{Verliflation Approach}

Document Review

Observation of work in progress

\section{Lnes of Inquiry}

1. Reviewed (9) SRWPs/RWPs and (3) ALARA Reviews.

2. Reviewed (3) Separations Work procedures

3. Observed different phases of (8) jobs involving radiological area work.

4. Interviewed (10) personnel involved in radiological area work.

$$
x
$$

5. General tour of 221-F.

\section{Yerlfication Results}

Job 1 Reviewed SRWPs used for simulated start-up of the 2nd Pu cycle. SRWPs were adequale. for the work performed. Work procedure contained adequate RC holdpoints for work being performed.

Observed 2nd level operator performing valving for the start-up of the 2nd Pu cycle on 5/26/94. Operator requested RC Inspector's assistance when needed based on simulated radiological conditions.

Interviewed the Operator and RC Inspector. Both understood the SRWP and the radiological hazards associated with the job. The Operator answered correctly as to the dress requirements for the simulated contamination area. The Separations Supervisor on the job was interviewed arid he understood the SRWP and radiological hazards associated with job.

Jeb2 Reviewed RWP \# 94-FC-390 and ALARA Review 94-FC-390 used for Building Hut and Deconning overhead piping on 2nd level, Section 5 hotside on 6/1/94. RWP and ALARA Review were adequate for proposed work. The ALARA Review 94-FC-390 did not have a review date at the top of the form.

Observed ALARA Review in progress. The RC Supervisor reminded everyone of alpha's ability to penetrate sweat soaked protective clothing. Workplace air sampling, hut checklists were discussed. As stated above the ALARA Review was adequate for the proposed work.
Documents Reylewed

94-FC-001, 002

$221-\mathrm{F}-20502$
94-FC-390

ALARA Review 94-FC-390
Finding? $\underset{\text { Yes }}{\square} \square_{\text {No }}$

If yes, complete OSR 28-131
ORR Board Member:

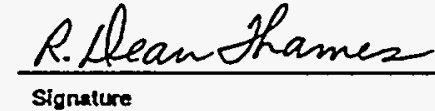

Revlewed

$$
\text { A.7.m '7arlane }
$$

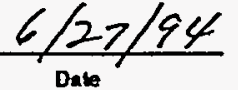

$6 / 27 / 94$

Signabure 


\section{WSRC ORR - CHECK LIST FORM}

\section{Functlonal Area TItle RADIATION PROTECTION}

\section{Element Title}

Paciological Protection Procedures \& Posting
ORR \# 93-0

Check List \#

11-01
Rev. \# 1 Page 4 of 6

\section{Verlfleation Results (contlnued)}

Job 3 Reviewed RWP \# 94-FC-340 used for Repair of Old Crane South Monorail. The scope of work was not clearly identified in the RWP. There were supports added to the monorail and this was not mentioned on the RWP. The extremity dosimeter locations were not specified on the RWP. The extremity man-Rem estimate is the limiting factor, but is never mentioned anywhere else on the RWP, pre-job brief or ALARA review (See Note 1). Requested a copy of

F-Canyons GASP (General Air Sampling Plan), the copy I recieved was dated 12/89. 5Q1.2, Procedure 458 requires this to be updated annually. After more followup, the GASP had been completed by 221-F RC in the proper timeframe. However, it was not approved by HPT. (A. properly reviewed and approved document was supplied later.) Reviewed Special Procedure \# 221-F-730011, contained adequate RC holdpoints for work performed.

Observed the repair of the Old Crane South Monorail from the HCMA vestibule on 5/25/94. Two personnel were in contamination area with TLD and Security badge outside PCs (reference HP Reporter 94-03). There was a unprotected respirator being used more than once in the HCMA vestibule. There was no air sample taken to characterize the actual work area per 5Q1.2, Procedure 132. Observed as personnel were cut out of plastic suits, exited area and SOP was not surveyed by the RC Inspector. Observed waste being bagged and removed across SOP and SOP was not surveyed. The scissors used to cut personnel out of suits were no: surveyed prior to be placed back up on hook in contamination area (See Note 2). There were tools in the contamination area that were not painted yellow. Poor Planning: There were two sets of saw horses inside the high contamination area used for the monorail work when only one set was required. For this and other observations described below Finding 11-01/3 was written to address excess material being carried into RCAs/CAs.

The RC Inspector was knowledgeable of radiological conditions (contämination levels, general area and extremity doserates) on job and specific work that was being performed. Standby Man stated that he would not enter area to rescue personnel if both men passed out. Interviewed Separations Supervisors on the job and he was knowledgeable of RWP requirements and radiological conditions for the job. Stated that the Standby Man would follow his instructions during an emergency. Interviewed other Separations Supervisors and there was not a consistent answer given for the Standby Man's actions in emergency situations. The Standby Man procedure 221-F-20502 does not address this type of emergency condition. Facility Management was iniormed of the concern (See Note 3).

Job 4 Reviewed RWP \# 94-FC-383 and ALARA Review 94-FC-383 used for the Inspection and Lube of a Fan which is in a High Radiation Area on 5/27/94. RWPIALARA Review were adequate for the job. The review date on the ALARA Review is blank.

Observed Pre-job Brief in progress. The Pre-job Brief was adequate for the job to be performed. The RC Inspector that covered the job pointed out in the briefing that the mechanics that would perform the work were not on the proper bioassay program. They were only on the Pu program, should have been on the Sr/Pu program for $221-\mathrm{F}$. This was corrected before the work was performed.

Interviewed Separations Mechanics, they were knowledgeable of the RWP and radiological hazards associated with job after the pre-job briefing was given.' The RC Inspector was very knowledgeable of radiological conditions and RWP \# 94-FC-383.

Job5 Reviewed RWP \# 94-FC-331 used for Replace/Repair damaged insulation in the HGVC. It had an extremity estimate of 1.84 Rem for an individual and extremity monitoring was nol used. 501.2, Procedure 217 requires extremity dosimetry if the extremity is expected to
Documents Revlewed (cont.)

94-FC-340

5Q1.2, Procedure 458

5Q1.2, Procedure 132

SOP 221-F - 50055

$221-F \cdot 730011$

94-FC-383

ALARA Roview 94-FC-383

94-FC- 331,346

5Q1.2, Procedure 217

5Q1.1, Procedure504

$$
\begin{aligned}
& \text { Finding? } D \text { ORR Board Member: } \frac{R \text {. Dean Themes }(p e r a m 47) 9 / 19 / 94}{\text { Signature }} \\
& \text { If yes, complete OSR 28-131 }
\end{aligned}
$$

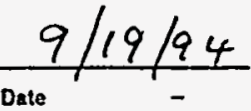


WSRC ORR - CHECK LIST FORM

Functlonal Area Title

RADIATION PROTECTION
Eloment Title

Raciological Protection Procedures \& Posting
ORR \# 93-0

\begin{tabular}{l|l}
\hline $\begin{array}{l}\text { Check List \# } \\
11-01\end{array}$ & $\begin{array}{l}\text { Rev. \# } 0 \\
\text { Page } \$ 5 \text { of } A 6\end{array}$ \\
\hline
\end{tabular}

Documents Beviewed (cont)
Yeriflcatlon Results (contlnued)

exceed $400 \mathrm{mRem}$ for the month or the duration of the job. RC Facility Manager was informed of the problem and are taking immediate actions to correct (See Note 1).

Reviewed RWP \# 94-FC-346 used for Removing asbestos insulation from valve using glovebag in the HGVC. It had an extremity estimate of 65 Rem (the yearly limit is 50 Rem). No actions were taken per the RWP. RC Facility Manager was informed of the problem and are taking immediate actions to correct (See Note 1).

The limiting factor, i.e., the extremity to penetrating ratio should be 62.5:1 instead of the 50:1, since the adminstrative limit is now $800 \mathrm{mRem} / \mathrm{yr}$. There is a note in the 5Q1.2, Procedure 504 that explains that this ratio may changed (See Note 1).

Jeb 6 Observed RC Inspector performing habitability surveys in Hot Sample Aisle on 6/1/94. RC Inspector was very knowledgeable of RWP requirements and radiological hazards associated with job.

Jeb 7 Observed Gang Valve Operator performing rounds in Warm Gang Valve Corridor on $6 / 1 / 94$. Operator was knowledgeable of RWP requirements and the radiological hazards associated with job.

Jeb 8 Reviewed RWP \# 94-FC-137 and ALARA Review 94- FC-137 for the Wire Rope Inspection on the New Warm Crane. The issue date for the RWP is 2/3/94, the expiration date is $12 / 31 / 94$. The total man-Hrs estimated for the job is 15 . This RWP provides approximately 11 months to complete 15 man-Hrs of work. 5Q1.1. Procedure 504 requires a current survey. RC Facility Manager was informed of the problem and are taking immediate actions to correct (See Note 1).

Reviewed RWP \# 94-FC-141 and ALARA Review 94-FC-141 for the Wire Rope Inspection on the Old Warm Crane. The issue date for the RWP was $2 / 2 / 94$, the expiration date was 12/31/94. The total man-Hrs estimated for the job is 9 . The extremity to penetrating ratio in section $V$, part 2 of the RWP form is 1677:1. This ratio was not noted anywhere else on the RWP, ALARA Review or the Pre-job Brief. The review date on ALARA Review form is blank. RC Facility Manager was informed of the problem and are taking immediate actions to correct (See Note 1).

Observed wire rope inspection of the Old and New Warm Cranes in the WCMA on 5/27/94. There was not an air sample pulled to characterize work area per 5Q1.2, Procedure 132 (Finding 11-01/4). Observed an unprotected respirator in contamination area that was later used by personnel (Finding 11-01/5). Observed personnel with TLDs, Security Badges outside PCs (reference HP Reporter 94-03). Observed personnel exiting the area and the RC Inspector did not survey the SOP (See Note 2).

Interviewed some of the CSWE and Separations personnel working job. They were knowledgeable of the RWP requirements and the radiological hazards associated with job. Also, interviewed the Stand By Man. He stated that he would enter area if personnel in plastic suit passed out (See Note 3).

General Tour (5/25-6/1/94) There are many tools in contamination areas that are not marked with yellow paint in 221-F Canyon (HCMA Vestibule, WCMA Vestibule, WGV Corridor, Cold Feed Tank Gallery) (See Note 4). Noticed personnel dressed out in PCs in contamination areas routinely pushing safety glasses up on their faces with their hands (See Note 2).
RSLC \# 2565

SRWP \# 94FC-002

5Q1.2, Procedure 133

5Q1.2, Procedure 219

- 94-FC-137, 141

ALARA Review 94-FC-137, 141

5Q1.2, Procodure 132
5Q Rad Con Manual, Article 442 5Q1.2, Procedure 518

FIndlng? $\square \square$ ORR Board Member:

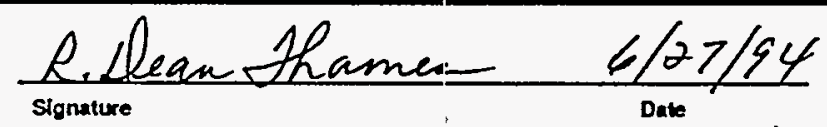

If yes, complete OSR 28-131

Revlewed By: $\quad$ G.7.2u'7artane

$6 / 27 / 94$ 
WSRC ORR - CHECK LIST FORM

ORR \# 93.0

\section{Functlonal Area Title RADIATION PROTECTION}

Element Title

Radiological Protection Procodures \& Posting
Cheisk List \#

$11-01$
Rev. \#0

Page $A 6$ of $A 6$

Verlfication Results (continued)

There was an excess of materials in contaminated waste boxes in contaminated areas (3rd level Cold Feed Tank Gallery rolls of wire). Observed personnel routinely throwing away rubber gloves after use in contamination areas. Observed personnel routinely throwing clean RCA waste into contaminated waste boxes. A finding was written to address excess materials in RCAs and disposal of recyclable gloves (Finding 11-01/3).

Entrance to the 3rd level Cold Feed Tank Gallery was posted as a contamination area on $5 / 25 / 94$ at 1445 . There was no information on the postings such as : date, contamination levels, RC Inspectors initials, etc. (5Q1.1, Procedure 518). This was brought to facility managements attention and promptly corrected. This being an isolated observation, no finding was written.

Note 1 A supplementary facilities Readiness Self Assessment was performed (NMP-SFC-94-0326, 6/8/94) for this Functional Area. The facility identified weaknesses in personnel understanding of RWPs (RSA finding RSA-11-01). The corrective actions accepted by the ORR Board on 6/14/94 address the problems noted above.

Note2. Various isolated incidents of poor contamination control practices were observed. These were brought to the attention of facility management. These instances were deemed not sufficient to warrant an ORR finding.

Note 3 Personnel understanding of actions to be taken by the Standby man is not consistent. This was brought to the attention of facility management, but was deemed not sufficient to warrant an ORR finding.

$$
\therefore
$$

Note 4 The corrective actions to supplementary RSA findings RSA-11-02 address this tool control deficiency.

Finding? $\square . \square$ ORR Board Member:

If yes, complete OSR 28-131
Reviewed By:

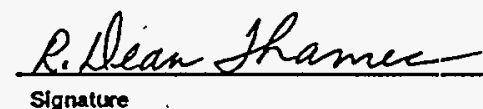
$6 / 27 / 94$ $6 / 2>/ 94$ Date 


\section{WSRC ORR - CHECKLIST FORM}

\section{Functlonal Area Tițlo} FIRE PROTECTION
Element Title

2.7 Program Implementation
Checklist \#

12-01
Rev. \# 0

Page 1 of 1

\section{Performance objective}

A fire protection program is in place to effectively provide and maintain an improved risk level of fire protection that also emphasizes nuclear fire safety, employee life safety, as well as the programmatic aspects of an effective fire protection program.

\section{Criterion}

A Fire Hazard Analysis (FHA) is prepared as a documented comparison/review of the Fire Proteclion Program based on applicable orders, codes, or standards performed in accordance with DOE Orders, WSRC 2Q, and nationally recognized standards to ensure, by examination of objective evidence, that applicable elements of a Fire Protection Program have been installed, developed, documented, and effectively implemented. (SDC-4, FA-12, criteria 2.4, 2.5, 2.7.5, 2.7.9, 2.7.10 and 3.1; 6E, FA-12, criterion 2.6).

\section{Verlflacatlon Approach}

Reviow FHA Document

Field Walkdown FHA

Reviow CSAs/Exemption Documents

\section{Lines of Inquiry}

1. Review FHA document for correct information, conduct field verification of content, evaluate corrective action, and FHA approval prior to completion of WSRC ORR.

2. Conduct field verification of FHA to evaluate adequacy of the hazards and fire system descriptions.

3. Review status of compensatory actions and exemption requests for Fire Code non-compliancés.

\section{Veriflcation Results}

1. A review was conducted of the FHA for correct content and approvals, and a field verification of the FHA was made to determine correct content and proper corrective actions. The FHA lacks adequate and correct technical material in the description of some hazards and fire systems. For additional details see below. This is a Finding (12-01/1).

2. A field verification was made to determine the adequacy of hazards and fire systems descriptions as contained in the FHA. Deficiencies include: 221-F Third Level hazards during liquid transfer operations at tanks; the means of detection of potential fire in the Canyons; the correct: identification of PA System problems; impact on facilty ventilation by the potential loss of the 292-F Emergency Generator. These were noted in Finding 12-01/1.

3. A review was conducted of the adequacy of Compensatory Actions as contained in the CSAs and STCSs for adequate coverage of the identified hazards. The review found that the firewatch program appears to lack an adequate design or capacity to cover all the hazards identified in the documents. For specific deficiencies see checklist 12-02. It was also noted that the facility response to deficiencies, as noted in the Emergency Light Survey FPOS-93-198, has been inadequate in that corrective actions and completion dates have not been submitted (Finding 12-01/2).

Documents Reviewed

-Fire Hazards Analysis (FHA), M-FHA-F-00026, 17/94, NMPD, 221-F-Canyon -DOE 5480.7A, Fire

Protection, FHA Section -WSRC M-FHA-G-00001, Guideline for the Preparation of Fire Hazards Analysis for SRS (Rev. 1) -SRS-DOE-5480.7A-CSA-170, 9/7/93

-SRS-DOE-5480.7A-CSA-026, 12/22/93

-SRS-DOE-5480.7A-STCS-93$013,12 / 23 / 93$

-SOP-221-F-51100 and 51100, Continuous Facility Firewatch (7-26-93)

\section{Finding?

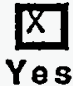 No} If yes, complete OSR 28-131

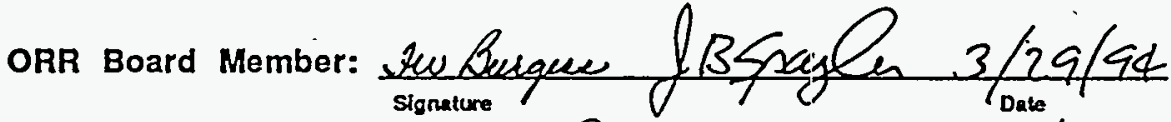

Reviewed

By: Q.7.2u.7arlane $3 / 29 / 94$ 


\section{WSRC ORR - CHECKLIST FORM}

\section{Functional Area Title}

FIRE PROTECTION
Element TItle
Public Protection
Chizcklist \#

12-0:2
Rev. \# 0

Page 1 of 2

Perfermance Qbjectlve

All facilities onsite provide adequate protection to prevent any added threat to the public as the result of an onsite fire causing the release of hazardous materials beyond the site boundary.

\section{Criterlon}

Facility operating procedures acknowledge the risk of fire. Appropriate provisions are in place to assure safe operation and shutdown, and that fire protection features are not compromised. The facility must write and implement a comprehensive Fire Protection Program Plan (FPPP) modeled on WSRC Manual 2Q. (SCD-4, FA-12, criteria 2.3.1 and 3.2).

\section{Verlfleatlon Approach}

Roviow FPPP and related procedures

Field verification of FPPP

Porsonnel interviews

\section{Lines of Inquiry}

1. Review FPPP and related procedures for order compliance and WSRC approval.

2. Fleld verify that FPPP and related procedure content and practices are adequate for facility cperation. Welding/cutting operations, flammable liquids, hazardous materials, fire barriers, fire system operation and maintenance, offsite release of hazardous materials, containment systems, etc. are included in review.

3. Interview personnel to evaluate knowledge acquired through training in the FPPP and related procedures.

\section{Veriflcation Results}

1. A review was made of the FPPP compliance and approval with DOE Orders and WSRG-2Q, Firi Protection Manual and found to be adequate.

2. Fleld verifications and reviews were conducted of the FPPP and related facility procedures for proper content and practices as applicable to the facility. The review included: Welding/Cutting operations, flammable liquids storage and handling, hazardous materials storage and emergency fire fighting methods, fire system operation and maintenance, and offsite release of hazardous materials due to fire. A number of deficiencies were found during the review. They are listed as: lack of required annual testing of the Canyon Deluge and the (4) MCC Dry-Pipe systems. Finding (12-02/7); lack of maintenance of the (4) MCC Dry-Pipe control valves. Finding (12-02/3); lack of immediate replacement of impaired battery operated emergency lights with working lights. Findirg (12-02/4); PA deficiencies throughout the structure and lack of an emergency program for notification of personnel during an emergency condition in case of PA system failure. Finding (12-02/2); the thermal detectors in the Canyons need to be assessed for proper operation and placed in service. Finding (12-02/1); and the (4) MCC dry-pipe systems are deficient as they are not wet systems. Finding (12-02/8). The firewatch program appears not to cover all the hazards identified in the FHA. An assessment of the effectiveness of the program is lacking. This is a Finding (12-02/6). The review also found that a significant number of firewatch rounds are being missed and there is no accountability of the program to monitor and correct such deficiencies. This is a Finding (12-02/5).

(See continuation sheet)

\section{Documents Reviewed}

-SOP-221-F-51120, Fire Protection Program Plan (9/10/93) -SOP-221-F-51114, Fire Warden Facility Inspection $(9 / 15 / 93)$ -SOP-221-F-51050, Emergency Battery Light Inspection (11/29/90) -SOP-22t-F-51110, Fire Control Systems (11/25/92) SOP-221-F-51112, Control and Inspection of Portable Electric Heaters (10/28/93)

-SOP-221-F-51111, Monthly Inspection of Fire Extinguishers (2/11/91)

-SOP-221-F-51117, Control of Cutting and Welding (10/29/93) -SOP-221-F-51118, Fire System Impairments (11/3/93) -SOP-221-F-51115, Emergency Fire Response (10/27/93) SOP-221-F-51105, Control of Combustibles (6/27/91) -221-F-Tickler \#134, 221-F and OF-F Public Address System Check list
Finding? $\underset{Y \in S}{\square}$

If yes, complete OSR 28-131
ORR Board Member:
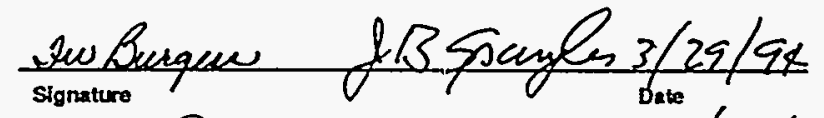

Revlewed By: 
WSRC ORR - CHECK LIST FORM

Functional Area Title

FIRE PROTECTION
Element Title

Public Protection
ORR \#

Check List \#

12-0:?
Rev. \# 0

Page 2 of 2

Veriflcatlon Results (continued)

Documents Revlewed (cont.)

3. Three operators and one supervisor were interviewed to evaluate their knowledge of the FPPP and related procedures. The personnel were knowledgeable of the program and procedures.

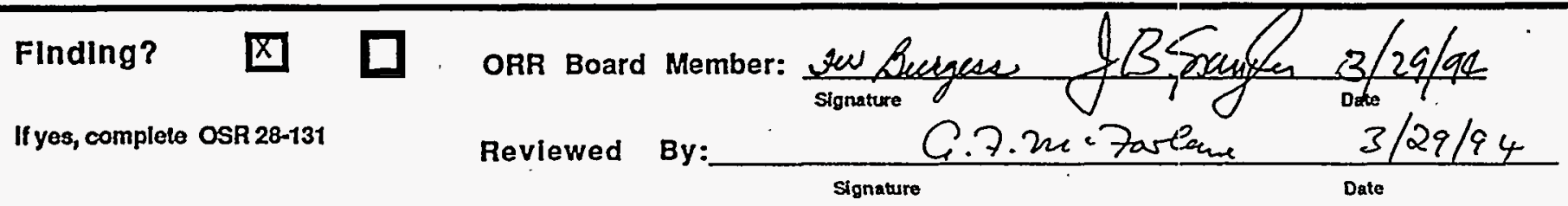


WSRC ORR - CHECKLIST FORM

\section{Functional Area Title FIRE PROTECTION}

Life Protection
ORR \#

93-0

Checklist \#

$12-03$

Rev. \# 0

Page 1 of 1

\section{Perfermance objectlve}

All facilities onsite provide adequate life safety provisions against the effects of fire.

\section{Criterlon}

Security considerations do not jeopardize life safety provisions. (SDG-4, FA-12, criteria 2.2.3).

\section{Yerlfication Appreach}

Reviow documentation

Field ovaluation

Roviow deficiency correction

\section{Lines of inguiry}

1. Review facility documentation providing direction on the life safety and security interface for content and compliance to Orders.

2. Fleld evaluation of life safety and security interface to evaluate life safety/security interface.

3. Evaluate facility tracking and corrective actions for completion.

\section{Yerlfilcation Besults}

1. A review was made of documentation containing life safety and security interfaces for content and compliance with DOE Orders. Documentation review indicated that the interface between lifie safety and security complies with WSRC and DOE guidelines.

2. A field evaluation was conducted to determine if the physical aspect of life safety and security interface(s) was in compliance with WSRC and DOE Orders. A number of personnel doors from rooms into corridors were found to have lock hasps installed. This is a Finding (12-03/1).

3. An evaluation of the tracking mechanism for deficiencies related to the life safety and security interface was performed. There are no deficiencies outstanding for entry into a tracking system. A tracking system would have to be developed or an existing system petitioned to track such deficiencies. (See finding 20-03/2 against tracking system deficiencies).
Documents Reviewed -NFPA-101, Chapter 5, Life Safety Code -DOE 5480.7A, Fire Protection

\section{FInding? Yes $\underset{N o}{\square}$} If yes, comploto OSR 28-131
ORR Board Member:

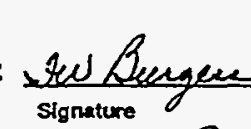

Reviewed
By:

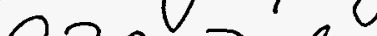

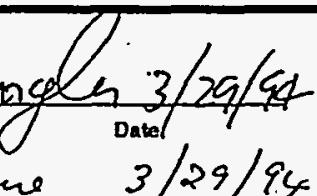

$3 / 29 / 94$ 
WSRC ORR - CHECKLIST FORM

Functlonal Area Titlo

FIRE PROTECTION

Element TItle

2.6 Fire Department Operations
ORR \#

93-0

Chisckllst

$12-0.4$
Rev. * 0

Page 1 of 2

\section{Performance Oblective}

The Fire Department has the capacity to promptly terminate and mitigate the effects of a fire in a: safe and effective manner.

\section{Criterlon}

There are pre-fire plans which reflect the current conditions at the facility. The fire departmentfire brigade are drilled in their use. (SCD-4, FA-12, criteria 2.6.3).

\section{Verifleatlon Approach}

Review Preplan

Field verification of preplan

Interview Fire Dept./Interview facility response team

\section{Lhes of Inquiry}

1. Review Fire Department preplan for format and content including: Facility constructions, fire systems, hazardous materials response, life safety, emergency response conditions, facility interaction, hazards identification, hazardous materials response toam.

2. Field verificaton to check correctness and completeness of preplan.

3. Interview Fire Department to evaluate knowledge of preplan through training and drills.

4. Interview facility response team to evaluate knowledge of preplan through drills.

5. Interview Fire Departiment to evaluate scheduled tours of the facility for content and correction of deficiencies.

\section{Verlflcation Besults}

1. A review was made of the Fire Department Preplan for proper format and content, including: facility construction, fire systems, hazardous materials response, life safety, emergency response conditions, facility interaction during emergencies, hazard's identification, and the hazardous materials response team. The review found that the Preplan contained sufficient information addressing the criteria included in the review.

2. A field verification was conducted to check the validity of the Preplan against facility components, operations, hazards, and fire safety systems. The Preplan adequately covers the criteria verified against in the facility. Some minor items were found and comments were given to the Functional Area Coordinator to give to the Fire Department Preplan interface. The verification also noted that not all facility personnel, that may be expected to respond to operate the manual fire systems at the Canyons and the Motor Control Centers (4), were trained in the operation of those systems. This is a Finding (12-05/1).

(see continuation sheet)

\section{Documents Reviewed -WSRC-202-4-F Canyon Fire Control Preplan (1/93) -WSRC-2Q, Fire Protection Manual -1991 Uniform Building Code -SOP-221-F-51110, Fire Control Systems (11/25/92)}

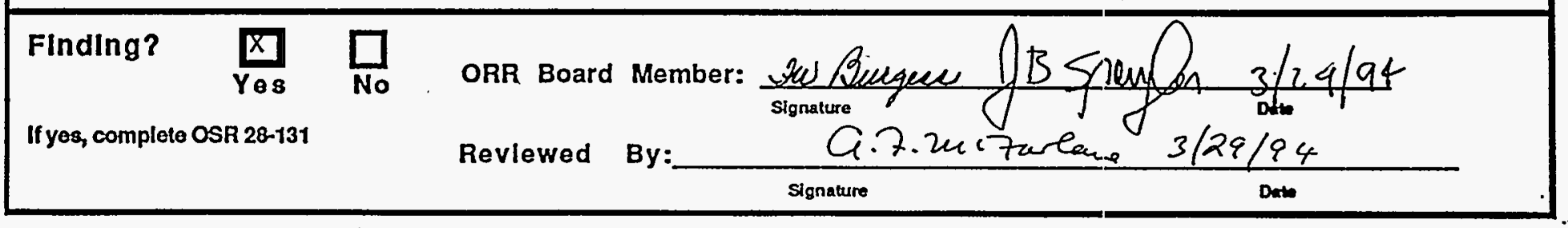


WSRC ORR - CHECK LIST FORM

Functlonal Area Titlo

FIRE PROTECTION
Element Title

2.6 Fire Department Operations
Cheok List

12-0.4
Rev. * 0

Page 2 of 2

\section{Verlfication Results (continued)}

Decuments Revlewed (cont)

3. An Interview was conducted with Fire Department personnel during the 1/14/94 facility

Emergency Drill and again at the Fire Department to evaluate their knowledge of the Preplan as developed through training and drills. It was found that Fire Department personnel have acquired an adequate knowledge of the Preplan through training and drills.

4. An Interview was made with the First Aid Responders during the 1/14/94 facility Emergency Drill to determine their knowledge of the Fire Department Preplan through drills. The interview found that facility responder personnel understand their role in the first aid portion of an emergency and the interactions of the Fire Department to first aid emergencies. Some basic deficlencies in first aid technique were noted during the drill and comments were given to the facility Emergency Preparedness Coordinator.

5. An interview with Fire Department personnel was conducted to review fire protection tours of the facility for proper content and timely correction of deficiencies. The tours are satisfactory in schedule and content: Deficiencies found during the tours are tracked by the Fire

Department to completion. The Fire Department contacts the facility, whenever necessary, to discuss deficiency resolutions.

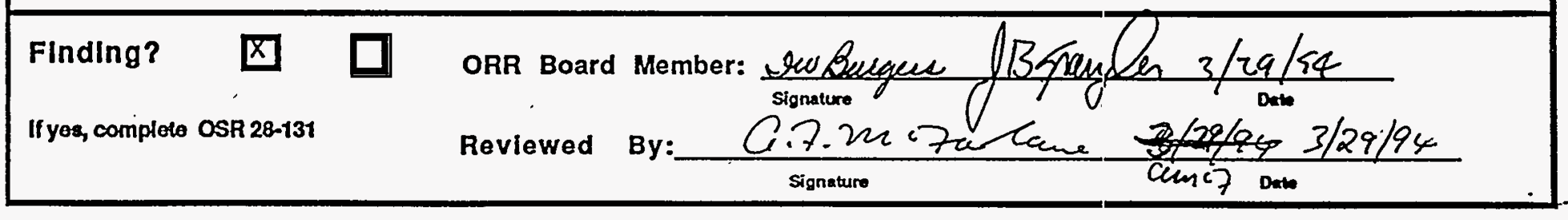


WSRC ORR - CHECKLIST FORM

ORR \#

93-0

\section{Functional Area Titlo}

FIRE PROTECTION
Element Titlo

2.6 Fire Department Operations
Chuckllst *

12-0:5
Rev. * 0

Page 1 of 1

\section{Performance oblectlve}

The Fre Department has the capacity to promptly terminate and mitigate the effects of a fire in a safe and effective manner.

\section{Criterlon}

The Fire Emergency Response Team (Fire Brigade or Fire Department) conducts periodic drills in response to simulated fires in actual facilities to assure familiarity with facilities and adequacy of emergency response and pre-fire plans. Drills are appropriately evaluated and the results are documented. (SCD-4, FA-12, criteria 2.6.6; 6E, FA-12, criterion 2.7).

\section{Yerlfleatlon Approach}

Witness Emergency Drill

Review Training Records

Interview Facility Personnel

\section{Lines of Inquiry}

1. Observe fire drill to evaluate adequacy of scenario, drill procedure followed, response operation, critique, etc.

2. Review training procedures of facility emergency response personnel for facility hazards, fire systems, preplan, and fire department interaction.

3. Interview facility emergency response personnel for knowledge of drill events and procedureis.

$$
\therefore
$$

\section{Yerifleatlon Results}

1. An observation of the $1 / 14 / 94$ facility emergency drill evaluated the adequacy of the fire porticn of the drill, including: scenario credibility, emergency response organization actions, and the critique. Deficiencies were noted during the drill and are included in the findings of Functional Arisa 13, Emergency Preparedness. Findings include deficiencies in facility first aid response, Fire Department response, and the credibility of the scenario.

2. A review was made of the facility first aid responder training procedures for response to facility hazards, fire system operatons, and Fire Department Preplan interface. The review found that the procedures are adequate but additional training is needed. Periodically scheduled training does not exist for operations personnel on the operations of the manual fire suppression systems in the Motor Control Centers and the Hot and Warm Canyon deluge suppression systems. This is a Finding 12-05/1.

3. Interviews were held with facility First Aid Responders at the 1/14/94 Emergency Drill, and with three operators and one supervisor to determine their level of knowledge of drill events and procedures concerning fire and industrial safety actions during emergencies. All interviewed personnel are knowledgeable of the required facility safety response requirements.
Decuments Revlewed

-Doc. 15, 1993 F-Canyon Fire

Drill Report

(SSE-APS-9330157)

-F-Canyon WSRC ORR

Emergency Response

Prepartedness Exercise

Comments, January 18, 1994,

$M$. Findlay to A. McFarlane

-SOP 221-F-51115,

Emergency Fire Response

221-F and OF-F

- Fire Control Preplan, WSRC-2Q-4-F for 221-F

Canyon (1/93)

-Functional Area-12, Fire

Protection Interview

Questions and Answers.

(1-94, F. W. Burgess). -WSRC-2Q, Fire Protection Manual

\section{Finding?}

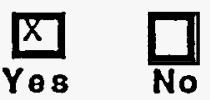

If yes, completo OSR 28-131

ORR Board Member:

Reviewed

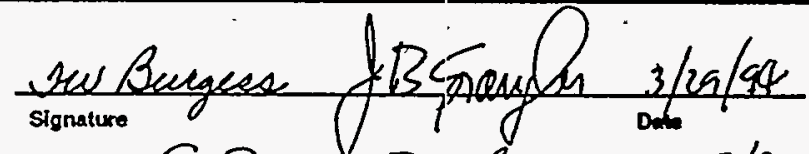

a.7. un czarlane 
WSRC ORR - CHECKLIST FORM

ORR \#

93-0

Functlonal Area Title

EMERGENCY PREPAREDNESS

Element Title
Administration and Organization/Drills and

Checkllst \#

13-01

Rev. \# 0

Page 1 of 2

Performance Objectlve

Emergency preparedness organization and administration ensure effective planning for, and implementation and control of, siteffacility emergency response.

\section{Criterion}

An emergency preparedness program is established for $F$ Canyon. (SCD-4, FA-13, criteria 2.1.1 and 2.2.4)

\section{Verlflcation Approach \\ Review documents \\ Interviow personnel \\ Observe EP drills and exercises}

Lines of Inquiry

1. Review drill and exercise scenarios to determine if they adequately cover existing $F$ Canyon hazards.

2. Review lesson plans that are used in the training of the ERO and validate that OSHA 1910.120 requirements are being met.

3. Review facility MSDSs and EALs to determine if chemical hazards are planned for per 6Q8.

4. Observe two shift drills and determine their applicability to the above criteria.

5. Review controller/player comments and actions taken to correct deficiencies identified during these drills.

6. Interview the Scenario development personnel as to their understanding of the above.

\section{Verlflcatlon Results}

1. Upon review of the WSRC ORR F Canyon EP Exercise (1/14/94) and the proposed DOE ORR Exercise no consideration of hazardous material emergencies/incidents were found. Finding 13-01/1.

2. Upon review of the AFEC Overview and F Canyon Area Emergency Operations (AEO) course:s limited information was presented on hazards material emergency response. Additionally, no courses were provided to the $F$ Canyon ERO which is required by CFR 1910.120. Finding 13-01/2. 3. EPIP-FCAN-001, Emergency Classifications (EALs), limits emergency classifications to nitric acid incidents and does not allow for other hazardous materials located in F Canyon. See Checksheet 13-4, Finding 13-04/1.

4. The shift drills provided in the fourth quarter of 1993 (2 different scenarios) did not include response to hazardous materials other than radiation, i.e., they included only fire, personal injury and radiological rolease. Finding 13-01/1.

5. Controller/player comments were identified and added to the shift drill reports by the Lead Drill Team Controller but no tracking system is in place to allow for the facility to track comments (corrective actions) and items identified did not get corrected in a timely manner and in many instances re-appeared in later drills and exercises as comments. Finding 13-01/3.

6. (Continued on next page)
Documents Revlewed 1/14/94 WSRC ORR F Canyon EP Exercise Package AFEC Overview and $F$ Canyon AEO EPIP-FCAN-001 and F Canyon MSDSs

Shift drill scenario packages Shift Drill Reports and Exercise Report

\section{FIndIng?

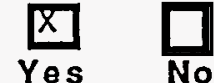

If yes, complete OSR 28-131
ORR Board Member:

Revlewed

By:

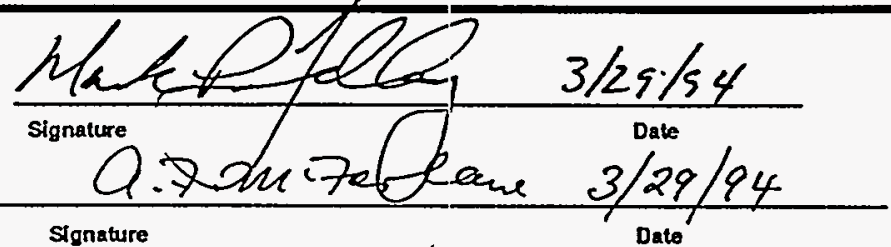


WSRC ORR - CHECK LIST FORM

Functional Area Title EMERGENCY PREPAREDNESS
Element Titlo

Administration and Organization/Drills and
ORR \#

93-0

Rev. \# 0

Check List \#

13-01

Verlfication Results (continued)

6. Upon Interviewing two ESD Drill Team Leaders, they stated that comments/concerns from the first shift drills in the last quarter of 1993 continued to be identified throughout the other drills and correctuve actions were not completed. This was primarily due to lack of time between drills. Additionally, procedural interface conflicts between F-Area and F Canyon were identified during the shift drills and were again identified during the F Canyon WSRC ORR Drill on 1/14/94. There is no tracking system in use to identify activities to be changed or revised. Finding 13-01/3.

\section{Documents Revlewed (cont.)}


WSRC ORR - CHECKLIST FORM

ORR \#

93-0

Functlonal Area Titlo

EMERGENCY PREPAREDNESS
Element Title

Administration and Organization
Cheicklist \#

13-0द?
Rev. \# 0

Page 1 of 1

\section{Performance Objective}

Emergency preparedness organization and administration ensure effective planning for, and implementation and control of, siteffacility emergency response.

\section{Criterlon}

Responsibility is assigned to an individual for coordination of $F$ Canyon emergency response plarning, and for maintaining the emergency management program documentation current, including plan and the emergency plan implementing procedures.

\section{Verlfleation Approach}

Interview personnel

Reviow documents

\section{Lines of Inquiry}

1. Review job description of the coordinator for emergency preparedness for F Canyon.

2. Review F Canyon organizational charts as to the reporting chain for the EP Coordinator.

3. Interview the EP Coordinator and question him/her on program implementation

\section{Verifleatlon Results}

1. No job description for the F Canyon EP Coordinator exists per interview with W. Smith. Finding $13.02 / 2$.

2. F Canyon organizational charts identifies the position of the EP Coordinator reporting to $F$ Canyon Line Management.

3. Interview of the F Canyon and F-Area EP Coordinators took place on 1/20/94 with the F-Area E:P Coordinator answering the questions due to the $F$ Canyon EP Coordinator's lack of experience in the position and in emergency preparedness. The $F$ Canyon EP Coordinator identified in the $F$ Canyon Organizational chart, is not knowledgeable to complete the functions of that position as defined in $6 Q$ (Savannah River Site Emergency Plan). While the F-Area EP Coordinator is attempting to provide assistance, there is no formal reporting relationship between these positions (matrixed or otherwise). The SS\&ES Emergency Services Department has assigned a level thre! manager to F-Area and the F-Area EP Coordinator has been informally matrixed to this manager to compensate for this individual's limited emergency preparedness knowledge and experience.

Finding 13-02/1.
Documents Reviewed

F Canyon Organizational Chart

FInding?


WSRC ORR - CHECKLIST FORM

ORR \#

93-0

Functlonal Area Titlo
EMERGENCY PREPAREDNESS

Element Title

Emergency Plan Implementing Procedures

Checkllst \#

13-03

Rev. \# 0

Page 1 of 1

\section{Performance Qblective}

The emergency plan, the emergency plan implementing procedures, and their supporting documintation provide effective response tooperational emergencies.

\section{Criterion}

The detailed actions required to carry out the Separations F Emergency Plan are specificied in area and F Canyon facility specific implementing procedures.

\section{Yerlfleation Approach}

Review documents

\section{Lnes of Inquiry}

1. Review all F-Area and F Canyon EPIPs (implementing procedures) and EPAPs (administrativiz procedures) as to their appropriateness and completeness to support emergency response.

2. Verfiy that EPIPs and EPAPs have required reviews and approvals.

\section{Veriflcation Results}

1. F-Canyon and F-Area EPIPs are not integrated and in certain instances contradict each other, F-Area procedure EPIP-FSEP-003 utilizes Remain in Doors for a radiological event and F-Canyon procedure EPIP-FCAN-002 utilizes Remain in Doors only for a toxic gas release. Finding 13-03/1.

2. The EPIPs had the appropriate signatures and covered the appropriate subjects. EPAP-301 was reviewed and found to be satisfactory.
Documents Revlewed

F-Canyon EPIPs

F-Area EPIPs

\section{FindIng?}

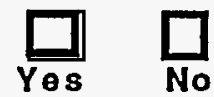

If yes, complete OSR 28-131
ORR Board Member:

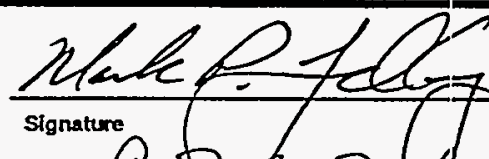

Reviewed By:
$3 / 29 / 94$

Date 


\begin{tabular}{|c|c|c|c|}
\hline WSRC ORR & - CHECKLIST FORM & \multicolumn{2}{|c|}{ ORR \# } \\
\hline $\begin{array}{l}\text { Functlonal Area Title } \\
\text { EMERGENCY PREPAREDNESS }\end{array}$ & $\begin{array}{l}\text { Element Title } \\
\text { Emergency Assessment and Notification }\end{array}$ & $\begin{array}{l}\text { Checkllst \# } \\
13-04\end{array}$ & $\begin{array}{l}\text { Rev. \# } 0 \\
\text { Page } 1 \text { of } 1\end{array}$ \\
\hline
\end{tabular}

Performance Qbjective

Emergency assessment and notification procedures enable the emergency response organization to classify emergencies, assess consequences, notify emergency response personnel, and recommend remedial actions.

\section{Criterion}

A system of Emergency Action Level (EAL) criteria is established to aid in classifying events.

\section{Veriflaation Approach}

\section{Document review}

Observation

\section{Lines of Inquiry}

1. Review all EPIPs and associated activities to verify that Phase I EALs have been implemented for $F$ Canyon.

2. Review the $F$ Canyon Hazards Assessment document (or compensating information described in CSA) as to its compliance with DOE Orders and Emergency Management Guidelines.

3. Review the F Canyon EALs to determine if chemical hazards are incorporated into them.

4. Observe an EP Drill or exercise as to the operations use of the currently approved EALs for F Canyon.

5. Verify status of DOE-SR approval of a CSA for DOE 5500.3A for non-complaint EALs prior to restart.

\section{Verlfleation Results}

1. Phase I EALs have been incorporated into the classification EPIP. However, it was noted tha: EPIP-FCAN-001 and EPIP-FBL-001 Emergency Classification Levels are not integrated as to the radiological release rates from the stack for a Notification of Unusual Event (Finding 13-04/2).

2. The F Canyon Facility has drafted a CSA to cover the lack of development of a Hazards Assessment with compensatory measures identified as the SAR, Basis for Interim Operation, and Chemical Screening documents.

3. EPIP-FCAN-001, Emergency Classifications (EALs), limits emergency classifications to nitric: acid incidents and does not allow for other hazardous materials located in F Canyon. Finding 13.04/1.

4. During the WSRC ORR F Canyon EP Exercise (1/14/94) the AEC incorrectly classified the initial incident. Additionally, the FEC had the responsibility of determining and declaring classifications in F Canyon and not the AEC. Further detail may be found in memorandum ESH-ORR-94-0002-0, dated 1/18/94. Finding 13-07/2, see also checklist 13-07.

5. As of this writing (3/1/94) the CSA for non-compliant EALs has not been approved by DOE.

\section{Documents Revlewed}

F Canyon EPIPs

EPIP-FCAN-001

WSRC ORR F Canyon Drill

Report and Memorandum to A. McFarlane
FInding?
Yes
No
ORR Board Member:

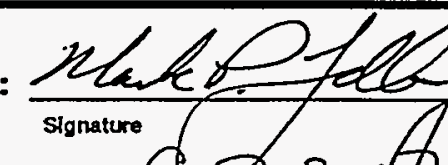
Reviewed By:

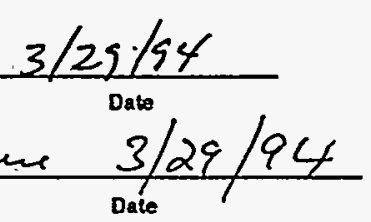
If yes, complete OSR 28-131
Signature 


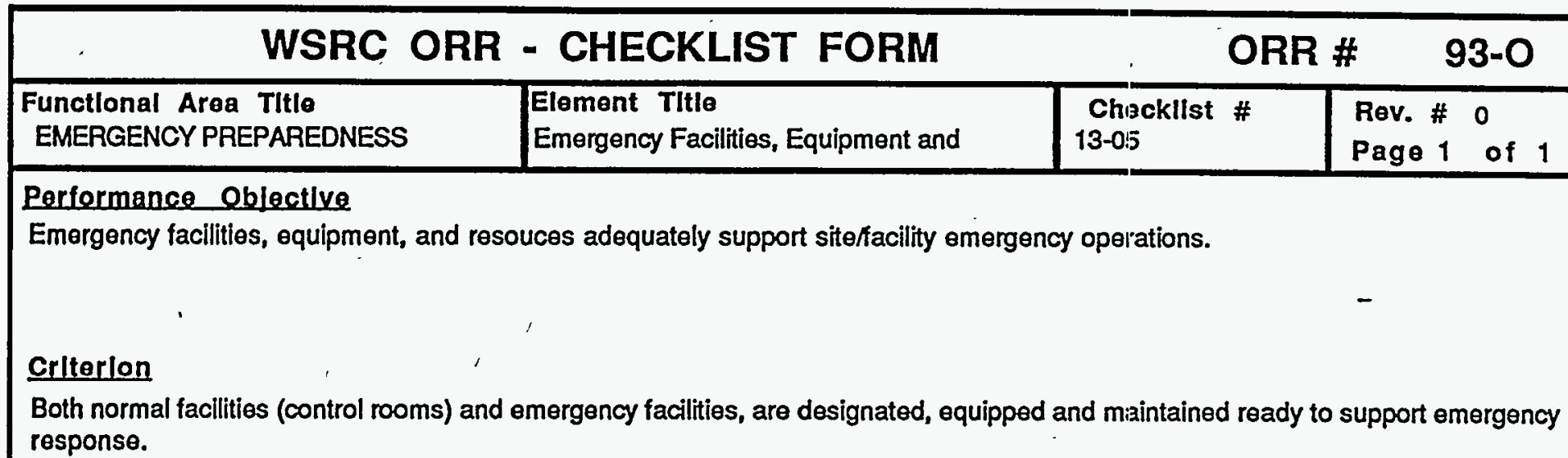

response.

\section{Yerifleatlon Approach}

Document reviow; Interview personnel

Walkdown F-Canyon emergency response equipment.

Observe use of equipment during a chill.

\section{Lines of Inquiry}

1. Review procedures that outline the equipping and maintaining emergency response facilities and equipment.

2. Review equipment inspection sheets to verify availability of equipment and facilities.

3. Interview the responsible individual who maintains the emergency response equipment and facilities and verify that operability of the emergency equipment and facilities are maintained.

4. Observe a drill or exercise and determine the operability of emergency equipment and facilities that have been identified to support a emergency response in $\mathrm{F}$ Canyon.

\section{Yerlfleation Results}

1. The procedures that are utilized in the equipping the emergency facilities, i.e., emergency cabinets, was reviewed and found to be satisfactory.

2. The equipment inspection sheets were reviewed and while required to be completed on a monthly basis were not, i.e., inspection of the emergency cabinet was not completed from 9/93 to 11/93. Additionally, SCBAs identified for emergency use were not inspected on a monthly basis, i.e., 12/93 inspection missed. Finding 13-05/1.

3. Interviewed the EP Coordinator and found that the above procedures are controlled by a ticklïr system and once identified as needing to be completed the procedure is provided to the Shift Manager who assigns it to a shift member who utilizes the equipment during drills and emergencies.

4. Evaluator comments identified that the first aid responders did not know where the splinting materials were located. These splints were clearly in the cabinet but the players were unfamiliar as to what they looked like.

\section{Findling?

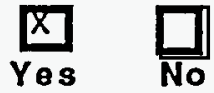

If yes, complete OSR 28-131

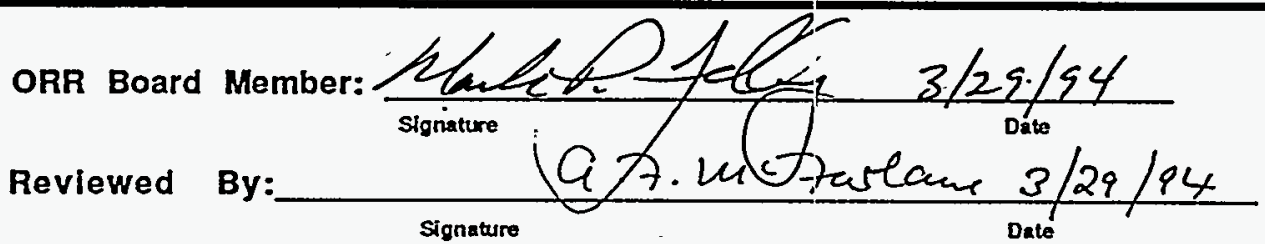

Documents Revlewed SOP 221-F-51051 and SOP 221-F-51053 SOP $221-F-51051$ and SOP 221-F-51053 
WSRC ORR - CHECKLIST FORM

ORR \#

$93-0$

Functional Area Titlo

EMERGENCY PREPAREDNESS
Element Title

Emergency Facilities \& Resources
Chicklist \#

13-0.5
Rev. \# 0

Page 1. of 1

\section{Performance Objective}

Emergency facilities, equipment, and resources adequately support siteffacility emergency operations.

\section{Criterlon}

Primary and backup communications systems are available and operable (including facility-wide coverage) in F Canyon to accommodate normal operations and emergency needs.

\section{Verlfication Approach}

Document Review

Observation of drill

Lines of Inquiry

1. Review shift drill controller/player comments concerning the communications capability of F-Canyon.

2. Observe a shift drill and determine coverage of $P A$ and emergency related phones and radios.

\section{Verlfication Results}

1. Controller/player comments were reviewed and identified areas where the coverage of the PA system and radios in $\mathrm{F}$ Canyon were inadequate. Additional information concerning the review of the PA system can be found in Functional Area 12 with an identified finding (12-02/2).

2. The PA system utilized for emergency communications in $F$ Canyon does not adequately provide coverage in F Canyon, ref. WSRC Memorandum from Findlay to McFarlane ESH-ORR-94-0002-O, dated 1/18/94. Also, phones in the OSC were inadequate to support emergency response during the WSRC ORR F-Canyon EP Exercise (Finding 13-06/1).
Documents Revlewed

Shift drill reports
Findlng?

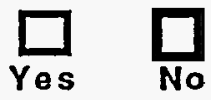

- If yes, complete OSR 28-131

ORR Board Member:

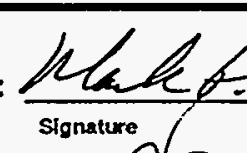

Reviewed

By: Date 


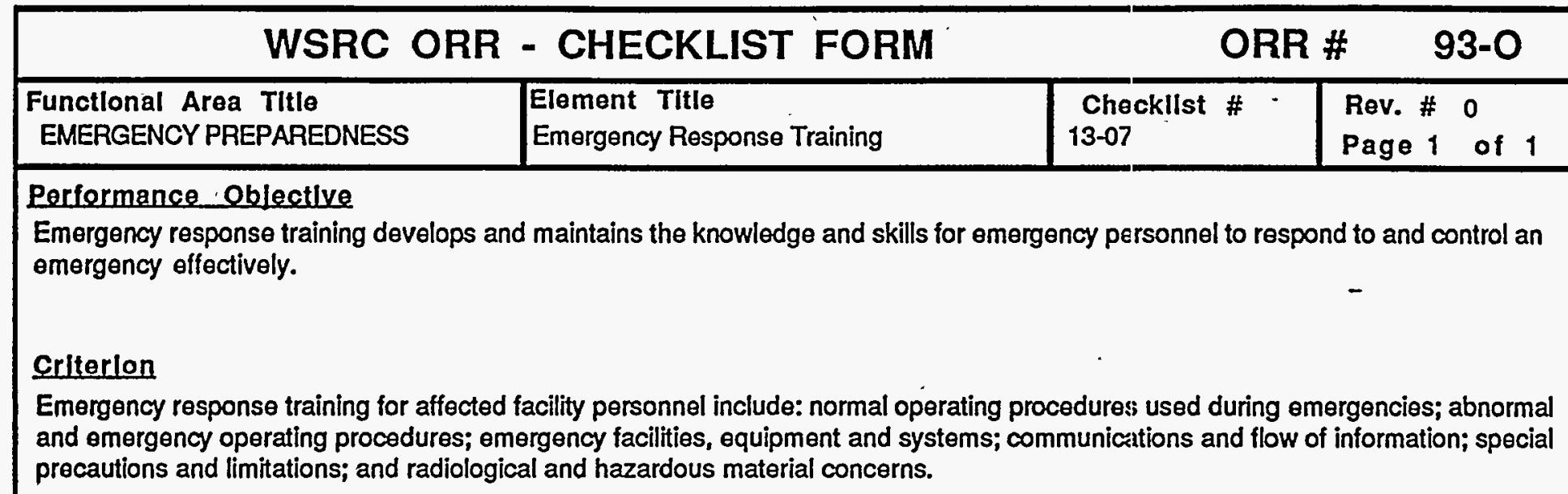

Yerlfleation Approach

Document review

Interview Operations personnel

Lines of Inquiry

1. Review training documentation for the AEC (Shift Managers) on the AEO and AFEC EMD Training courses.

2. Interview two Shift Managers, two Control Room Operators and two members of the Emergency Teams as to retained knowledge from the EP training received.

3. Interview the Training Coordinator and determine that there is a tracking system in place that identifies ERO individuals and their training requirements.

4. Interview two Shift Managers on their line of succession during emergency events.

\section{Verlfication Results}

1. Training records for the F Canyon AECs and FECs identify that not all Shift Managers and F Canyon Control Room Supervisors are currently qualified as identified in 6Q, i.e., taken AFEC Overview within the last twelve months (Finding 13-07/1).

2. Interviews were conducted with two Shift Managers, one Control Room Supervisor, one HP Inspector, one Maintenance Mechanic and two Control Room Operators. While amount of retained knowledge varied all individuals had satisfactory amounts.

3. Interview was conducted with the Training Manager on 1/20/94 and it was determined that a tracking system was in place to track the classroom portion of the emergency preparedness training requirements but did not track the drill participation portion of the Area Emergency Operations course (Finding 13-07/3). This system is a good computerized system with good management attention. Finding issued on lack of recording drill participation.

4. Interviews were conducted with two Shift Managers and one F Canyon Control Room Supervisur who identified their line of succession correctly. However, the Concept of Operations for emergency operations identified in the F Canyon EPIPs does not adequately reflect the Concept of Operations for normal activities, i.e. the shift manager is the Area coordinator and classifies emergencies only for F-Area, however in the drill he took the responsibility to classify an F-Canyon incident. This is properly the responsibility of his subordinate, the control room supervisor (Finding 13-07/2).

\section{Documents Reviewed \\ SS\&ES/ESD AFEC Database}

Finding?




\section{WSRC ORR - CHECKLIST FORM}

\section{Functlonal Area Titlo}

Issue Management

Performance Objective

Issue are categorized and processed through a proceduralized notification and reporting system.

\section{Criterlon}

Facility issue management procedures guide personnel in determining whether action items to correct conditions identified in Occurrence Reports must be completed before or after startup. (SCD-4, FA-17, Element 2.3, criterion 2.3.1.4)

\section{Yerlfileation_Aperoach \\ Document Review}

\section{Lines of Inquiry}

1. Review facility commitment tracking system data for recent Occurrence Reports and associated corrective actions.

2. Review categorization of corrective actions into pre or post restart category.

3. Review closure packages for pre-restart corrective actions.

4. Review CTS to verify that Stack ORR Corrective Actions have been properly entered into the OTS.

\section{Verlficatlen Besults}

1. RSA Corrective Action 22-CA8, which requires the facility to reduce the backlog of overdue
Occurence Reports to less than 5, remained open at the time of the ORR initiation (Finding

RSA-17-01). Interviews with Separations $Q A$ and facility management personnel, review of $O R$

files and War Room progress charts indicated that the backlog of ORs to be written was reduced to

the required level during the course of the ORR $(1 / 5 / 94)$ with an acceptable DOE rejection rate also

being noted $(\sim 10 \%)$.

Three RSA finding closure packages pertaining to the facility review of Issues Management (CA 22-F8, 9 and 10) were reviewed and determined to be adequate in both the scope of the corrective actions and documentation.

Interviews with facility managers indicated that, until recently, there has been no ownership of the OR program. This is recognized by the facility as being partially responsible for the OR backlog and fallure to track Corrective Actions. This has recently been addressed by the facility by appointing an individual responsible for proper implementation of the $O R$ process. Interview of the designated individual revealed his knowledge of OR needs and procedures to be adequate.

Further review into the causes of OR deficiencies indicated that the Separations Operations Reviow committee is responsible for confirming the appropriate closure methods for all corrective actions and action items involving occurrences and also for ensuring periodic audits of the occurrence reporting and investigation process are performed (OP 2.07-01, Att. 5.2). Based on

\section{Documents Reviewed}

Closure packages for $\mathrm{CA}$ 22-F8, 9 and 10.

OP 2.07-01

\section{FInding?

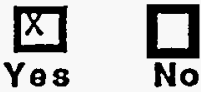 \\ ORR Board Member:}

If yes, complete OSR 28-131

Reviowed By: $\frac{\text { Q.? }}{\text { sgnature }}$
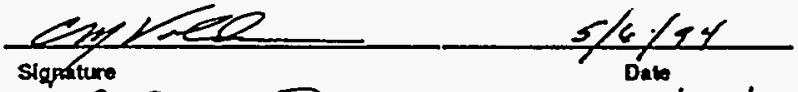

IIfes, completo OSR $20-131$

$5 / 6 / 24$


WSRC ORR - CHECK LIST FORM

ORR \#

93-0

Functlonal Area Title

Issue Management
Element Title

Issue Categorization, Notification, and
Check LIst \#

i7-0il
Rev. \# 1

Page 2 of 2

\section{Verlfleation Results (continued)}

the state of the OR procoss upon initiation of the RSA and ORR, review of SORC meeting minutes for the last 15 months and interviews with facility managers, it was determined that the SORC was not fulfilling these functions (Finding 17-01/2).

The Commitment Tracking System (CTS) was still being developed at the time the ORR was initlated. The development process was monitored and the final product evaluated. A sampling of approximately 25 CAs randomly chosen from 1991 and 1992 ORs indicated that all had been incorporated into the CTS indicating a thorough determination of outstanding CAs. In addition, a field check of 11 CAs which had completion dates indicated in the final ORs revealed that they had been adequately implemented. The nature of the CAs included procedure and drawing revisions and equipment repair/changeout/modification. The $11 \mathrm{CAs}$ checked are those under Documents Reviewed (Completed CAs). This provides reasonable assurance that CAs identified as being completed have been implemented.

Review of the CTS early in its development stage revealed that the CTS had several redundant corrective actions and several improper or severely delinquent due dates. In addition, several of the CTS entries actually entailed several separate corrective actions for which no evidence of their being evaluated for restart applicability was found. This was initally noted as a finding (17-01/1). However, the finding was cancelled when noted that the facility had recognized the deficiency and was aggressively addressing it.

New procedures which were developed for dealing with work initiators and the CTS (SOP 221-F-50000 and 50001) were reviewed and appeared adequate.

2. Three "scrubbing" meetings at which CAs were categorized as pre-or post-startup items were attended by several Board members. Appropriate facility technical personnel were present at the meetings. Although the process was rapid, any doubts regarding the validity of. the classification of a CA were thoroughly discussed.

A review of the CTS by Board members indicated that classification of CAs as pre- or post-startup was reasonable.

Board member discussions with QA personnel overseeing other classification meetings indicated that they were satisfied with the process and results.

No deficiencies noted.

3. Non-RSA Corrective Action closure packages (14) were examined for completeness and adequacy which were deemed adequate. QA and facility management approved and signed off each package before final closure. The Board noted that the closure process did not appear to address performance-based verifications of the CAs. The closure process was modified by the facility to address this concern. No other deficiencies were noted in the closure packages.

4. A review of Stack ORR CAs indicated that all CAs identified as pre-restart requirements have either been completed or identified in the CTS as pre-restart items.
Documents Reylewed (conte)

$-$

Occurence Reports FCAN$1992-0058,0059,0060,0061,0062$, $0069,0070,0071,0073$, $0074,0075,1993-0003,0004,0008$ $0013,0016,0017,0020,0022,0024$ $0026,0032,0033,0035,0041,0042$ $0043,0044,0045,0046,0047,0048$ For completed CAs: FCAN-1991-0024, \#4 FCAN-1991-1039, \#2 FCAN-1992-0055, \#1 FCAN-1992-0057, \#1 and 2 FCAN-1992-0059, \#1 FCAN-1993-0005, \#1 and 2 FCAN-1993-0016, \#1,3 and 6

SOPs $221-F-50000$ and 50001.

Closure Package Nos.:

ORPS-117,128,507

CONOPS-101,118

QAA-323

SAFET-348,349

ASA-459

SADC-645

STACK-153,156,143,142

Closure Package nos.:

Stack-152,470,468,141,144,145, $146,157,153,155,156,147,159,469$, $143,154,151,158,142,148,149,150$, 467

Finding? $\square$ ORR Board Member:

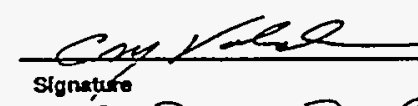

If yes, complete OSR 28-131

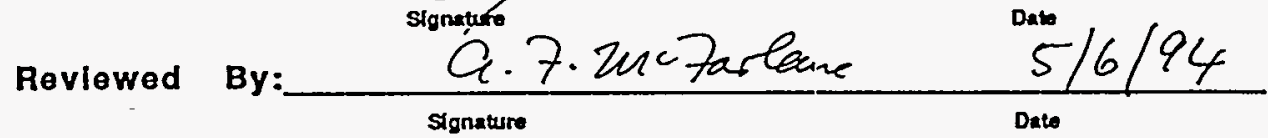




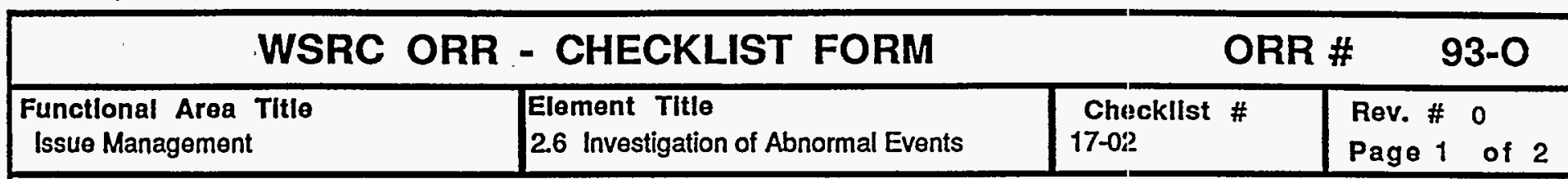

\section{Perfermance Qbjectlve}

Abnormal events are defined and trained personnel conduct defensible investigations to determine the root cause(s) and recommend specific actions to prevent reoccurrence.

\section{Criterlon}

2.6.4 Program/procedures are in place to ensure the trending and evaluation of Abnormal Events is conducted and the utilization of lessons learned from event investigations by facility personnel. [WSRC-IM-91-105, Ch. 6, Sec. 5.3 and 5.10; WSRC 2S, Proc. 5.2]

\section{Verlfleatlon Approach}

Review procedures related to Abnormal Event handling

Review lessons-learned program

\section{Llnes of Inquiry}

1. Review Abnormal Event procedures to verify the existence of a trending and lessons-learned program.

2. Identify and interview personnel responsible for the trending and lessons-learned programs to verify the adequacy of implementation of these programs.

3. Interview at least 2 operators to determine whether lessons-learned information is being incorporated into operator training.

\section{Verlfication Results}

1. DOE Order and Site procedure requirements for lessons learned and trending were reviewed and their requirements compared to the Separations Department lessons-learned and trending programs. There appears to be adequate compliance with these procedures (See LOI 2).

As followup, Separations Procedure 2.07-01 (Identification and Reporting of Events, Conditions and Concerns(U)) was also to reviewed to determine facility requirements. A compliance check revealed certain deficiencies. These include:

- OP 2.07-01, Attachment 5.2 requires the Area Separations manager to establish procedures and designate responsibility for executing the requirements of OP 2.07-01. These procedures do not exist (Finding 17-02/1).

-Review of associated Occurrence Reports revealed that Justifications for Operation (JCOs) which are required to be written for Unusual Occurrences (UOs) are not being handled properly. Section 2 of the JCO form (OP 2.07-01, Att. 5.4) requires interim or compensatory corrective actions to be stated along with the time period they are expected to remain in effect. However, the JCOs which were reviewed do not address the time periods the corrective actions are to remain in effect. In addition, expiration of the JCO appears to be automatic and based on an arbitrary date rather than based on an evaluation of whether adequate compensatory measures have been and will or should remain implemented. (Finding17-02/4).
Documents Revlewed

DOE Order $5000.3 B$

MP 4.19 and MRP 4.14

Manual 1B, Procedure 3.56

OP 2.07-01, Identification and Reporting of Events, Conditions and Concerns(U), Rev. 7, 12/8/93.

WSRC-FCAN-1993-0010,0012, 0016,0039, 0040,0042
Finding? $\underset{Y e s}{\square} \square_{\text {No }}$ ORR Board Member:

If yes, complete OSR 28-131

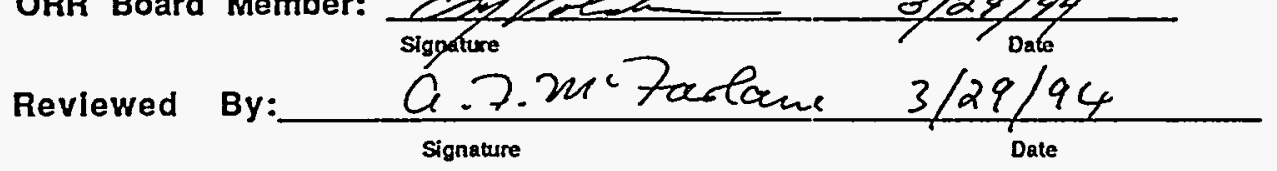




\section{WSRC ORR - CHECK LIST FORM}

Functlonal Area Title Issue Management
Element Title

2.6 Investigation of Abnormal Events
Cheisk List \#

17-02
Rev. \# 0

Page 2 of 2

\section{Verlflcation Results (contlnued)}

- Further review of Attachment 5.2 indicated that the Separations Operations Review committee is responsible for confirming the appropriate closure methods for all corrective actions and action items involving occurrences and also for ensuring periodic audits of the occurrence reporting and investigation process are performed. Based on the state of the OR process upon initiation of the RSA and ORR, review of SORC meeting minutes for the last 15 months and interviews with facility managers, it was determined that the SORC was not fulfilling these functions (Finding 17-01/2).

- OP 2.07-01, Section 2.8 requires SIRIM training for the Facility Manager and report writers. In addition, the $2 S$ Manual Section 5.2, requires Occurrence Investigators (Evaluation Group Leaders) to be trained on the requirements of Section 5.2. A comparison of OR authors for the last 6 months to a list of individuals having received SIRIM training revealed that all report writers have not received the required training (Finding 17-02/5).

- As further followup, a review of facility critiques, or preliminary investigations (PIs), indicated that they are not being retained in accordance with Division Retention Requirements, as required by Manual 2S, Section 5.2; Section J (Finding 17-02/2).

2. The individual responsible for operations-related trending on the facility level stated that this is a very low priority item. A report documenting specific performance indicators was issued on a monthly basis until May of this year, at which time it was discontinued. Currently, selected performance indicators are only displayed on Level One in a display case (no formal distribution). These include square footage of RCAVA, housekeeping ratings, gamma exposure, NCRs, solid waste generation, contamination cases, safety performance. The indicators on display were, in several cases, noted to be 3-4 months out of date. However, there appear to be no specific requirements for operations-related performance indicators. Performance indicators pertaining to radiation protection and maintenance are required but were not reviewed as part of this Functional Area. Separations QA managers provide trends of root causes, nature of occurrences, NCRs, surveillances and CARs to the facility manager. Discussions indicated that regular reports are issued to the facilities and if significant negative trends are detected, corrective actions are tracked by Separations QA.

The Separations Lessons-Learned program obtains input from FSES and the site daily log. Applicable input is forwarded to the facility engineering group, facility managers, and/or training, as appropriate. This appears to be in compliance with site procedures (MP 4.19 and MRP 4.14).

The newly appointed facility lessons-learned coordinator was interviewed. He stated that the new duties associated with the lessons-learned program are in addition to several other duties. Currently, lessons-learned materials are distributed to the appropriate facility departments but no response is required. A newly developed facility lessons-learned procedure which will formalize the process was reviewed and determined to be adequate. However, the procedure is stlll in draft form and the intended implementation date has expired (Finding 17-02/3).

The ORR Board member responsible for the Training Functional Area stated that he has observed that all lesson plans have a section for applicable lessons learned and that liberal use of this mechanism using ORPS material has been noted.

3. Two CR operators were interviewed and both stated that lessons-learned information was provided to them via training and Required Reading mechanisms and that the information included was both relevant and useful.
Documents Revlewed (cont.) SORC Meeting Minutes, 9/92-12/93 $-$
Manual 2S, WSRC Conduct of Operations Manual

221-F Canyon and Outside Facilities Monthly Report, March 1993 (U), - NMP-SFC-93-0045, May 17, 1993.
SOP F-SEP-0003, F Area Separations Operating Experience Program (U), Rev. 0, Draft A.

Finding? $\quad[\quad \square$ ORR Board Member;

If yes, complete OSR 28-131

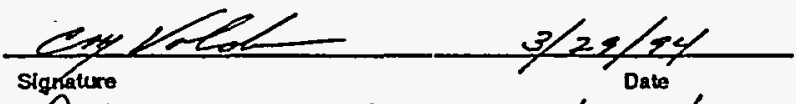

Reviewed By:

Q.7. nuctarlane

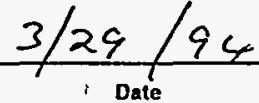

Signature 


\begin{tabular}{|c|c|c|c|}
\hline WSRC & ORR - CHECKLIST FORM & & $93-0$ \\
\hline $\begin{array}{l}\text { Functlonal Area Title } \\
\text { OCC. SAFETY \& HEALTH }\end{array}$ & $\begin{array}{l}\text { Eloment Title } \\
\text { 2.1 Occupational Safety }\end{array}$ & $\begin{array}{l}\text { Checklist \# } \\
20-01\end{array}$ & $\begin{array}{l}\text { Rev. \# } 0 \\
\text { Page } 1 \text { of } 1\end{array}$ \\
\hline
\end{tabular}

\section{Performance Oblectlve}

Procedures and documentation provide direction, record generation, and support for the occupational safety programs.

\section{Critorlon}

Written safety policies are readily available to all organization elements, periodically reviewed, and kept current. (SCD-04, FA-20, criterion 2.1.2.2)

\section{Verifleatlon Aperoach}

Document review of policies and programs

Field walkdowns of policies and programs

Personnel interviows

\section{Lines of Inquiry}

1. Review safety policies and programs including QISS, the Hotline programs, and the Safety Observer Program for DOE-WSRC compliance, applicability and effectiveness.

2. Review and conduct field walkdowns of safety programs for adequacy, including: Documented Safety Program; Work Control Program; Hazardous Energy Control; Life safety and OSHA for personnel and equipment saferty; Housekeeping condition and audits; Electrical safety; welding and cutting program; Lockout/tagout procedure.

3. Interviow personnel to evaluate level of knowledge of safety policies and programs resulting from training.

$$
\therefore
$$

\section{Yerlfleatlon Results}

1. Safety policies and programs, including QISS, Hotline, and Safety Observer programs were reviewed for compliance, applicability and effectiveness. Manual 8Q, Procedure 1 requires annual instruction in seven basic safety procedures. This instruction is given at monthly safety meetings. A review of Safety meeting attendance records found a lack of required attendance by personnel. This is a Finding (20-01/1).

2. Field walkdowns were conducted to determine the adequacy of documented safety programs, including: Work Control, Hazardous Energy Control, Life Safety, OSHA, Housekeeping, Electrical, Welding and Cutting, and the Lockout/Tagout Procedure. A facility safety program implementing WSRC-8Q Safety Manual is not yet completed and implemented at the facility. This is a Finding (20-01/2). The review also found a number of deficient housekeeping items throughout the facility. This is Finding (20-01/3).

3. Three operators and one supervisor were interviewed to evaluate their level of knowledge of safety policles and programs. The personnel are familiar with the content of each as applied to their workplace.

\section{Documents Reviewed}

-SOP-221-F/OF-F Safety \& Industrial Hygiene Program (Draft SOP-F-50003) -WSRC-QISS-F Canyon -WSRC-8Q, Safety Manual, Procedure 81, Safety Observer Program (8/9/93) -SOP-291-059, Separations Maintenance Work Control Program (1/6/94) -NFPA-101, Life Safety Codo - OSHA Title 29 CFR, Parts 1910/1926.

\section{Finding?
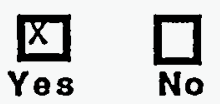

If yes, complete OSR 28-131
ORR Board Member:
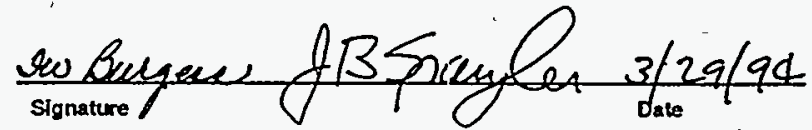

Reviewed By: 
WSRC ORR - CHECKLIST FORM

$93-0$

Functlonal Aroa TItle
OCC. SAFETY \& HEALTH

Element Title

2.1 Occupational Safety

20-0?

Rev. \# 0

Page 1 of 1

\section{Performance objectlve}

Safety Concerns arising from physical, or other environmental stresses in the workplace, are idintified, evaluated and controlled.

\section{Criterion}

Occupational safety equipment is available, its use is enforced, and training for its use is provided. (SCD-04, FA-20, criterion 2.1.3.4).

\section{Verlfleation Appreach}

Document review of safoty equipment

Field walkdown of safety equipment

Personnel interviews

\section{Lines of Inquiry}

1. Review safety equipment requirements for personnel and equipment, preventative maintenance, and inspection program for adequacy, including hand and portable tools.

2. Conduct field walkdown of safety equipment to observe proper application and availability.

3. Interview personnel to evaluate level of knowledge of types of protective equipment, proper use/storage locations, as developed through training.

\section{Yerlflcatlon Besults}

1. A review was conducted of the adequacy of equipment safety requirements for personnel ancl equipment, including: preventative maintenance, inspection programs, and portable hand tool safety. The review found impaired safety equipment not replaced with working safety equipment in an expeditious manner. This is a Finding (20-02/1).

2. A walkdown was conducted of facility safety equipment to observe proper application and availability. The walkdown found that some Caution Tags are not accounted for in the Control Room Log. This is a Finding (See Checklist 20-03).

3. Three operators and one supervisor were interviewed to determine their level of knowledge of the proper identification and use of protective equipment and the storage/use locations. The personnel are knowledgeable of the types of equipment to don during work and the storage location.
Documents Reviewed -SOP-221-F-51053, Rescue Team Cabinets \& Emergency Vehicle Inspection (2/2291)

-SOP-221-F-541052, Decon Cabinets Inspections (2222193) -SOP-221-F-50811, Emergency Radio Weekly Functional Check (12/10192)

-SOP-221-F-62110, Breathing Air Manifold Filters Inspection, (5/21/91) -SOP-221-F 51051 , Emergency Cabinets Inspections (3/19993) -SOP-221-F-51057, Inspecting \& Testing Safety Showers and Eye-Wash Stations -SOP-221-F-51054, Inspection of Stretchers (3/9/93) -WSRC-8Q, Safely Manual, Procedure 31 .

\section{Finding?

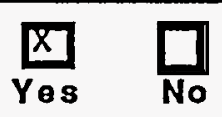
If yos, completo OSR 28-131.
ORR Board Member: Revlewed By:

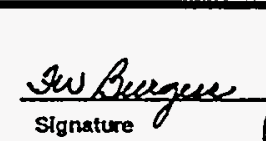
signature
Q.7. un fartions

Signature

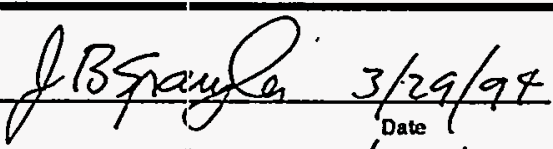

$3 / 29 / 94$ 


\section{WSRC ORR - CHECKLIST FORM}

\section{Functlonal Area Titlo} OCC. SAFETY \& HEALTH

\section{Element Title}

2.1 Occupational Safety
Chacklist

20-03
Rov. * 0

Page 1 of 1

Performance Qbjective

Survellance of activities is conducted to measure safety performance.

\section{Criterion}

Audits, surveillances, and inspections are performed to assess compliance with industrial safety and hygiene requirements of WSRC-8Q and $4 Q$.

\section{Yerlfleatlon Approach}

Document reviews of audits, surveillances, and inspections field walkdown of findings.

\section{Lines of Inquily}

1. Review safety and hygiene audits, surveillances, and inspections for compliance to WSRC-8Q, 4Q including the areas of: facility ticklers for testing and maintaining facility safety equipment; SMI-31; SR\&A OSHA Baseline Assessments; facility inspoctions; SR\&A Independent review and oversight, and a safety deficiency corrective action tracking system.

2. Conduct field walkdown to evaluate adequacy of audits, surveillances, and inspections, and closure of findings.

\section{Verifleatlon Results}

1. A review was conducted of the safety and hygiene audits, surveillances, and inspections for compliance to WSRC-4Q and $8 Q$. The review included: Facility Ticklers for testing and maintenance of equipment, SR\&A OSHA Baseline assessments, facility inspections, SR\&A Independent oversight, and the deficiency tracking system. The review found that not all safety deficiencies are entered into a tracking system. This is a Finding (20-03/2). The review found an inconsistent management safety reporting format. This is Finding (20-03/4). The review also found missed management/supervisory housekeeping inpsections and no accountability systern to provide visibility for the missed inspections. This is a Finding (20-03/3).

2. A walkdown was conducted to evaluate the adequacy of safety assessments of: audits, surveillances, inspections; and the closure of deficiencies. The safety assessments are found to be adequate with the exception that not all deficiencies are tracked to completion. See Finding 20-03/2. The safety equipment walkdown (Checklist 20-02) found that some Caution Tags are not accounted for in the Control Room Log. This is a Finding (20-03/1).
Documents Roviowed

- Compliance Assessment to DOE Order 5483.1A, Rev. 2 (12/10/93) -ESH-Industrial Hygiene Noise Level Survey of F-Canyon (12/93) -ESH-SR\&A OSHA Baseline Assessment of F-Canyon (1993)

-F-Canyon Commitment Tracking System Program -WSRC-8Q, Safety Manual, Procodures 6, 87, 88 -WSRC-4Q, Industrial Hygiene Manual, IH-101
FInding? Yes 믕 If yes, complete OSR 28-131

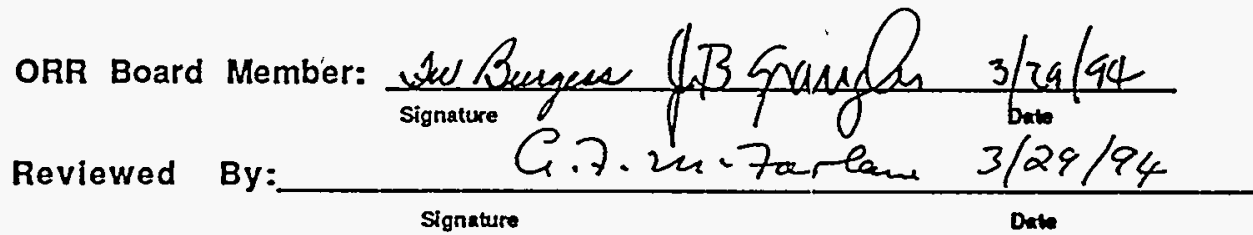




\begin{tabular}{|c|c|c|c|}
\hline WSRC ORR & - CHECKLIST FORM & OR & 93-0 \\
\hline $\begin{array}{l}\text { Functlonal Area TItlo } \\
\text { OCC. SAFETY \& HEALTH }\end{array}$ & $\begin{array}{l}\text { Element Title } \\
2.2 \text { Industrial Hygiene }\end{array}$ & $\begin{array}{l}\text { Cheicklist \# } \\
20-04\end{array}$ & $\begin{array}{l}\text { Rev. \# } 0 \\
\text { Page } 1 \text { of } 1\end{array}$ \\
\hline \multicolumn{4}{|c|}{$\begin{array}{l}\text { Perfermance Oblectlve } \\
\text { Facility organization and administration ensures implementation and control of the industrial hygiene program. }\end{array}$} \\
\hline \multicolumn{4}{|l|}{ Criterlon } \\
\hline
\end{tabular}

\section{Yerlfleation Approach}

Document reviow of program

Field Walkdown of practices

Personnel interviows

\section{Lines of Inquiry}

1. Review procedures for compliance to WSRC- $8 Q$ and $4 Q$ including protective clothing requirments, breathing air systems, heat stress; carcinogen program and procedures, and scheduled facility noise level surveys.

2. Review Hazards Communication Program for compliance to WSRC-4Q.

3. Conduct field walkdown to evaluate adequacy of Industrial Hygiene program including protective clothing and equipment and the Hazards Communication Program.

4. Interview personnel to evaluate level of knowledge of industrial hygiene resulting from training.

\section{Yerlfication Results}

1. A review was conducted to review hygiene procedures for proper compliance to WSRC-4Q, including: protective clothing requirements, breathing air systems, heat stress, carcinogen programs, and scheduled noise level surveys. The review found that E\&I Mechanics have not received Bloodborne Pathogen Training. This is a Finding (20-04/2). The review also found that a workplace carcinogen program for lead is not developed per WSRC-4Q. This was a Finding (20-04/1) later canceled after a revised WSRC-4Q Manual (1/94) was issued. The revision contains a more closely defined designation of what form of lead carcinogen programs are to be doveloped.

2. A review was conducted of the facility Hazards Communication Program for compliance to WSRC-4Q. The program is in compliance with WSRC-4Q.

3. A walkdown was conducted to evaluate the adequacy of the Industrial Hygiene program for protective clothing and equpment, and the Hazards Communication Program. The program adequately covers the types and use of protective clothing and equipment, and the Hazards Communication Program.

4. Three operators and one supervisor were interviewed to determine their level of knowledge of industrial hyglene requirements in the workplace. The personnel are knowledgeable of the requirements of the program. The personnel also understood the different parts of the Hazards Communication Program and how to access information from the MSDS on hazardous chemicals and substances.

\section{Documents Reviewed}

-SOP-0221-F-51250, Material Safety Data Sheets (2/1/93) -SOP-221-F-63150, Removing Asbestos in Building (1/9/93) -SOP-221-F-55011, Controlled Purchasing Chemical Products (11/26/92) -SOP-221-F/OF-F-(Draft SOP-F-50003) Safety \& Industrial Hygiene Manual -WSRC-4Q, Industrial Hygiene Manual, $\mathrm{IH}-300$ and $\mathrm{IH}-1300$

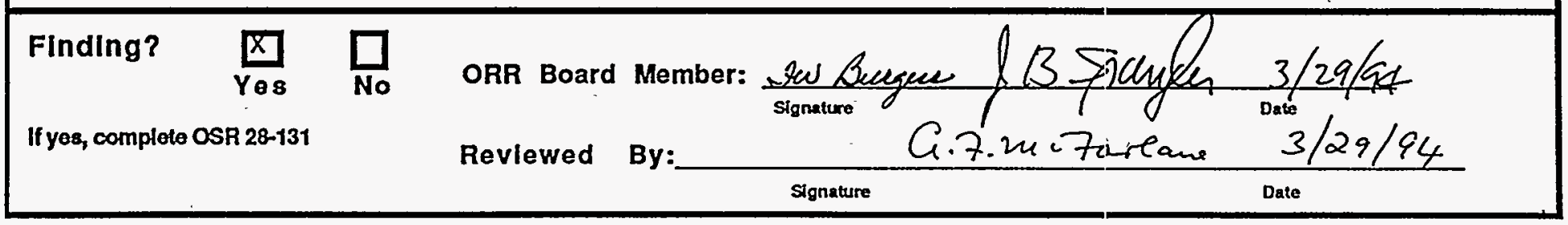




\section{WSRC ORR - CHECKLIST FORM}

\section{Functional Area Titlo}

Conduct of Operations

\author{
Element Title \\ 2.1 Operations Organization and
}

ORR \#

93-0

Checklist \#

22-01

\section{Performance Qbjestive}

Excellence in operations is implemented by establishing high operating standards by management, communicating standards to employees, providing training commensurate with achieving defined standards, assuring sufficient resources to satisfy standards, and monitoring operating performance to correct identified deficiencies.

\section{Crilterlon}

2.1.7 Operating problems are documented and evaluated. Based on assessment of these problims, corrective actions are taken to Improve the performance of the Operations Department. Frequent direct observation of operations activities by supervisors and managers is occurring.

\section{Yerlflagtlon Approach}

Review Control Room logbook(s) and work orders

Interview Control Room and/or building operators/supervisors.

\section{Lines of Inquiry}

1. Interview at least two operators to determine adequacy of facility response to identificiation of problems/deficiencies.

2. Review Operations logbooks to verify documentation of deficiencies.

3. Verify corrective actions have been satisfactorily documented, implemented and closed.

4. Interview at least two facility managers/supervisors to determine frequency, nature and results of their observations/tours.

5. Interview at least 2 operators to determine whether they have observed or are aware of supervisor/management tours.

\section{Yerlfication Results}

1. Two facility operators who were interviewed both indicated that the response by all facility organizations to problems and deficiencies identified by Operations was timely and effective in correcting the problem.

2. Review of Control Room log entries for the one week period ending 1/16/94 noted thorough documentation of recently occuring deficiencies in the facility.

3. Review of Control Room log entries for the week ending 1/16 indicate adequate documentation of equipment deficiencies and resolution of those deficiencies.

4. Interviews with two Shift Managers indicated that they typically tour the facility twice per shift, except possibly on weekdays, when workloads sometimes prohibit the tours. When asked what they would typically observe on such tours, they responded with housekeeping, personnel locations and activities, and facility conditions. Both Managers stated that when deficiencies were noted, they were usually related to housekeeping.

5. Two operators stated that the Shift Manager is usually seen patrolling the building at least twico per shift, except on weekdays, when workloads prevent regular tours.

\section{Documents Revlewed}

Control Room shift supervisor $\log$

\section{FIndIng?

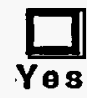 \\ No \\ ORR Board Member:}

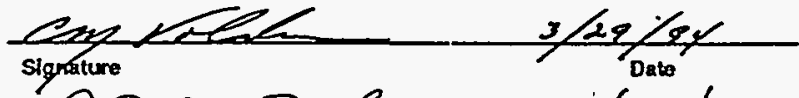

If yes, complete OSR 28-131 


\section{WSRC ORR - CHECKLIST FORM}

\section{Functlonal Area Title \\ Conduct of Operations}

\author{
Element Title \\ 2.2 Shift Routine and Operating Practices
}

ORR \#

93-0

Chracklist \#

22-0.2
Rev. \# 0 20ur?

Page 1 of $X$

\section{Perfermance Qbjectlve}

Shift routines and operating practices are defined and implemented to assure professional conduct of operations, clear understanding of responsibilities and authorities, clarity of understanding of on-coming shift on processing and equipment status, completion of accurate shift records, and timely quality communications between all organizations on shift.

\section{Crilterlon}

2.2.4 Operator tours (surveillances) and supporting Round Sheets (data sheets) for assigned work areas and processing support equipment are defined to assure processes and equipment are operating in the desired envelope, and actions are taken to reverse any observed trends toward violating the envelope. [DOE 5480.19, Ch. II, Sec. C.3 and 4; WSF.C-IM-91-105, Ch. 2, Sec. 5.3 and 5.4; WSRC 2S, Procs. 4.4 and 5.4]

\section{Verifleatlon Approach}

Review Round sheots

Interview Control Room and/or building operators/supervisors

\section{Lines of Inquilry}

1. Examine operator roundsheets (Building and Control Room) to determine whether abnormal operating parameters are clearly identified.

2. Discuss the adequacy of roundsheets (i.e., scope of equipment checks, recognition of abnormalities, actions to be taken if an abnormality is observed) with at least two operators.

$$
\therefore \text { in }
$$

\section{Verlflcation Results}

1. Examination of numerous recently-completed $(1 / 1-1 / 19 / 93)$ and audited roundsheets which were pulled at random from the Control Room file box indicate a higher than typical rate at which abnormal data is not being circled. Also, a few completed and audited procedures were noted in which the revision check on the first page was not signed (Finding 22-01/1.)

2. Two Control Room operators stated that the scope of roundsheets is adequate with acceptable ranges usually specified by the procedure. They correctly stated that when abnormal data was noted, it was to be circled in red and supervision notified:

FInding? $\underset{Y \in 8}{\mathbb{N}} \underset{\text { No }}{\square}$

If yes, complete OSR 28-131
ORR Board Member:

Reviewed

By:

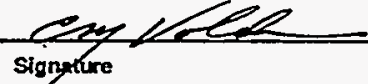

Q.7.2u torlan. $3 / 391 / 54$ Signature 
WSRC ORR - CHECK LIST.FORM

ORR \# 93-0

Functlonal Area Title
CONDUCT OF OPERATIONS

\section{Veriflcatlon Results (continued)}

Review of roundsheets and interviews of control room personnel had the following results:

- Some confusion over use of "initial reading". SOP-F-4011 allows some limits to be changed based on supervisor review and written justification. Roundsheet Item 28 specified a minimum limit of 30 . Tank was empty and reading was zero. Reading had been sporadically red circled as required by $2 \mathrm{~S}$. Operations decided to create a new initial reading per Step 5.2.7. However, step 5.2.7 can not be used to change limits which are specifically identified in the procedure.

- Similarly, Item 78 had a specific limit of 55 identified in the procedure. Operations had identified a new initial reading of 52.3. The readings ranged from 52.6 to 52.9 (always above initial reading of 52.3). Sometimes operators would red circle, sometimes not. This indicates operators are confused over initial readings and how they apply to limits. Supervisor review has not corrected this problem.

- Items on roundsheets identified as having OSR impact had no limits specified. When questioned, the CRS agreed that some limit should be specified but could not find limits in OSR. STE readily found limits but could not address why limits were not in procedure.

- Roundsheet started on 6/7/94 had pen and ink changes made to Step 5.2 Note 2, Item 60, and Item 61. When questioned, CRS indicated that shift manager (who had initialed and dated changes) could make pen and ink changes for correction of typo's. Follow up with procedures (Pam Griffith) indicated SM did not have this ability. An IPC has been initiated. Since chariges were not controlled in any manner, the changes were not transferred to roundsheet started on 6/9/94 which was being.performed without changes.

- Rounds do not always start within 1 hour of specified time (Rounds 6/8/94ẩt 0400, 6/5/94 at 1200,1600 , etc.). $2 S$ requires written documentation of reason for delayed rounds. No documentation was provided.

- On Roundsheets for $6 / 7 / 94$ and $6 / 9 / 94$, Item 8 was lined through and N/A'ed with a note indicating "point is out of service". This is an inappropriate use of N/A as specified by $2 S$.

- Red circled data was not always explained in narrative log. Reference $6 / 5 / 94$ Item $76,83,8$, $28,62,70$ and $6 / 7 / 94$ item 70 , etc.

The above deficiencies in roundsheets generated Finding 22-02/2

- An IPC was initiated (94-246) to incorporate pen and ink changes observed on 6/9.

246 fixed changes to data points 60 and 61 but failed to correct typo on Step 5.2 Note.

- An additional IPC (94-245) was also incorporated to change minimum limits on point 28 and point 78. This IPC was incorporated but no documentation could be produced to show IPC was ever approved. No copy of 245 could be located.

The IPC deficiencies identified above resulted in Finding 22-08/7

\section{Good Practices}

- Roundsheets are reviewed for each performance. Review is documented in procedure.

- Previously performed roundsheets are maintained in the control room for operating reference.
Documents Revlewed (cont.) SOP 221-F-40011, WCCR Process Shutdown Round Sheets (U)
Check List \# 22-02
Rev. \# Page 2 of 2

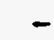




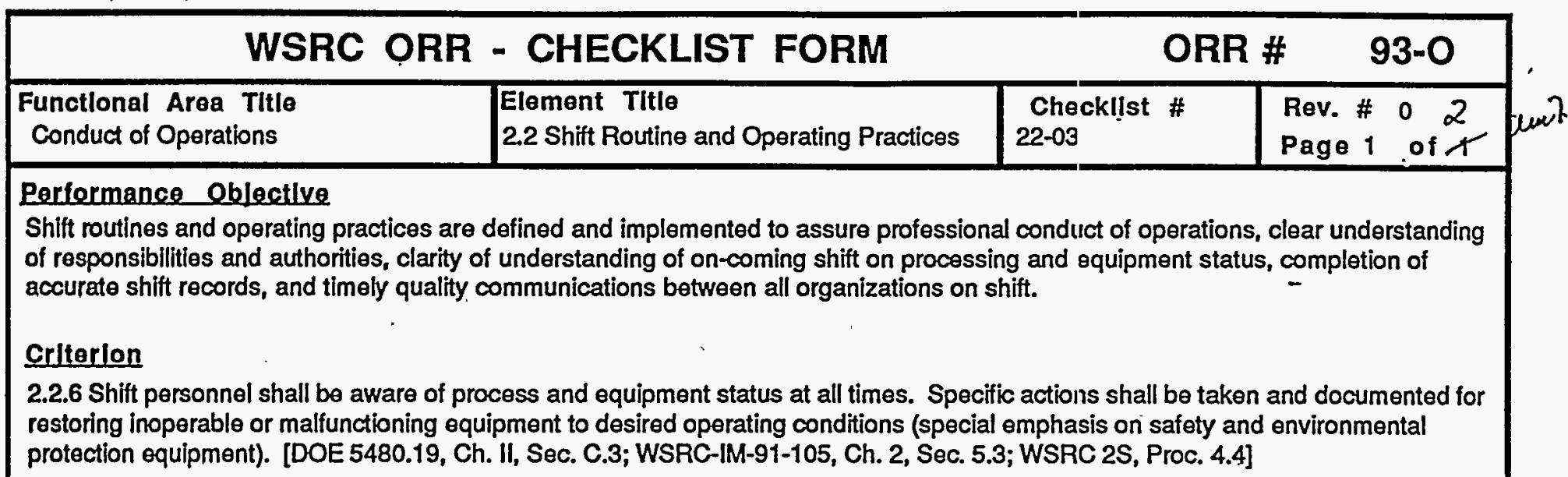

\section{Yerlfication Approach}

Interview Control Room and/or building operators/supervisors

Observe use of status boards and logbooks

\section{Lines of Inquiry}

1. Interview at least two shift personnel to determine

- how they are kept aware of plant status in a timely fashion,

- their awareness of current plant status,

- their familiarity with processes/procedures to be followed for restoration of equipment to opeirating conditions.

2. Review at least 5 completed roundsheets to verify their completion in accordance with procediural requirements.

3. During maintenance work in progress, review CCR documentation of affected equipment status.

\section{Verlfication Results}

Documents Revlewed

1. Two operators stated that shift turnovers are highly effective in informing them of current facility status. Further questioning indicated that they were adequately aware of current overall facility status and work in progress. They were also aware of actions to be taken when deficiencies were noted but were not aware that Alarm Response Procedures had supposedly been implemented. (Finding 22-03/1) See Checklist 22-08.

2. Review of approximately 10 recently completed roundsheets indicated several abnormal data readings which had not been circled (see Checksheet 22-02, LOI \#1).

3. Review of very recent Control Room log entries (1/9 - 1/16/94) indicated that equipment deficiencies, and followup through final resolution of those deficiencies were being adequately documented. However, during review of the Deficiency Tag log, deficiencies were noted in implementation of SOP 221-F-50080, "221-F/OF-F Deficiency Tagging (U)" (Finding 22-03/1). Specifically:

Control Room Deficiency Tag Log Book contains a transcription error in the entry for tag \#B0428\&, 10/25/93 (should be \#B04287), no entry for tag \#B13909, 12/20/93, and a duplicate entry for tag \#B04065.

FInding? $\sum_{\text {Yes }} \square_{\text {No }}$ ORR Board Member:

If yes, completo OSR 28-131

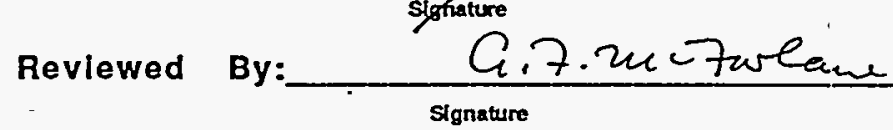

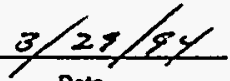

Date

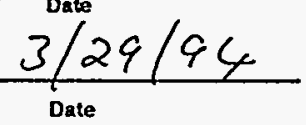


WSRC ORR - CHECK LIST FORM

ORR \# 93-0

\section{Functlonal Area Title}

CONDUCT OF OPERATIONS
Element Title

2.2 Shift Routines and Operating Practices
Chec:k List \#

22-0:3
Rev. \# 0

Page 2 of 2

Verification Results (continued)

Documents Reviewed (cont.)

Beview of control of Temporary Modifications:

- Temp Mod 221F 91-GP078-02 was installed on 8/26/93 and expired on 7/94. This is in excess of 6 month limit specified by procedure. (Located on third level). Several Temp Mods existed which exceeded the 6 month limit. Review determined they were installed prior to implementation of 6 month limit. Facility will revise existing Temp Mods to reflect this.

- Temp Mod 94-006 approved 3/14/94 and extended from 4/13/94 to 6/10/94 and again from $6 / 10 / 94$ to $7 / 10 / 94$.

(1) Mod installed one tag (TM001) on alarm panel.

(2) Two tags were hanging in field "TM001" on alarm panel and "1" on DG at switch.

(3) Tag No. "1" was updated to show extension from 4/13 to 6/10 but did not show 7/10 extension and therefore indicated temp mod had expired.

(4) Tag No. "TM001" did not show either extension and had also expired. :

- Only one Temp Mod was observed to have problems with multiple tags and no extension.

- Temp Mod 94-004 installed two temp switches to replace a dual cooling water temp switch which provided pre-alarm and shutdown logic. Temp Mod did not work and switches tripped prematurely. Temp Mod 94-006 was installed to by-pass the high-high cooling water temp alarm and interlock. This left the EDG without any cooling water temp protection.

- Temp Mod 006 initiated 3 procedure changes: (1) 221-F-60704 Rev 2, TMC-94-006-001; (2) 221-F-60706 Rev 6, TMC-94-006-002; and (3) 221-F-60707 Rev 1, TMC-94-006-003. Approved copies of the three temporary procedure changes could not be located. Current revisions to procedures do not have temporary changes incorporated and provide no guidance for compensatory actions under diesel High-High temperature conditions. Temporary IPCs were generated according to IPC Log. However, IPCs were either lost or canceled prior to Temp Mod removal. IPCs may have been inadvertently lost when procedures were revised.

These IPC deficiencies resulted in Finding 22-08/7. See Checklist Form 22-08.

\section{FInding?}

If yes, complete OSR 28-131
ORR Board Member:

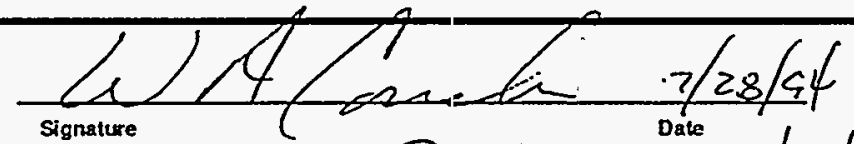

Reviewed By:
$8 / 2 / 94$

Date 
WSRC ORR - CHECKLIST FORM

Functlonal Area Title
Conduct of Operations

2.6 Investigation of Abnormal Events
Element Title
ORR \#

93-0
Rev. \# 0

Page 1 of 1

\section{Performance objectlve}

Abnormal events are defined and trained personnel conduct defensible investigations of determine the root cause(s) and recommend spectilic actions to prevent reoccurrence.

\section{Criterion}

2.6.3 Each event must receive a critique of the event scenario including the personnel directly involved and most knowledgeable as soon as possible after the event is identified [DOE 5480.19, Ch. VI, Sec. C.4; WSRG-IM-105, Ch. 6, Sec. 5.2; WSRC 2S, Proc. 5.2]

\section{Yerifleation Approach}

Roviow critique writeups

Interview supervisors/managers

Lnes of Inquiry

1. Review 5 recent critique writeups to determine clarity, adequacy of detail, timeliness, followup and thoroughness of the writeup.

2. Interview at least 2 supervisors/managers to verify that their knowledge of the critique process is adequate.

\section{Verlfleation Results}

1. Review of 5 recent critiques indicated that the Critique Report Form (Att. B of Manual 2S (NMPI) CONOPS Manual), Procedure 5.2) is not being filled out as required by Step C.1. Although the data pertaining to the event which is gathered is adequate, analysis and immediate corrective actions are not ensured in the critique format currently in use. Use of the required form would ensure that short term concerns are adequately addressed (Finding 22-04/1). The facility stated, and the OFIR Board concurred, that the intent of the form is met through timely issuance of the Initial Notification Occurrence Report. Also, the template for the critique report and the Notification Report have recontly been consolidated in the 9B Manual.

2. Interviews with two Shitt managers revealed their knowledge of the critique process and associated procedures to be adequate. Both had received training on critiques and had experience in investigating and documenting events.

\section{Documents Revlewed}

PI Event Notes for Event \#s: TEMP-FCAN-0048, 0040, 0056,0055 , and TEMP-SEPGEN-0042

\section{Finding? X] \\ ORR Board Member:} If yos, complete OSR 28-131

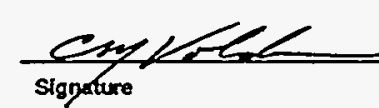
Signature

Reviewed

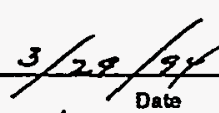

$3 / 29 / 94$ 


\section{Functlonal Area Title \\ Conduct of Operations}

Element Title
2.7 Notifications
Checklist \# 22-05
Rev. \# 0

Page 1 of 1

\section{Performance Objectlve}

A program is in place and implemented that results in timely notification of WSRC management, DOE, and other agencies as appropriate, of events, conditions, or concerns that have safety, health, quality assurance, security, or environmental significance. [Emergency event reporting requirements are covered in FA 13, Emergency Preparedness, and in FA 17, Issue Management.]

\section{Crlterlon}

2.7.2 Procedure is in place at the facility for implementing the notification program and personnell are trained in its use. [DOE 5480.19, Ch. VII, Sec. C.1; WSRC-IM-91-105, Ch. 7, Sec. 5.1 and 5.2; WSRC 2S, Proc. 2.3]

\section{Yerlfleatlen Appreach}

Review Abnormal Events procedures

Interviow personnel responsible for notifications

\section{Lines of Inquiry}

1. Review Abnormal Event procedures to verify that notification steps are in accordance with site and DOE procedures.

2. Interview at least two shift managers to verify that their level of understanding of notification procedures is adequate

\section{Veriflcation Results}

1. Review of the facility abnormal event procedure indicated general compliance with site and DOE notification requirements. A deficiency pertaining to abnormal event procedure compliance was noted in the review of the, Issues Management Functional Area (see Checklist 17-01)

2. Interviews with two Shift Managers revealed an adequate knowledge and understanding of notification procedures. Both Managers were queried on notification requirements, number and location of the applicable procedure, and their specific duties during an abnormal event.

During the interviews with one of the Shift Managers, the apparent use of a non-qualified shift manager as sole supervisor for relief in the Control Room was noted (Finding 4-02/1). The F-Canj/on Restart Plan states that Organization and Staffing in F-Canyon meets the requirements of the referenced governing DOE requirements and WSRC procedures. The facility took the position that the Shift Manager is qualifed to oversee non-discretionary operations per the old standards; therefore the practice is allowable." The Corrective Action formalizes the facility position.

\section{Documents Reviewed}

Separations Manual S1-1. Procedure OP 2.07-01, Identification and Reporting of Events, Conditions and Concerns (U)
Finding? $\underset{\text { Yes }}{\square}$

If yes, complete OSR 28-131
ORR Board Member:
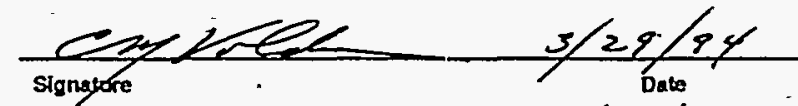

Signgutore

Date

Reviewed By: $\quad$ Q.7.2u 7arlane $3 / 29 / 94$ 
WSRC ORR - CHECKLIST FORM

\section{Functional Area Title}

Conduct of Operations

Element Title
2.9 Lockouts and Tagouts

ORR \#

93-0

Chiscklist \#

22-05

\section{Performance Objectlve}

An effective lockout/agout program is implemented to control lockout/tagout preparation, approval, placement, removal, and provide for adequate documentation. The program also includes detailed administrative procedures, training of personnel, and the use of uniquely identifiable tags.

\section{Criterlon}

2.9.2 Personnel are thoroughly trained on both the administration and field implementation of the program. [DOE 5480.19, Ch. IX, Sec. C.10; WSRC-IM-91-105, Ch. 9, Sec. 5.11]

\section{Yerlfication_Appreach}

Interview personnel responsible for directing/implementing lockouts tagouts.

Roviow training rocords

Walkdown of facility

\section{Lines of Inquiry}

1. Interview at least one supervisor and one operator to assess their level of understanding of lagout/lockout procedures.

2. Review a sample of personnel training records to verify that personnel are trained on current lockout/tagout procedures.

3. Conduct a facility walkdown for the purpose of verifying the proper implementation of tagout/lockout procedures.

\section{Yerlficatlon Results}

1. Interviews with one shift manager and an operator indicate that operator and supervisory knowledge of tagout/lockout requirements as defined in the 80 Manual are adequate. Personnel were questioned on the content and quantity of training on lockouts/tagouts and specifics pertaining to program requirements. No deficiencies were noted.

2. Review of personnel training records indicate that all personnel listed as qualified for tagout/lockout activities are trained on the lockout/tagout procedures. Further document revieuf indicated that Canyon Shift Managers are not listed on the OF Lockout/Tagout Authorization List. (Finding 22-06/1)

3. A walkdown of the facility on $1 / 13 / 94$ revealed deficiencies in implementation of SOP 221-F-50080, "221-F/OF-F Deficiency Tagging (U)". Specifically, the Control Room Deficiency Tag Log Book contains a transcription error in the entry for tag \#B04288, 10/25/93 (should be \#B04287), no entry for tag \#B13909, 12/20/93, and a duplicate entry for tag \#B04065. (See Checksheet 22-03, Finding 22-03/1)

During the walkdown, it was also noted that the Second Level 221-F Lockboard was found unlocked which is a violation of the $8 Q$ Manual, Procedure 32, Section 6.13 and 6.14 (Finding 22-06/2).

\section{Finding? \\ Yes

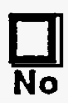

If yes, comploto OSR 28-131
ORR Board Member:

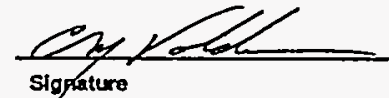

$$
\text { sigpature }
$$

Revlewed $\begin{array}{lll}\text { Rev. \# } & 3 \\ \text { Page } 1 & \text { of } & x\end{array}$ 
WSRC ORR - CHECK LIST FORM

ORR \# 93-0

\section{Functional Area Title CONDUCT OF OPERATIONS}

\section{Element Title \\ 2.9 Lockouts and Tagouts}

Rev. \#

Page 2 of 3

Verlflcation Results (continued)

Performed review of lockout practices through observation of two lockouts, observation of work package performance, and interviews of personnel involved in work.

- Equipment to be locked out had no labels however, installer (Dukes) had detailed knowledge of equipment and demonstrated the ability to identify supply and discharge valves based on system configuration.

- Prior to installation, Dukes offered to allow E\&I to review installation of LO. E\&I observation is not required by $8 Q$. Following installation (prior to IV) E\&I recognized that LO was not adequate for performance of job.

- LO had been reviewed by Operations and E\&I. Neither review identified LO as inadequate. In discussions with Dukes, it was stated that LO preparation, review, and approval was based solely on a diagram from Procedure 63420 for a "typical system". No field walkdown was conducted. $8 \mathrm{Q}$ requires preparer to perform a field walkdown if adequate controlled documents do not exist."

- LO was stopped and re-initiated under same number adding required points.

- Once LO 94-0218 was established, review determined LO referenced Work Activity TEAB6. Two Work Packages were in progress TEAB5 and TDZZ9 neither activity was referenced on LO. When questioned why neither work package was referenced on LO, E\&I mechanics could not answer. Maintenance supervisor indicated TEAB6 (on LO) was a typo and should be TEAB5. Also indicated TDZZ9 was a PM which E\&I had decided to do last minute and had not been added to $L O$ Order. When questioned about work package numbers, operations supervisor changed TEAB5 to TEAB6 on WCP.

- LO was initiated by SOP-221-F-63420. Step 4.8 was to have HP present for initial line break. Step 4.9 was to request E\&I to perform work. Neither step was signed off by Operations indicating procedure was not being signed off as performed. Two copies of 63420 were in package. One for $6.1 \mathrm{D}$ system and one for $6.4 \mathrm{D}$. When questioned, steps were signed off by operations supervision.

- Review of package indicated maintenance was to slowly valve in supply valve with discharge valve closed. LO had return to normal positions specified as "open" for all valves and sequence which did not match E\&I procedure. Maintenance supervisor agreed LO did not match work package requirements. Operations supervisor decided to not revise LO but would remove LO opening all valves then re-close valves and reopen valves in order required by $E \& I$ procedure.

- Two concerns were expressed: (1) Safety of putting system in service, without leak check. Operations supervisor indicated he would valve in slowly. (2) The order of LO return to normal could permit water to back into air system and without a leak check, could result in a water leak. Operations supervisor indicated this was not a concern.

- Following removal of third lock, water leak developed. No leak collection rig was present. No HP'contacted. Work stopped. SM notified.

(continued on next sheet)

Finding? $\square \quad \square \quad$ ORR Board Member:

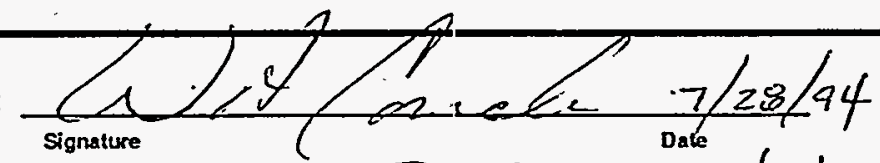

If yes, complete OSR 28-131

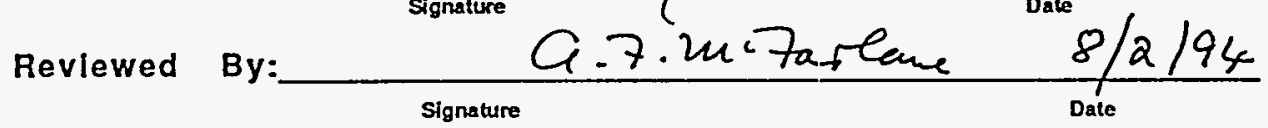


WSRC ORR - CHECK LIST FORM

\section{Functlonal Area Title}

CONDUCT OF OPERATIONS

\section{Element Title}

2.9 Lockouts and Tagouts
ORR \#

Check List \# 22-06;
Rev. \#

Page 3 of 3

Verlfication Results (continued)

Documents Reviewed (cont.)

- Operator became slightly confused during installation of $L O$ and inadvertently closed supply valve from radiator prior to closing supply valve from expansion tank. This was caught by operations supervision.

- Resulted in valve manipulation not in the order specified by LO when Block 22 (sequence required) was checked YES.

- LO identified MBQ54 as work activity. Actual activity was KMQ54. When this was brought to Lockout FCAN-94-0216 the attention of operations, the LO activity number was changed to agree with field activity. No maintenance review was obtained for the change even though maintenance had already signed onto LO for the work activity.

The above deficiencies resulted in Finding 22-06/3

\section{Lockout FCAN-94-0204}

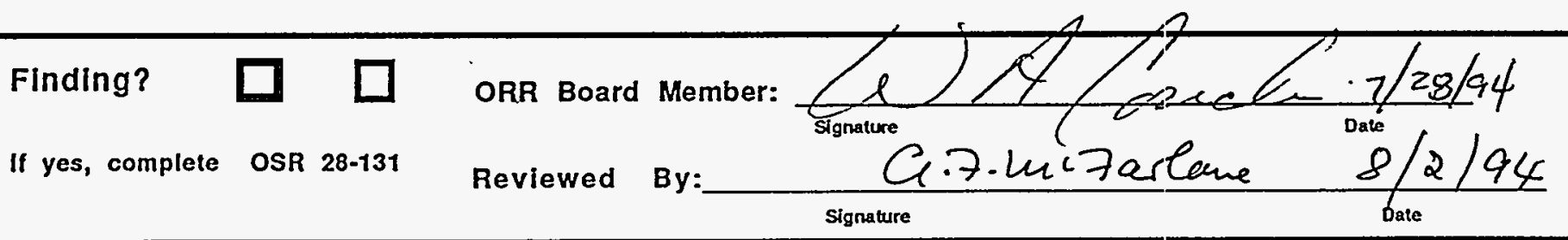


WSRC ORR - CHECKLIST FORM

ORR \#

$93-0$

Functlonal Area Title

Conduct of Operations
Element Title
2.12 Operations Turnover
Checklist \# $22-07$
Rev. \# 0

Page 1 of 1

\section{Perfermance Qbjectlve}

Information transfer at shift turnover is accurate and provides the on-coming shift with information on plant status and needed near-term actions to maintain the facility in a safe condition and continue operations within an axceptable operating envelope.

\section{Criterlon}

2.12.2 Provisions are in place for the on-coming and departing shift to communicate on key iterns affecting plant status, safety and environmental protection. The on-coming shift shall then communicate among themselves (early in the shift) on major actions anticlpated during the shift. [DOE 5480.19, Ch. XII, Sec. C.1.; WSRC-IM-91-105, Ch. 12, Sec. 4.0, 5.1, 5.2, 5.8; WSRC 2S, Proc. 4.1]

\section{Verlificatlon Approach}

Review turnover procedures/checksheets

Observe shift turnovers

\section{Llnes of Inquiry}

1. Review shift turnover procedures/directives to verify their conformance with conduct of operiations directives and industry good practices.

2. Observe at least two shift turnovers to verify implementation of shift turnover procedures.

\section{Yerlflcation Results}

1. Review of the Shutdown Operator Turnover and Shift Manager Checklist notebooks showed them to be adequate, although the format could probably be improved.

2. It is the conclusion of 2 ORR Board members after observation of 2 shift turnovers that the turnover process is generally conducted according to procedure and industry good practices. Turnover is initiated approximately 1 hour before the oncoming shift assumes its duties and is initiated with a one-on-one discussion at each operator position. A meeting is then held between the Shift Manager and each of his supervisors and followed up by a meeting with the support organizations (e.g., HP, Maintenance) to coordinate shift activities. The process was found to tre highly effective in informing the oncoming shift of facility status and planned shift activities. It was noted that not all positions are making use of the checksheets consistently.
Documents Reviewed

Shutdown Operator Turnover and Shift Manager Checklist

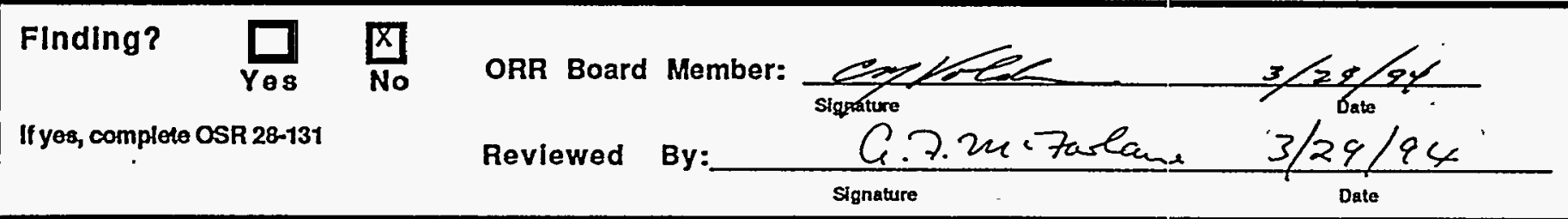


WSRC ORR - CHECKLIST FORM

Functional Area Title
Conduct of Operations

\section{Perfermance ObJective}

Up-to-date Operations Procedures are written to provide direction for operating the facility within its design bases and are available in the required workplace to provide specific direction for operating systems and equipment during rormal, abnormal, and emergency conditions.

\section{Criterion
2.16.4 Specific guidelines are defined and understood by Operators on the use of procedures in the field (e.g. followed step by step
for involved steps vs. routine operations with little consequence from an error). [DOE 5480.19, Cih. XVI, Sec. C.7; WSRC-IM-91-105, \\ Criterion
2.16.4 Specific guidelines are defined and understood by Operators on the use of procedures in the field (e.g. followed step by step
for involved steps vs. routine operations with little consequence from an error). [DOE 5480.19, Ch. XVI, Sec. C.7; WSRC-IM-91-105, \\ Criterion
2.16.4 Specific guidelines are defined and understood by Operators on the use of procedures in the field (e.g. followed step by step
for involved steps vs. routine operations with little consequence from an error). [DOE 5480.19, Ch. XVI, Sec. C.7; WSRC-IM-91-105, Ch. 16, Sec. 5.7; WSRC 2S, Proc. 1.3]}

\section{Verifleatlon Approach}

Review guidelines

Interview Control Room/Building operators

Observe work in progress

\section{Lines of Inquiry}

1. Review facility guidelines on use of procedures to verify their conformance to conduct of operations and industry good practice guidelines.

2. Interview at least two operators to verify their awareness of requirements pertaining to procedure useage

3. Observe at least two jobs in progress to verify proper use of procedures.

\section{Yerlfication_Results}

1. Review of SOP 221-F/OF-F, Procedure System, SOP 221-F-50600 determined that this procedure reflects conduct of operations and industry good practice guidelines.

2. Interviews with operators indicated that their awareness of procedure useage guidelines as defined in SOP 221-F-50600 was very good. However, one deficiency which was noted:

Guidelines for use of Alarm Response Procedures have not been clearly defined. Interviews with Control Room personnel and the Operations Manager resulted in contradictory answers as to whether these procedures are in use or whether their use is optional or mandatory (Finding 22-08/1.

3. During observation of Control Room Activity associated with this LOI and Cold Chemical runs, several deficiencies were noted. Specifically;

- The S1 Manual, Procedure OP2.17, Attachment 8.1 defines operator aids as including plaques, conversion charts, formulas posted in the vicinity of installed indicating equipment (e.g., gages, meters, recorders, etc.). There are several labels which have conversion charts for specific gravity meters in the Control Room which are not in the Operator Aid logbook. The facility operator aid procedure definition of operator aids allows use of these labels without their being logged, indicating a discrepancy in the procedures (Finding 22-08/2).

- There is a conversion chart on the stack monitor which is contained in the HP Operator Aid log but is not in the Operations Operator Aid log (Finding 22-08/3)
Documents Revlewed SOP 221-F/OF-F, Procedure System, SOP 221-F-50600

S1 Manual

Flnding? $\underset{Y Q S}{\square} \square_{\text {No }}$ ORR Board Member:

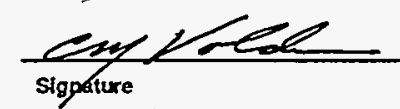

Rev. \# 03 Page 1 of 2

ORR \#

93-0

Checklist \#

\begin{tabular}{|l|l|}
\hline 2.16 Operations Procedures & Ches \\
\hline
\end{tabular} 3. Observe at loast two pabs in progress to veily proper use of procedures.

If yes, complete OSR 28-131 


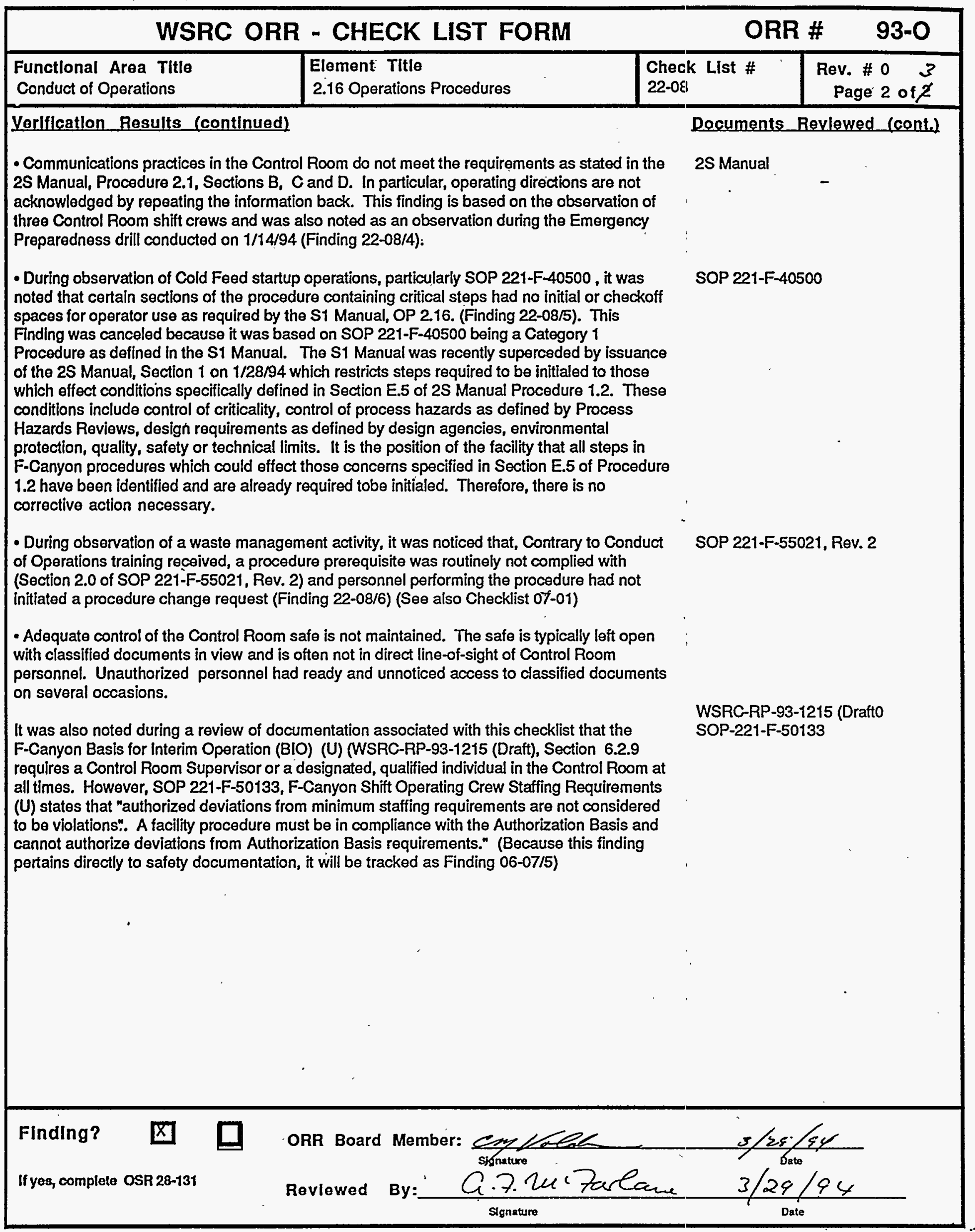


WSRC ORR - CHECK LIST FORM

Functional Area Title CONDUCT OF OPERATIONS

\section{Element Title}

2.16 Operations Procedures
ORR \# 93-0

\begin{tabular}{|l|l|}
\hline $\begin{array}{l}\text { Check LIst \#. } \\
22-08\end{array}$ & $\begin{array}{l}\text { Rev. \# } 0 \\
\text { Page } 3 \text { of } 3\end{array}$ \\
\hline
\end{tabular}

Documents Reviewed (cont.)

Verification Results (continued)

Observations during simulator evaluated drills:

- Step 5.2.9.g of startup procedure specified to maintain "conditions" but no conditions were specified. When asked (by DNFSB observer) what conditions were being maintained, operations staff was unsure. Resulted in significant prompting by controller.

- A discrepancy was identified between startup and operating conditions. Condition was quickly resolved by staff (numbers were correct). Staff agreed to add clarification note.

- During transfer between tanks, operator called to verify sufficient volume was available in receiving tank. Operator received confirmation that volume was available but never specified how much liquid was to be transferred. When questioned by controller, operator had to call and verify sufficient space was available.

- Good communications were displayed by control room staff including repeat backs, phonetic alphabet, addressing by position title not personnel name, started PA and telephone communication with "This, is a drill".

\section{Observation of EDG No Load Test 221-F-60700:}

- Two procedure errors were identified: 1) 2.0 Scope referenced Appendix 8.2 should have been 9.2. Typo was reviewed by Operations who decided it had no effect on performance and test was continued. 2) Step 6.3.2 referred to Appendix 8.1 should have been 9.1. This typo was not recognized during performance of test.

- Overall, diesel ran without problems and operator displayed good communications and high level of equipment knowledge during performance of test.

- An IPC was initiated to revise 60700 to correct typo's observed during performance.

- OPS noticed a broken eyewash station and took immediate action to correct deficiency.

\section{Observations of SOP W-730002}

Observation of SOP-W-73002 was conducted by Steve Pye. Steve's observations are as follows:

- Procedure specified a test pressure but failed to specify an acceptance criteria for the test.

- The specified test pressure exceeded the test pressure specified in the vendor supplied test procedure. No technical review had been conducted to determine if the higher pressure was within the design of the valve.

The above observations resulted in Finding 22-08/8.

\section{Other}

During a review of roundsheets deficiencies in the use of Immediate Procedure Changes (IPC) were observed. See Checklist Form 22-02. IPC deficiencies were also observed during a review of control and equipment status. See Checklist Form 22-03. These deficiencies resulted in Finding 22-08/7.

Finding?
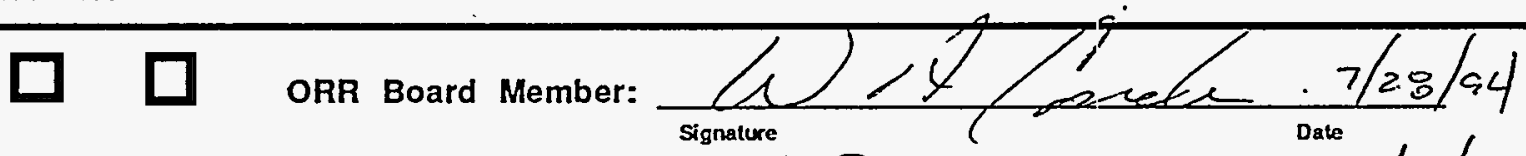

If yes, complete OSR $28-131$

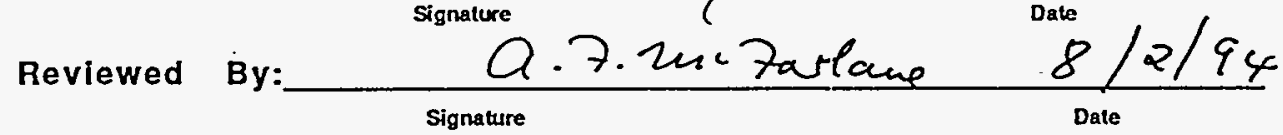




\section{WSRC ORR - CHECKLIST FORM}

\section{Functional Area Title}

Conduct of Operations
Element Title

2.18 Equipment and Piping Labeling
Checkllst \#

22-09
Rev. \# 2

Page 1 of 2

\section{Performance oblectlve}

Equipment and piping are accurately labeled to assist operations and maintenance personnel in identifying equipment they operate or repair and to satisfy Occupational Safety and Health Administration (OSHA) regulations.

\section{Critorion}

2.18.2 System is in place for periodic review of facility areas and equipment to assure labeling accuracy, and that missing and damaged labels are replaced. [DOE 5480.19, Ch. XIII, Sec. C.4; WSRC-IM-91-105, Ch. 113, Sec. 5.2; WSRC 2S, Proc. 5.11]

\section{Verlfication Approach}

Review any labeling program documentation

Interview Control Room/Building operators

Perform field walkdown to verify program implementation

\section{Lings of inquiry}

1. Verify the existence and adequacy of a system which provides for the periodic review cf facility equipment labeling adequacy.

2. Interview at least two operators to obtain their impression of facility labeling adequacy.

3. Perform a walkdown of the facility to assess adequacy of equipment labeling.

\section{Vorlfication Results}

1. A walkdown of the facility revealed that system components are currently being renumbered and relabled to comply with CONOPS Manual labeling standards. The equipment and piping labeling program is not scheduled to be fully implemented until 6/94. A relabeling action plan is in clraft status and a memo has been issud (NMP-SFC-93-0352) to "212-F Personnel" indicating that old labels will remain beside new labels until the second level relabeling is complete and affected procedures are revised and approved. Further investigation indicated that there was no tiansition plan in place to account for the effect of renumbering equipment on procedures, safety documentation, training, etc. (Finding 22-09/2)

2. Operators stated that labeling was adequate and that they had no problems identifying specific system components. The operators were aware of the component renumbering program.

3. A walkdown of the second level indicated that labeling is adequate for on-the-job trained operators. Labeling is incomplete, as the facility identified in the RSA. Some components had the old label attached with the new one also in place. A walkdown of the Hot Gang Valve Corridor found the labeling minimal. However, procedures in use (e.g., 221-F-120005) provide a diagram of the standard gang valve with parts and input streams identified by standard location. Labelin! of individual gang valves provided information on the tank connection made when the valve is operated, the nozzle number, the actuation control panel identifier and the electrical source. Noted paper labels in use in Section 6 . Adhesive deteriorated on one label to an extent that label was about to fall off. Use of paper labels in an environment such as HGVC is unsatisfactory (Finding

\section{Finding? $\underset{Y \in S}{\square} \square_{\text {No }}$ ORR Board Member:}

If yes, complete OSR 28-131

Reviewed By:

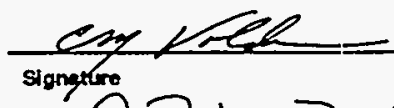

Documents Revlewed NMP-SFC-93-0352

221-F-12005 


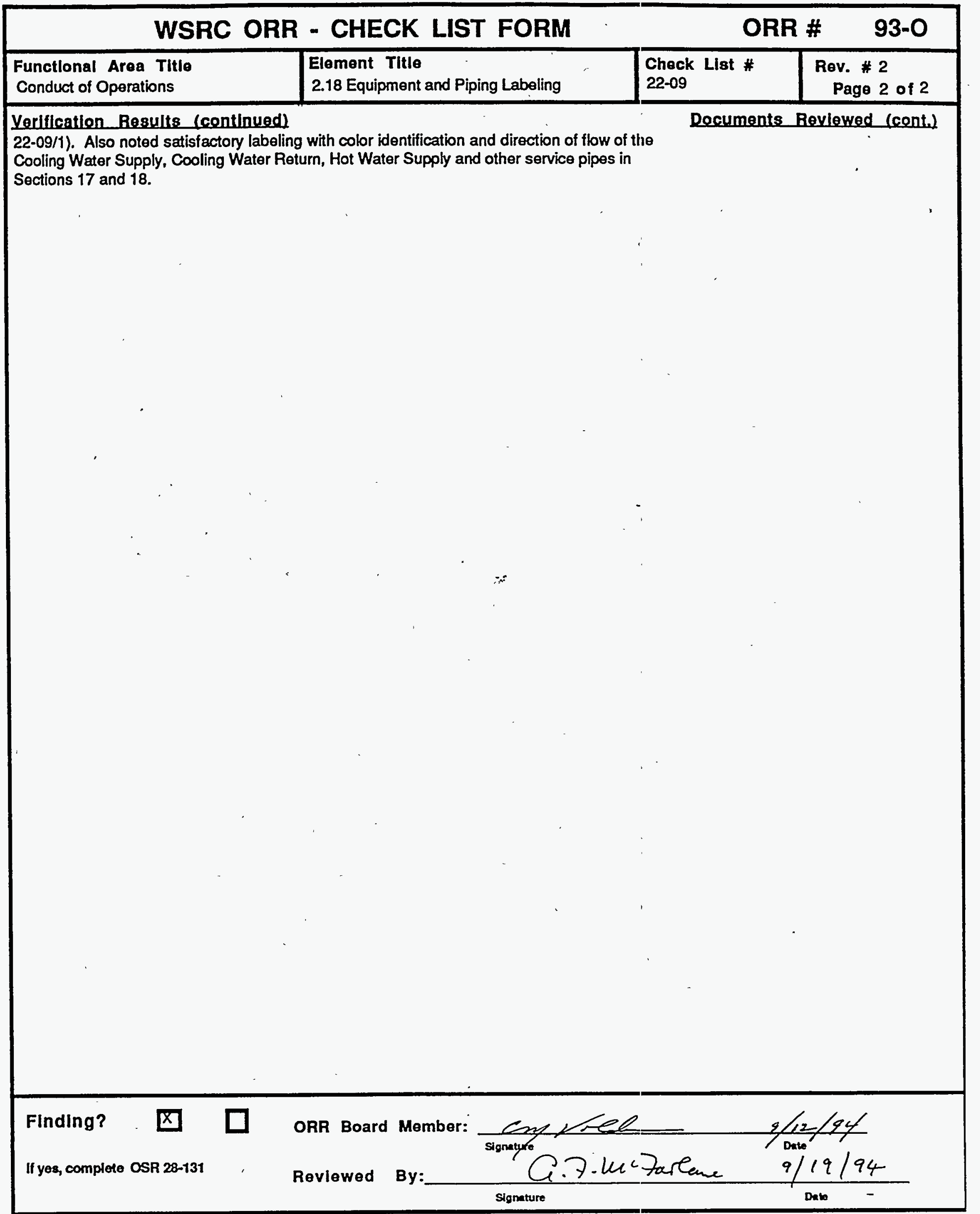




\section{WSRC ORR - CHECKLIST FORM}

Functional Area Title

Conduct of Operations

\begin{tabular}{|l|c}
\hline Element Title & Checkllst \# \\
2.13 Operations Aspects of Facility & $22-10$
\end{tabular}

Rev. \# 0

Page 1 of 1

Perfermance Qbjectlve

Chemical processing safety and the operating envelope are defined and Operations and Technical Support personnel are trained and in place to monitor key process parameters and execute defensible actions to maintain process safety.

\section{Criterlon}

2.13.3 Technical Support Engineer's duties on shift are specifically defined with respect to both technical guidance and authority during Interfaces with Operations. [DOE 5480.19, Ch. XIII, Sec. C.4; WSRC-IM-91-105, Ch. 13, Sec. 5.0; WSRC 2S, Proc. 5.1]

\section{Verlflcatlon Approach}

Roviow documentation pertaining to Technical Support Engineers duties

Interview Technical Support Engineers and Operations supervisors/managers

\section{Lines of Inquiry}

1. Review charters/procedures pertaining to the role of the Technical Support Engineer to verify that the duties and responsibilities of this position have been adequately defined.

2. Review the Shift Engineer training program to verify adequacy of the program scope.

3. Interview at least one Shift Technical Engineer and one Operations supervisor/manager to velify personnel awareness of requirements and to assess the effectiveness of this position.

1. Interviews with two STEs indicated that their duties were not clearly defined or documented.

(Finding 22-10/1)

2. Review of the STE training program indicated that a training needs assessment had not been conducted and therefore, the content of the STE training program cannot be assessed. This is at Finding in the Training Functional Area.

3. Interviews with the STEs indicated that they had not yet been put on shift and were unclear as to what their roles on shift would be. Because they had not yet been placed on shift, the effectiveness of this position could not be assessed. Control Room Shift Managers were also unclear as to the duties of the STE and who he would report to. Two Shift Managers discussed how they would like to use the individual and were under the impression that the STE would report to them. These deficiencies are addressed in Finding 22-10/1, Corrective Actions .

\section{FIndlng?

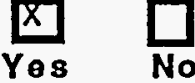

If yes, completo OSR 28-131
ORR Board Member:

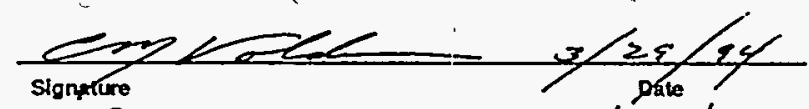

Revlewed

By:
$3 / 29 / 96$ 